\title{
Source Term Estimation During Incident Response to Severe Nuclear Power Plant Accidents
}

Manuscript Completed: October 1988

Date Published: October 1988

T. J. McKenna, J. G. Giitter

Division of Operational Assessment

Office for Analysis and Evaluation of Operational Data

U.S. Nuclear Regulatory Commission

Washington, DC 20555

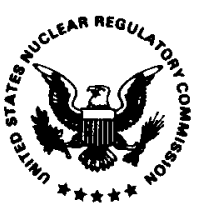




\section{DISCLAIMER}

This report was prepared as an account of work sponsored by an agency of the United States Government. Neither the United States Government nor any agency Thereof, nor any of their employees, makes any warranty, express or implied, or assumes any legal liability or responsibility for the accuracy, completeness, or usefulness of any information, apparatus, product, or process disclosed, or represents that its use would not infringe privately owned rights. Reference herein to any specific commercial product, process, or service by trade name, trademark, manufacturer, or otherwise does not necessarily constitute or imply its endorsement, recommendation, or favoring by the United States Government or any agency thereof. The views and opinions of authors expressed herein do not necessarily state or reflect those of the United States Government or any agency thereof. 


\section{DISCLAIMER}

Portions of this document may be illegible in electronic image products. Images are produced from the best available original document. 


\section{ABSTRACT}

This document presents a method of source term estimation that reflects the current understanding of source term behavior and that can be used during an event. The various methods of estimating radionuclide release to the environment (source terms) as a result of an accident at a nuclear power reactor are discussed. The major factors affecting potential radionuclide releases off site (source terms) as a result of nuclear power plant accidents are described. The quantification of these factors based on plant instrumentation also is discussed. A range of accident conditions from those within the design basis to the most severe accidents possible are included in the text. A method of gross estimation of accident source terms and their consequences off site is presented. 

TABLE OF CONTENTS

Page

ABSTRACT

i ii

FOREWORD

..

ACKNOWLEDGEMENTS.

xi ii

ACRONYMS AND INITIALISMS

$x v$

xvii

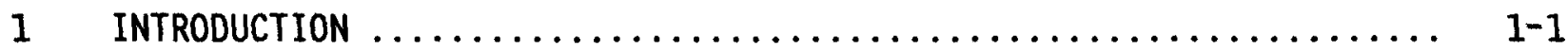

1.1 objective $\ldots \ldots \ldots \ldots \ldots \ldots \ldots \ldots \ldots \ldots \ldots \ldots \ldots \ldots \ldots \ldots, 1-1$

1.2 Prerequisites $\ldots \ldots \ldots \ldots \ldots \ldots \ldots \ldots \ldots \ldots \ldots \ldots \ldots \ldots \ldots, 1-1$

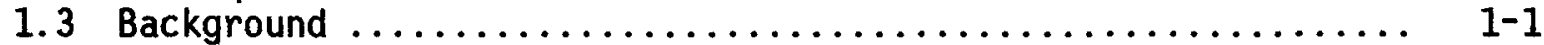

1.4 Bases for Source Term Estimation .................... 1-3

1.4.1 Source Term Estimates Based on Effluent Monitors ...... 1-4

1.4.2 Source Term Estimation Based on Accidents Analyzed as

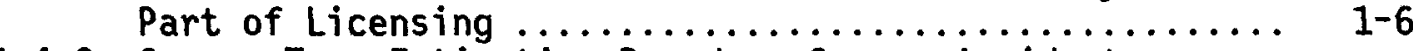

1.4.3 Source Term Estimation Based on Severe Accident Consequence Studies ......................... 1-6

1.4.4 Source Term Estimates Based on Detailed Analysis of Plant Conditions .......................... 1-8

1.4.5 Source Term Estimates Based on Precalculated Assumptions of Dominant Accident Conditions ............. 1-10

2 RADIONUCLIDES IMPORTANT IN SOURCE TERM ASSESSMENT $\ldots \ldots \ldots \ldots \ldots .2-1$

2.1 Objective $\ldots \ldots \ldots \ldots \ldots \ldots \ldots \ldots \ldots \ldots \ldots \ldots \ldots \ldots \ldots \ldots, 2-1$

2.2 Fission Products $\ldots \ldots \ldots \ldots \ldots \ldots \ldots \ldots \ldots \ldots \ldots \ldots \ldots \ldots, 2-1$

2.2.1 Source of Fission Products $\ldots \ldots \ldots \ldots \ldots \ldots \ldots \ldots, 2-1$

2.2.2 Inventory of Fission Products in the Core .......... 2-1

2.2.3 Fission Products Important to Offsite Consequences .... 2-1

2.3 Inventory Assumptions To Be Used for Source Term Estimation .. 2-5

3 RADIONUCLIDE TRANSPORT MECHANISMS UNDER NORMAL OPERATING CONDITIONS

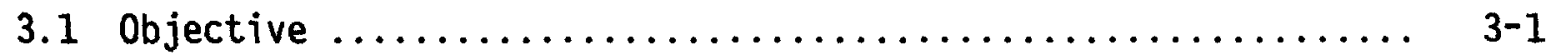

3.2 Barriers to Fission Product Release .................. 3-1

3.3 Radionuclide Transport From the Fuel Matrix Into the Fue 1Cladding Gap ................................. $3-1$

3.4 Radionuclide Transport From the Fuel Into the Coolant ....... 3-4

3.5 Routine Effluent Releases ............................ 3-10 
TABLE OF CONTENTS (Continued)

Page

4 ESTIMATING RADIONUCLIDE TRANSPORT MECHANISMS UNDER SEVERE

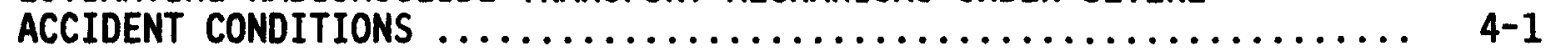

4.1 objective......................................

4.2 Major Considerations $\ldots \ldots \ldots \ldots \ldots \ldots \ldots \ldots \ldots \ldots \ldots \ldots \ldots, 4,1$

4.3 Estimating Core Fission Product Inventory $\ldots \ldots \ldots \ldots \ldots \ldots .44,2$

4.4 Estimating Fission Product Inventory Released From the Core .. 4-3

4.4.1 Normal Fue] Pin Leakage $\left(600^{\circ} \mathrm{F}\right) \ldots \ldots \ldots \ldots \ldots \ldots . . .4$

4.4.2 Fuel Cladding Rupture/Gap Release $\left(1300^{\circ}-2100^{\circ} \mathrm{F}\right) \ldots . . .4$ 4-5

4.4.3 Grain Boundary Release $\left(3000^{\circ} \mathrm{F}\right)$ and Melt Release

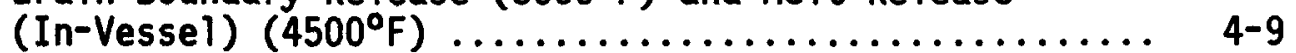

4.4.4 Reactor Vessel Melt-Through (Ex-Vessel Melting) ...... 4-11

4.4.5 Form of Release From the Fuel $\ldots \ldots \ldots \ldots \ldots \ldots \ldots \ldots .4-11$

4.5 Movement of Fission Products From the Core to Atmosphere (Re-

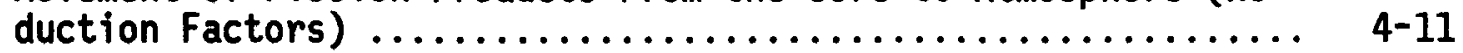

4.5.1 Basic Fission Product Reduction Mechanisms .......... 4-13

4.5.1.1 Gaseous Release Reduction Mechanisms ....... 4-13

4.5.1.1.1 Plateout in the Reactor Coolant

4.5.1.1.2 Removal of Aerosois and Particu-

lates Suspended in Large Volumes... 4-13

$\begin{array}{lll}\text { 4.5.1.1.2.1 } & \begin{array}{l}\text { Natural Removal } \\ \text { Reduction Factors ..... }\end{array} & 4-14 \\ 4.5 .1 .1 .2 .2 & \begin{array}{l}\text { Spray Removal Reduc- } \\ \text { tion Factors ......... }\end{array} & 4-14\end{array}$

4.5.1.1.3 Filters ................. 4-14

$\begin{array}{lll}\text { 4.5.1.1.3.1 BWR Standby Gas } & \\ & \text { Treatment System .... 4-16 }\end{array}$

4.5.1.1.3.2 PWR Containment Recirculating Filter System ............ 4-16

4.5.1.1.3.3 PWR Auxiliary Building Filter Systems ... 4-17

4.5.1.1.4 BWR Suppression Pool .......... 4-17

4.5.1.1.5 PWR Ice Condenser ............. 4-18

4.5.1.2 Liquid Release Reduction Mechanisms ........ 4-18

4.5.2 Basic Release Pathways and Characteristics ......... 4-22 
TABLE OF CONTENTS (Continued)

Page

4.5.2.1 Reactor Coolant System (Third Fission Product

Barrier)

4-22

4.5.2.1.1 PWR Reactor Coolant System Breaks/Leaks ................ 4-22

4.5.2.1.2 PWR Power-Operated Relief Valves .. 4-35

4.5.2.1.3 PWR Steam Generator Tube Rupture... 4-35

4.5.2.1.4 PWR and BWR Bypass Accidents ..... 4-36

4.5.2.1.5 PWR and BWR Vesse1 Me1t-Through ... 4-37

4.5.2.1.6 PWR and BWR Leakage From Process

Lines .................... 4-38

4.5.2.1.7 BWR Reactor Coolant System

Breaks/Leaks ................. 4-40

4.5.2.1.8 BWR Automatic Depressurization

System and/or Safety Relief

Valves

4-40

4.5.2.2 Primary Containment (Fourth Fission Product

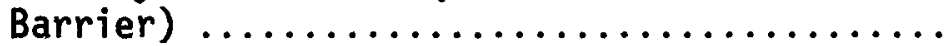

4-40

4.5.2.2.1 Design Leakage ................ 4-41

4.5.2.2.2 Isolation Failures ............. 4-42

4.5.2.2.3 Catastrophic Containment

Failures ................... 4-42

4.5.2.2.3.1 Hydrogen Detonation/

4.5.2.2.3.2 Steam Explosions,

Direct Heating, and

Missiles ........... 4-46

4.5.2.2.3.3 Containment Over-

pressurization ...... 4-46

4.5.2.2.4 Containment Bypass ............. 4-47

4.5.2.2.5 Controlled Venting of
Containment .................. 4-47

4.5.2.3 Other Barriers ..................... 4-48

4.6 Plant Instrumentation $\ldots \ldots \ldots \ldots \ldots \ldots \ldots \ldots \ldots \ldots \ldots \ldots \ldots \ldots, 4-49$

4.6.1 Radiation Monitors $\ldots \ldots \ldots \ldots \ldots \ldots \ldots \ldots \ldots \ldots, 4,49$

4.6.2 Grab Samples ................................ 4-53

4.6.3 Key Plant Parameters $\ldots \ldots \ldots \ldots \ldots \ldots \ldots \ldots \ldots \ldots \ldots \ldots \ldots \ldots \ldots \ldots, 4-54$

4.6.3.1 Core Temperature $\ldots \ldots \ldots \ldots \ldots \ldots \ldots \ldots \ldots$ 4. 4-54

4.6.3.1.1 Pressurized-Water Reactor ....... 4-54

4.6.3.1.2 Boiling-Water Reactor .......... 4-56 
4.6.3.2 Reactor Coolant Temperature and Pressure ..... 4-56

4.6.3.3 PWR Pressurizer Level .................... 4-56

4.6.3.4 Reactor Vesse1 Water Leve1 ............. 4-57

4.6.3.4.1 BWR Water Leve] Indicator ....... 4-57

4.6.3.4.2 PWR Vessel Coolant Level
Detectors .................. 4-57

4.6.3.5 Engineered Safety Feature and Critical Safety

Function Status Indication ............... 4-57

4.6.3.6 Containment Isolation Status ............. 4-58

4.6.3.7 Containment Atmosphere Temperature and

Pressure ........................... 4-58

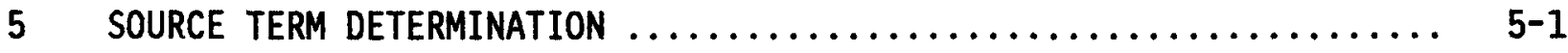

5.1 Objective $\ldots \ldots \ldots \ldots \ldots \ldots \ldots \ldots \ldots \ldots \ldots \ldots \ldots \ldots \ldots, 5-1$

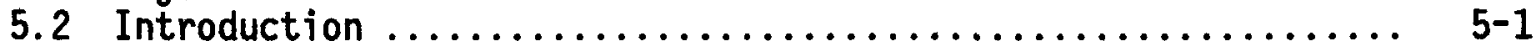

5.3 Sample Source Term Calculation ...................... 5-2

5.3.1 Step 1: Gather/Assess Plant Information ........... 5-2

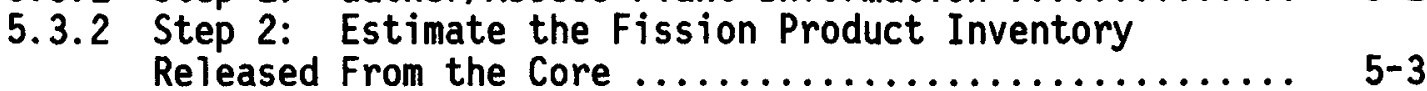

5.3.3 Step 3: Estimate the Fission Products Available for

5.3.4 Step 4: Estimate 1-Hour Release ................ 5-4

5.4 Use of Event Trees To Estimate Release ................ 5-6

5.5 Comparison With Current Source Term Results .............. 5-28

5.6 Estimate the Uncertainties .......................... 5-28

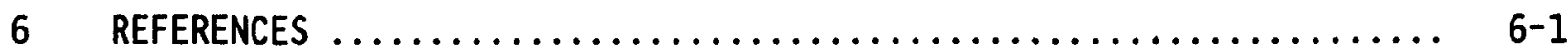

APPENDIX A PROCEDURE FOR ESTIMATING OFFSITE CONSEQUENCES BASED ON PLANT CONDITIONS

\section{List of Figures}

1.1 Source term estimation based on effluent monitors $\ldots \ldots \ldots \ldots \ldots$ 1-5

1.2 Relationship of plant conditions to WASH-1400, siting source terms and consequences $\ldots \ldots \ldots \ldots \ldots \ldots \ldots \ldots \ldots \ldots \ldots, 1-7$

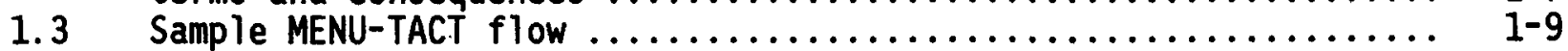

1.4 Examples of major aerosol/particulate reduction mechanisms ..... 1-11

2.1 Relative importance to bone marrow dose of the radioactive elements found in the core of a reactor given a major release ... 2-4

2.2 Inventory of $\mathrm{Kr}-85$ in core of a 1000 MWe PWR ............ 2-5 


\section{TABLE OF CONTENTS (Continued)}

$\underline{\text { Page }}$

3.1 Fission product barriers to release of radioactive material for

3.2 Cross section of fue 1 pei $i$ et $i$ i ustrating cracking $\ldots \ldots \ldots \ldots \ldots \ldots$

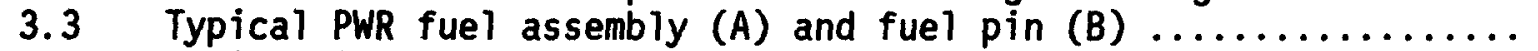

3.4 Typical iodine spike following shutdown $\ldots \ldots \ldots \ldots \ldots \ldots \ldots \ldots \ldots \ldots$

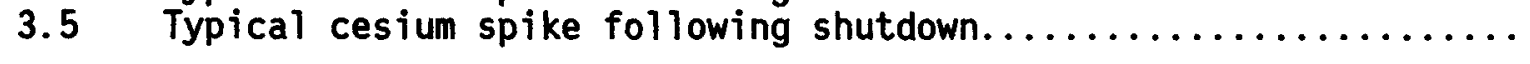

4.1 Fission product release rate constants from fuel - smoothed

4.2 Comparison of removal of airborne aerosols and particulates by

4.3 Typical pathways for release of radionuci 1 ides to the atmosphere from a steam generator tube rupture ................... 4-20

4.4 Conditions in radionuclide release pathways following a "U" tube steam generator tube rupture to the environment ...........

4.5 PWR dry containment simplified release pathways ...............

4.6 PWR ice condenser containment simplified release pathways .......

BWR Mark I simplified release pathways $\ldots \ldots \ldots \ldots \ldots \ldots \ldots \ldots \ldots$

BWR Mark II simplified release pathways $\ldots \ldots \ldots \ldots \ldots \ldots \ldots \ldots \ldots$

4. 10

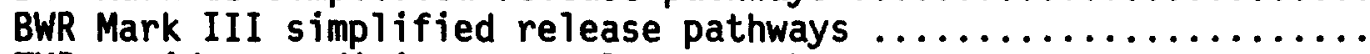

TMI accident radioisotope release pathways

4-10

4. 12

Comparison of early containment failure

Low-temperature and-pressure flammability and detonation

limits of hydrogen, air, and steam mixtures

4.13 Response (CPs) of selected process monitors during the TMI

accident

4.14 Response of selected area radiation monitors during the TMI

$$
\text { accident }
$$

4.15 TMI-2 accident: map of core exit temperature $\left({ }^{\circ} \mathrm{F}\right), 8: 00 \mathrm{a} . \mathrm{m}$. 9:00 a.m., March 28, 1979

4.16 Relationship among critical safety functions, maintaining fission product barriers, and preventing a release

5.1 Release pathway for sample calculation case .............. 5-5

5.2A PWR large, dry or subatmospheric containment release event tree

5.2B for a gap release from the core .......................................

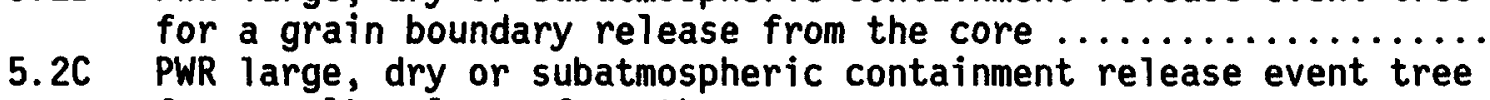

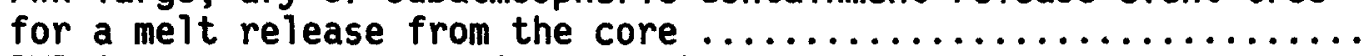

5. 3A PWR ice condenser containment release event tree for a gap release from the core $\ldots \ldots \ldots \ldots \ldots \ldots \ldots \ldots \ldots \ldots \ldots \ldots \ldots \ldots \ldots$

5.3B PWR ice condenser containment release event tree for a grain boundary release from the core .........................

5.3C PWR ice condenser containment release event tree for a melt release from the core..$\ldots \ldots \ldots \ldots \ldots \ldots \ldots \ldots \ldots \ldots \ldots \ldots$

5. 4A A PWR steam generator tube rupture event tree for a release of normal and $100 \mathrm{X}$ spike coolant 
5.4B PWR steam generator tube rupture event tree for a release of coolant contaminated with a gap release from the core ...........

5.4C PWR steam gneerator tube rupture event tree for a release of coolant contaminated with a grain boundary release from the$$
\text { core }
$$

PWR steam generator tube rupture event tree for a release of coolant contaminated with a melt release from the core $\ldots . . . \ldots$.

5.5A BWR containment, dry-well leakage/failure release event tree

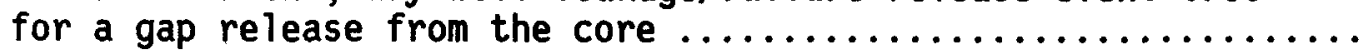

5.5B BWR containment, dry-well leakage/failure release event tree for a grain boundary release from the core

5.5C BWR containment, dry-well leakage/failure release event tree

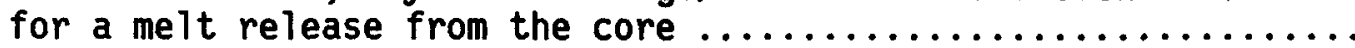

5.6A BWR containment, wet-well leakage/failure release event tree

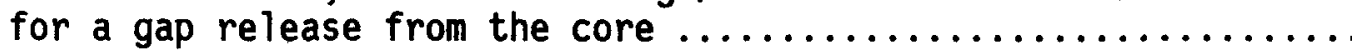

5.6B BWR containment, wet-well leakage/failure release event tree

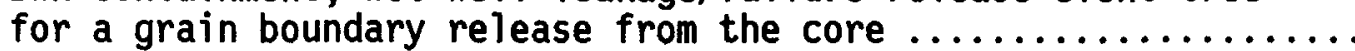

5.6C BWR containment, wet-well leakage/failure release event tree

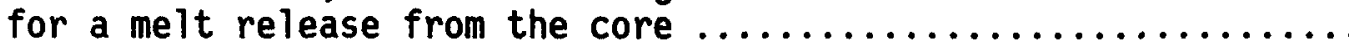

5.7A PWR and BWR containment bypass release event tree for a gap

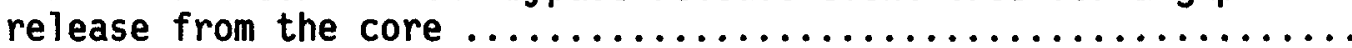

5.7B PWR and BWR containment bypass release event tree for a grain boundary release from the core $\ldots \ldots \ldots \ldots \ldots \ldots \ldots \ldots \ldots \ldots \ldots$.

5.7C PWR and BWR containment bypass release event tree for a meit

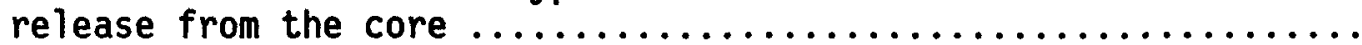

5.8 Comparison of source term projection results for station blackout scenarios at Surry

\section{List of Tables}

2.1 Factors that have the greatest effect on radionuclide

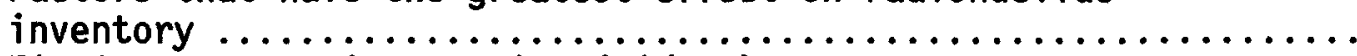

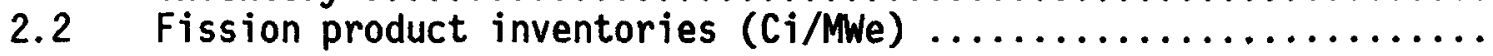

3.1 Melting point and boiling point $\left({ }^{\circ} \mathrm{F}\right)$ of selected materials ..... 3-5

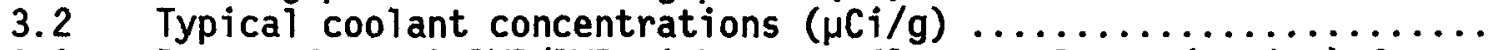

3.3 Range of total BWR/PWR airborne effluent release (curies) for 1980

3.4 Release rate $(\mathrm{C} i / \mathrm{sec})$ needed to meet benchmarks $\ldots \ldots \ldots \ldots \ldots \ldots$

4.1 Core release fraction assumptions (1-hour release) ........... 4-4

4.2 Average LWR fuel, cladding, and coolant operational

4.3 PWR baseline coolant concentrations for various levels of core 
TABLE OF CONTENTS (Continued)

4.4 BWR baseline coolant concentrations for various levels of core

$4.5 \quad$ Summary of particulate/aerosoi gaseous reduction mechanisms $\ldots \ldots . .4 \quad 4-7$

4.6 Typical BWR standby gas treatment system suction locations ...... 4-16

4.7 Summary of major PWR release pathway reduction mechanisms ....... 4-28

4.8 Summary of major BWR release pathway reduction mechanisms $\ldots \ldots \ldots$ 4-31

4.9 Key to release pathway references on Figures 4.5 through $4.9 \ldots . .404$

4.10 Assumed containment and steam generator tube rupture escape fraction for 1 hour .................................. 4-37

4.11 Sample containment design pressures and failure pressures ...... 4-47

5.1 1-mile doses for release of various core and coolant

5.2 Comparison of event tree doses with $C R A C$ whole-body dose

projections for WASH-1400 PWR release categories at 1 mile ..... 5-30 



\section{FOREWORD}

In the event of a severe nuclear power accident, the initial public protective measures or plant action to mitigate the accident may be revised based on an estimate of possible offsite consequences. 'This requires a method to relate key accident conditions to the distance to which the U.S. Environmental Protection Agency's Protective Action Guides (PAGs) may be exceeded and the distance to which early health effect or early death dose levels are possible.

The U. S. Nuclear Regulatory Commission (NRC) headquarters Protective Measures Team recognized that the current methods used to estimate radionuclide release (source term) consequences for severe accidents are inadequate. These methods either require an accident to fit a specific sequence already analyzed or to run a detailed computer code for which there are no commonly agreed-on set of assumptions. Both methods require a person with a detailed knowledge of all aspects of source term research, a detailed knowledge of plant conditions, and considerable time. Experience has shown in many cases that the events either do not fit a specific sequence already analyzed or that the analyst does not have sufficient time or information to conduct a detailed analysis. Furthermore, there is limited experience with source term assessment in the NRC regions and in licensee or State/local response organizations. Therefore, it is unlikely that early responders could benefit from these methods. Moreover, the results of a headquarters analysis often would be difficult to explain or reproduce since they are not based on commonly accepted and documented assumptions.

The Incident Response Branch was requested to develop a simple method of relating basic plant conditions to the distance to which PAGs may be exceeded and early health effect or early death dose levels may be possible. This document and procedure are the result of this effort. This document is written to be used by personnel without a detailed source term background and explains the basics of source term estimation. The resulting simple method presented in Section 5 and incorporated in a stand-alone procedure (Appendix A) uses a set of condition trees that relate dominant reactor accident conditions to consequences. These trees present, in a form that can easily be related to reactor plant conditions, the results of calculations performed by the models used in the NRC Operations Center. The goal is to have a common method to quickly bound the possible consequences of an accident available to all responders. The method and assumptions presented in this document will be reviewed on an ongoing basis and revised as appropriate to reflect advances in our understanding of severe accident source terms.

Please provide your comments to Incident Response Branch.

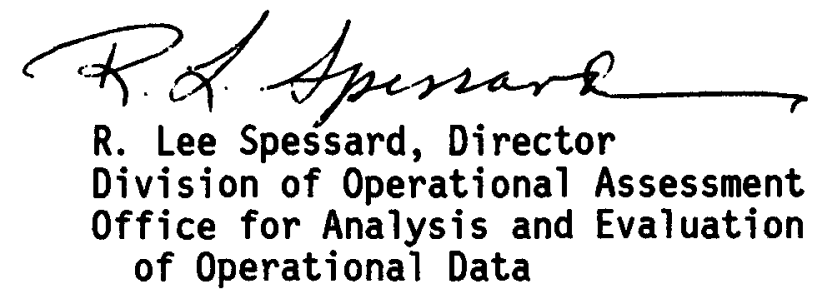

NUREG-1228 



\section{ACKNOWLEDGEMENTS}

Walter Pasedag and Patrick Easely (formerly of the U.S. Nuclear Regulatory Commission) were responsible for recognizing the need for this work and for providing the basic concepts on which it is based. 

ACRONYMS AND INITIALISMS

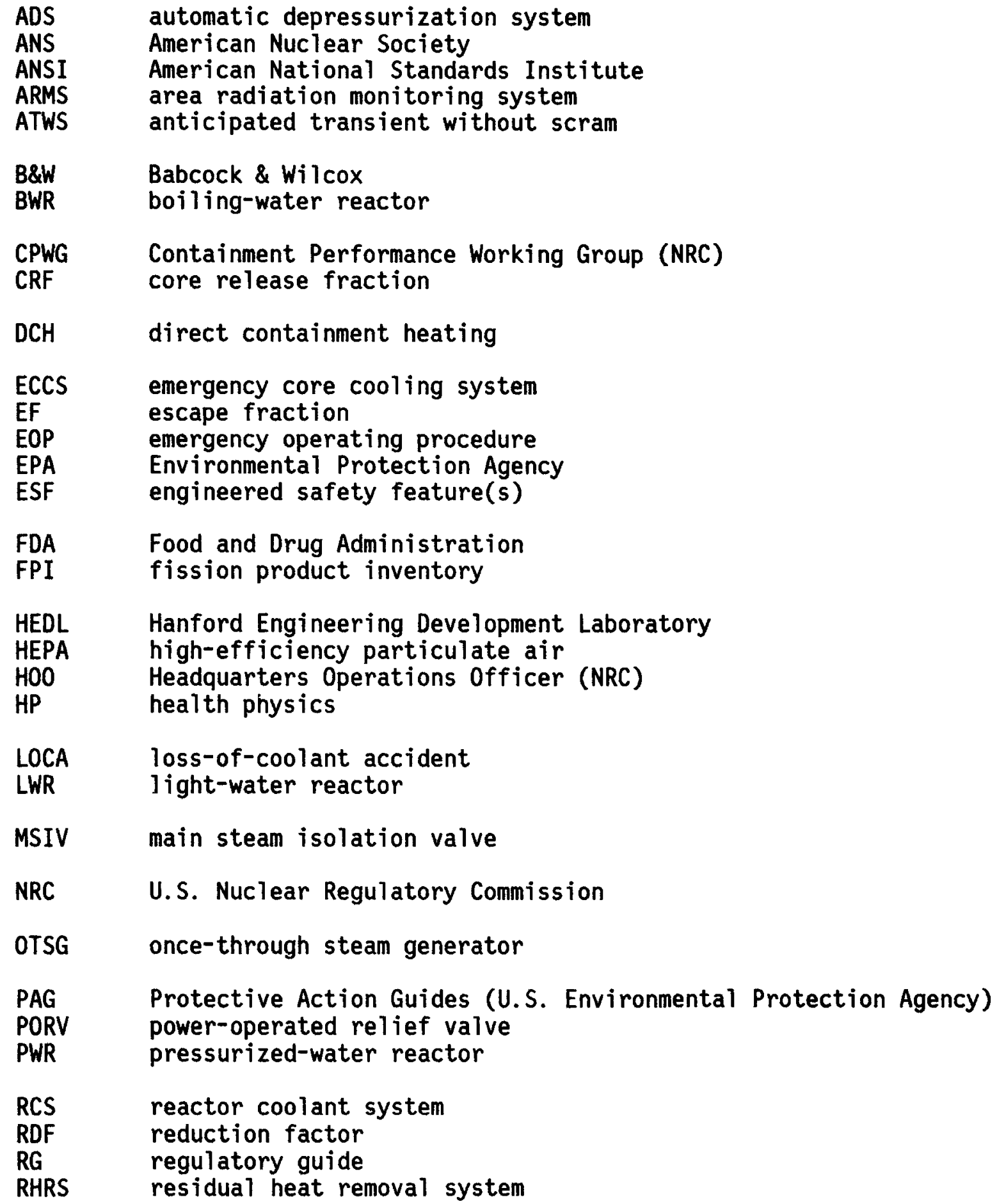


SBGTS standby gas treatment system

SG steam generator

SGTR steam generator tube rupture

SRV safety relief valve

SST siting source term

TMI Three Mile Island Nuclear Power Station 


\section{INTRODUCTION}

\subsection{Objective}

To enable the reader to

- $\quad$ specify the role of radionuclide release (source term) assessment in emergency response

- illustrate the necessity of recognizing and identifying the great uncertainties associated with performing a source term assessment

- understand the utility of the various source term estimation methods for use during an accident

\subsection{Prerequisites}

For the reader to understand the concepts in this manual, a basic understanding of reactor systems is required along with an understanding of protective actions related to severe reactor (core damage) accidents. It is highly recommended that Volumes 2 and 4 of NUREG-1210, "Severe Reactor Accident Incident Response Training Manual," be studied before reading this document.

\subsection{Background}

A radioactive release (source term) for accidents involving major core damage that could result in early injuries or deaths to the public near the plant can always be projected. As discussed in NUREG-1210, Volumes 2 and 4 , those projections are based on an assumption of a major early release (containment failure). A wide range of these types of accidents has been analyzed. It may be impossible to produce an analysis during a severe accident that will provide additional insight into possible consequences and appropriate offsite protective actions. The results of the vast amount of analysis of severe accidents have been incorporated into the current NRC guidance on protective actions for core damage accidents. Therefore, initial protective action decisions for core damage accidents (general emergency) should never be based on source term or dose calculations performed at the time of the accident. These decisions must be based on predetermined plans based on NRC guidance. In fact, for core damage accidents, the source term calculations required for initial decisions have already been done, forming the basis for the current guidance.

For a severe nuclear power plant accident (core damage), the immediate predetermined protective actions are taken based on in-plant indicators of core and containment conditions (e.g., core and containment temperatures and pressures). If core damage is projected or exists, the population near the plant (2-5 miles) should be evacuated, and people within a 10-mile radius of the site should be sheltered. This protective action strategy was determined based on considerations of consequence analyses for a wide range of core damage accidents involving containment failure, bypass, or leakage. These actions would 
provide adequate immediate protective actions for most core damage accidents. However, there may be core damage accidents that would warrant taking additional protective actions or that would require various plant response options (e.g., venting) to be assessed. These assessments may require promptly assessing accident source terms during the accident.

The first step in a dose assessment is to determine the amount of various radionuclides that are postulated or estimated to be released to the environment. This characterization of radionuclides that may be released to the environment, in conjunction with release rate and height, is referred to as the "source term." In the past, these dose assessments have been based on estimates of releases provided by plant radiation monitors. However, this approach is inadequate under severe accident conditions, for the reasons discussed in Volume 2 of NUREG-1210. In addition, in a severe accident situation, it would be undesirable to wait until the release occurs before taking the necessary additional protective action because effective protective action requires prompt implementation. Therefore, an attempt should be made to project the magnitude of a release before it occurs. To be useful, these projections should be based on a best-estimate assessment of the source term and not on artificial assumptions intended only for licensing purposes. There has been a tendency in the past to utilize the source term assumptions in Regulatory Guides (RGs) 1.3 and 1.4, which indicate that $100 \%$ of the noble gases, $25 \%$ of the halogens, and $1 \%$ of the other fission products are released to the containment. These assumptions should not be used to characterize an actual accident. The regulatory guide assumptions also tend to reinforce the erroneous assumptions that only noble gases and iodine would be released during a severe accident.

By their very nature, severe accidents involve conditions that make the prediction of the source term very difficult: the plant is beyond design conditions, instrument readings may be unreliable, accident progression is unpredictable, specific in-plant conditions may not be known or can change quickly and unexpectedly. In addition, even if plant conditions and accident progression were completely understood, the ability to project the source term would be very limited because of the limited understanding of source term physics and chemistry. The result is that for a severe accident there is little hope of actually predicting the source term; only approximations of source term with large uncertainties can be produced. Because of these great uncertainties, there is little purpose being served by performing complex detailed assessments that consider secondary or little understood effects. Recent studies of the uncertainties associated with source term estimation indicate that source term projections based on accident conditions are only accurate within a factor of 100 or more, even if all of the accident conditions are known (NUREG-0956 and NUREG-1150). Furthermore, experience has indicated that the details of accident conditions usually are not available until the event is terminated--thus a full understanding of the accident conditions will probably not be immediately available to the analyst performing the dose assessment. Thus, any result obtained during an accident will have a possible error of 1 to 3 orders of magnitude or more. However, source term studies do provide important insights into what accident conditions dominate the characteristics of a release. This information allows relative consequence comparisons to be made between different release pathways or conditions. The possible consequences of various accident sequences can be ranked based on consideration of these dominant accident conditions. For example, it is clear that there is considerably less risk from a 
release that has passed through the suppression pool in a boiling-water reactor (BWR) as compared with one that has not been filtered by the suppression pool. There also should be sufficient information to rank specific accidents relative to their consequence potential. For example, it is clear that it requires major damage to the core of a reactor or possibly the spent fuel pool and a fast and substantially unfiltered pathway to the environment to result in early deaths or injuries off site. Source term assessments conducted during an accident must be based on fast, best-estimate calculations that account for the dominant effects. If a change in assumptions does not result in a change to the source term by at least 1 order of magnitude, it is not worth considering because it will provide no useful information. These assessments are best directed at comparisons of the potential offsite consequences from various possible accident sequences. Because of the great uncertainties associated with specific source term estimates, these rankings do not require detailed consideration of offsite transport and dose. In most cases, the estimate of offsite consequences should be used, and not dose estimates, when discussing the results. Additionally, in most cases, it will not be possible to project a source term with sufficient accuracy to estimate an offsite dose that can be reasonably expected to match that resulting from the release. However, the relative risk of the accident and its projected sequences can be judged.

For the decision-makers to be able to use the source term estimate in their decision process, these uncertainties must be understood and their bases must be clear. To support any decision by the decision-makers, the following tasks must be performed:

(1) Only the dominant plant conditions that influence the potential risk to the offsite population, resulting from the release, must be identified and considered.

(2) Based on current and projected plant conditions, a best estimate of the magnitude of any offsite releases and the assumptions on wich these estimates are based must be provided for the sequences considered.

(3) The confidence the analyst has in the estimate must be specified. A discussion of the great uncertainties always associated with source term must be included.

(4) The reasonable bounds of the analyst's estimate must be specified.

(5) The upper and lower bounds of the release must be stated based on possible courses of the accident or changes in key assumptions as related to offsite consequences such as doses large enough to result in early health effects (50-100 rem) or to exceed the Environmental Protective Agency's Protective Action Guides (1-5 rem whole body) (EPA-520/1-75-001).

\subsection{Bases for Source Term Estimation}

There are five bases that may be used to estimate source term (radionuclide release) from a severe reactor accident. These are

(1) effluent monitor readings 
(2) accident analysis contained in the safety evaluation report

(3) various severe accident consequence studies such as the Reactor Safety Study (WASH-1400)

(4) detailed analysis of plant conditions conducted during an accident

(5) precalculated estimates that relate dominant accident conditions to potential radionuclide releases (source terms)

Each of these bases will be discussed briefly although this document concentrates on providing a methodology for basis 5 above.

\subsubsection{Source Term Estimates Based on Effluent Monitors}

Obviously if a release is out of a monitored pathway, the monitor could provide useful information on the size of the release. However, a monitor does not provide a direct measure of release rate $(\mathrm{Ci} / \mathrm{sec})$ for the various isotopes being released. As shown in Figure 1.1 an isotopic release rate estimate is based on measured flow and activity (counts/sec) and assumptions about monitor efficiency and isotopic mixture. The nuclear plant operators have developed calibration values based on assumed release mixture that relate monitor measurements (counts/sec) to a specific isotopic release rate (e.g., $100 \mathrm{Ci} / \mathrm{sec}$ $\mathrm{kr}-85)$.

On-line radiation monitors capable of measuring the noble gases released through plant vents were installed at nuclear facilities following the Three Mile Island, Unit 2, accident. However, on-line monitors for iodine and other particulates were not considered practical. The amounts of iodine and particulates in a release are normally determined through analysis of samples taken during the release. This could require several hours.

Use of effluent monitors as the sole basis of a source term estimate/projection has four disadvantages:

(1) Major releases may bypass the monitors (e.g., major containment failure) and therefore will not be characterized.

(2) The mixture being released may not be that assumed in the calibration for the monitor. The actual composition of the release may not be known for several hours until samples have been analyzed.

(3) Effluent monitors provide source term estimates at the time of the release. As discussed in Volumes 2 and 4 of NUREG-1210, this may be too late for implementation of the most effective protective actions.

(4) Accident conditions may influence the monitor; for example, because of contamination of the monitors, they may indicate releases long after the releases have stopped.

Consequence/dose estimates based on effluent monitors are important, even considering their shortcomings. Such estimates are of a known release while all other bases are for projected pathways. Estimates based on effluent monitor 


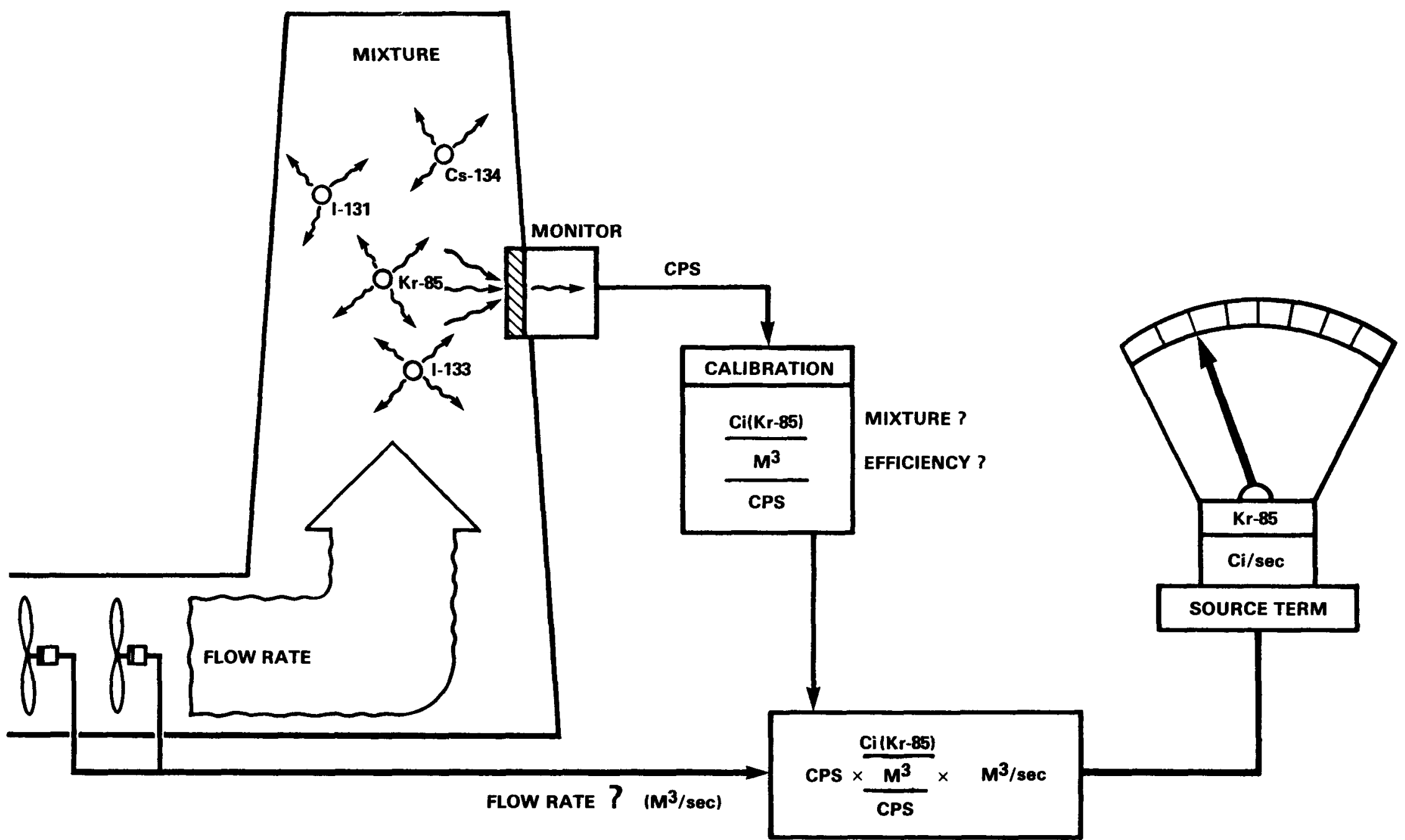

Figure 1.1 Source term estimation based on effluent monitors 
readings, when compared to actual field monitoring data, can confirm or discount the existence of other release pathways. During events not involving core damage, effluent monitor readings may be the primary basis of source term estimation.

\subsubsection{Source Term Estimation Based on Accidents Analyzed as Part of Licensing}

As part of the licensing process, analyses are conducted of various postulated accidents, some of which have the potential for offsite releases. These postulated accidents are listed in Section 15 of the Standard Review Plan

(NUREG-0800). They include

control rod drop accidents

steam generator tube failures

loss-of-coolant accidents (LOCAs)

waste tank leak/failure

fuel handing accidents

spent fue 7 drop accidents

anticipated transients without scram

These analyses are based on very conservative assumptions and, in many cases, unrealistic accident scenarios. The result is that for the accident conditions analyzed, the projected offsite doses are much greater than realistic projections. In some cases, the differences between realistic and assumed calculations found in the Standard Review Plan could be several decades. Because of the unrealistic nature of these evaluations, they normally should not be used to estimate actual accident source terms or offsite doses. These analyses cannot even form an upper bound of offsite consequences since the containment is typically assumed to remain intact and only single failures are allowed.

\subsubsection{Source Term Estimation Based on Severe Accident Consequence Studies}

Starting with the Reactor Safety Study (WASH-1400, 1975), studies have been conducted to estimate the source terms that could result from various accidents involving core damage. The Reactor Safety Study analyzed many specific accidents and the results were grouped into "release categories." Tables 1.a and 1.b of NUREG-1062 show the fission products released for each pressurized-water reactor (PWR) and BWR release category. These release categories are sometimes used to characterize the possible accident source terms by persons knowledgeable of probabilistic risk assessment (PRA) research.

The specific accidents that are associated with a release category are typically described by symbols (e.g., AE- $\alpha$ ). Tables 4 through 7 of NUREG-1062 provide a key to the set of letters used in WASH-1400 and other studies to identify specific accidents. However, these designations normally are not understood by people not knowledgeable of PRA. In addition, a specifically studied, postulated accident sequence may not fit the actual accident conditions or the actual accident conditions may not be known sufficiently to be categorized.

As an aid, Figure 1.2 shows the relationship of basic accident conditions to WASH-1400 and other release categories and possible offsite consequences. This figure is in the form of an event tree. Moving from left to right, "yes/no" 


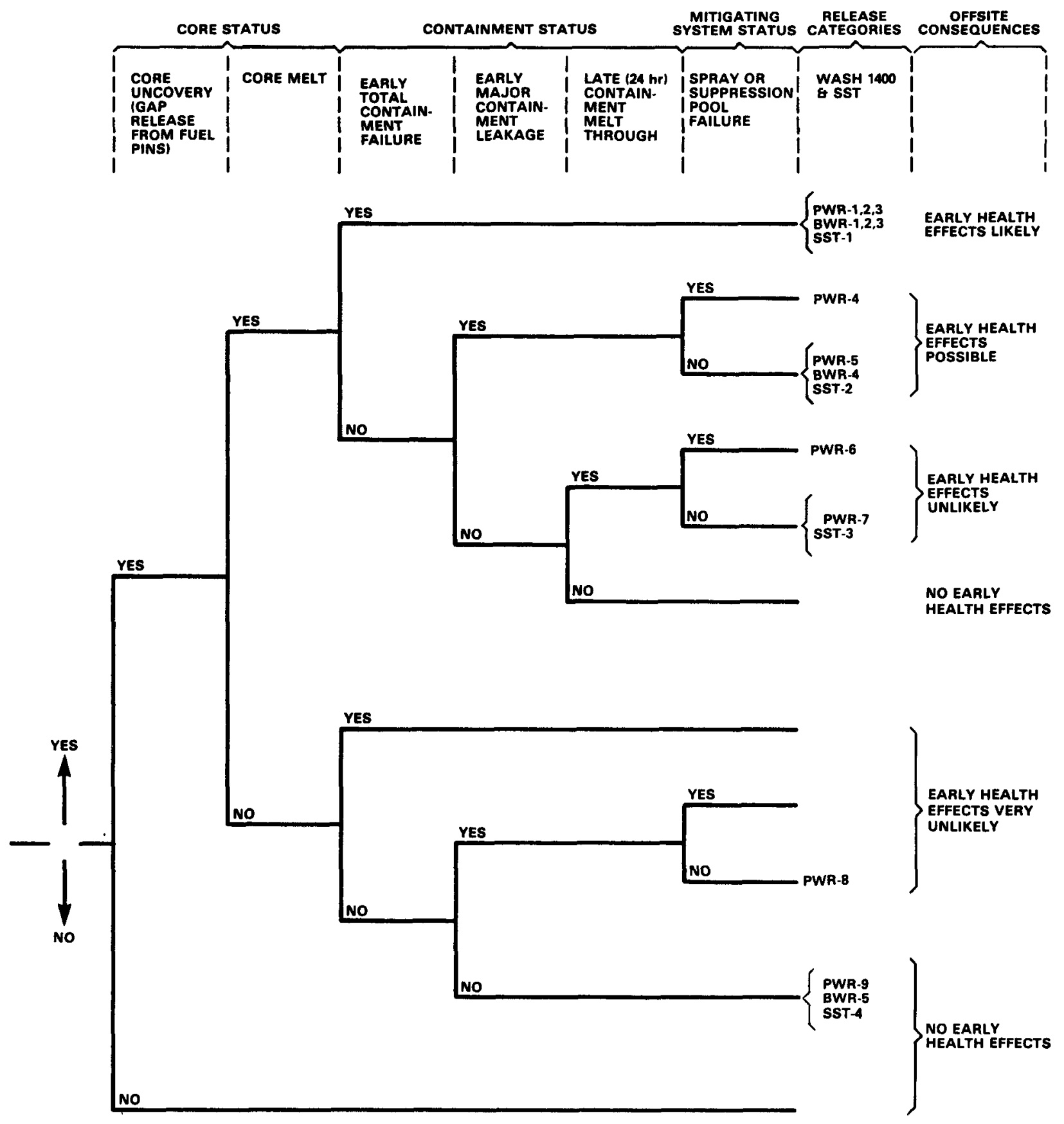

Figure 1.2 Relationship of plant conditions to WASH-1400, siting source terms and consequences 
answers to the accident conditions at the top result in a series of branches of possible source term categories and offsite consequences.

Since 1975, many additional studies have been conducted to correct shortcomings in the WASH-1400 analyses. In 1982, a set of source term categories (NUREG/ CR-2239) were constructed that also spanned the range of possible source terms associated with major reactor accidents. These source terms are denoted as siting source terms (SSTs). Figure 1.2 also shows the relationship of plant conditions to these source terms.

Figure 1.2 shows that knowledge of the status of major plant systems during an accident only allows a crude estimate of the source term. In the case of the most serious accident shown in Figure 1.2, several release categories (BWR/ PWR 1-2-3) all are associated with the most severe accident conditions. This may appear to be an unacceptable range, but this may be as accurate as possible during an actual accident. The NRC assessment of the Chernobyl source term was that it was a PWR 1,2, or 3. However, the magnitude of the offsite consequences for Chernobyl are not comparable to those projected for these release categories. This was the result of the release being in the form of a very high plume. This type of release is not thought to be possible at a U.S. reactor site.

The WASH-1400 and SST release categories, if they can be related to the conditions during an accident by a knowledgeable analyst, or by Figure 1.2 , could provide a valuable tool in predicting the possible consequences of core damage accidents. NUREG-1062 provides a simple tool for relating WASH-1400 release categories (source terms) to offsite doses for a wide range of meteorological conditions. The advantages of this basis are that core damage accidents and unmonitored pathways are considered and various dominant accident scenarios can be compaired. However, in using this and all other source term estimation methods, the analyst must keep in mind the limitations and uncertainties involved.

\subsubsection{Source Term Estimates Based on Detailed Analysis of Plant Conditions}

Computer codes (e.g., TACT, NUREG/CR-3287, NUREG/CR-4722) have been developed by the NRC to predict releases (source terms) resulting from accidents. One such code, TACT, allows the user to specify releases from the core, the pathway to the environment (nodes), and conditions that may affect the release (e.g., sprays). Figure 1.3 provides an example of the TACT code flow. These codes require considerable detailed information about the plant (e.g., containment volume), accident conditions (e.g., leak rates), and effectiveness of source term reduction mechanisms (e.g., sprays). In most cases, this detailed information is not known during an accident. Moreover, these models, which are designed for use during severe accidents, are very crude compared to the stateof-the-art models that have been developed to estimate source terms for research purposes. As discussed in NUREG-0956, the state-of-the-art models are accurate only within a factor of 100 even if all the accident conditions are known.

Therefore, the results of the models designed for use during an accident would have greater than a factor of 100 uncertainties. Another disadvantage of these codes is that they require considerable time and information, neither of which seems to be available during an accident. Finally, these codes are very flexible, and this also can be a problem if standard documented assumptions have not 


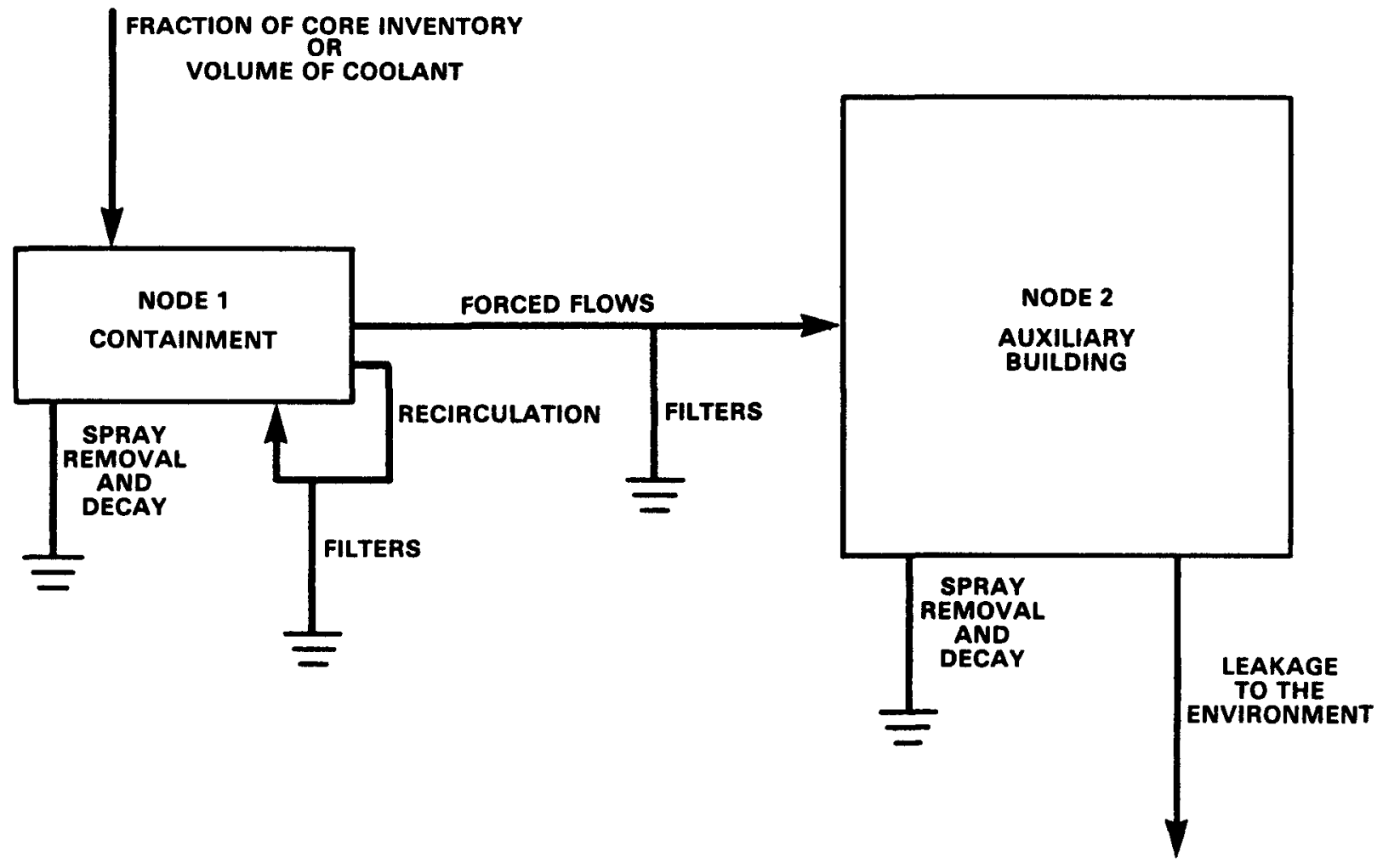

Figure 1.3 Sample MENU-TACT flow 
been established for the various model inputs. An additional problem with flexibility is that the results of these codes can be difficult to explain to others, to reproduce or compare with other analyses. This makes it very difficult to use these codes to rank consequences of various accident sequences.

These codes may be useful for analyzing lesser accidents for which conditions are well understood and when time allows this type of analysis. However, it is uncertain if the results of this approach would be any more accurate than using precalculated source terms. Considering the limited possible calculational improvement compared with the limitations, these codes do not currently appear to provide a useful response tool.

\subsubsection{Source Term Estimates Based on Precalculated Assumptions of Dominant Accident Conditions}

The remainder of this document describes, in general terms, the severe accident conditions that should dominate possible accident releases as a result of damage to the reactor core or primary coolant system. A method has been developed for estimating source term based on precalculated assumptions of dominant accident conditions. The basic assumptions of this method are that (1) there is a small set of accident conditions that dominate any severe accident release, (2) there are values that can characterize these dominant conditions, and (3) these conditions can be recognized/characterized during an actual accident.

The following are the basic steps for source term estimation:

(1) Estimate the inventory of fission products in the core.

(2) Estimate the amount of fission products released from the core.

(3) Identify the dominant release pathway.

(4) Characterize the dominant mechanisms that will act to reduce the release. These would include filters, pools of water, sprays, or natural processes as illustrated in Figure 1.4.

(5) Estimate the release rate.

This method attempts to bridge the gap between using precalculated severe accident source terms (WASH-1400) and conducting detailed calculations at the time of the event. In fact, this method arose from the observation that the same source conditions/accident assumptions were being analyzed over and over during events, drills, and exercises. The results will be a set of precalculated doses that can be used to compare possible consequences of various accident sequences.

This method allows a large range of accident conditions and core damage states to be analyzed based on a small set of predetermined assumptions that are well documented. The major disadvantage of this method, as with other methods, is the large uncertainties. However, a comparison (ranking) of the potential consequences associated with various accident scenarios will be possible. 
WATER + SLOW FLOW

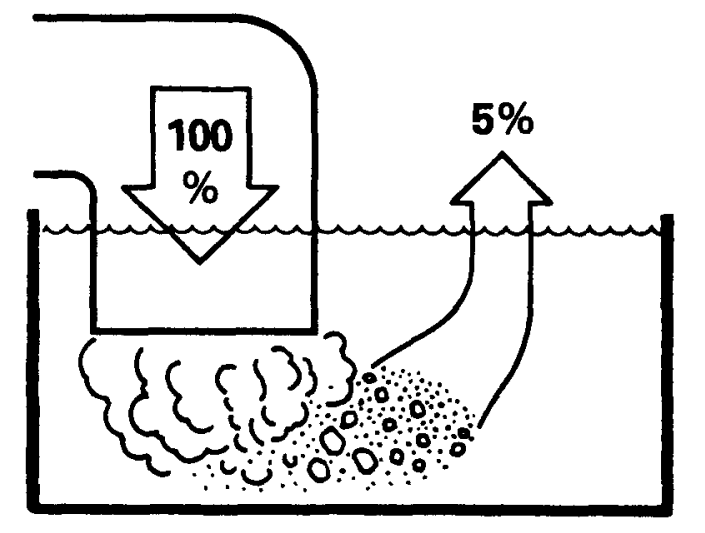

FILTER + SLOW \& DRY FLOW

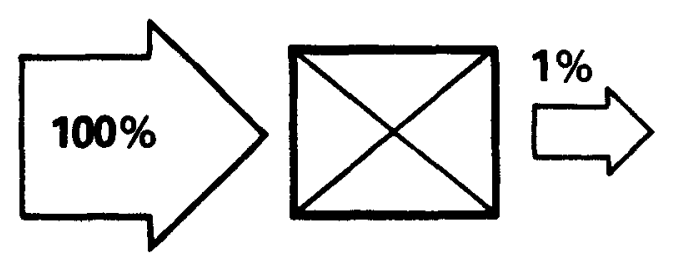

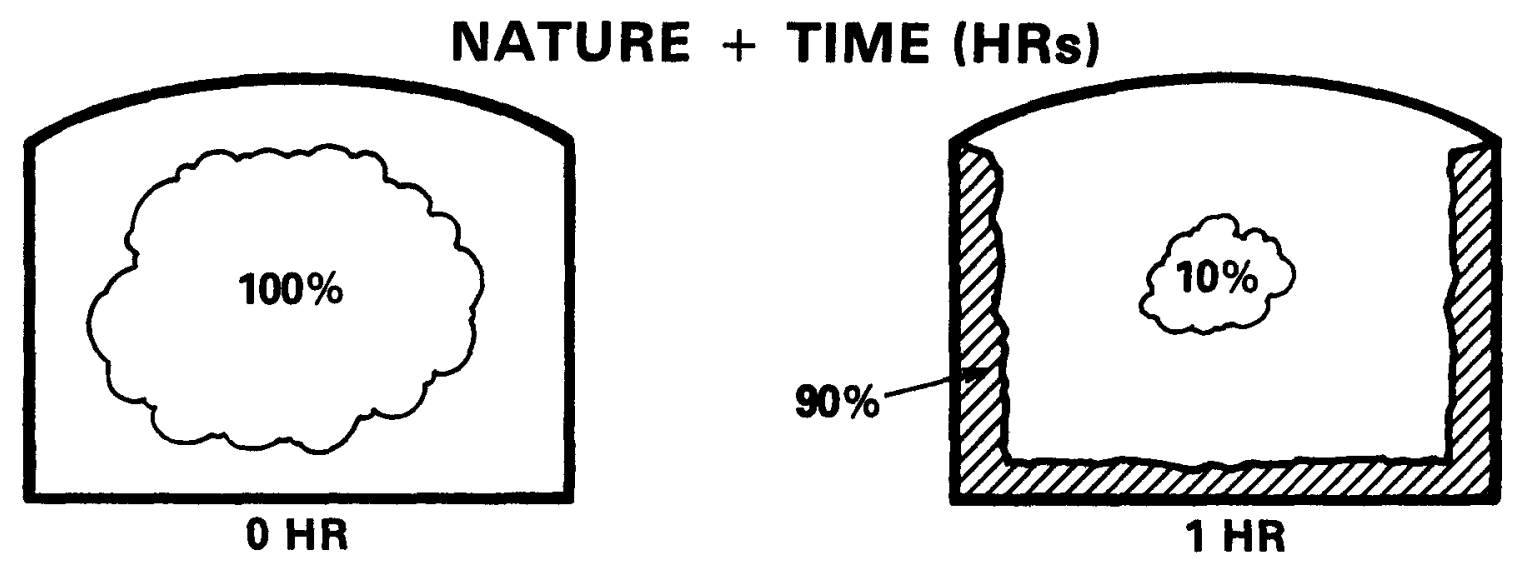

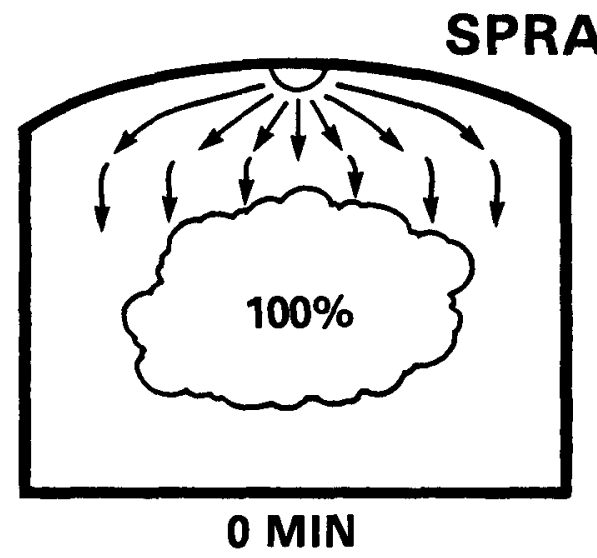

(MINs)

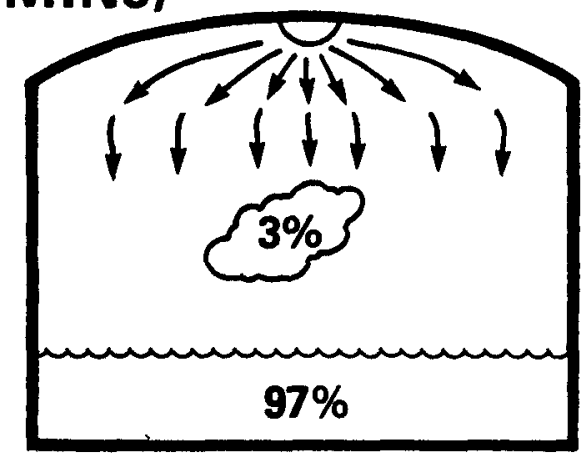

10 MINs

Figure 1.4 Examples of major aerosol/particulate reduction mechanisms 


\section{RADIONUCLIDES IMPORTANT IN SOURCE TERM ASSESSMENT}

\section{1 objective}

To enable the reader to

- identify the factors that have the greatest effect on radionuclide inventory in the reactor core

- identify the fission products that are important to offsite consequences

\subsection{Fission Products}

To understand the significance of the radioactive materials in reactor accidents, it is necessary to describe how they originate and why they are hazardous to human health.

\subsubsection{Source of Fission Products}

There are many mechanisms by which radioactive materials are created in a reactor core. The term "fission product" as used in this document will include not only the isotopes produced directly in fission (primary fission products) but also those produced indirectly through primary and fission product decay (secondary fission products) and other methods.

\subsubsection{Inventory of Fission Products in the Core}

The first consideration in determining the contribution of a particular fission product to the overall source term is how much of the radionuclide is available in the core at the time of the accident. This is a difficult question to answer because the fission product inventory is influenced by a number of factors as shown in Table 2.1. However, as suggested by Table 2.1, the inventory of short-lived radionuclides is affected primarily only by reactor thermal power. Since short-lived radionuclides are the principal contributors to early health effects, reactor thermal power will be the only factor used to adjust assumed core inventory. Average power densities of operating reactors of a given size and type would be very similar; therefore, power density considerations would not significantly change core inventories if core power and type are known. Burnup, although unimportant in considering the inventory of short-lived fission products, is an important factor in determining the inventory of long-lived fission products.

\subsubsection{Fission Products Important to Offsite Consequences}

Many fission products in the core do not need to be considered in source term estimation because they contribute little or nothing to offsite consequences.

Many studies have been performed to determine which fission products are the most important in terms of offsite consequences during severe core damage 
Table 2.1 Factors that have the greatest effect on radionuclide inventory

\begin{tabular}{ll}
\hline Factor & Effect \\
\hline Burnup & $\begin{array}{l}\text { Inventory of the long-lived radionuclides (e.g. } \\
\text { Cs-137) is proportional to burnup. }\end{array}$ \\
& $\begin{array}{l}\text { Inventory of short-lived isotopes is not sensitive to } \\
\text { burnup after the initial buildup (several weeks of } \\
\text { full-power operation). }\end{array}$ \\
Power density & $\begin{array}{l}\text { Inventory of short-lived isotopes (those that reach } \\
\text { equilibrium) is directly proportional to power density. }\end{array}$ \\
& $\begin{array}{l}\text { Inventory of long-lived isotopes is not sensitive to } \\
\text { power density at a given exposure (burnup). }\end{array}$ \\
Reactor power & $\begin{array}{l}\text { Power reactors will produce fission product inventories } \\
\text { proportional to the long-term thermal power level. }\end{array}$ \\
Reactor type & $\begin{array}{l}\text { Fission product generation (inventory) is similar for } \\
\text { BWRs and PWRs. }\end{array}$ \\
\hline
\end{tabular}

accidents. Perhaps the most comprehensive study performed in this area is the Reactor Safety Study (WASH-1400). In this study the contributions of selected radionuclides to various organ doses as the result of a severe (core damage) accident were estimated. The results for early health effects are represented in Table VI 13-1 of WASH-1400.

A scale from 0 to 2 was established in the Reactor Safety Study to delineate the contribution of a radionuclide to early and late health effects. A value of 2 indicates that the radionuclide contributed significantly to the specified effect, and a value of 1 indicates that the radionuclide had a small contribution. A rough ranking of the importance of each group of radionuclides (e.g., iodine) from a health effects perspective can be obtained by summing the assigned scale values for each radionuclide.

Those fission products that had a total score of 2 or more in WASH-1400, Table VI 13-1, in the areas that contributed to early health effects, have been selected to be considered in source term assessment. These are listed in Table 2.2.

From the ranking in WASH-1400 it can be seen that most of the noble gases (xenon, krypton) make a small contribution to health effects. However, noble gases are the most likely group of fission products to be released to the environment following a severe accident because they are chemically inert, are available in large quantities, and would not be affected by the various reduction mechanisms that would remove other fission products before they could be released. In addition, if all the noble gases in the core were released promptly, whole-body doses of about 100 rem are possible 1 mile from the plant. Therefore, noble 
Table 2.2 Fission product inventories ( $\mathrm{Ci} / \mathrm{MWe}$ )

\begin{tabular}{lr}
\hline $\begin{array}{l}\text { Fission } \\
\text { product }\end{array}$ & $\begin{array}{r}\text { Inventory } \\
\text { (Ci/MWe) }\end{array}$ \\
\hline $\mathrm{Kr}-85$ & 560 \\
$\mathrm{Kr}-85 \mathrm{~m}$ & 24,000 \\
$\mathrm{Kr}-87$ & 47,000 \\
$\mathrm{Kr}-88$ & 68,000 \\
$\mathrm{Sr}-89$ & 94,000 \\
$\mathrm{Sr}-90$ & 3,700 \\
$\mathrm{Sr}-91$ & 110,000 \\
$\mathrm{Y}-91$ & 120,000 \\
$\mathrm{Mu}-99$ & 160,000 \\
$\mathrm{Ru}-103$ & 110,000 \\
$\mathrm{Ru}-106$ & 25,000 \\
$\mathrm{Te}-129 \mathrm{~m}$ & 5,300 \\
$\mathrm{Te}-131 \mathrm{~m}$ & 13,000 \\
$\mathrm{Te}-132$ & 120,000 \\
$\mathrm{Sb}-127$ & 6,100 \\
$\mathrm{Sb}-129$ & 33,000 \\
$\mathrm{I}-131$ & 85,000 \\
$\mathrm{I}-132$ & 120,000 \\
$\mathrm{I}-133$ & 170,000 \\
$\mathrm{I}-134$ & 190,000 \\
$\mathrm{I}-135$ & 150,000 \\
$\mathrm{Xe}-131 \mathrm{~m}$ & 1,000 \\
$\mathrm{Xe}-133$ & 170,000 \\
$\mathrm{Xe}-133 \mathrm{~m}$ & 6,000 \\
$\mathrm{Xe}-135$ & 34,000 \\
$\mathrm{Xe}-138$ & 170,000 \\
$\mathrm{Cs}-134$ & 7,500 \\
$\mathrm{Cs}-136$ & 3,000 \\
$\mathrm{C} s-137$ & 4,700 \\
$\mathrm{Ba}-140$ & 160,000 \\
$\mathrm{La}-140$ & 160,000 \\
$\mathrm{Ce}-144$ & 85,000 \\
$\mathrm{~Np}-239$ & $1.64 \times 106$ \\
\hline $\mathrm{S}$ &
\end{tabular}

Source: WASH-1400

gases will be included in the list of radionuclides to consider in source term estimation.

The importance of the various radioactive elements in terms of contribution to bone marrow dose can be seen in Figure 2.1. This figure shows the contribution assuming the most serious accident (e.g., BWR/PWR-1). 


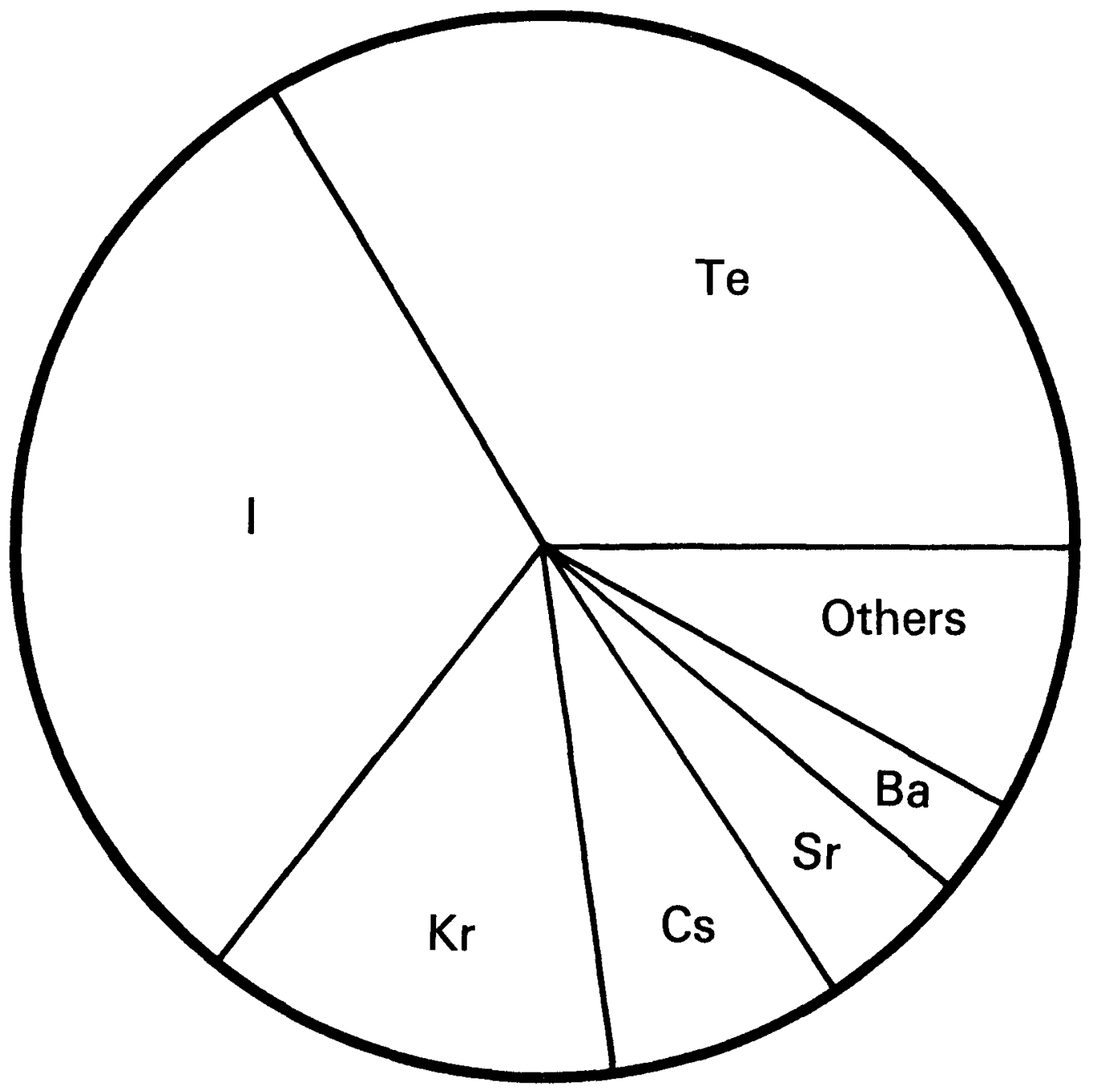

Figure 2.1 Relative importance to bone marrrow dose of the radioactive elements found in the core of a reactor given a major release Source: NUREG/CR-4467 


\subsection{Inventory Assumptions To Be Used for Source Term Estimation}

For each of the radioisotopes listed in Table 2.2, a specific inventory expressed in $\mathrm{Ci} / \mathrm{MWe}$ is provided. These data are the standard starting inventory cited in many source term studies, such as NUREG-0956, and are in agreement with other computer codes, such as CINDER results (NUREG/CR-3108). The computer codes used to estimate core inventory are considered to be the most accurate of all the codes used in estimating source term. These codes are considered to be accurate only within $25 \%$ for the given core burnup assumptions. The values for specific activity correspond to the end-of-equilibrium cycle and should generally provide an upper bound for fission product inventory. A rough approximation of the inventory (in curies) of a particular isotope can be obtained by multiplying the values in the "inventory" column by the electrical rating of the plant (in megawatts).

Generally, the fission product activity would increase as burnup increased for isotopes with relatively long half-lives as illustrated by Figure 2.2 for $\mathrm{Kr}-85$ (half-life $=10.7$ years). The decreases in fission product activity, shown in Figure 2.2, were the result of decay and unloading of spent fuel. Therefore, it should be noted that if the above assumptions are used, the resulting inventory estimates for a new core could greatly overestimate the quantities of long-lived fission products, such as $\mathrm{Kr}-85, \mathrm{Cs}-134$, and $\mathrm{Cs}-137$.

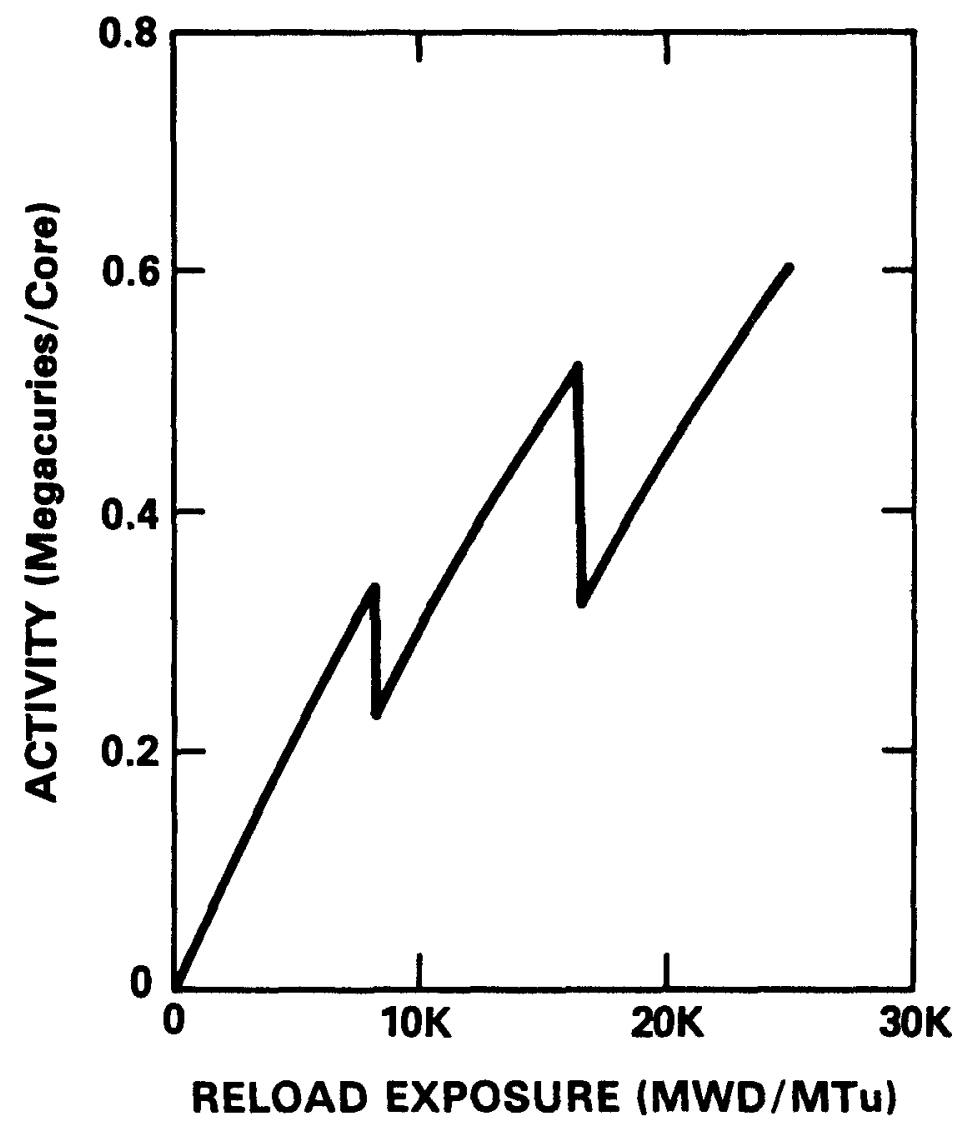

Figure 2.2 Inventory of $\mathrm{Kr}-85$ in core of 1000 MWe PWR Source: NUREG/CR-3108 


\section{RADIONUCLIDE TRANSPORT MECHANISMS UNDER NORMAL OPERATING CONDITIONS}

\subsection{Objective}

To enable the reader to

- describe the fission product barriers

- describe the changes that occur in fuel during normal operation and what effect these changes have on fission product transport from the core

- identify the fission products most likely to be released from the fuel and plant during normal operation

- recognize normal versus accident release rates

- specify the coolant concentration typical of an operating reactor that could be used to estimate the source term for a coolant release assuming no fuel damage and how these concentrations can change during rapid power changes (spikes)

\subsection{Barriers to Fission Product Release}

For the fission products generated within the core to reach the environment, they must pass through four fission product barriers. These barriers are illustrated in Figure 3.1 for a pressurized-water reactor (PWR). The first barrier is the fuel pellet often referred to as the fuel matrix. The second barrier is the fuel pellet cladding. The reactor coolant system provides a third barrier to fission product release. The final and ultimate barrier to fission product release is the reactor containment.

The purpose of this section is to describe the transport of fission products that routinely takes place under normal conditions (not accident) past these fission product barriers. It is necessary to understand fission product transport during normal operation to recognize those release rates outside of the norm that may indicate an accident. Section 4 discusses the transport of fission products during accident conditions.

\subsection{Radionuclide Transport From the Fuel Matrix Into the Fuel-Cladding Gap}

The first barrier is the fuel pellet. After a reactor reaches full power, the fuel used in commercial light-water reactors (LWRs) undergoes thermal distortion and cracking because of the large temperature differences that exist between the center line and the surface of the fuel pellet. Figure 3.2 shows a cross section of a fuel pellet and the cracking that forms during operation.

As gaseous fission products are formed, they will move to cracks where they can escape the fuel pellet. The rate at which fission products are released from the pellet will increase with increasing fuel temperatures. 


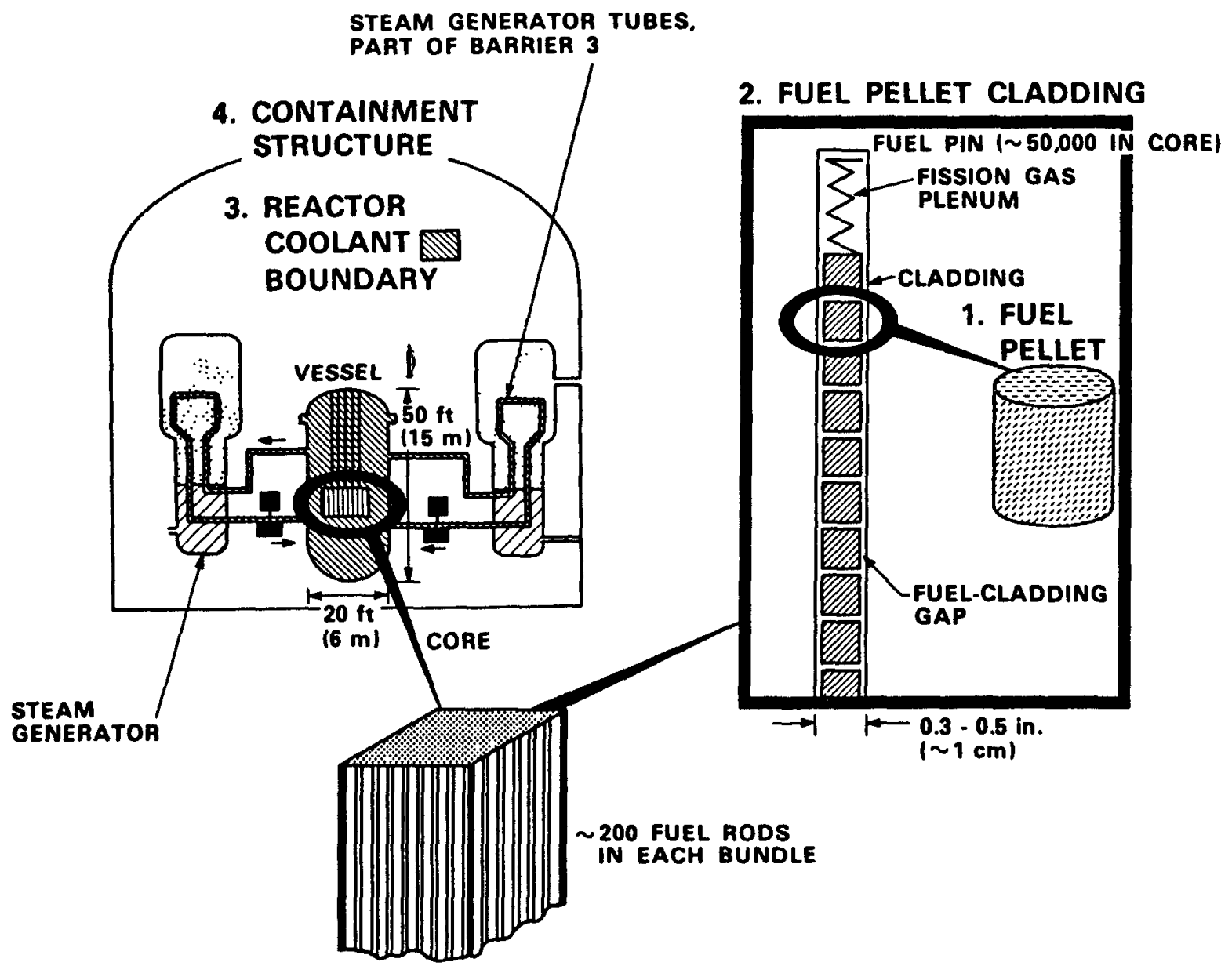

Figure 3.1 Fission product barriers to release of radioactive material for a PWR

Source: NUREG-1210 


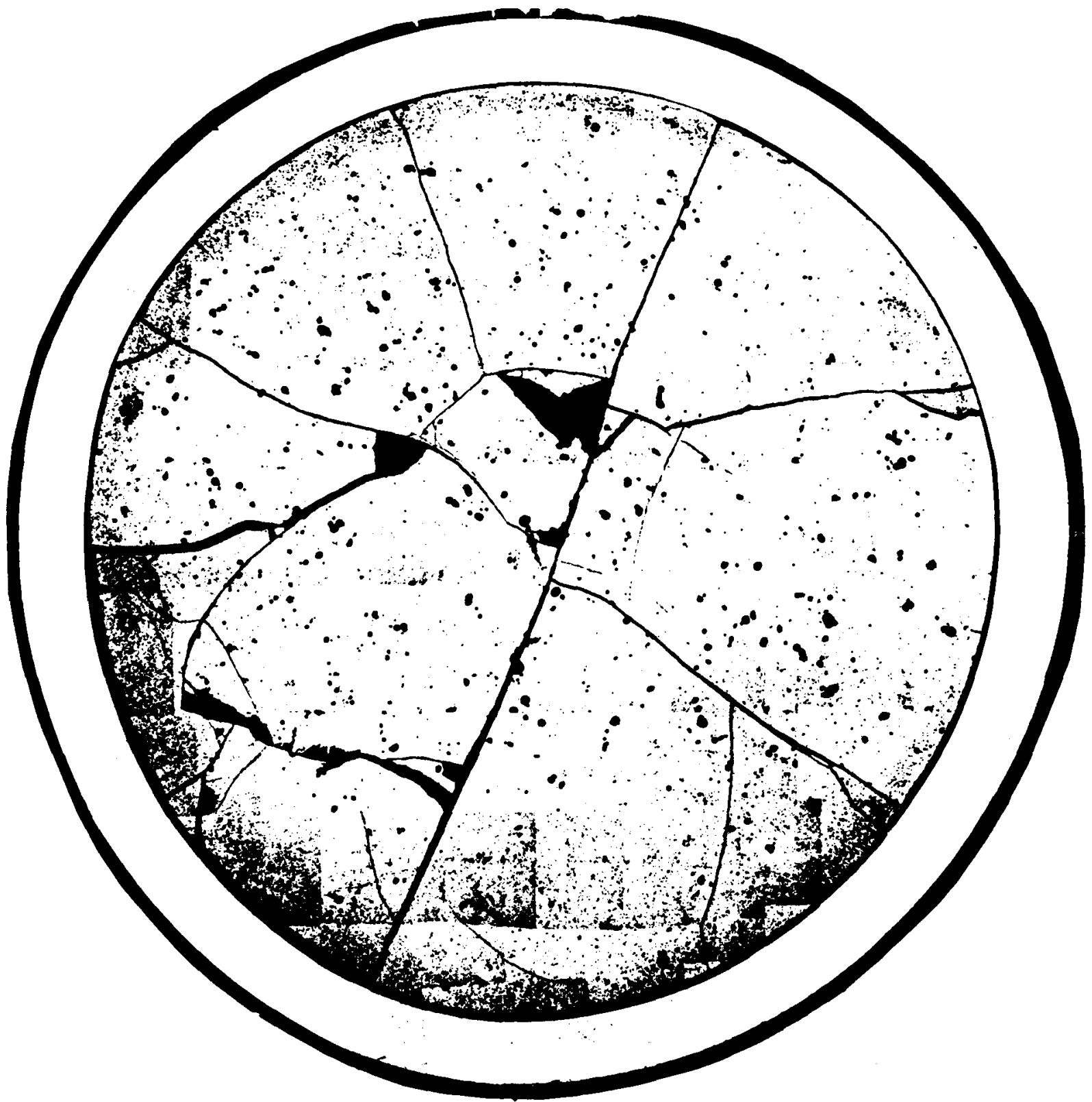

Figure 3.2 Cross section of fuel pellet illustrating cracking 
Noble and volatile fission product gases are the most likely to escape the fuel during normal operation. The volatile fission products include iodine, cesium, and tellurium (see Table 3.1).

The fission product gas that escapes the fuel pellet is released to the gap formed by the fuel cladding or the fuel pin plenum specifically designed to accommodate the fission gas pressures over the life of the fuel. The collection of fission products in the voids and plenum is often referred to as just "gap" activity.

A cross section of a PWR fuel pin showing the fission gas plenum is shown in Figure 3.3.

\subsection{Radionuclide Transport From the Fuel Into the Coolant}

The second barrier to fission product release, fuel cladding or pins, prevents the fission products that leave the fuel pellet from entering the coolant. The coolant refers to the water contained in the reactor coolant system that surrounds the fuel pins that form the core. Thus, an important objective in designing fuel pins is to preclude cladding failures. However, a small fraction of fuel pin cladding will leak during normal operation because of manufacturing flaws, irradiation-induced creep, and other mechanisms. Current LWR fuel designs have demonstrated cladding failure rates of less than $0.1 \%$ over the in-core time of the fuel pins.

The American Nuclear Society (ANS) Standards Committee Working Group has prepared a set of typical radionuclide concentrations for estimating the nonaccident radioactivity in the principal fluid streams of an LWR over its life time [American National Standards Institute (ANSI)/ANS-18.1-1984]. The expected coolant concentrations for the reference plant types in the ANS standard are shown in Table 3.2 and can form the bas is for source term estimation for coolant releases where actual coolant samples are not available. Actual coolant concentration levels can be several orders (10-100) higher than the ANS standard in plants with poor fuel performance; but generally these levels are in reasonable agreement (i.e., within a factor of 5) with actual measured coolant levels (NUREG/CR-4245). Coolant concentrations under accident conditions are discussed in Section 4.4.

Rapid increases in the iodine and other fission products concentration as high as 3 orders of magnitude (i.e., a factor of 1000) may be seen following shutdowns, startups, rapid power changes, and reactor coolant system depressurization. Such increases are referred to as iodine spikes. Iodine spikes are increases that may not be a result of additional cladding failures. The NRC has established standard technical specifications for primary coolant iodine concentrations that make allowances for iodine spikes by permitting temporary excursions above the equilibrium concentration limit, as long as they do not exceed 48 hours.

The failure to recognize the potential for an iodine spike may lead to confusion. It is important to recognize the fact that iodine spikes are possible and likely during an accident. Figure 3.4 illustrates a typical iodine spike following a reactor shutdown. Figure 3.5 illustrates a typical cesium spike and the fact that iodine may not be the only fission product to spike. Spikes have been measured in a wide range of isotopes (NUREG/CR-4245). In examining 
Table 3.1 Melting point and boiling point $\left({ }^{\circ} \mathrm{F}\right)$ of selected materials

\begin{tabular}{|c|c|c|}
\hline Material & Melting point & Boiling point \\
\hline \multicolumn{3}{|c|}{ Volatile fission products } \\
\hline $\begin{array}{l}\mathrm{I}_{2} \\
\mathrm{CsI} \\
\mathrm{CsOH} \\
\mathrm{Te}\end{array}$ & $\begin{array}{r}237 \\
1158 \\
599 \\
842\end{array}$ & $\begin{array}{r}365 \\
2336 \\
1814 \\
1810\end{array}$ \\
\hline \multicolumn{3}{|c|}{ Refractory fission products } \\
\hline $\begin{array}{l}\mathrm{BaO} \\
\mathrm{Ru} \\
\mathrm{SrO} \\
\mathrm{La}_{2} \mathrm{O}_{3}\end{array}$ & $\begin{array}{l}3493 \\
4082 \\
4406 \\
4199\end{array}$ & $\begin{array}{r}5086 \\
7502 \\
5880 \\
>7232\end{array}$ \\
\hline \multicolumn{3}{|c|}{ Control rods } \\
\hline $\begin{array}{l}\mathrm{Ag} \\
\text { In } \\
\mathrm{Cd} \\
\mathrm{B}_{4} \mathrm{C} \\
\mathrm{Hf}\end{array}$ & $\begin{array}{r}1761 \\
314 \\
609 \\
4478 \\
4031\end{array}$ & $\begin{array}{r}3925 \\
3763 \\
1412 \\
>6332 \\
8042\end{array}$ \\
\hline \multicolumn{3}{|l|}{ Zircaloy } \\
\hline $\begin{array}{l}\mathrm{Zr} \\
\mathrm{Sn}\end{array}$ & $\begin{array}{r}3365 \\
449\end{array}$ & $\begin{array}{l}7968 \\
4717\end{array}$ \\
\hline \multicolumn{3}{|c|}{ Stainless Steel } \\
\hline $\begin{array}{l}\mathrm{Fe} \\
\mathrm{Cr} \\
\mathrm{Ni} \\
\mathrm{Mn}\end{array}$ & $\begin{array}{l}2795 \\
3434 \\
2647 \\
2271\end{array}$ & $\begin{array}{l}5183 \\
4841 \\
5277 \\
3743\end{array}$ \\
\hline \multicolumn{3}{|l|}{ Fuel } \\
\hline $\mathrm{UO}_{2}$ & $5144^{*}$ & 5959 \\
\hline
\end{tabular}

*0xidized $\mathrm{Zr}$ will form a liquefied two-phase mixture with $\mathrm{UO}_{2}$ at about $3484^{\circ} \mathrm{F}$. 


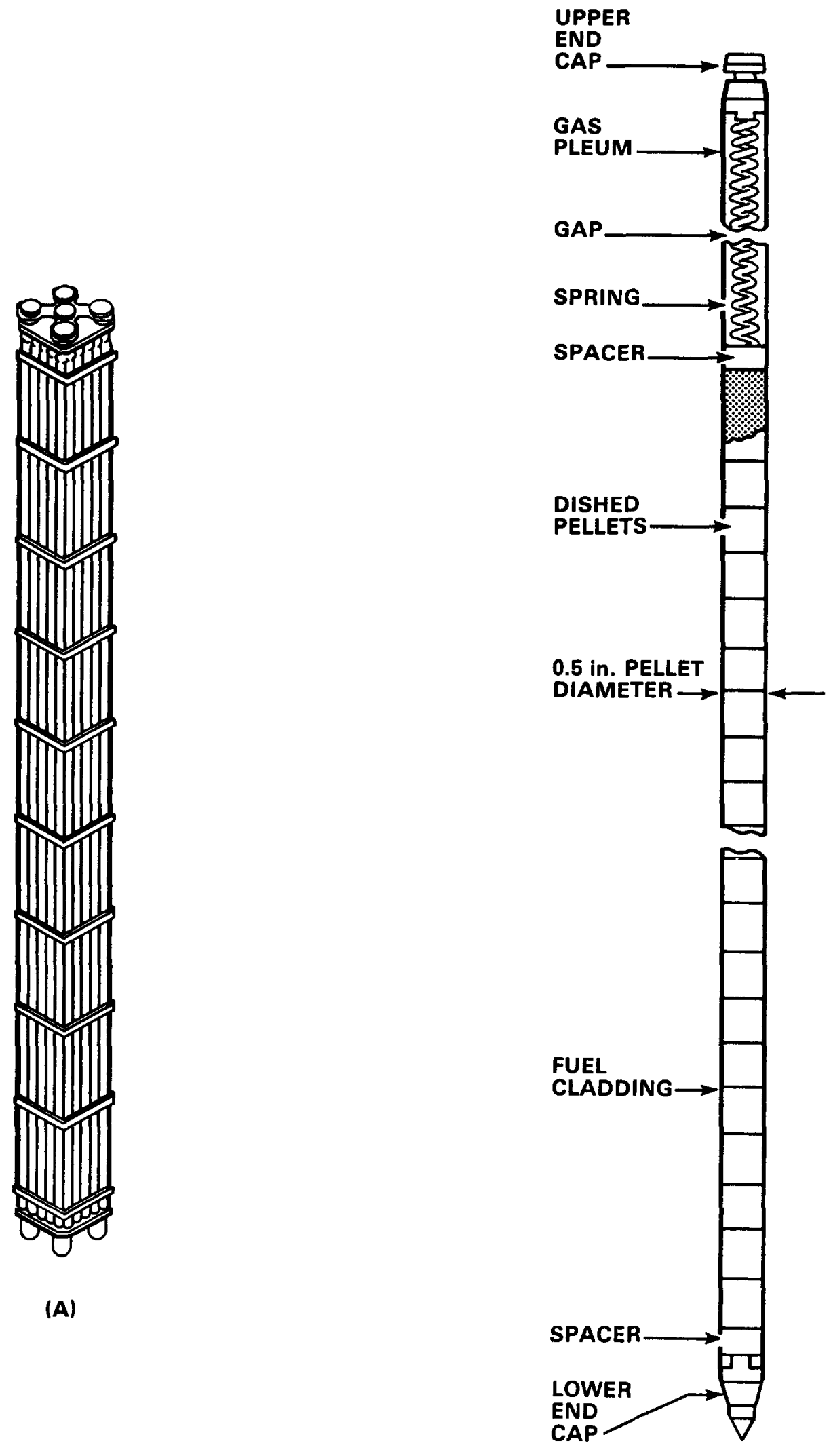

(B)

Figure 3.3 Typical PWR fuel assembly (A) and fuel pin (B) 
Table 3.2 Typical coolant concentrations $(\mu \mathrm{Ci} / \mathrm{g})$

\begin{tabular}{lll}
\hline Radioisotope & BWR & PWR \\
\hline $\mathrm{Kr}-88$ & - & $2.8 \times 10^{-1}$ \\
$\mathrm{Xe}-133$ & - & 2.6 \\
$\mathrm{Xe}-135$ & & $8.5 \times 10^{-1}$ \\
$\mathrm{I}-131$ & $2.2 \times 10^{-3}$ & $4.5 \times 10^{-2}$ \\
$\mathrm{I}-132$ & $2.2 \times 10^{-2}$ & $2.1 \times 10^{-1}$ \\
$\mathrm{I}-133$ & $1.5 \times 10^{-2}$ & $1.4 \times 10^{-1}$ \\
$\mathrm{I}-134$ & $4.3 \times 10^{-2}$ & $3.4 \times 10^{-1}$ \\
$\mathrm{I}-135$ & $2.2 \times 10^{-2}$ & $2.6 \times 10^{-1}$ \\
$\mathrm{Cs}-134$ & $3.0 \times 10^{-5}$ & $7.1 \times 10^{-3}$ \\
$\mathrm{Cs}-137$ & $8.0 \times 10^{-5}$ & $9.4 \times 10^{-3}$ \\
$\mathrm{Ru}-106$ & $3.0 \times 10^{-6}$ & $9.0 \times 10^{-2}$ \\
$\mathrm{Te}-132$ & $1.0 \times 10^{-5}$ & $1.7 \times 10^{-3}$ \\
$\mathrm{Ce}-144$ & $3.0 \times 10^{-6}$ & $4.0 \times 10^{-3}$ \\
\hline
\end{tabular}

Source: ANSI/ANS-18.1-1984. 


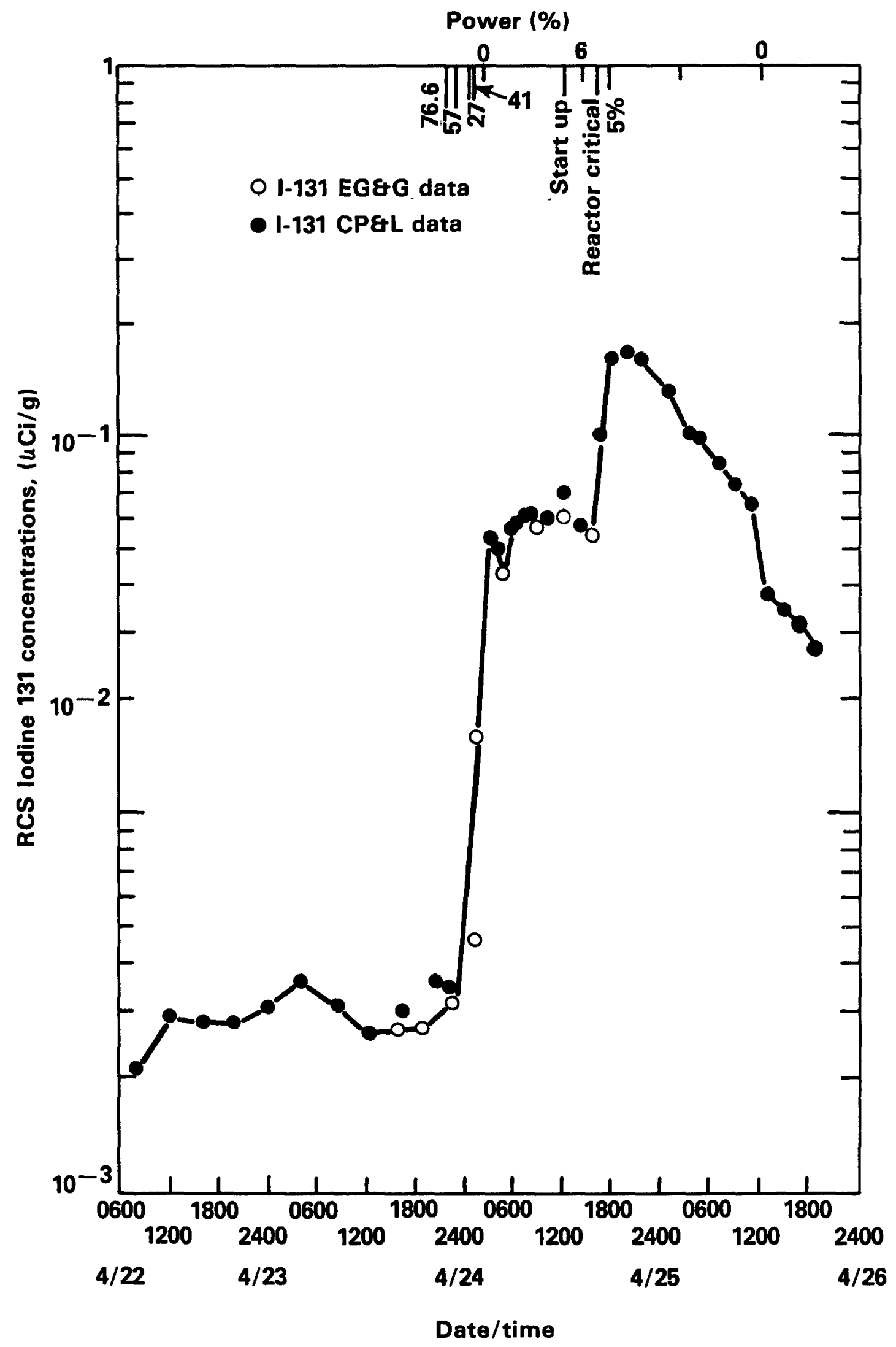

Figure 3.4 Typical iodine spike following shutdown Source: NUREG/CR-4245. 


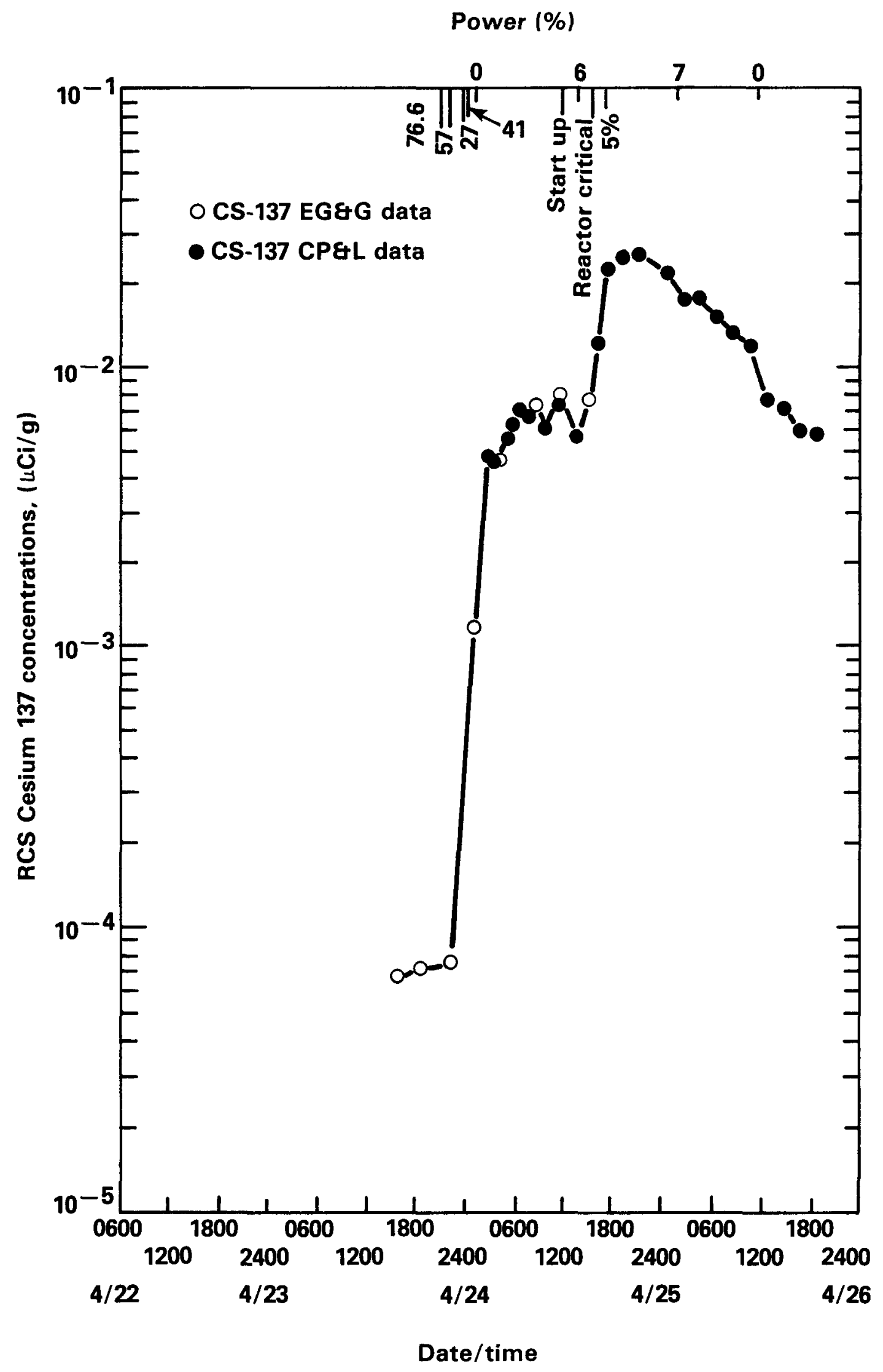

Figure 3.5 Typical cesium spike following shutdown Source: NUREG/CR-4245. 
Figures 3.4 and 3.5 , note the rapid increase in coolant concentration when the power was reduced. These increases were observed during normal conditions.

Fission products and other radionuclides released into the coolant are removed by cleanup systems to maintain the reactor coolant activity at equilibrium levels. The standard technical specification limits for reactor coolant activity are $1.0 \mu \mathrm{Ci} / \mathrm{g} \mathrm{I}-131$ dose equivalent for PWRs and $0.2 \mu \mathrm{Ci} / \mathrm{g}$ for boiling-water reactors (BWRs).

Licensees routinely collect and analyze coolant samples. Such samples would provide the best estimate of actual coolant levels (assuming no iodine spike). However, the concentrations shown in Table 3.2 also could be used because actual differences would be well within the uncertainties if these were to be used to estimate the release resulting from a coolant leak.

\subsection{Routine Effluent Releases}

Radionuclides are routinely released in nuclear power plant effluents during normal operation or as a result of anticipated operational occurrences. Releases during normal operation can be planned or unplanned, but they do not result in consequences that would warrant consideration of the event as an accident. The ranges of airborne effluent releases (curies) from BWRs and PWRs for the year 1980 are summarized in Table 3.3. Releases are not necessarily a function of plant size. Releases from a particular plant are most sensitive to factors such as the number of fuel cladding defects, design features of the plant radioactive waste treatment systems, the number of operational occurrences, and equipment performance. The major constituents of the airborne release for the PWR and the BWR are isotopes of the noble gases, xenon and krypton.

Total releases, however, do not give any insight into which release rates (i.e., $\mathrm{Ci} / \mathrm{sec}$ ) are normal and which require action. Table 3.4 shows the reTease rate benchmarks required (1) to exceed Environmental Protection Agency (EPA) and Food and Drug Administration (FDA) Protective Action Guides (PAG), (2) to reach the maximum reported annual airborne releases, and (3) to warrant further examination by the NRC Headquarters Operations Officer (HOO). These last levels were established for the NRC $\mathrm{HOO}$ to indicate when further health physics (HP) expertise and information on cause and corrective action should be obtained for events called into the NRC Operations Center.

Therefore, it is clear that release rates at least 1000 times normal are required to exceed the offsite PAG. See NUREG-1210, Volumes 2 and 4 , for a discussion of release rates relative to health effects and PAG. 
Table 3.3 Range of total BWR/PWR airborne effluent release (curies) for 1980

\begin{tabular}{llllll}
\hline & \multicolumn{2}{c}{ BWR } & & \multicolumn{2}{c}{ PWR } \\
\cline { 2 - 3 } \cline { 5 - 6 } Range & Gases & $\begin{array}{l}\text { I-131 and } \\
\text { particulate }\end{array}$ & & Gases & $\begin{array}{l}I-131 \text { and } \\
\text { particulate }\end{array}$ \\
\hline Maximum & $3.8 \times 10^{4}$ & 2.2 & & $3.8 \times 10^{4}$ & $8.4 \times 10^{-1}$ \\
Minimum & $7.0 \times 10^{1}$ & $1.3 \times 10^{-2}$ & & $7.0 \times 10^{1}$ & $5.4 \times 10^{-5}$ \\
\hline
\end{tabular}

Source: NUREG/CR-2907, Vol. 3.

Table 3.4 Release rate $(\mathrm{Ci} / \mathrm{sec})$ needed to meet benchmarks

Benchmarks

\begin{tabular}{|c|c|c|c|c|c|}
\hline $\begin{array}{l}\text { Release } \\
\text { type }\end{array}$ & $\begin{array}{l}\text { Maximum } \\
\text { reported } \\
\text { annual } \\
\text { release in } \\
1 \text { year (1) }\end{array}$ & $\begin{array}{l}\text { EPA whole- } \\
\text { body PAG in } \\
1 \text { hr (2)(4) }\end{array}$ & $\begin{array}{l}\text { EPA thyroid } \\
\text { PAG inhala- } \\
\text { tion in } \\
1 \text { hr (3)(4) }\end{array}$ & $\begin{array}{l}\text { FDA thyroid } \\
\text { PAG inges- } \\
\text { tion in } \\
1 \mathrm{hr}(3)(4)\end{array}$ & $\begin{array}{l}\text { NRC } \mathrm{HOO} \\
\text { evaluation } \\
\text { levels } \\
\text { (rate) (5) }\end{array}$ \\
\hline Noble gas & $1 \times 10^{-3}$ & $3 \times 10^{2}$ & - & - & $1 \times 10^{-1}$ \\
\hline$I-131$ & $1 \times 10^{-7}$ & - & $3 \times 10^{-1}$ & $3 \times 10^{-4}$ & $1 \times 10^{-5}$ \\
\hline
\end{tabular}

(1) Assumes a constant release rate for 1 year to reach maximum reported. Source: NUREG/CR-2907.

(2) 5 rem whole body. Source: NUREG-1210.

(3) 15-25 rem thyroid. Source: NUREG-1210.

(4) Dose at $1 \mathrm{mile}$, E stability, $4 \mathrm{mph}$ wind speed. Source: NUREG-1210.

(5) Level if reported to the NRC Headquarters Operations Officer (HOO) would warrant further evaluation by the NRC. Source: NUREG-1210. 
4 ESTIMATING RADIONUCLIDE TRANSPORT MECHANISMS UNDER SEVERE ACCIDENT CONDITIONS

\subsection{Objective}

To enable the reader to

- describe the phenomena that occur as a result of core heatup, beginning with normal operating conditions and ending with melting of the fuel pellets, and the relationship of these phenomena to release of fission products from the core

- describe pathways that allow radionuclides to be transported from the core to the environment and explain what effect the pathway has on the fraction of radionuclides released

- describe the dominant mechanisms that act to reduce an offsite release and how to characterize those mechanisms during an event

- describe the procedure for bounding the source term for a potential release during an accident

\subsection{Major Considerations}

Section 5 will outline a very simple method for estimating source terms for various severe accident conditions. This method is based on two assumptions:

(1) that there is a limited number of accident conditions that characterize the size of source terms and (2) that these accident conditions can be estimated during an accident. This section will identify these conditions and characterize their effects on source terms and discuss how these accident conditions can be estimated based on observable plant conditions. The hope is to relate actual plant conditions to the range of possible source terms.

This section will be the bridge between source term science and actual source term estimation during severe accidents. Section 5 will show how this can be applied to compare various possible accident sequences in terms of consequences or how the range of possible offsite consequences can be estimated.

To make the first approximation of a severe accident source term the analyst must:

(1) estimate the inventory of fission products in the core

(2) estimate the fraction of the fission product inventory released from the core

(3) estimate the fraction of the fission product inventory released from the core that is removed on the way to the environment 
(4) estimate the amount of the available fission product inventory with potential for release to the environment

An estimate of the amount of material released from the core, if available (e.g., containment monitor readings), can be the starting point of the assessment. If this is the case, only steps 3 and 4 above would be performed. However, care must be taken because an unmonitored and unanticipated release pathway may exist.

This section will identify the basic fission product inventory (FPI) in the core, core release fraction (CRF), reduction fraction (RDF), and escape fraction (EF) for various plant conditions. A severe accident source term can be estimated by:

$$
\text { Source term } \text { te }_{i}=\mathrm{FPI}_{\mathbf{i}} \times \mathrm{CRF}_{\mathbf{i}} \times\left(\prod_{j=1}^{\mathrm{n}^{\mathrm{RDF}}}(i, j)\right) \times E F_{i}
$$

for radionuclide $i$ and $n$ reduction mechanisms

where

$$
\begin{aligned}
& \mathrm{FPI}_{i}=\text { element } i \text { core or coolant inventory } \\
& \mathrm{CRF}_{i}=\frac{\text { element } i \text { released from core }}{\text { element } i \text { inventory in core }} \\
& \mathrm{RDF}_{i}=\frac{\text { element } i \text { available for release after reduction mechanisms }}{\text { element } i \text { available for release before reduction mechanisms }} \\
& \mathrm{EF}_{i}=\frac{\text { element } i \text { released to environment }}{\text { element } i \text { available for release }}
\end{aligned}
$$

The assumption that the total effectiveness of the RDFs can be estimated by multiplying them together is obviously suspect. The various reduction mechanisms (e.g., pools or sprays) may be acting on the same form of a radioisotope. Therefore, except for filters, a maximum total reduction factor of 0.001 will be assumed for the combined action of any set of reduction factors (except for filters) on non-noble fission products. This maximum RDF $(0.001)$ appears to be the maximum value observed in experiments involving any of the mechanisms studied. The effectiveness of a filter in a release path will not be so 1 imited since under appropriate conditions filters are assumed to act on a wide range of the forms of the fission products.

\subsection{Estimating Core Fission Product Inventory}

To estimate the inventories of fission products in the core, Table 2.2 can be used. Specific plant inventory can easily be estimated by multiplying Table 2.2 values by the long-term steady-state power level (MWe) at the time of the accident. 
When using the fission product inventories specified in Table 2.2, keep in mind that these values will greatly overestimate long half-life fission product (e.g., cesium) inventory in a new core.

\subsection{Estimating Fission Product Inventory Released From the Core}

The second step in estimating source term is to estimate the fraction of core inventory released following the failure of the first and second fission product barriers (fuel pellets and fuel pin cladding). Fuel and/or cladding failures and subsequent release of fission products will primarily be a function of temperature. For the purpose of severe accident source term estimation, four core damage temperature regimes will be discussed:

(1) normal fuel pin leakage (normal operating temperature $600^{\circ} \mathrm{F}$ )

(2) fuel cladding rupture release (gap release) $\left(1300^{\circ}-2100^{\circ} \mathrm{F}\right)$

(3) grain boundary release $\left(>3000^{\circ} \mathrm{F}\right)$

(4) melt (in-vessel) release $\left(>4500^{\circ} \mathrm{F}\right)$

However, because of the difficulties in specifically identifying core temperatures and conditions during a severe accident, only three of the levels of damage would normally be used to represent the full range of core damage: normal fuel pin leakage, fuel cladding rupture, and melt.

Licensees have established specific procedures to assess the degree of core damage. In addition, the major reactor vendors have established guidelines for relating instrument readings (e.g., containment monitor, coolant levels, exit thermocouple temperatures) to the level of core damage. These procedures are discussed generally in NUREG-1210, Volume 2.

Table 4.1 shows the fraction of fission products that can be assumed to be released from the core for each of the fuel damage states. Recall that these fission products were identified in Section 2 because of their importance to early health affects. Average operating fuel temperatures for light-water reactors (LWRs) are shown in Table 4.2 for comparison. The basis for these release fractions will now be discussed.

\subsubsection{Normal Fuel Pin Leakage $\left(600^{\circ} \mathrm{F}\right)$}

The first fuel damage regime corresponds to releases from fuel pins (the second fission product barrier) during normal operation.

As discussed in Section 3.4, small quantities of fission products escape through small holes in the fuel pin cladding into the reactor system coolant during normal operation. Typical primary coolant fission product concentrations are shown in Table 3.2. Table 3.2 concentrations will be used to estimate source terms from normal coolant leaks. Results from plant coolant sample analysis could be used to scale (up or down) any results based on Table 3.2 concentrations. This obviously simple method provides sufficiently accurate results when considering all of the uncertainties.

It is important to note, as discussed in Section 3.4, that following plant shutdowns or other rapid changes in power levels, there can be rapid changes (as high as a factor of a 100) in iodine, cesium, and other fission product coolant 
Table 4.1 Core release fraction assumptions (1-hour release)

\begin{tabular}{|c|c|c|c|}
\hline Core condition & $\begin{array}{l}\text { Fuel cladding } \\
\text { temperature }\end{array}$ & $\begin{array}{l}\text { Fission } \\
\text { product }\end{array}$ & $\begin{array}{l}\text { Assumed release } \\
\text { fraction from fuel }\end{array}$ \\
\hline $\begin{array}{l}\text { Fuel pin cladding } \\
\text { intact - normal } \\
\text { leakage }\end{array}$ & $600^{\circ} \mathrm{F}$ & $\begin{array}{l}\text { Normal, use } \\
\text { Table } 3.2\end{array}$ & \\
\hline $\begin{array}{l}\text { Gap release } \\
\text { (cladding failure) }\end{array}$ & $1300^{\circ} \mathrm{F}-2100^{\circ} \mathrm{F}$ & $\begin{array}{l}\mathrm{Xe}, \mathrm{Kr} \\
\mathrm{I} \\
\mathrm{Cs} \\
\mathrm{Te}, \mathrm{Sb}\end{array}$ & $\begin{array}{l}0.03 \\
0.02 \\
0.05 \\
1 \times 10^{-4}\end{array}$ \\
\hline $\begin{array}{l}\text { Grain boundary } \\
\text { release }\end{array}$ & $>3000^{\circ} \mathrm{F}$ & $\begin{array}{l}\mathrm{Xe}, \mathrm{Kr} \\
\mathrm{I}, \mathrm{Cs} \\
\mathrm{Te} \\
\mathrm{Sb} \\
\mathrm{Ba} \\
\mathrm{Mo} \\
\mathrm{Sr} \\
\mathrm{Ru}\end{array}$ & $\begin{array}{l}0.5 \\
0.5 \\
0.1 \\
0.02 \\
0.01 \\
0.01 \\
1 \times 10^{-3} \\
1 \times 10^{-4}\end{array}$ \\
\hline $\begin{array}{l}\text { Core melt } \\
\text { (in-vessel)(1)(2) }\end{array}$ & $>4500^{\circ} \mathrm{F}$ & $\begin{array}{l}\mathrm{Xe}, \mathrm{Kr} \\
\mathrm{Cs} \\
\mathrm{I} \\
\mathrm{Sb} \\
\mathrm{Te}(3) \\
\mathrm{Ba} \\
\mathrm{Sr}(3) \\
\mathrm{Mo} \\
\mathrm{Ru} \\
\mathrm{La} \\
\mathrm{Y} \\
\mathrm{Ce} \\
\mathrm{Np}\end{array}$ & $\begin{array}{l}1.0 \\
1.0 \\
1.0 \\
0.02 \\
0.3 \\
0.2 \\
0.07 \\
0.1 \\
7 \times 10-3 \\
1 \times 10-4 \\
1 \times 10-4 \\
1 \times 10^{-4} \\
1 \times 10^{-4}\end{array}$ \\
\hline
\end{tabular}

(1) Based on Tables 4.8 and 4.9 of NUREG-0956.

(2) For $\mathrm{La}, \mathrm{Y}, \mathrm{Np}$, and $\mathrm{Ce}$, the $\mathrm{Zr}$ release fraction was used, based on BMI-2104, Vol. VI, page 6-24 grouping, Battelle Columbus Laboratories, 1984.

(3) Ex-vessel (melt-through) melt release fractions may be much larger $(0.4$ to 0.8$)$. 
Table 4.2 Average LWR fuel, cladding, and

coolant operational temperatures

\begin{tabular}{lrl}
\hline & \multicolumn{2}{c}{ Temperature $\left({ }^{\circ} \mathrm{F}\right)$} \\
\cline { 2 - 3 } Areas & PWR & BWR \\
\hline Inlet core coolant & 569 & 532 \\
Outlet core coolant & 625 & 547 \\
Outer surface cladding & 670 & 565 \\
Inner surface cladding & 810 & 615 \\
Fuel pellet surface & 1235 & 1000 \\
Fuel centerline & $\sim 3700$ & $1650-3300$ \\
\hline
\end{tabular}

concentrations. These cesium and iodine spikes are seen during normal operation. Therefore, under accident conditions any coolant samples taken before the plant shutdown or accident must not be considered as representative of actual coolant concentrations. Simi Tarily, during an event, elevated coolant concentrations can result from spikes that do not indicate accident conditions.

The good news on coolant concentrations is that even if a very large fraction of the coolant inventory at 100 times normal coolant concentrations were released into the atmosphere, doses in excess of the upper limit of whole-body Environmental Protection Agency (EPA) Protective Action Guides (PAG) (5 rem) are not possible 1 mile from the plant (NUREG-1210 Vol. 2). Doses to the thyroid in excess of the upper limit of the thyroid EPA PAG (25 rem) are possible, but would require the release of a large fraction of the total iodine in the coolant combined with adverse meteorological conditions. This is very unlikely.

Tables 4.3 and 4.4 show the calculated coolant concentrations for selected isotopes that can be assumed if various levels of core damage take place and the core is reflooded trapping the majority of the fission products released from the core in the coolant. The tables also show for comparison the American Nuclear Society (ANS) typical concentration (Section 3.4) and those measured at Three Mile Island (TMI) following the accident. The TMI concentrations are discussed in Section 4.5.2.1.6.

\subsubsection{Fuel Cladding Rupture/Gap Release $\left(1300^{\circ}-2100^{\circ} \mathrm{F}\right)$}

The second fuel damage regime, cladding rupture (gap release), corresponds to fuel cladding temperatures sufficient to result in the failure of the fuel pins/walls (second fission product barrier).

As discussed in Section 3, gaseous fission products are released from the fuel during operation. Because the fuel is encapsulated in the cladding, fission 
Table 4.3 PWR baseline coolant concentrations for various levels of core damage

\begin{tabular}{|c|c|c|c|c|c|c|c|}
\hline Nucl ide & $\begin{array}{l}\text { Core inven- } \\
\text { tory } \\
(1000 \mathrm{MWe}) \\
(\mathrm{Ci})\end{array}$ & $\begin{array}{l}\text { Normal con- } \\
\text { centration } \\
(\mu \mathrm{Ci} / \mathrm{g})\end{array}$ & $\begin{array}{l}\text { Gap } \\
\text { release } \\
\text { fraction }\end{array}$ & $\begin{array}{l}\text { Gap coolant } \\
\text { concentra- } \\
\text { tion } \\
(\mu \mathrm{Ci} / \mathrm{g})\end{array}$ & $\begin{array}{l}\text { Melt } \\
\text { release } \\
\text { fraction }\end{array}$ & $\begin{array}{l}\text { Melt cool- } \\
\text { ant concen- } \\
\text { tration } \\
(\mu \mathrm{Ci} / \mathrm{g})\end{array}$ & $\begin{array}{l}\text { TMI concen- } \\
\text { tration } \\
+48 \mathrm{hrs}^{\star} \\
(\mu \mathrm{Ci} / \mathrm{g})\end{array}$ \\
\hline
\end{tabular}

Assumptions: WASH-1400 inventory.

ANSI/ANS 18.1-1984 normal coolant concentrations.

$2.5 \times 10^{5} \mathrm{~kg}$ primary coolant inventory.

${ }^{*}$ Concentrations of sample taken $3 / 29 / 79,1600$ counted $3 / 30 / 79$ ( $>48$ hours after accident). 
Table 4.4 BWR baseline coolant concentrations for various levels of core damage

\begin{tabular}{|c|c|c|c|c|c|c|}
\hline Nuclide & $\begin{array}{l}\text { Core } \\
\text { inventory } \\
\text { (1000 MWe) } \\
\text { (Ci) }\end{array}$ & $\begin{array}{l}\text { Normal } \\
\text { concentration } \\
(\mu \mathrm{C} i / g)\end{array}$ & $\begin{array}{l}\text { Gap } \\
\text { release } \\
\text { fraction }\end{array}$ & $\begin{array}{l}\text { Gap } \\
\text { coolant } \\
\text { concentration } \\
(\mu \mathrm{Ci} / \mathrm{g})\end{array}$ & $\begin{array}{l}\text { Melt } \\
\text { release } \\
\text { fraction }\end{array}$ & $\begin{array}{l}\text { Melt } \\
\text { coolant } \\
\text { concentration } \\
(\mu \mathrm{Ci} / \mathrm{g})\end{array}$ \\
\hline $\begin{array}{l}\mathrm{Kr}-85 \\
\mathrm{Kr}-85 \mathrm{~m} \\
\mathrm{Xe}-133 \\
\mathrm{Xe}-135 \\
\mathrm{I}-131 \\
\mathrm{I}-133 \\
\mathrm{I}-135 \\
\mathrm{C} s-134 \\
\mathrm{C} s-137 \\
\mathrm{~S} r-90 \\
\mathrm{~Np}-239\end{array}$ & $\begin{array}{l}5.60 \times 10^{5} \\
2.40 \times 10^{7} \\
1.70 \times 10^{8} \\
3.40 \times 10^{7} \\
8.50 \times 10^{7} \\
1.70 \times 10^{8} \\
1.50 \times 10^{8} \\
7.50 \times 10^{6} \\
4.70 \times 10^{6} \\
3.70 \times 10^{6} \\
1.60 \times 10^{9}\end{array}$ & $\begin{array}{l}0.00 \\
0.00 \\
0.00 \\
0.00 \\
2.20 \times 10^{-3} \\
1.50 \times 10^{-2} \\
2.20 \times 10^{-2} \\
3.00 \times 10^{-5} \\
8.00 \times 10^{-5} \\
7.00 \times 10^{-6} \\
8.00 \times 10^{-3}\end{array}$ & $\begin{array}{l}3.00 \times 10^{-2} \\
3.00 \times 10^{-2} \\
3.00 \times 10^{-2} \\
3.00 \times 10^{-2} \\
2.00 \times 10^{-2} \\
2.00 \times 10^{-2} \\
2.00 \times 10^{-2} \\
5.00 \times 10^{-2} \\
5.00 \times 10^{-2} \\
0.00 \\
0.00\end{array}$ & $\begin{array}{l}9.88 \times 10^{1} \\
4.24 \times 10^{3} \\
3.00 \times 10^{4} \\
6.00 \times 10^{3} \\
1.00 \times 10^{4} \\
2.00 \times 10^{4} \\
1.76 \times 10^{4} \\
2.21 \times 10^{3} \\
1.38 \times 10^{3} \\
0.00 \\
0.00\end{array}$ & $\begin{array}{l}1.00 \\
1.00 \\
1.00 \\
1.00 \\
1.00 \\
1.00 \\
1.00 \\
1.00 \\
1.00 \\
7.00 \times 10^{-2} \\
1.00 \times 10^{-4}\end{array}$ & $\begin{array}{l}3.29 \times 10^{3} \\
1.41 \times 10^{5} \\
1.00 \times 10^{6} \\
2.00 \times 10^{5} \\
5.00 \times 10^{5} \\
1.00 \times 10^{6} \\
8.82 \times 10^{5} \\
4.41 \times 10^{4} \\
2.76 \times 10^{4} \\
1.52 \times 10^{3} \\
9.41 \times 10^{2}\end{array}$ \\
\hline
\end{tabular}

Assumptions: WASH-1400 inventory.

ANSI/ANS-18.1-1984 normal coolant concentrations.

$1.7 \times 10^{5} \mathrm{~kg}$ of coolant. 
products are retained in void regions or in the gap between the fuel pin cladding and fuel. This collection of fission products is often referred to as the "gap." These fission products can be released very quickly if the cladding fails.

If the gas pressure within the fuel pins is considerably less than the primary system pressure, the cladding may buckle or collapse at about $1300^{\circ} \mathrm{F}$ (NUREG-0900).

The cladding may balloon and oxidation may become extremely rapid between $1400^{\circ} \mathrm{F}$ and $2000^{\circ} \mathrm{F}$, leading to rapid fuel pin failure.

After a fuel pin cladding failure occurs, most of the fission gas in the fission gas plenum will be released into the reactor coolant system (third fission product barrier). This release mechanism is often referred to as a burst release. Once the fuel pin plenum fission gas has been vented, shallowly embedded gas atoms in the fuel pellet and interior cladding surface near the rupture area will diffuse into the reactor coolant system. The release mechanisms discussed in this section will be collectively referred to as a "gap release."

Table 4.1 shows the assumed gap release fractions. These fractions are those used in the Reactor Safety Study (WASH-1400). When using these release fractions, it is assumed that all the fuel cladding fails, resulting in a total core gap release, and that the core temperature is not substantially above that required for cladding failure. Higher temperatures would result in a release of substantially more fission products, as will be discussed. Obviously this is an unrealistic model of damaged core, but can be useful to bound accident consequences.

The amount of radioactive fission products associated with a gap release will depend primarily on the number of failed fuel pins and on the plenum fission gas inventory. It is important to realize that the variation in fuel temperature throughout the core could be considerable. This is evident from the different levels of core damage seen in the TMI core. Portions of the core were melted while other parts were not damaged. It is important also to realize that once the core is sufficiently uncovered, core temperature will increase rapidly (at about $1 F^{\circ}$ per second for a pressurized-water reactor [PWR]). In a PWR, cladding failure could begin in about 15 minutes following core uncovery and core melt in less than an hour. Therefore, if core conditions allow cladding failure, rapid failure of all the fuel pins and even fuel melt could result, if conditions are not improved quickly.

The consensus is that even for the worst accident analyzed, if the plant safety systems work as designed, less than $20 \%$ of the fuel pin cladding will fail, releasing a large fraction of the gap in those pins. This failure would occur during the short period of core uncovery before flooding of the core. Under these conditions, most of the non-noble fission products released from the fuel would be trapped in the reactor system coolant. This type of accident (within plant design limits) would result in release of considerably less than $20 \%$ of the gap from the reactor coolant system. Therefore, any accident that releases more than $20 \%$ of the gap from the reactor coolant system is considered a severe accident.

One of the best indicators of gap release will be the containnent monitor, if the release is into the containment. The specific relation of containment 
monitor reading to fuel damage should be contained in the licensee's emergency plans. Another good indicator would be PWR core thermocouple readings or BWR water level.

\subsubsection{Grain Boundary Release $\left(3000^{\circ} \mathrm{F}\right)$ and Melt Release (In-Vesse 1$)\left(4500^{\circ} \mathrm{F}\right.$ )}

Once the cladding fails, the release rate of various fission products increases rapidly with temperature. The release rate has been assumed to double approximately with every $180 \mathrm{~F}^{\circ}$ increase in temperature. At about $3600^{\circ} \mathrm{F}$, the fraction of the remaining inventory is assumed to be released at about $10 \%$ per minute for noble gases, iodine, and cesium (NUREG-0772). By the time the fuel melts at about $4500^{\circ} \mathrm{F}$, most of the volatile fission products may have been released from the fuel. However, these are basic assumptions, and, as was shown at TMI, they may not be correct. At TMI up to $20 \%$ of various fission products expected to be released during a melt were still retained in the melted core.

It will be impossible to specifically determine the rate of release during core heatup and melt. Consequently, fuel releases during this phase will be characterized by two discrete points in the progression of fuel heatup. As the fuel heats up, following cladding failure, bubbles form and expand causing the fuel grains to separate creating pathways out of the fuel. This is called the grain boundary release.

The release fractions for grain boundary and core melt shown in Table 4.1 are based on a very simple model that relates the release rates to fuel temperature. This model is discussed in NUREG-0772. Figure 4.1 shows the curves that form the basis for the release assumptions (NUREG-0772). These curves are based on very scattered data and are estimated to be accurate only within plus or minus a factor of 10 . So even if the specific accident core temperature distributions could be accounted for (which they could not), the estimate of release rate from the fuel would only be within a factor of 10 .

The Table 4.1 grain boundary release fractions represent the fraction released in 1 hour assuming a core temperature of $3000^{\circ} \mathrm{F}$. This temperature was chosen because the release rate at this temperature is midway between that at start of fuel damage (cladding failure) and that at fuel melt $\left(4500^{\circ} \mathrm{F}\right)$.

The Table 4.1 melt release fractions are typical of those projected for various core melt accidents by the Battelle Columbus Laboratories' calculations (BMI-2104) performed as part of the NRC reassessment of the technical bases for estimating source terms (NUREG-0956). This phase of the core damage process is referred to as "in-vessel melting."

Once the fuel is uncovered, temperatures sufficient to melt fuel could be reached in an hour. It will be very difficult to actually estimate the extent of core damage once it begins. Therefore, if plant/accident conditions indicate prolonged core uncovery, a core melt release fraction should be assumed once core damage beyond cladding failure is expected. Direct indications of this degree of core damage could be thermocouples, neutron monitor, or area and process radiation monitors (e.g., containment monitor readings). 
孞

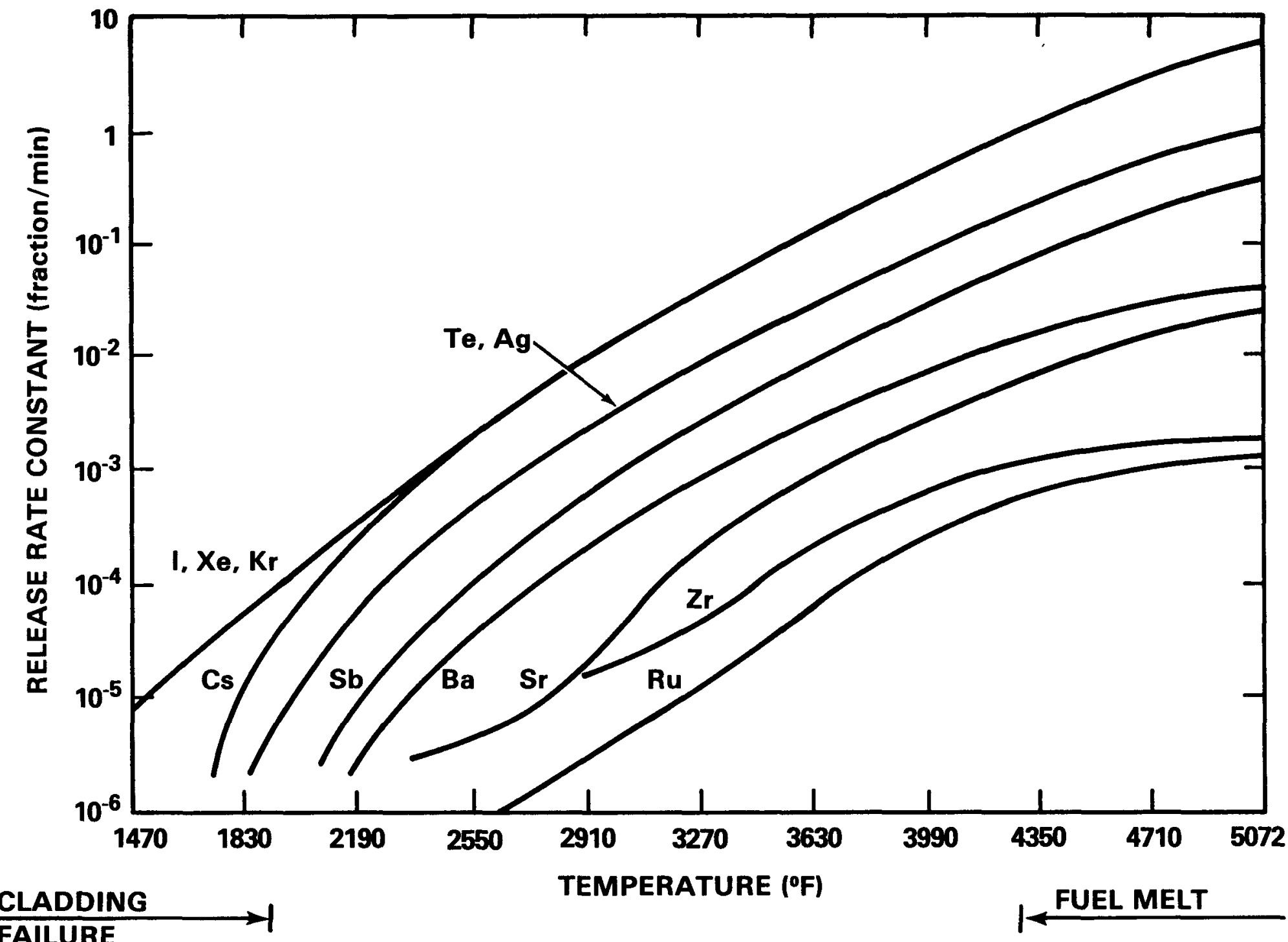

Figure 4.1 Fission product release rate constants from fuel - smoothed curves Source: NUREG-0772 


\subsubsection{Reactor Vessel Melt-Through (Ex-Vessel Melting)}

There is one additional release fraction that is often discussed, vessel meltthrough. If the core melt is allowed to continue (the core is not reflooded/ cooled), it may eventually melt through the bottom of the reactor vessel (the third fission product barrier) and fall on the concrete containment floor. This phase of the core melt process is often referred to as "ex-vessel melting. "If the floor is covered with water (e.g., from a leak), it may provide adequate cooling, stopping further release from the core. However, if the molten core contacts dry concrete, or if, in some cases, the flooded conditions do not provide cooling, the concrete will rapidly decompose, yielding steam and carbon dioxide. Such processes increase the access of the fission products to the surface of the molten mass leading to the formulation of aerosols. Thus, there is a potential for additional fission products to be released.

Current information (e.g., TMI core examination) indicates that there may be relatively high retention of volatile fission products (e.g., iodine, cesium) in a melted core. However, this material may be released after vessel meltthrough. The melt case release fractions for cesium and iodine, shown in Table 4.1, may be representative for the worst-case melt-through, but may underestimate the release of strontium during the ex-vessel phase of a core melt. The release fractions for strontium have been estimated (NUREG-0956) to be between 0.4 and 0.8 for some melt-through cases versus the 0.07 assumed in Table 4.1 for the in-vessel melt case. The release of a large fraction of this additional strontium to the atmosphere could increase the whole-body dose by as much as 50\% above that estimated for the release on the basis of the core melt fractions shown in Table 4.1. However, the melt release fraction will be used to represent the core melt and vessel melt-through cases.

\subsubsection{Form of Release From the Fuel}

In the next sections the transport of fission products from the fuel to the environment will be discussed. The filter efficiency and other reduction factors used in calculating a source term would vary depending on the chemical and physical form of the specific radionuclides. The current consensus is that, during a severe core damage accident, most non-noble fission products will form particulates and aerosols. Therefore, it is assumed that all non-noble fission products will form a homogenous mass of aerosols and particulates. Filter efficiencies and removal coefficients will be applied equally to all non-noble fission products. Noble gases are assumed not to be reduced by any of these mechanisms once released from the fuel. The primary way to reduce noble gas effects is to contain them to allow time for decay or to control the conditions under which they are released.

\subsection{Movement of Fission Products From the Core to Atmosphere (Reduction Factors)}

To estimate the amount of fission products released from the fuel that reach the atmosphere, one must: (1) estimate the pathway the fission products will follow through the plant and (2) estimate the effectiveness of the various fission product removal mechanisms encountered. On the basis of this information, the reduction factor (RDF) for that particular release pathway can be estimated. Table 4.5 lists those that have been selected to represent the dominant removal mechanisms. 
Table 4.5 Summary of particulate/aerosol gaseous (unless noted) reduction mechanisms

Standby Gas Treatment System Filters:

Dry-low pressure flow

Wet-high pressure flow (blowout)

0.01

1.0

Other Filters:

Dry-low pressure flow

Wet-high pressure flow (blowout)

0.01

1.0

Suppression Pool Scrubbing:

Slow steady flow (decay heat)

Pool subcooled

0.01

Pool saturated

0.05

Pool bypass

1.00

Removal of Suspended Aerosols and Particulates:

Natural processes (no sprays)

0.5-hour holdup time

2- to 12-hour holdup time

0.40

24-hour holdup time

0.04

Sprays on

0.5 -hour holdup time

2- to 12-hour holdup time

24-hour holdup time

0.01

Ice Condenser:

One pass through condenser (no recirculation)

Continual recirculation through condenser ( $1 \mathrm{hr}$ or more)

Ice bed exhausted before core damage

0.03

0.02

0.002

Primary System Retention (Plateout):

Bypass accidents only

0.5

0.25

1.0

SG Partitioning (Liquid Release from RCS):

Normal partially filled "U" tube SG (liquid release)

Water solid secondary side "U" tube SG (1iquid release)

Normal once-through SG

0.40

$S G=$ steam generator .

RCS = reactor coolant system . 
These issues will be addressed in two steps. First, each of the major removal mechanisms that may be encountered by the fission products as they travel through plant systems will be discussed in general terms. Second, the release pathways from the reactor coolant system (third fission product barrier) through the containment (fourth fission product barrier) and other possible barriers will be discussed along with the removal mechanisms that should be considered.

\subsubsection{Basic Fission Product Reduction Mechanisms}

Two groups of fission product removal media that may be encountered on the way to the atmosphere are discussed below; these are gaseous and liquid.

Table 4.5 summarizes the various removal mechanisms and associated RDFs. Although effects will be discussed in terms of specific plant systems, the concepts also may be applicable to related conditions. For example, the boilingwater reactor (BWR) suppression pool scrubbing effects also may be applicable for any large pool of water through which gaseous fission products pass.

\subsubsection{Gaseous Release Reduction Mechanisms}

The aerosols and particulates will be carried through plant systems by steam and other gases released as a result of the core damage, if the core is not reflooded with water. This section discusses only those mechanisms that will be effective in removing aerosols and particulates from the gaseous/steam flow.

\subsection{Plateout in the Reactor Coolant System}

Depending on the conditions in the system through which the fission products pass, large quantities of the aerosols and particulates could condense and/or plate out on system surfaces (e.g., piping). Plateout is principally applied to movement of material through the reactor coolant system (RCS). There are many factors influencing this effect including surface areas and temperatures, flow rates, and aerosol or particle size.

As discussed in NUREG-0956, a comparison of available computer projections shows dramatically different plateout (RCS retention) for different chemical forms and events. NUREG-0956 also states that "primary retention factors cannot be used rigorously as a multiplier of accident source term, nor can they be combined linearly with other retention factors (e.g., suppression pools or containment sprays)." Therefore, RCS retention generally will not be considered. However, for bypass accidents, system retention is the only reduction mechanism, and a reduction factor typical of those predicted by computer codes for this accident will be assumed (RDF of 0.4 ). This will be discussed in Section 4.5.2.1.5.

\subsection{Removal of Aerosols and Particulates Suspended in Large Volumes}

The fission product aerosols and particulates may be released into the containment or another large, closed structure or volume (e.g., the auxiliary building). If these structures hold for a sufficient time to allow either natural processes (e.g., gravitational settling) or sprays to act, there will be a substantial reduction in the amount of material airborne and thus availabie for release through any existing pathways to the environment. There are two basic aerosol and particulate removal rates, as shown in Table 4.5, one for natural conditions 
and a second for sprayed volumes. If there is a major failure, it is possible that some of this material may become airborne and be released. However, this will not be considered.

\subsection{Natural Removal Reduction Factors}

There are a large number of natural processes that work to reduce the airborne concentrations of aerosols and particulates. These processes have been examined by various codes and experiments. Figure 4.2 shows a typical result.

Figure 4.2 shows natural processes reducing the concentrations by about a factor of 20 in the first 2 hours, followed by a dropoff in reduction rate. The concentration is reduced by a factor of about 100 in 24 hours. This agrees with other experimental data and is within a factor of 10 of various computer predictions (NUREG/CR-4081) for the early timeframe. The codes generally predict reduction by a factor of 500 to 1000 in 24 hours (NUREG/CR-4081). For the purpose of source term estimation, a set of reduction factors as a function of time for large volumes was developed based on Figure 4.2. This is a very simple assumption. In most accidents there will be continual release from the core that could be replacing the fission products airborne in the containment. This effect may be compensated by the core release assumption.

\subsection{Spray Removal Reduction Factors}

Reactor containments have sprays designed to remove airborne fission products and to condense steam to prevent overpressurization following an accident. 0ther large structures, such as the auxiliary building, also may have spray systems (e.g., fire suppression) that could be used to remove airborne fission products. Some reactor containments also have fire protection sprays that may be helpful in removing airborne fission products, but these are very site specific.

Sprays can be very effective in reducing airborne fission production concentrations. Figure 4.2 shows typical results for a well-designed system. As in the case of natural processes the initial effectiveness lessens with time. A reduction factor of about 20 is observed for sprays in the first hour and a factor of 500 in 24 hours. Table 4.5 lists reduction factors for sprays based on Figure 4.2.

Airborne concentrations under accident conditions in the containment will not be as wel1 behaved as shown in Figure 4.2. These predictions assume a we11designed and fully operational system. Variations as a result of accidentspecific conditions, such as the rates of fission product release from the reactor coolant system must be expected.

\subsection{Filters}

Aerosol and particulate fission products released from the core may encounter a number of filter systems. These systems can be very effective for relatively small and dry flows. However, they can be blown out under high differential pressure or can be clogged with aerosols. 


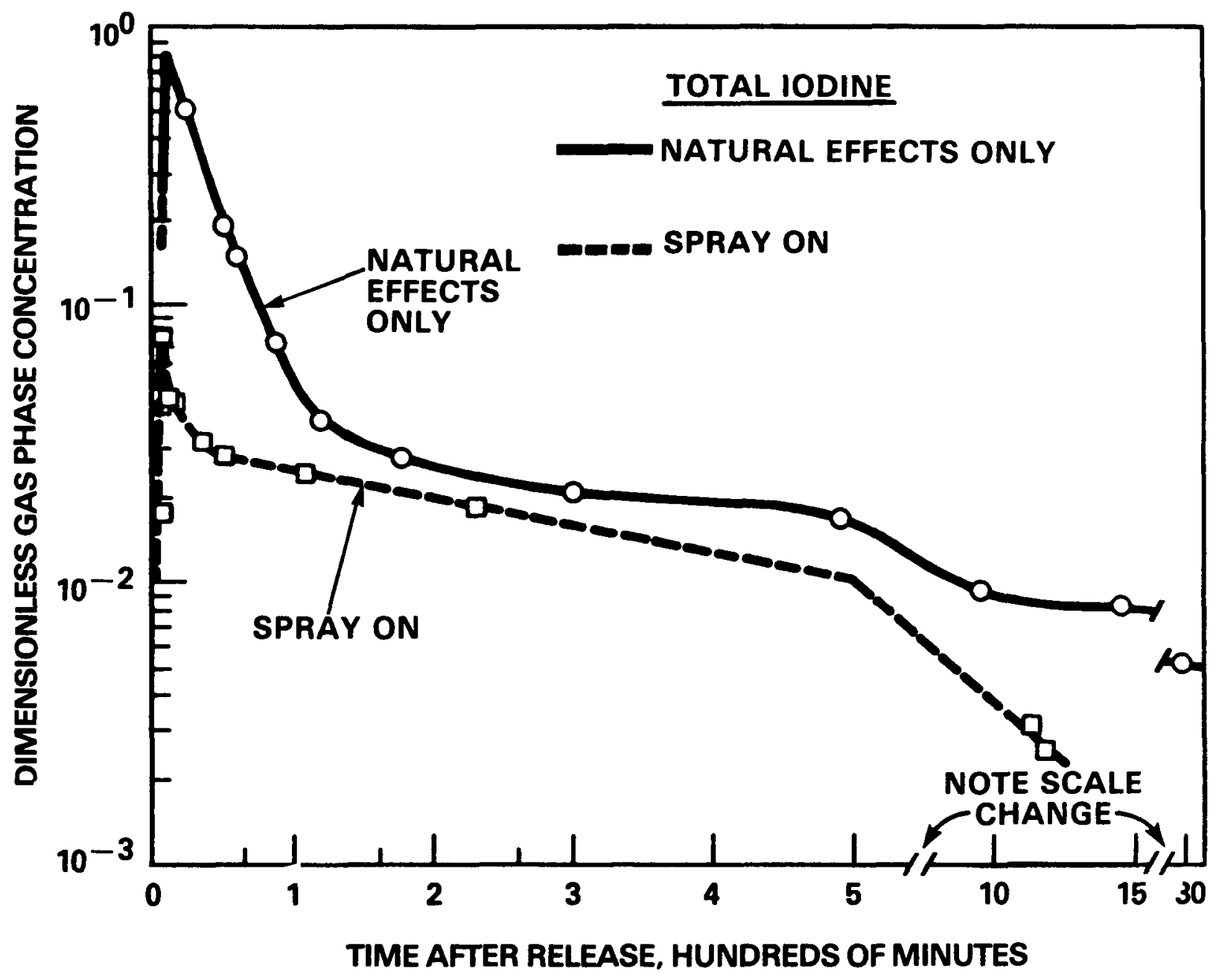

Figure 4.2 Comparison of removal of airborne aerosols and particulates by natural effects and sprays

Source: Hanford Engineering Development Laboratory, HEDL-SA 2254 FP, 1980 


\subsection{BWR Standby Gas Treatment System (SBGTS)}

The purpose of the SBGTS is to collect and filter any release from the BWR primary containment--in some cases, from the downstream leakage of the main steam isolation valves (MSIVs)--and filter the release to the plant stack. Typical SBGTS suction locations for various containment types are shown in Table 4.6.

Table 4.6 Typical BWR standby gas treatment system suction locations

\begin{tabular}{|c|c|}
\hline Compartment & $\begin{array}{l}\text { Containment type } \\
\text { (Mark) }\end{array}$ \\
\hline $\begin{array}{l}\text { Drywell } \\
\text { Suppression chamber } \\
\text { HPCI gland seal exhaust blower } \\
\text { Reactor building } \\
\text { Refueling zone } \\
\text { Fuel building } \\
\text { Auxiliary building } \\
\text { Shield building annulus } \\
\text { Enclosure building } \\
\text { Mainsteam isolation valve leakage } \\
\text { control system }\end{array}$ & $\begin{array}{l}\text { AII } \\
\text { I, II } \\
\text { I } \\
\text { I, II } \\
\text { I, II } \\
\text { III } \\
\text { III, IIIA* } \\
\text { III } \\
\text { IIIA* } \\
\text { II, III }\end{array}$ \\
\hline
\end{tabular}

*Alternative Mark III design.

Source: NUREG/CR-2940

The SBGTS can be very effective ( $99 \%$ efficiency) in removing aerosol and particulate fission products. However, the SBGTS will perform effectively only for an accident where there is a minimal aerosol loading (dry) and limited pressure and temperature conditions with low flows; if the accident causes a high pressure differential, the filter or ductwork would be expected to rupture. In addition, the SBGTS will be bypassed during severe primary containment failure accidents where the secondary containment blowout panel fails as a result of excessive secondary containment pressures (NUREG/CR-2672). Therefore, no credit should be given for the SBGTS for major primary system leakage or failure, and a reduction factor of 0.01 ( $99 \%$ efficiency) should be assumed for small primary containment leaks in removing aerosol and particulate (non-noble) fission products.

\subsection{PWR Containment Recirculating Filter System}

Many PWRs have a containment air recirculating system to trap fission product iodine following an accident. These systems have moisture separators to remove water droplets; however, they are not designed to remove the large quantities of aerosols expected in the containment atmosphere as a result of a severe core damage accident (NUREG-0772). These systems are expected to operate effectively only for cases of limited core damage (e.g., gap release). 
For a core melt accident, no credit should be given for these systems. These systems only complement and back up the containment sprays, and their effectiveness would be difficult to predict. These systems will not be considered in the method presented in this document.

\subsection{PWR Auxiliary Building Filter Systems}

These filters are intended to treat exhaust air from equipment areas and volumes outside containment where there is a potential for the release of small quantities of airborne fission products as a result of leaks in systems processing primary coolant system water that has been contaminated. As with other filter systems, these systems use high-efficiency particulate air (HEPA) and activated carbon absorbers and can be very effective in removing particulates and aerosols.

As was the case during the TMI accident, if filters are exposed to only small amounts of leakage, they should be assumed to be very effective ( $99 \%$ efficiency) with an assumed reduction factor of 0.01 . However, for accidents that result in large releases into the auxiliary building, the flow rates are expected to result in pressures that would cause a major leak to develop, thereby creating a direct pathway to the environment. Under these conditions with high aerosol loads in the filtered material, the system might also plug and fail. Therefore, for major releases into the auxiliary building, it should be assumed that these filters will not be effective.

\subsection{BWR Suppression Pool (NUREG/CR-3727)}

All BWRs have pressure suppression pools as part of their containments, which are designed to condense steam following loss-of-coolant accidents. The suppression pool is a large mass of water through which the steam released from a break in the BWR reactor coolant system (third fission product barrier) blows down. Although the suppression pool is not designed as a fission product removal system, a byproduct of the pressure suppression process is the scrubbing of fission products. In a severe accident involving overpressures caused by hydrogen or the accumulation of noncondensible gases, the failure or bypass of the suppression pool is possible. Accidents involving vessel melt-through have been postulated that involve the core melting through the containment liner, providing a suppression pool bypass. Obviously, the suppression pool is effective only if releases from the reactor coolant system leakage pass through the pool.

The ability of the system to remove fission products will depend on (1) the energy of the blowdown and (2) the pool temperature. Tests have shown that the pools would have a very low decontamination efficiency $(\sim 15 \%)$ for violently flashing steam that may be present if more than decay heat (reactor not shut down) was being removed by the blowdown. However, there will be some retention resulting from condensation of steam and other factors. As a result, an RDF of 0.05 ( $50 \%$ retention) is estimated. However, for most postulated BWR accidents, the release of fission products is expected to be relatively slow with a steady flow of steam generated by decay heat. In this case, the removal rate could be very high depending on the temperature of the pool. If the pool were allowed to heat to the saturation temperature (e.g., because of inoperability of the residual heat removal system [RHRS]), the scrubbing efficiency would be reduced. The assumed scrubbing efficiencies for various cases are shown in Table 4.5. Obviously, if the pool is bypassed it will not affect the release. 
There may be other cases, such as a pipe break in a flooded area, where the gaseous release flows are scrubbed by a pool of water. If the pool is large enough, considerable scrubbing could be assumed.

\subsection{PWR Ice Condenser (NUREG/CR-3727)}

An ice condenser containment was designed as an alternative to the large-volume containment traditionally used for PWRs. Like the large, dry containment, the ice condenser containment is designed to accommodate the large steam quantities associated with a loss-of-coolant accident (LOCA). However, the ice condenser feature permits a much smaller containment ( $50 \%$ less volume). In addition to suppressing the rise in containment pressure following a LOCA, the ice condenser also would tend to reduce the fission products in the containment air by entrapment and dissolution.

A typical ice condenser system consists of an annular compartment that contains about $2.4 \times 10^{6}$ ib of flaked borated ice at the outer circumference of the containment vessel. Following a large LOCA, the blowdown steam, fission products, and reactor compartment air will flow through the ice condenser, where the steam will be condensed and fission products will be attenuated. The circulation of the postaccident containment atmosphere through the ice condenser is maintained by two axial fans, each with a capacity of about $40,000-\mathrm{ft}^{3} / \mathrm{min}$. These fans transfer air from the upper to the lower containment compartments, thereby inducing a flow through the ice compartments.

Preliminary computer analys is concluded that the ice condenser has significant potential for removing fission products that pass through it. If the air return fans were not available for circulation, the radioactivity released from the reactor coolant system would make only a single pass through the ice condenser; even then, approximately one-half (RDF of 0.5 ) of the fission products released to the containment are predicted to be removed by the ice bed. If the air return fans are available to continually recirculate the containment atmosphere for an hour or more, even greater retention by the ice bed is predicted (e.g., 75\%). Therefore, for the purpose of source term estimation, a reduction factor of 0.25 for recirculation cases can be assumed. However, accidents have been postulated during which the ice is exhausted before major core damage; under these conditions, no credit should be given for removal of fission products by ice.

\subsubsection{Liquid Release Reduction Mechanisms}

Fission products may be carried by reactor coolant or other contaminated water to a point where they can be released to the atmosphere. The levels of contamination could be very high; for example, a severely damaged core could be reflooded resulting in vastly increased coolant concentration. During the TMI accident, the reactor coolant, after core damage, had 300,000 times the normal levels of fission product contamination (NUREG-0600). Another source of contaminated water could be the water in the containment following spray operations to scrub fission products from the containment atmosphere. In these cases, the quantity of contaminants released to the atmosphere will be a function of the rate the fission products escape from the liquid. Releases of fission products in water that are not released to the atmosphere directly (i.e., basemat melt-through) are not covered. 
The following release fractions for liquid transport cases will be discussed (Clinton, 1984):

(1) boiling water

(2) hot coolant (water) vented directly into the atmosphere that flashes to steam or is atomized

As shown in Figure 4.3, steam generator tube ruptures in a PWR can provide three major release pathways to the environment. If the main steam line does not isolate and the condenser is available, it would be preferred to direct the reactor coolant system leakage to the condenser. Under these conditions, it can be assumed (NUREG-0909) that only the noble gas in the coolant will be released through the steam jet-air ejector to the atmosphere. If the main steam line isolation valve is closed (as shown in Figure 4.3 ) the safety valve and auxiliary feedwater turbine exhaust provide pathways to the environment. However, in most cases such releases would be greatly reduced as a result of partitioning in the steam generator. The steam from boiling water has a considerably lower concentration of contaminants than the water being boiled. This process of decontamination is measured in terms of a partitioning factor where:

Mass partition factor $=\frac{\text { mass fission products entrained in unit mass of water }}{\text { mass fission products entrained in unit mass of steam }}$

In cases such as normal "U" tube steam generator operation where a clear boundary exists between the boiling water on the secondary side and steam generated (Figure 4.4, Case A), a mass partitioning factor of 20 to 250 has been measured. In this case, it will be assumed that only about $1 / 50$ (2\%) of the iodine and other non-noble fission products in the mass of boiled water (release) are passed on to the steam, based on a mass partition factor of 50 . Therefore, where a water/steam interface exists in a release pathway, a filter efficiency of $98 \%$ (RDF of 0.02 ) can be assumed for dry steam. However, if contaminated water is carried with the steam, the partition factor decreases. This can result from the steam generator design or size and condition of the steam generator tube rupture. The Babcock \& Wilcox (B\&W) steam generators, referred to as "once-through steam generators," do not produce a clear steam/water boundary, and considerable amounts of contaminated water leaking into the secondary side could be carried with the steam. For " $U$ " tube steam generator designs, the leak should be under the secondary side water as shown in Figure 4.4, Case $\mathrm{A}$. However, if the tube leak is massive, the secondary water could be boiling violentiy, and the secondary side steam would carry considerable contamination. This is called carryover. For large multitube failures or for the once-through steam generator (B\&W), an RDF of 0.5 should be assumed.

During the Ginna accident (NUREG-0909), the secondary side filled with coolant following isolation as shown in Case B of Figure 4.4. The primary coolant was then ejected into the atmosphere through the safety valve. Therefore, the iodine concentration in the release was considerably above what would be expected. This is an example of the contaminated water and all of its contaminants being ejected into the atmosphere, the water flashing to steam and atomizing, carrying much of its contamination into the atmosphere. However, it is expected that contaminated water will be diluted by the water in the secondary side. During the Ginna accident, secondary side dilution reduced the 


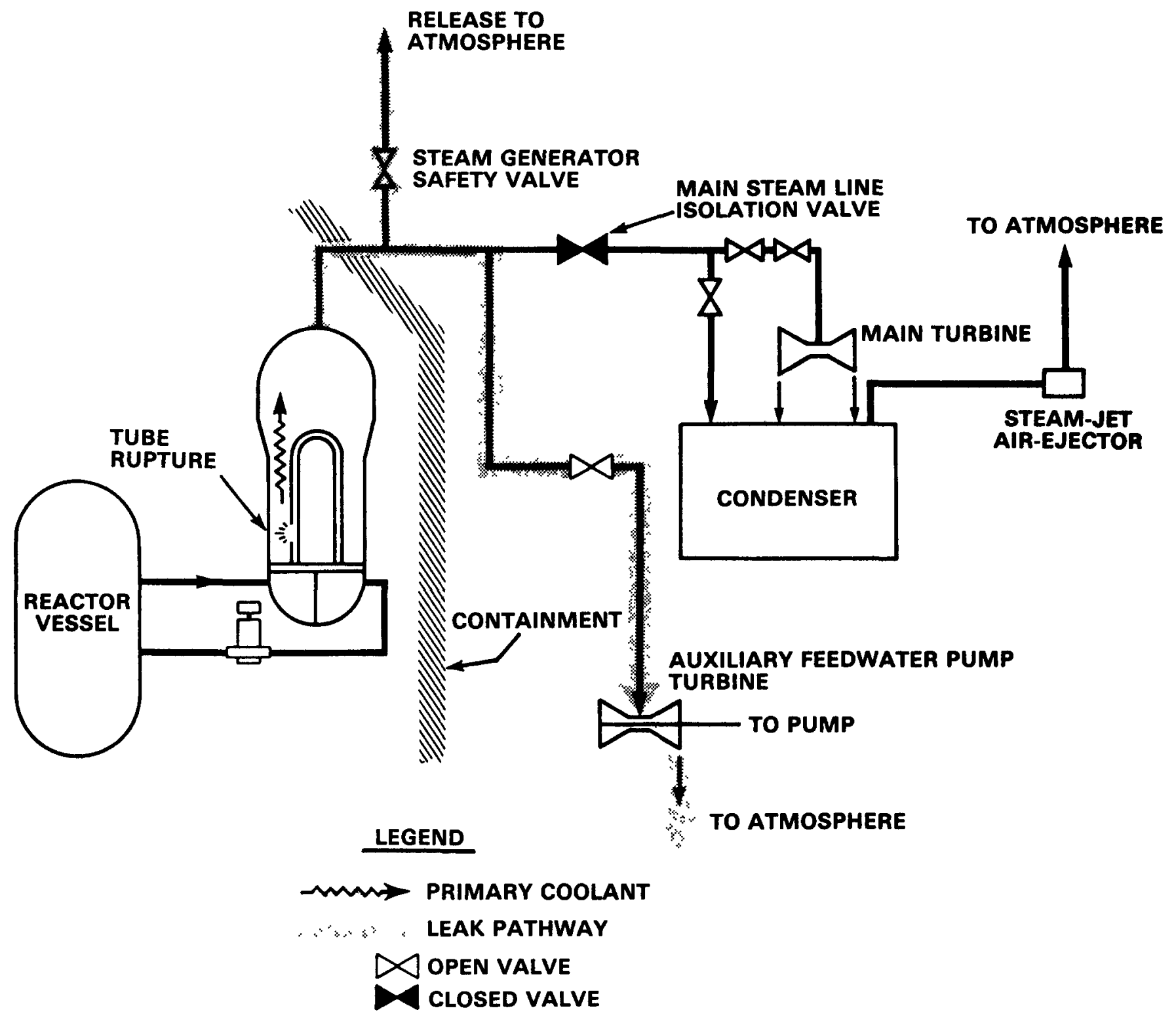

Figure 4.3 Typical pathways for release of radionuclides to the atmosphere from a steam generator tube rupture 


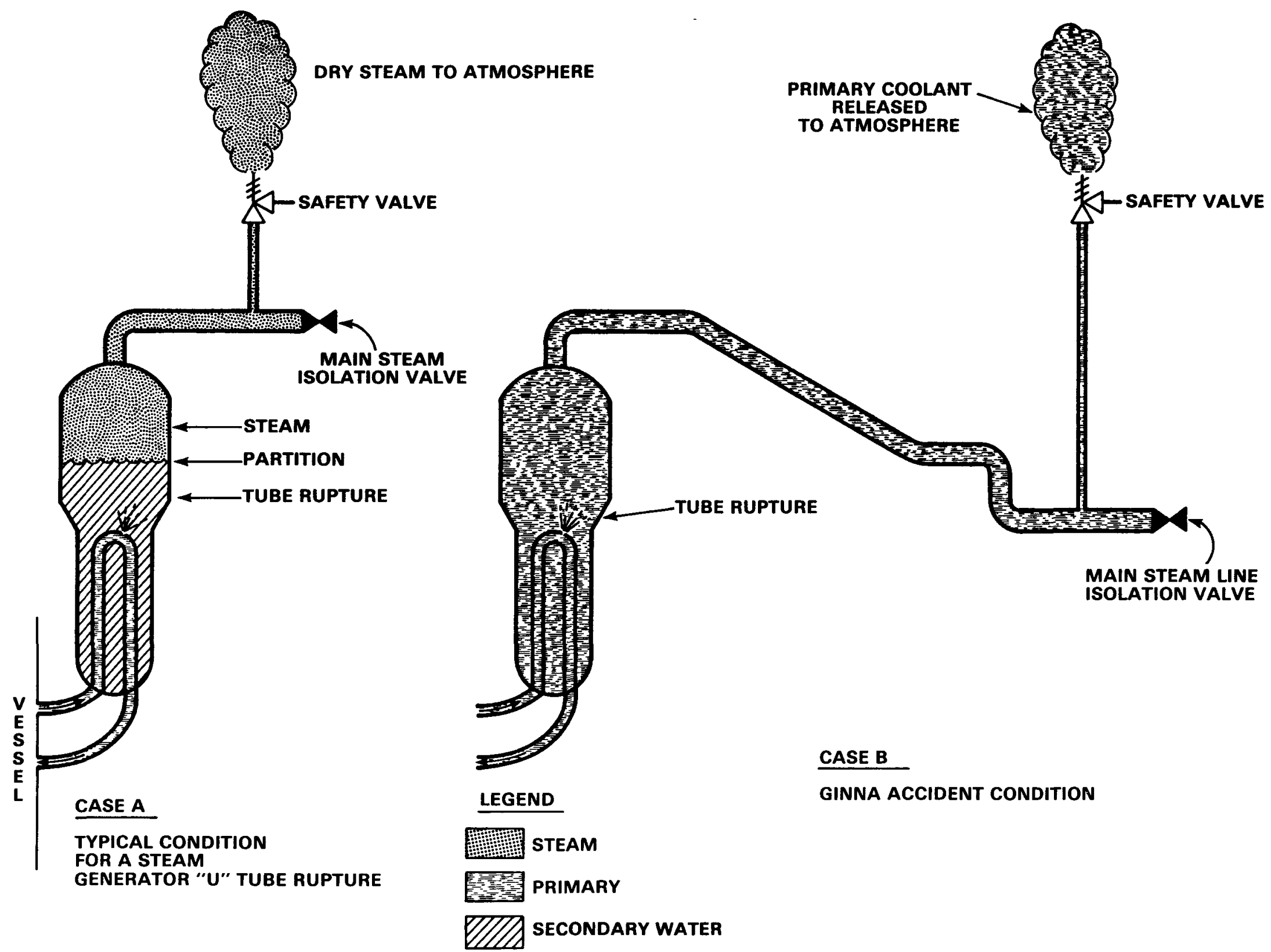

Figure 4.4 Conditions in radionuclide release pathways following a "U" tube steam generator tube rupture to the environment 
release concentration in half. Therefore, a RDF of 0.5 is assumed. This situation also may be encountered when a pipe breaks or safety valve opens directly into the atmosphere and releases hot and high-pressure water. Such cases also have the potential of leading directly to severe accidents that bypass the containment and releasing fission products dissolved in the coolant directly into the atmosphere.

\subsubsection{Basic Release Pathways and Characteristics}

Section 4.4 discussed the release of fission products into the reactor coolant system from the core. This section will show the major pathways the fission products can take through the remaining fission product barriers. The fission product reduction mechanisms encountered will be listed. Two simplified diagrams that highlight the basic release pathways of PWR dry and ice condenser containments (Figures 4.5 and 4.6 , respectively) and three simplified diagrams that highlight the BWR Mark I, Mark II, and Mark III containment release pathways (Figures $4.7,4.8$, and 4.9 ) will be referenced in the discussion. The basic release pathways are designated on the figures by letters and numbers. The letters refer to a specific barrier and the numbers specify a specific pathway through the barrier. Tables 4.7 and 4.8 list the specific PWR and BWR pathways and indicate the specific reduction mechanism that should be considered. Table 4.9 provides a key to the release pathways used in the figures.

\subsubsection{Reactor Coolant System (Third Fission Product Barrier)}

Once the core is damaged, the fission products are initially released into the reactor coolant system. Without a breach of the reactor coolant system, major fuel damage is not possible. Therefore, major fuel damage indicates that there was at some time a break in the reactor coolant system. Reactor coolant system breaches are shown as "A" on Figures 4.5, 4.6, 4.7, 4.8, and 4.9.

\subsection{PWR Reactor Coolant System Breaks/Leaks}

A break in the reactor coolant system (RCS) is shown as A-1 in Figures 4.5 and 4.6. The PWR RCS is contained within the containment. The discussion in this section will only deal with breaks that result in RCS breaks directly into the containment.

Most analyses of this event assume that the break in the RCS starts the accident. In this case, it is assumed that the break is followed by a failure of the systems designed to replace the coolant lost as a result of the break, which leads to core uncovery and damage. Therefore, the break exists before core damage and provides a direct pathway for fission product release from the fuel into the containment atmosphere.

For all the PWR containment designs, except for the ice condensers, the gas flow from the damaged core and through the break does not pass through any filter mechanisms. For those plants without ice condenser containments, the only reduction mechanism that is important is plateout in the RCS, and it will not be considered (as discussed in Section 4.5.1.1.1) except for bypass accidents.

In the ice condenser containment design, the flow from a break in the RCS flows through an ice condenser, where steam will be condensed and fission products 


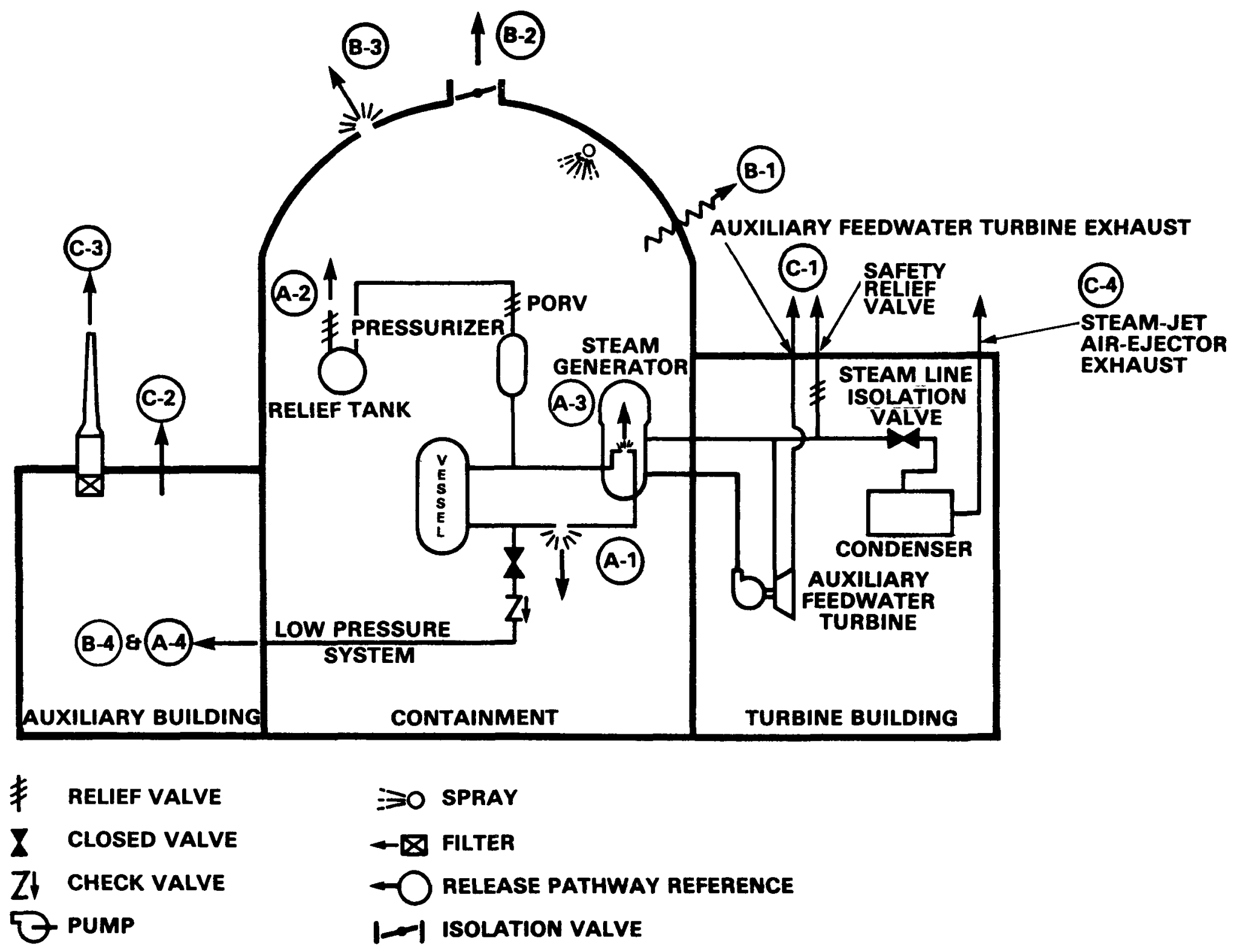

Figure 4.5 PWR dry containment simplified release pathways 


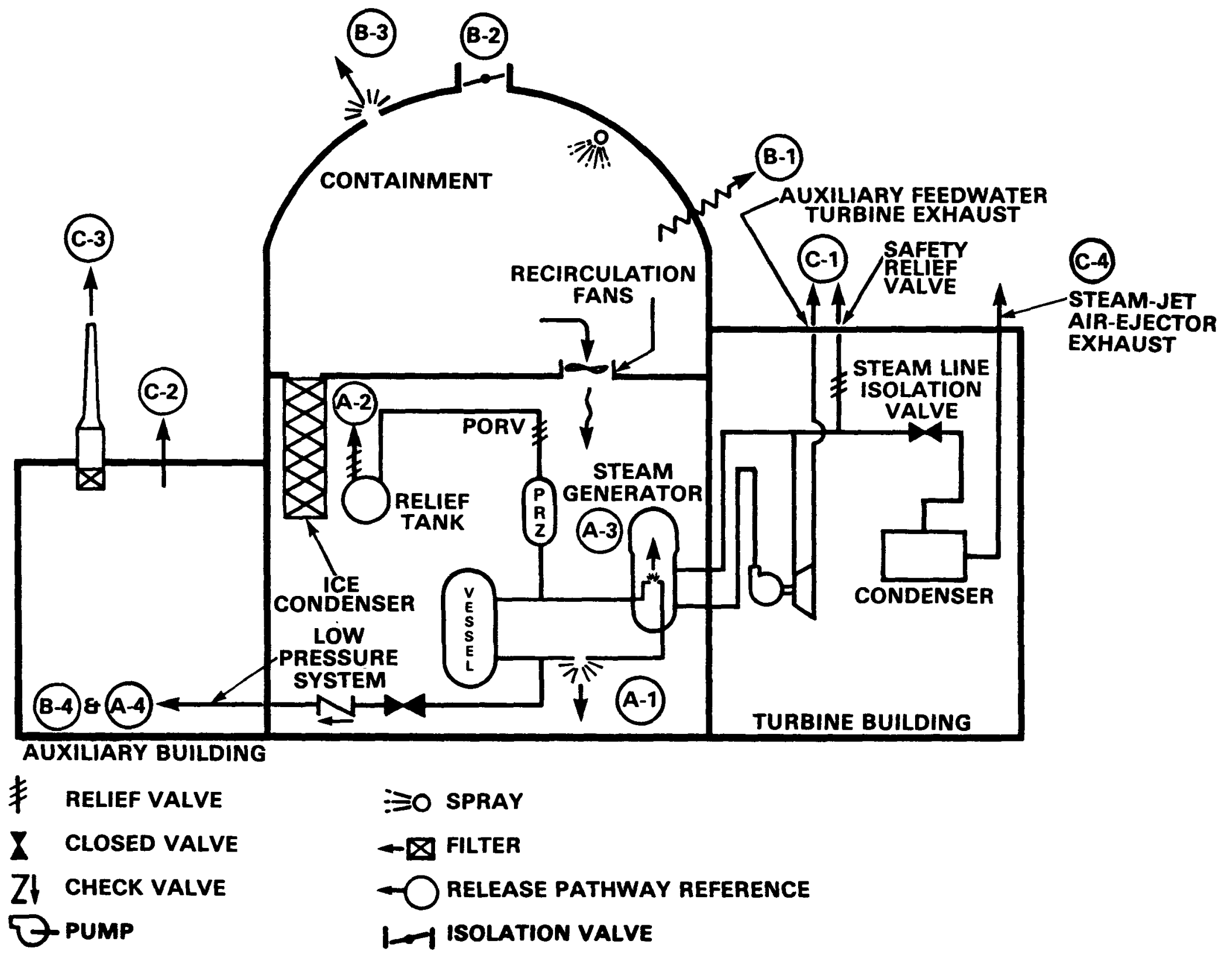

Figure 4.6 PWR ice condenser containment simplified release pathways 


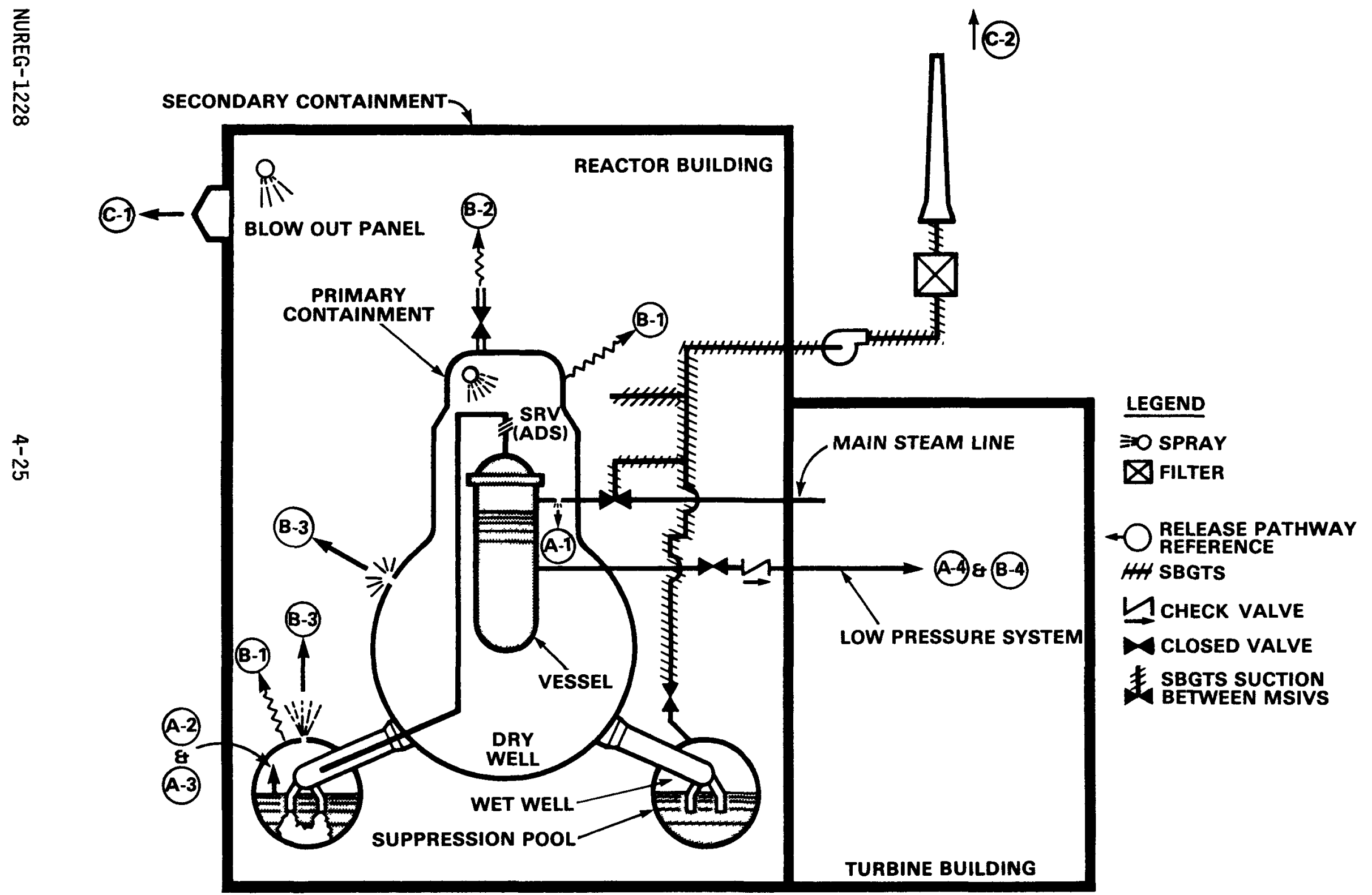

Figure 4.7 BWR Mark I simplified release pathways 

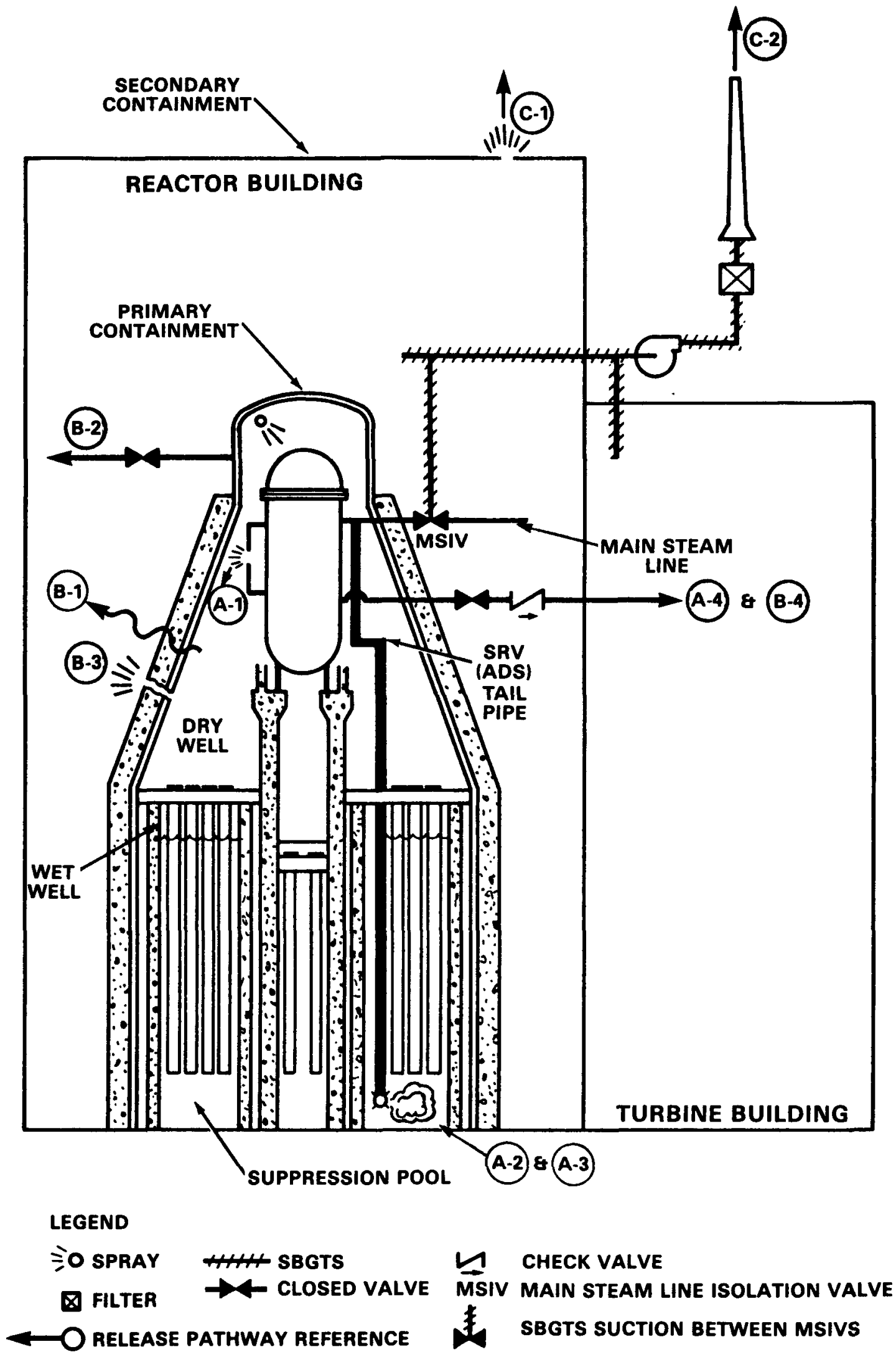

Figure 4.8 BWR Mark II simplified release pathways 


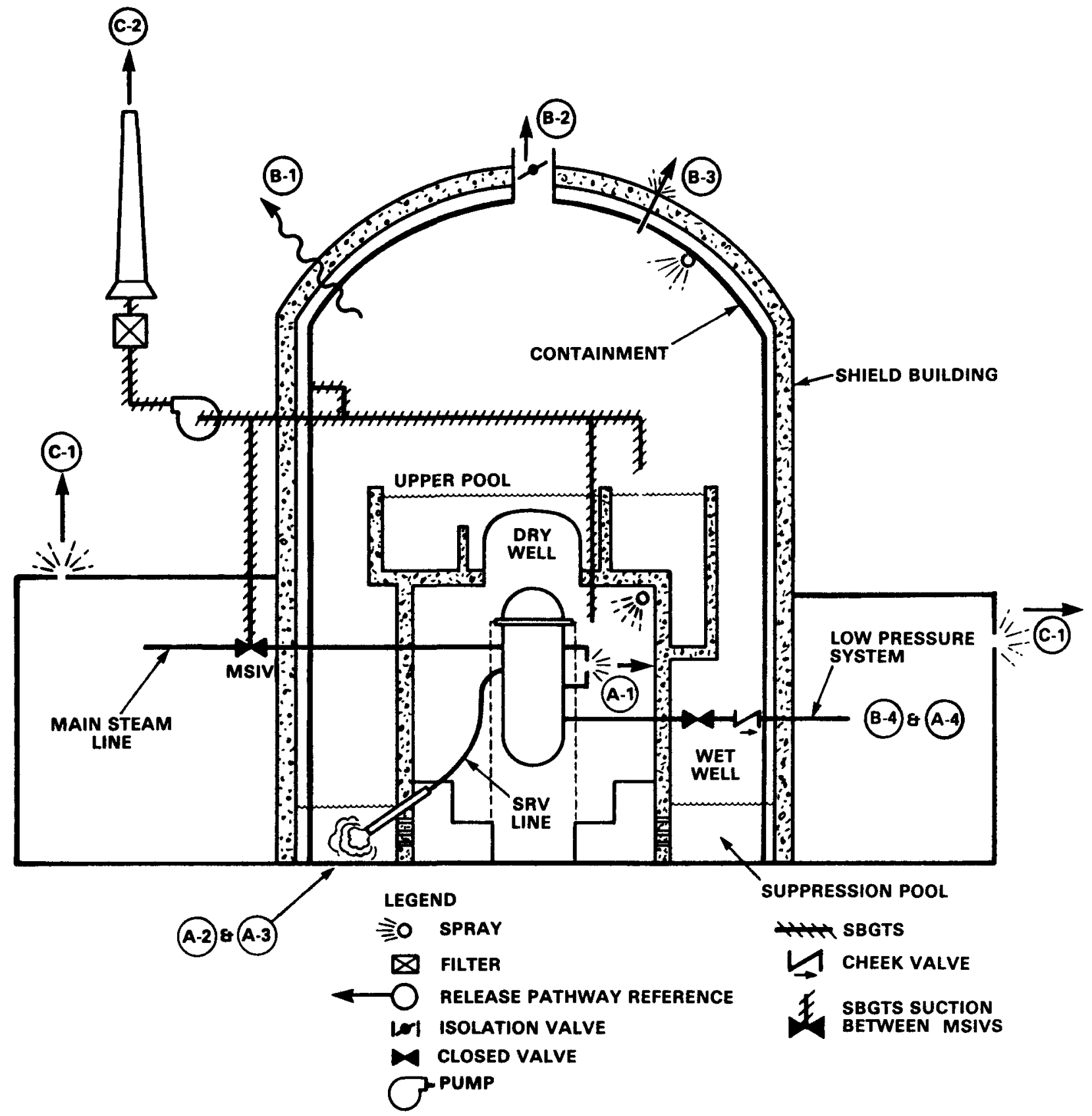

Figure 4.9 BWR Mark III simplified release pathways 
Table 4.7 Summary of major PWR release pathway reduction mechanisms

\begin{tabular}{|c|c|c|c|c|c|}
\hline $\begin{array}{l}\text { Fission product } \\
\text { barrier breached }\end{array}$ & Pathway & $\begin{array}{l}\text { Reference Fig- } \\
\text { ures } 4.5,4.6\end{array}$ & $\begin{array}{l}\text { Reduction } \\
\text { mechanism }\end{array}$ & Condition & $\begin{array}{l}\text { Non-noble } \\
\text { assumed RDF }\end{array}$ \\
\hline \multirow[t]{6}{*}{$\begin{array}{l}\text { Reactor coolant } \\
\text { system: }\end{array}$} & $\begin{array}{l}\text { Break/leak } \\
\text { and open PORV }\end{array}$ & $\begin{array}{l}A-1 \\
A-2\end{array}$ & Ice condenser & $\begin{array}{l}\text { Single-pass fans } \\
\text { fail }\end{array}$ & 0.50 \\
\hline & & & & $\begin{array}{l}1 \text { hour of recir- } \\
\text { culation through } \\
\text { ice condenser }\end{array}$ & 0.25 \\
\hline & $\begin{array}{l}\text { Steam generator } \\
\text { tube rupture }\end{array}$ & $A-3$ & $\begin{array}{l}\text { SG } \\
\text { partitioning }\end{array}$ & $\begin{array}{l}\text { "U" tube secondary } \\
\text { side boiling (dry } \\
\text { steam) }\end{array}$ & 0.02 \\
\hline & & & & $\begin{array}{l}\text { Normal OTSG (B\&W } \\
\text { steam generator) }\end{array}$ & 0.50 \\
\hline & & & & Dry steam generator & 1.00 \\
\hline & $\begin{array}{l}\text { Bypass (failure } \\
\text { into low-pressure } \\
\text { system) }\end{array}$ & $A-4$ & $\begin{array}{l}\text { Primary } \\
\text { system } \\
\text { retention }\end{array}$ & $\begin{array}{l}\text { For bypass accidents } \\
\text { only }\end{array}$ & 0.40 \\
\hline Primary containment: & $\begin{array}{l}\text { Design leakage } \\
(0.1 \%-0.25 \% / \text { day }) \\
\text { or } \\
\text { Smal1 isolation } \\
\text { valve seal failure } \\
(100 \% / \text { day }) \\
\text { or }\end{array}$ & B-2 & $\begin{array}{l}\text { Containment } \\
\text { sprays }\end{array}$ & $\begin{array}{l}0.5 \text {-hour holdup in } \\
\text { containment } \\
2-\text { to } 12 \text {-hour holdup } \\
\text { in containment }\end{array}$ & 0.02 \\
\hline
\end{tabular}


Table 4.7 (continued)

\begin{tabular}{|c|c|c|c|}
\hline $\begin{array}{l}\text { Fission product } \\
\text { barrier breached }\end{array}$ & Pathway & $\begin{array}{l}\text { Reference Fig- } \\
\text { ures } 4.5,4.6\end{array}$ & $\begin{array}{l}\text { Reduction } \\
\text { mechanism }\end{array}$ \\
\hline $\begin{array}{l}\text { Primary containment } \\
\text { (continued): }\end{array}$ & $\begin{array}{l}\text { Catastrophic } \\
\text { failure }(100 \% / \mathrm{hr})\end{array}$ & $B-3$ & \\
\hline & & & $\begin{array}{l}\text { Natural proc- } \\
\text { esses in } \\
\text { containment } \\
\text { (no spray) }\end{array}$ \\
\hline
\end{tabular}

Condition

Non-noble

24-hour holdup assumed RDF

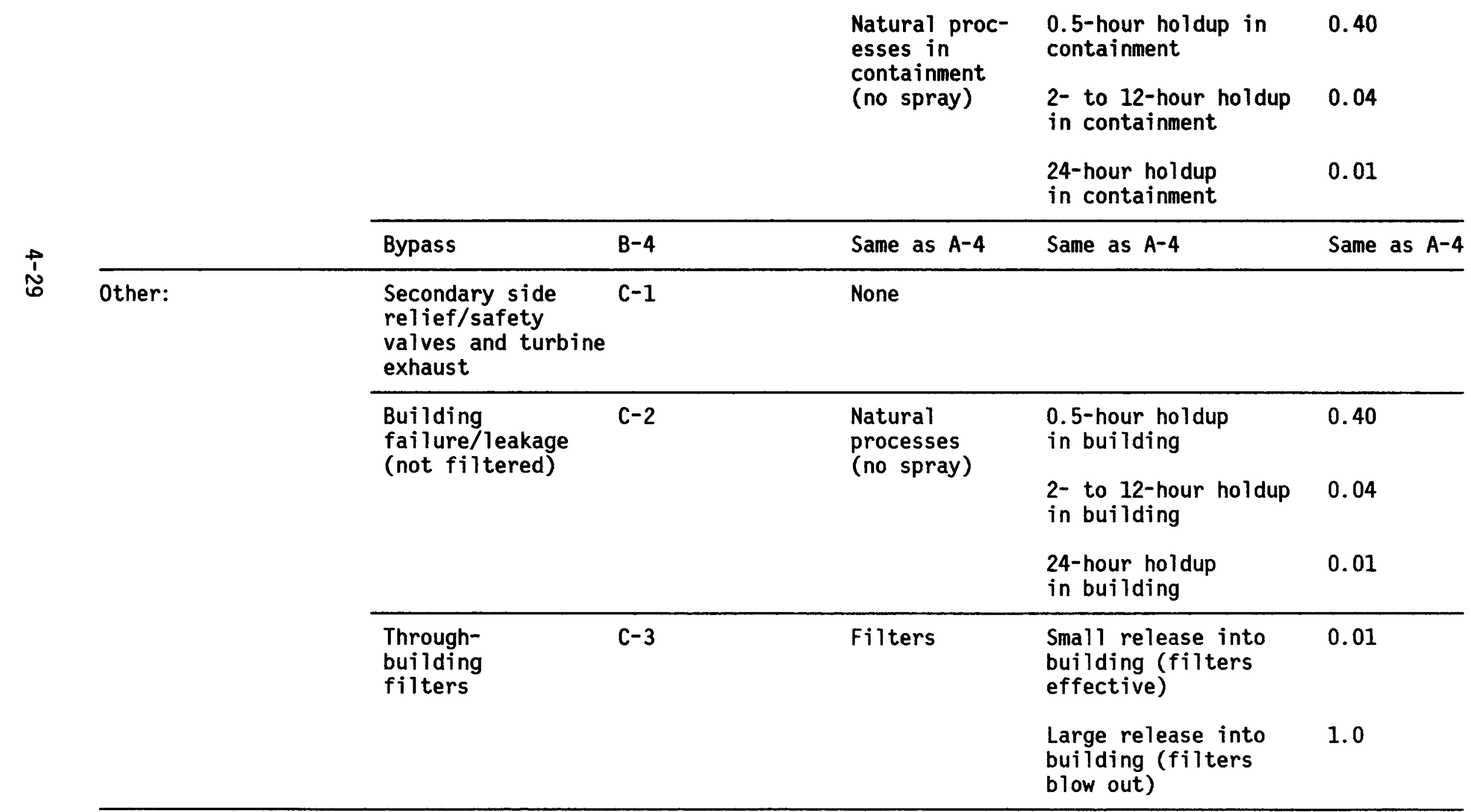


Table 4.7 (continued)

\begin{tabular}{lllll}
\hline $\begin{array}{l}\text { Fission product } \\
\text { barrier breached }\end{array}$ & Pathway & $\begin{array}{l}\text { Reference Fig- } \\
\text { ures 4.5, 4.6 }\end{array}$ & $\begin{array}{l}\text { Reduction } \\
\text { mechanism }\end{array}$ & Condition \\
\hline Other (continued): & $\begin{array}{l}\text { Steam-jet air- } \\
\text { ejector }\end{array}$ & $\mathrm{C}-4$ & $\begin{array}{l}\text { Non-noble } \\
\text { assumed RDF }\end{array}$ \\
\hline
\end{tabular}


Table 4.8 Summary of major BWR release pathway reduction mechanisms

\begin{tabular}{|c|c|c|c|c|c|c|}
\hline $\begin{array}{l}\text { Fission } \\
\text { barrier }\end{array}$ & $\begin{array}{l}\text { product } \\
\text { breached }\end{array}$ & Pathway & $\begin{array}{l}\text { Reference } \\
\text { Figures } 4.7 \text {, } \\
4.8,4.9\end{array}$ & $\begin{array}{l}\text { Reduction } \\
\text { mechanism }\end{array}$ & Condition & $\begin{array}{l}\text { Non-noble } \\
\text { assumed } \\
\text { RDF }\end{array}$ \\
\hline \multirow[t]{5}{*}{$\begin{array}{l}\text { Reactor } \\
\text { system: }\end{array}$} & \multirow[t]{5}{*}{ coolant } & $\begin{array}{l}\text { Break/leak } \\
\text { bypasses } \\
\text { suppression } \\
\text { pool }\end{array}$ & $A-1$ & None & None & 1.00 \\
\hline & & \multirow[t]{2}{*}{$\begin{array}{l}\text { Break/leak } \\
\text { through } \\
\text { suppression } \\
\text { pool }\end{array}$} & \multirow[t]{2}{*}{$A-2$} & \multirow[t]{2}{*}{$\begin{array}{l}\text { Suppression } \\
\text { pool } \\
\text { scrubbing }\end{array}$} & $\begin{array}{l}\text { Slow flow - decay heat } \\
\text { and pool subcooled } \\
\text { Slow flow - decay heat } \\
\text { and pool saturated }\end{array}$ & $\begin{array}{l}0.01 \\
0.05\end{array}$ \\
\hline & & & & & Pool bypassed & 1.00 \\
\hline & & $\begin{array}{l}\text { Through ADS/ } \\
\text { SRV }\end{array}$ & $A-3$ & Same as A-2 & Same as A-2 & Same as $A-2$ \\
\hline & & $\begin{array}{l}\text { Bypass of } \\
\text { containment }\end{array}$ & $A-4$ & $\begin{array}{l}\text { System } \\
\text { retention }\end{array}$ & $\begin{array}{l}\text { For bypass accidents } \\
\text { only }\end{array}$ & 0.40 \\
\hline \multicolumn{2}{|c|}{ Primary containment: } & $\begin{array}{l}\text { Design leakage } \\
(0.5 \% / \text { day } \\
\text { or } \\
\text { Isolation valves } \\
\text { seal failure } \\
\text { (100\%/day } \\
\quad \text { or } \\
\text { Catastrophic } \\
\text { failure } \\
(11 \% / h r)\end{array}$ & B-3 & $\begin{array}{l}\text { Dry we } 11 \\
\text { containment } \\
\text { sprays (ON) }\end{array}$ & $\begin{array}{l}\text { 0.5-hour holdup in } \\
\text { dry we } 11 \\
\text { 2- to } 12 \text {-hour holdup } \\
\text { in dry well }\end{array}$ & 0.02 \\
\hline
\end{tabular}


Table 4.8 (continued)

\begin{tabular}{|c|c|c|c|c|c|}
\hline $\begin{array}{l}\text { Fission product } \\
\text { barrier breached }\end{array}$ & Pathway & $\begin{array}{l}\text { Reference } \\
\text { Figures } 4.7 \text {, } \\
4.8,4.9\end{array}$ & $\begin{array}{l}\text { Reduction } \\
\text { mechanism }\end{array}$ & Condition & $\begin{array}{l}\text { Non-noble } \\
\text { assumed } \\
\text { RDF }\end{array}$ \\
\hline \multirow[t]{4}{*}{$\begin{array}{l}\text { Primary containment } \\
\text { (continued): }\end{array}$} & & & $\begin{array}{l}\text { Dry wel1 } \\
\text { and wet } \\
\text { well natural } \\
\text { processes } \\
\text { (no spray) }\end{array}$ & $\begin{array}{l}0.5 \text {-hour holdup in } \\
\text { dry well } \\
\text { 2- to } 12 \text {-hour holdup } \\
\text { in dry well }\end{array}$ & $\begin{array}{l}0.40 \\
0.04\end{array}$ \\
\hline & & & & $\begin{array}{l}\text { 24-hour holdup in } \\
\text { dry well }\end{array}$ & 0.01 \\
\hline & Bypass & $B-4$ & Same as A-4 & Same as $A-4$ & Same as $A-4$ \\
\hline & $\begin{array}{l}\text { Controlled } \\
\text { venting }\end{array}$ & $B-5$ & $\begin{array}{l}\text { Same as } \\
\text { standby gas } \\
\text { treatment } \\
\text { system } \\
\text { (SBGTS) }\end{array}$ & $\begin{array}{l}\text { Same as } B-1,2 \text {, or } \\
3 \text { and } C-2\end{array}$ & $\begin{array}{l}\text { Same as } B-1 \text {, } \\
2,3 \text { and } C-2\end{array}$ \\
\hline \multirow[t]{2}{*}{$\begin{array}{l}\text { Secondary } \\
\text { containment: }\end{array}$} & $\begin{array}{l}\text { Building } \\
\text { failure/leakage } \\
\text { (not filtered) }\end{array}$ & $c-1$ & $\begin{array}{l}\text { Natural } \\
\text { processes } \\
\text { (no spray) }\end{array}$ & $\begin{array}{l}0.5 \text {-hour holdup in } \\
\text { building } \\
2-\text { to } 12 \text {-hour holdup } \\
\text { in building }\end{array}$ & $\begin{array}{l}0.40 \\
0.04\end{array}$ \\
\hline & & & & $\begin{array}{l}\text { 24-hour holdup } \\
\text { in building }\end{array}$ & 0.01 \\
\hline
\end{tabular}


Table 4.8 (continued)

\begin{tabular}{|c|c|c|c|c|c|}
\hline $\begin{array}{l}\text { Fission product } \\
\text { barrier breached }\end{array}$ & Pathway & $\begin{array}{l}\text { Reference } \\
\text { Figures } 4.7 \text {, } \\
4.8,4.9\end{array}$ & $\begin{array}{l}\text { Reduction } \\
\text { mechanism }\end{array}$ & Condition & $\begin{array}{l}\text { Non-noble } \\
\text { assumed } \\
\text { RDF }\end{array}$ \\
\hline \multirow[t]{2}{*}{$\begin{array}{l}\text { Secondary containment } \\
\text { (continued) }\end{array}$} & \multirow[t]{2}{*}{ Through SBGTS } & \multirow[t]{2}{*}{$c-2$} & \multirow[t]{2}{*}{$\begin{array}{l}\text { SBGTS } \\
\text { filters (in } \\
\text { addition to } \\
\text { natural } \\
\text { process) }\end{array}$} & $\begin{array}{l}\text { Small release } \\
\text { (minimal aerosol } \\
\text { loading - filters } \\
\text { effective) }\end{array}$ & 0.01 \\
\hline & & & & $\begin{array}{l}\text { Filter failure - } \\
\text { rupture (heavy } \\
\text { aerosol loading/ } \\
\text { large high-pressure } \\
\text { release) }\end{array}$ & 1.00 \\
\hline
\end{tabular}

$\underset{\omega}{\stackrel{\leftrightarrow}{\omega}}$ 
Table 4.9 Key to release pathway references on Figures 4.5 through 4.9

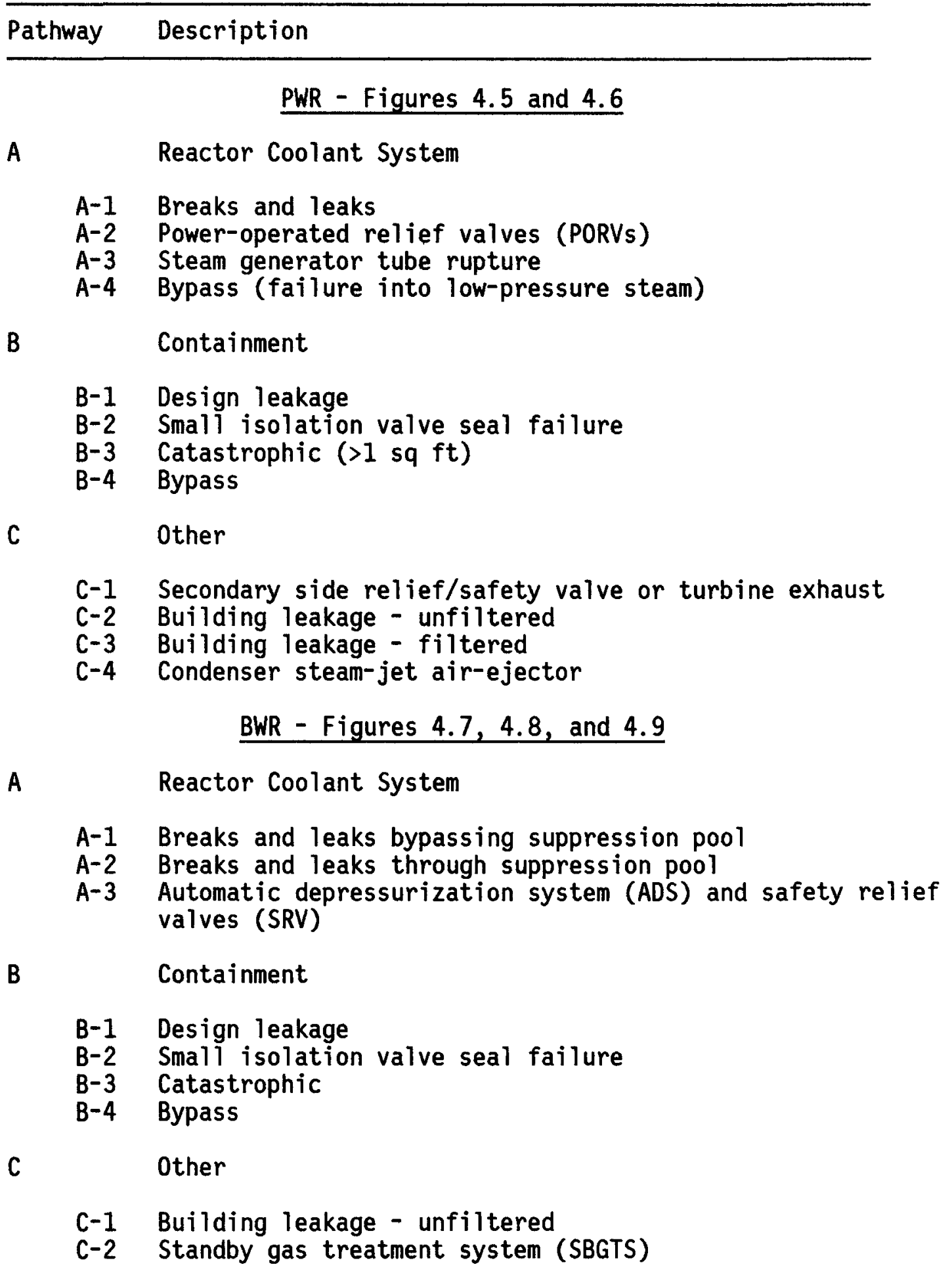


will be attenuated. For cases where air return fans are not available (fail), an RDF of 0.50 should be assumed. If the RCS release is circulated through the ice bed, an RDF of 0.25 should be assumed until the ice is exhausted. In some accidents analyzed, the ice is exhausted before core damage. Under those conditions no credit should be given for the ice bed (RDF of 1.00).

\subsection{PWR Power-Operated Relief Valves}

PWR RCS have relief valves designed to prevent the system from overpressurizing. If the systems designed to remove heat from the RCS fail, the RCS pressure will increase until the relief valves on the pressurizer open. If the rate of coolant loss through the relief valves exceeds the rate of coolant makeup (i.e., via safety injection), the core can become uncovered resulting in core damage. This same release pathway could become the release path from the RCS (A-2 on Figures 4.5 and 4.6 ). This was the primary pathway for the fission products released from the RCS during the TMI accident.

As shown in Figures 4.5 and 4.6 , the relief valves do not release directly into the containment, but through piping into a relief tank. The relief tank is designed to condense the steam released during normal operations. As happened during the TMI accident, large quantities of water fill the tank, resulting in the rupture of a disk and allowing a path for fission products into the containment.

Although some scrubbing may take place as the coolant passes through the relief tank, it will be difficult to estimate the extent to which fission products are retained. It is generally assumed that the relief tank rupture disk would open, providing a direct pathway before core damage. Consequently, no credit will be given for scrubbing.

\subsection{PWR Steam Generator Tube Rupture}

When the steam generator (SG) tubes fail, a pathway directly to the atmosphere (i.e., bypasses containment) may be provided. This is shown on Figure 4.3 and as pathway $\mathrm{A}-3$ on Figures 4.5 and 4.6 . When a steam generator tube rupture (SGTR) occurs, the fission products from the higher pressure primary system pass into the secondary side $(A-3)$ and possibly into the atmosphere through the secondary relief valves or turbine exhaust ( $C-1$ on Figures 4.5 and 4.6 ) or by the condenser steam-jet air-ejector exhaust.

Also as discussed in Section 4.5.1.2 and shown on Figure 4.3, if the condenser is available and the main steam line does not isolate, the release would be through the steam-jet air-ejector exhaust. In this case only the noble gas in the contaminated water is assumed to be released ( $C-4$ on Figures 4.5 and 4.6).

Generally, this is thought to be a release pathway for fission products dissolved in the primary coolant. This also could provide a dry (bypass) release pathway for a gaseous and aerosol releases from the core. Dry releases by SGTR will be considered as part of bypass accidents (Section 4.5.2.4).

If primary coolant leaks into the secondary side of the steam generator and the secondary side is allowed to boil, the resultant steam that escapes to the atmosphere by the relief valves $(c-1)$ will contain considerably lower fission 
product concentrations as a result of partitioning, as discussed in Section 4.5.1.2.2. In this case an RDF of 0.02 should be assumed.

In some designs, if sufficient primary coolant leaks into the secondary side of the steam generator, the generator will fill and not allow boiling. The entire secondary side could fill, pushing coolant directly into the atmosphere through the relief valve $(C-1)$ as happened during the Ginna accident (see Figure 4.4). There is considerable dilution when the coolant passes through the secondary side before release. Under these conditions, a $50 \%$ reduction would be assumed (RDF of 0.5 ).

As noted in Section 4.2, the last factor in estimating a source term is the estimated amount of fission products available for release that are actually released. This is referred to as the "escape fraction" (EF). In the case of an SGTR, there are some benchmark EFs that can be precalculated. A full rupture of one steam generator tube could result in leakage of about $500 \mathrm{gpm}$ ( $75 \mathrm{cfm}$ ) or about 35\% of the total primary coolant volume in 1 hour, assuming the reactor coolant system pressure remains near operating pressure and lost volume is replaced with the charging pumps. An EF of 0.35 should be used for a 1 -hour release by SGTR. This escape rate would fall rapidly as the primary system pressure falls. As soon as the reactor coolant system pressure equals that of the secondary system, the leak will cease. A second benchmark for the escape fraction could be the primary system makeup, provided by a single charging pump at $50 \mathrm{gpm}$ (EF of 0.03), which is being used to make up for coolant leakage at the break. Escape fractions are summarized in Table 4.10.

\subsection{PWR and BWR Bypass Accidents}

There are a number of low-pressure systems that connect to the high-pressure reactor coolant system (RCS). In some cases, low-pressure 1 ines and components (e.g., pumps) are located outside the containment and separated from the RCS by check valves. If these valves fail, the high-pressure coolant from the RCS could rupture the low-pressure system outside the containment as shown by pathway A-4 of Figures $4.5,4.6,4.7,4.8$, and 4.9 .

This failure would provide a pathway from the reactor coolant system to the environment that bypasses the containment. This type of accident is often called a bypass accident, interfacing LOCA, or an event $V$. In fact, the steam generator tube rupture accident discussed above is a type of bypass accident. Low-pressure lines providing a potential direct leakage path from the RCS to locations outside the containment have redundant isolation valves inside and/or outside of the containment so that leakage of coolant from pipe leaks or ruptures outside of the containment would be limited by closing the check valves or other isolation valves. Failure of these valves to close is possible however, resulting in loss of coolant and a potentially unisolable direct leakage path from the RCS to the auxiliary building or other buildings and from there to the environment (Figures 4.5 and $4.6, C-2$ or $C-3$; Figures $4.7,4.8$, and $4.9, C-1$ or $\mathrm{C}-2$ ).

Release by this pathway from the primary system would not be filtered unless the fission products would pass through pools of water. The primary reduction mechanism is reactor coolant/secondary system plateout/retention. An RDF for this pathway is assumed to be 0.4 for system retention, on the basis of results 
Table 4.10 Assumed containment and steam generator tube rupture escape fraction for 1 hour

\begin{tabular}{|c|c|}
\hline Release pathway & $\begin{array}{l}\text { Escape } \\
\text { fraction* }\end{array}$ \\
\hline \multicolumn{2}{|l|}{ Primary containment failure/leakage } \\
\hline \multicolumn{2}{|l|}{ Typical design leakage: } \\
\hline PWR - large dry $(0.1 \% /$ day $)$ & $4 \times 10^{-5}$ \\
\hline PWR - subatmospheric $(0.1 \% /$ day $)$ & $4 \times 10^{-5}$ \\
\hline PWR - ice condenser ( $0.25 \% /$ day $)$ & $1 \times 10^{-4}$ \\
\hline BWRs $(0.5 \% /$ day $)$ & $2 \times 10^{-4}$ \\
\hline \multicolumn{2}{|l|}{ Failure to isolate (100\%/day): } \\
\hline Failure of isolation valve seal & 0.04 \\
\hline \multicolumn{2}{|l|}{ Castastrophic failures: } \\
\hline 1-hr puff release & 1 \\
\hline \multicolumn{2}{|l|}{ Steam generator tube rupture } \\
\hline $\begin{array}{l}1 \text { tube at full pressure } \\
\text { (coolant leak) }\end{array}$ & 0.35 \\
\hline $\begin{array}{l}1 \text { tube at low-pressure single } \\
\text { charging pump flow } \\
\text { (coolant leak) }\end{array}$ & 0.03 \\
\hline
\end{tabular}

*Fraction of containment volume or primary system coolant inventory released in 1 hour.

described in NUREG-0956. In addition, the release is expected to be into another building (e.g., turbine building); therefore, consideration should be given to any removal mechanisms (e.g., natural processes or filters) that may be encountered as discussed in Section 4.5.2.3.

\subsection{PWR and BWR Vessel Melt-Through}

As discussed in Section 4.4.4, a core melt accident in the absence of any reflooding could lead to core melt debris penetration of the reactor vessel bottom head. For the reasons discussed in Section 4.4.4, the release pathways active during the melt phase will be used to characterize the release from the primary system melt-through. 


\subsection{PWR and BWR Leakage From Process Lines}

Fission products can be transported out of the RCS through connected lines that are run outside the containment building and into other areas of the plant. Because some of these processes are required even after an accident, these pathways exist after containment isolation. A leak or rupture in one of these lines would allow reactor coolant and the dissolved fission product gases to escape into an area outside the reactor containment building. Noble gases and the more volatile fission products would be released immediately to the area of the plant where the leak occurred and eventually could be released to the atmosphere.

This type of containment bypass was the major source of release during the TMI accident. As shown in Figure 4.10, there were two release pathways out of the containment during the TMI accident (NUREG-0600). The first resulted from the sump pump automatically starting and pumping the reactor coolant that had collected in the sump as a result of the PORV coolant release (see Section 4.5.2.1.2). This coolant was pumped to a waste holdup tank in the auxiliary building. This tank eventually filled, causing a rupture disk to open, which allowed noble gases and iodine contained in the coolant to be released to the auxiliary building. This transfer of coolant took place during the first hour of the accident and well before the first signs of cladding failure. Therefore, the amount of fission products released was small.

The second and major source of releases from TMI resulted from reactor coolant flow through the makeup and purification systems during the accident. Because these processes continued during the course of the accident, this coolant was highly contaminated. For example, a coolant sample taken on March 29, 1979, indicates an I-131 concentration of $1.3 \times 10^{4} \mu \mathrm{Ci} / \mathrm{CC}$ (NUREG-0600). A typical I-131 level (see Table 3.2) is $4.5 \times 10^{-2} \mu \mathrm{Ci} / \mathrm{cc}$. Tables 4.3 and 4.4 show the coolant concentrations for selected nuclides if either the total gap or melt inventories were released into a typical coolant inventory. These concentrations are based on Table 4.1. The TMI coolant I-131 concentrations were about 300,000 times normal. As shown in Table 4.3, the TMI I-131 concentrations fall between the gap and melt concentrations, as would be expected. The cesium concentrations are smaller than projected because this was a new core and the cesium had not yet built up, as discussed in Section 2.2.2. The TMI releases from the containment systems were into the auxiliary building, and the natural processes (discussed in Section 4.5.1.1) removed aerosols/particulates. The release also was filtered before escaping to the environment. Additionally, as was discussed in Section 4.5.1.2.1, only a small fraction of the iodine evolved (was released) from the coolant. All of these factors worked together to result in a small release to the environment. The key was that the primary containment did not fail or leak in a major direct dry pathway to the environment.

This experience indicates that leakage from process line pathways should not provide a major source of release. If it were a major pathway, it would be considered a bypass accident (see Section 4.5.2.1.4). Therefore, this pathway is not considered in the method developed here because it should not provide major offsite consequences. 


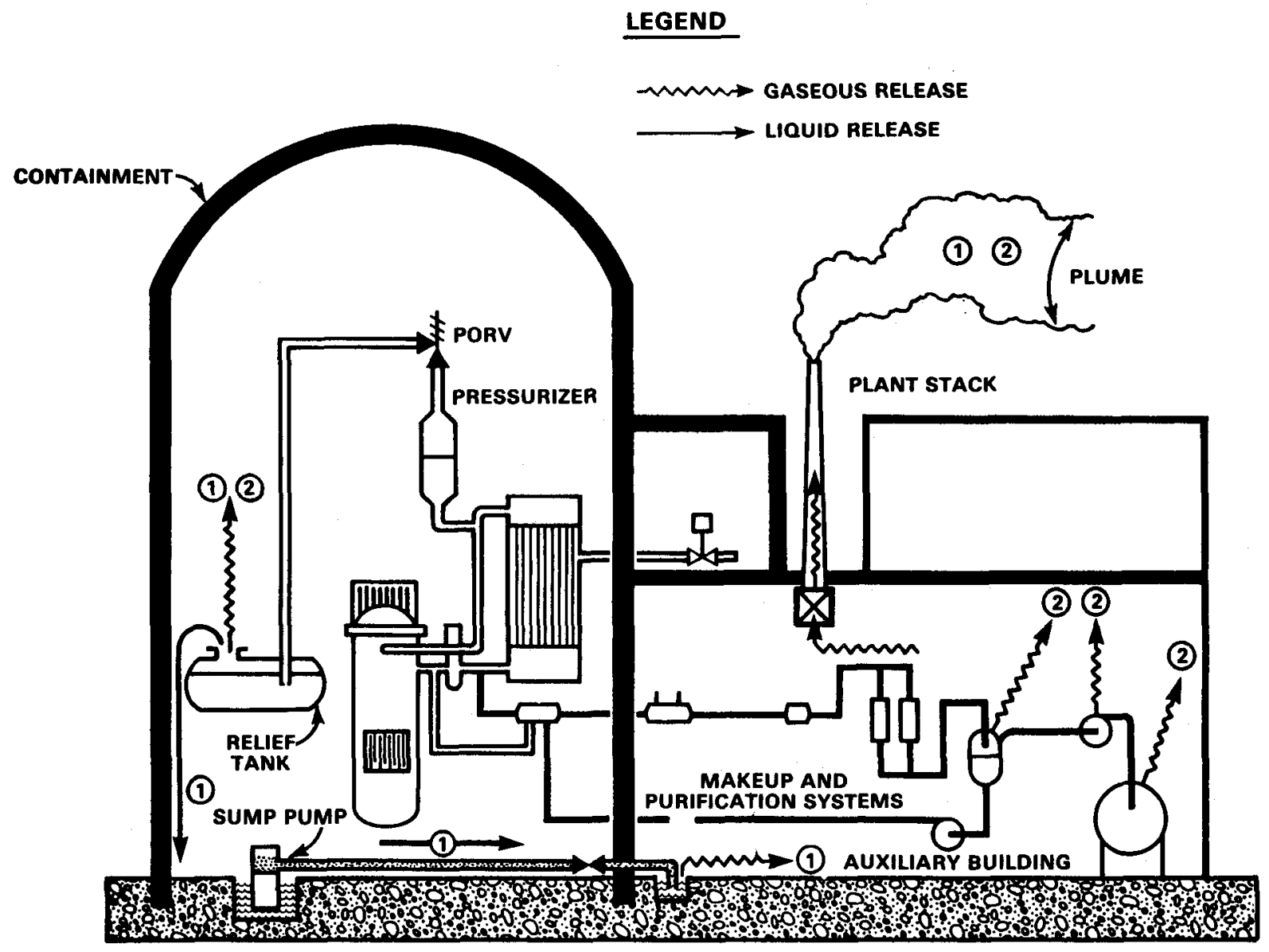

1. Early (first $38 \mathrm{~min}$ ) before core damage, normal coolant only, sump pump operation.

2. After core damage, leakage from makeup and purification system was the source of most of the release.

Figure 4.10 TMI accident radioisotope release pathways 


\subsection{BWR Reactor Coolant System Breaks/Leaks}

The BWR RCS (e.g., steam lines) extends beyond the primary containment. During a severe accident, these systems are isolated by valves that confine all reactor coolant to the primary containment. This section will assume that this isolation has taken place successfully and that the release from the RCS break is into the BWR primary containment.

There is another big difference between the PWR and BWR. In the event of a large break in the RCS (shown as pathway A-1 on Figures $4.7,4.8$, and 4.9 ), the steam blowdown from the break flows down into the dry well where it will be directed into and through a suppression pool (shown as pathway A-2 on Figures 4.7, 4.8, and 4.9). As discussed in Section 4.5.1.1.4, this pool can be very effective in removing fission products.

Therefore, if the RCS break is such that it does not fail the dry well before core damage--thus ensuring the major portion of the release is through the suppression pool--the reduction factors for the various pool conditions listed in Section 4.5.1.1.4 (Table 4.5) should be assumed. Obviously, if the drywell fails before major release from the fuel, allowing the suppression pool to be bypassed, no credit should be given for the suppression pool.

\subsection{BWR Automatic Depressurization System and/or Safety Relief Valves}

BWRs are equipped with an automatic depressurization system (ADS) that is designed to reduce the pressure in the RCS in the event of an accident so that the low-pressure emergency cooling system can inject water into the core to provide cooling. Automatic initiation of the ADS requires the following: (1) high dry well pressure, (2) low water level, (3) confirmation that a core spray train or residual heat removal (RHR) train is operable, and (4) a 120second delay. The ADS is a subset of the safety relief valves (SRVs) that are designed to prevent overpressurization of the primary system. The SRVs/ADS can open early in an event. If the systems designed to replace the water fail after the SRVs open, core damage could result. If the SRVs open following core damage, the products contained in the steam release to the suppression pool can be assumed to be scrubbed. The SRVs discharge into the suppression pool (see Figures 4.7, 4.8, and 4.9, pathway A-3).

The flow rate in the suppression pool is limited by the capacity of the SRVs, and the slow-flow condition should be assumed. Under these conditions, the RDF of the pool is a function of pool temperature; for example, a subcooled pool would assume an RDF of 0.01 and a saturated pool would provide an RDF of 0.05 .

\subsubsection{Primary Containment (Fourth Fission Product Barrier)}

In many PWR accidents the primary containment would be the last fission product barrier. Most BWRs and some PWRs have the equivalent of a secondary containment or confinement that encloses the primary containment structure. In some cases the leakage out of the containment may be into other structures such as the auxiliary building. These structures will be discussed later. 
This section will discuss primary containment failures only; these failures are shown as the $B$ pathways on Figures $4.5,4.6,4.7,4.8$, and 4.9 . The full range of containment failures will be considered. At the lower end of the consequence scale is leakage less than design limits, and at the upper end is catastrophic failure allowing direct releases to the atmosphere.

The fission products suspended in the containment atmosphere, thereby available for release following containment failure, will be reduced with time by natural processes and by the actions of containment spray (if available). The RDFs specified in Table 4.5 should be assumed.

There are a number of containment configurations. Containments are designed to withstand the pressure resulting from a depressurization of the RCS (blowdown). They also are used to contain any radioactive material released from the RCS.

A large, dry PWR containment building is generally free standing and is designed to withstand the blowdown resulting from a failure of the RCS. These containments vary in size from about 1.5 to $3.5 \mathrm{Mft}^{3}$. Some of the smaller containments are maintained at pressures below atmospheric (subatmospheric containments). The other type of PWR containment is the ice condenser containment, which uses a large bed of ice to absorb the energy from an RCS blowdown. This ice bed can provide substantial reduction in fission product in the blowdown as discussed in Section 4.5.1.1.5.

An important point is that a large radionuclide release does not require that the top of the containment be "blown off." Releases are insensitive to hole sizes larger than about $2 \mathrm{ft}^{2}$. A hole of this size or larger would be considered catastrophic containment failure. For the large-LOCA sequence, the pressures in the containment would rise at a much greater rate than for the smal1-LOCA sequence. A larger hole size would allow for a rapid pressure decay in the containment; thus, the driving pressures would be substantially reduced when fission products were released to the containment following initial blowdown. In summary, the consequence of an open containment penetration will vary, not necessarily with hole size but with accident sequence.

\subsection{Design Leakage}

The design leakage release is shown in Figures $4.5,4.6,4.7,4.8$, and 4.9 as pathway B-1. Each plant is allowed leakage rates between 0.1 and $0.5 \%$ a day of containment volume at design containment pressure. For lower pressure, containment leak rates should be much less than design as was the case during the TMI accident. Table 4.10 shows the EF that can be assumed for various containment failure/leakage cases. Under accident conditions, the leakage could be expected to increase with containment pressure. Some likely sources of containment leakage are penetrations such as process piping or air locks. Containment penetrations and seals are not designed to withstand the environment conditions in the containment following a core damage accident. Over an extended period of time (hours), the adverse conditions within the containment building may cause the containment penetrations and seals to deteriorate, thereby allowing the leak rate from the containment to increase. Large leakage is more appropriately treated as failure to isolate. 


\subsection{Isolation Failures}

Because the containment building is the final barrier to fission product release, pipes that penetrate the containment building are considered an extension of the containment boundary and must be capable of isolation. Systems penetrating the containment that serve a safety function, however, are not automatically isolated when containment isolation is initiated. A PWR and BWR release pathway attributed to a failure to isolate is shown as B-2 in Figures 4.5, 4.6, 4.7, 4.8, and 4.9.

Containment isolation failures (failure to isolate one or more penetrations and failures involving the signal that actuates containment isolation) can provide release pathways for fission products retained in water or suspended in the atmosphere. Some of these pathways lead to other areas of the plant outside the containment building where the fission products may be held up temporarily or indefinitely; however, other pathways lead directly to the environment.

There are a wide range of possible isolation valve failure sizes. This analysis uses the type of failure assumptions used in various consequence studies.

Isolation failure typically refers to a failure of the isolation valves to go to their required (closed) position. In this assessment, it is assumed that an isolation failure is the result of the failure of the valve seals. In Table 4.10, it is assumed that a failure to isolate is equivalent to $100 \%$ /day leakage. This approximates leakage of purge and vent system isolation valve seals. These valves are typically butterfly valves ranging in size from 20 to 40 in. in diameter. The metal-to-metal clearance between the valve disk and body is normally between $1 / 16$ and $1 / 8 \mathrm{in}$. Therefore, for a 40-in. diameter valve, a total seal failure would correspond to a 6 -in. ${ }^{2}$ hole (NUREG-1037). In WASH-1400, the assumption was that a failure to isolate corresponded to 1000 times design leakage $(100 \% /$ day $)$. This equals about an $8-\mathrm{in} .{ }^{2}$ hole. Therefore, the $100 \% /$ day assumption for the failure of the isolation valve seals appears to be reasonable. However, this does not characterize a major failure of an isolation system that results in a $1-\mathrm{ft}^{2}$ hole or larger, which should be assumed to be a catastrophic failure.

\subsection{Catastrophic Containment Failures}

A catastrophic containment failure is one that results in release of a large fraction of the fission products in the containment atmosphere in a short period (1-2 hours). The 1-hour EF for this type of failure is 1 (Table 4.10). This pathway is shown as B-3 in Figures $4.5,4.6,4.7,4.8$, and 4.9. This type of failure could be a very violent event. In such a containment failure, the fission products in the containment atmosphere would be carried to the outside atmosphere along with the pressurized gases through the breach in the containment shell. Some settling and plateout would be expected to prevent some of the fission product aerosols from being released. However, the turbulence and pressure reduction in containment could result in resuspension of some of the aerosols that had previously settled out, thus offsetting, somewhat, the previously mentioned effects.

A brief description of those accident conditions that result in this type of failure will now be discussed. There should be indicators in the control room (e.g., containment hydrogen levels or pressure) that indicate conditions with 
the potential to cause catastrophic containment failure. However, the actual timing or even occurrence of catastrophic failures would be very difficult to predict during a severe accident. This is further complicated because this type of failure has little warning. The great uncertainties associated with containment response, given core damage, are shown in Figure 4.11. This figure is the latest (NUREG-1150) estimate of the range of probability of early containment failure. This figure also shows that early containment failure cannot be ruled out, given core damage.

\subsection{Hydrogen Detonation/Burns (NUREG/CR-2726)}

The hydrogen-producing phenomenon that occurs during severe accidents is the reaction between the fuel cladding ( 2 ircaloy) and steam (water). The extent to which hydrogen would be produced from cladding/steam reactions depends on the particular accident sequence, although any accident that results in severe core damage will generate substantial amounts of hydrogen. Zircaloy-steam reactions were the primary source of hydrogen generated during the TMI- 2 accident.

If the accident progresses to the point of whole or partial core melt, the molten core will slump downward, melting as much as 200,000 pounds of steel. When the molten steel comes into contact with the water retained in the reactor vessel's lower plenum, the steel will oxidize and produce hydrogen. Any molten steel that enters the reactor cavity may oxidize and produce hydrogen. For conditions in which the fuel debris bed is uncoolable, melted core-concrete interactions will yield further hydrogen and the combustible gas carbon monoxide.

The triangular diagram, Figure 4.12, shows the standard assumption for the relationship between air, hydrogen, and steam required for combustion. This diagram is based on low-temperature and -pressure data. There is some experimental data indicating that at the high temperatures and pressures found in a containment under some accident conditions that Figure 4.12 is incorrect.

These experiments indicate that much lower concentrations of hydrogen may be required for burns and detonations under high pressures and temperatures. However, the following discussions will be based on Figure 4.12.

Hydrogen that accumulates in the containment cannot ignite until it reaches a concentration of at least $4 \%$ (with an oxygen concentration greater than $5 \%$ ). However, the reaction between hydrogen and oxygen will not be complete unless the hydrogen concentration is above $8 \%$. In addition, sufficiently high steam concentration can prevent hydrogen detonation. Therefore, under some accident conditions, actuation of the containment spray could reduce the steam concentrations in the containment resulting in conditions that could support combustion.

Hydrogen ignition will produce a large flare in the containment that would be sustained for a time on the order of minutes, depending on the hydrogen concentration. An ignition source could be provided by sparks from electrical equipment in the containment. The early presence of an ignition source would allow the hydrogen present in the containment to burn, potentially precluding hydrogen accumulation to detonable levels.

Hydrogen detonation would require hydrogen concentrations in excess of $13 \%$, depending on the concentration of steam in the containment atmosphere. It should be noted that a hydrogen detonation, either global or local (as a result 


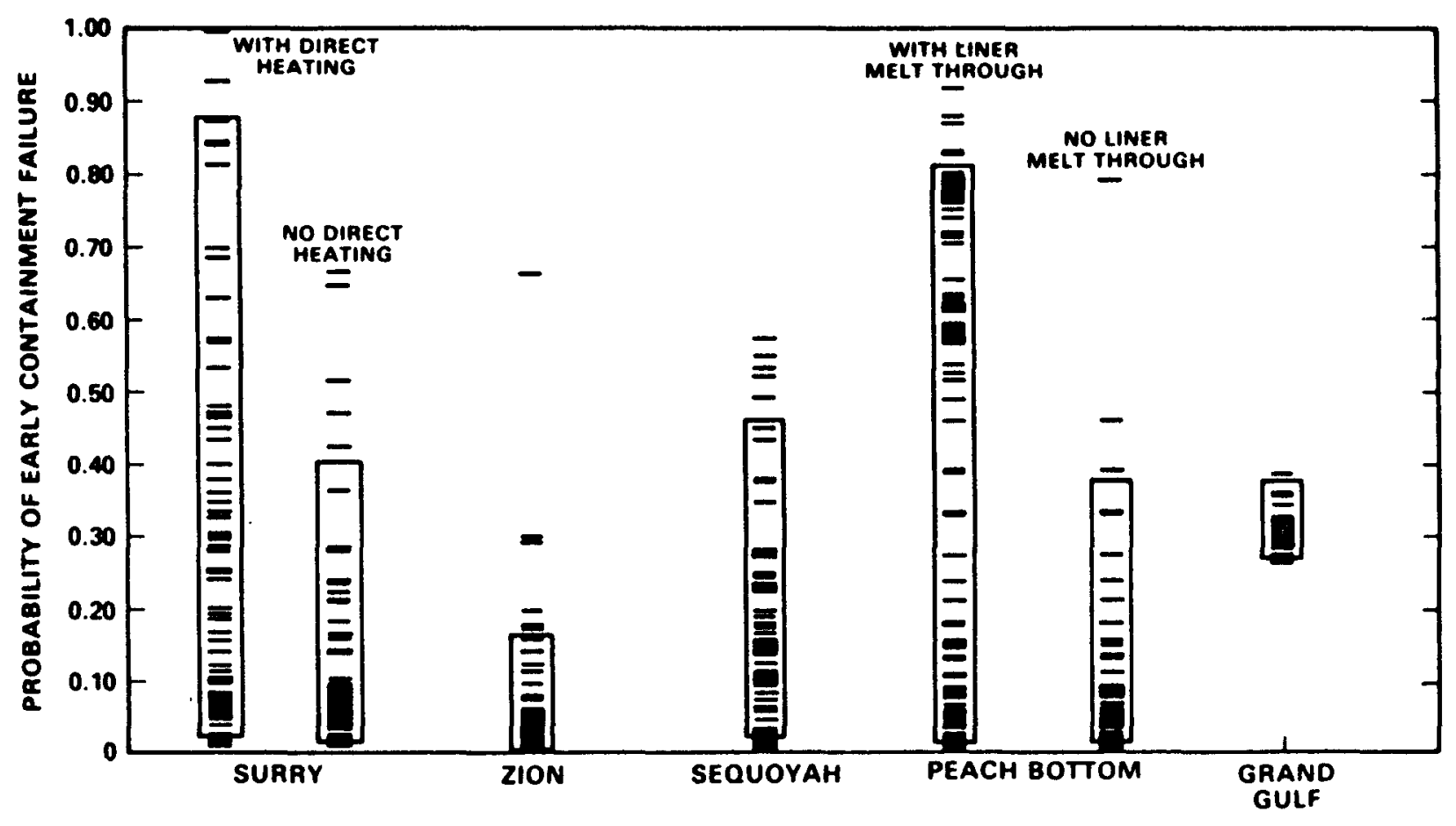

Figure 4.11 Comparison of early containment failure probabilities Source: Draft NUREG-1150, Vo1. 1 


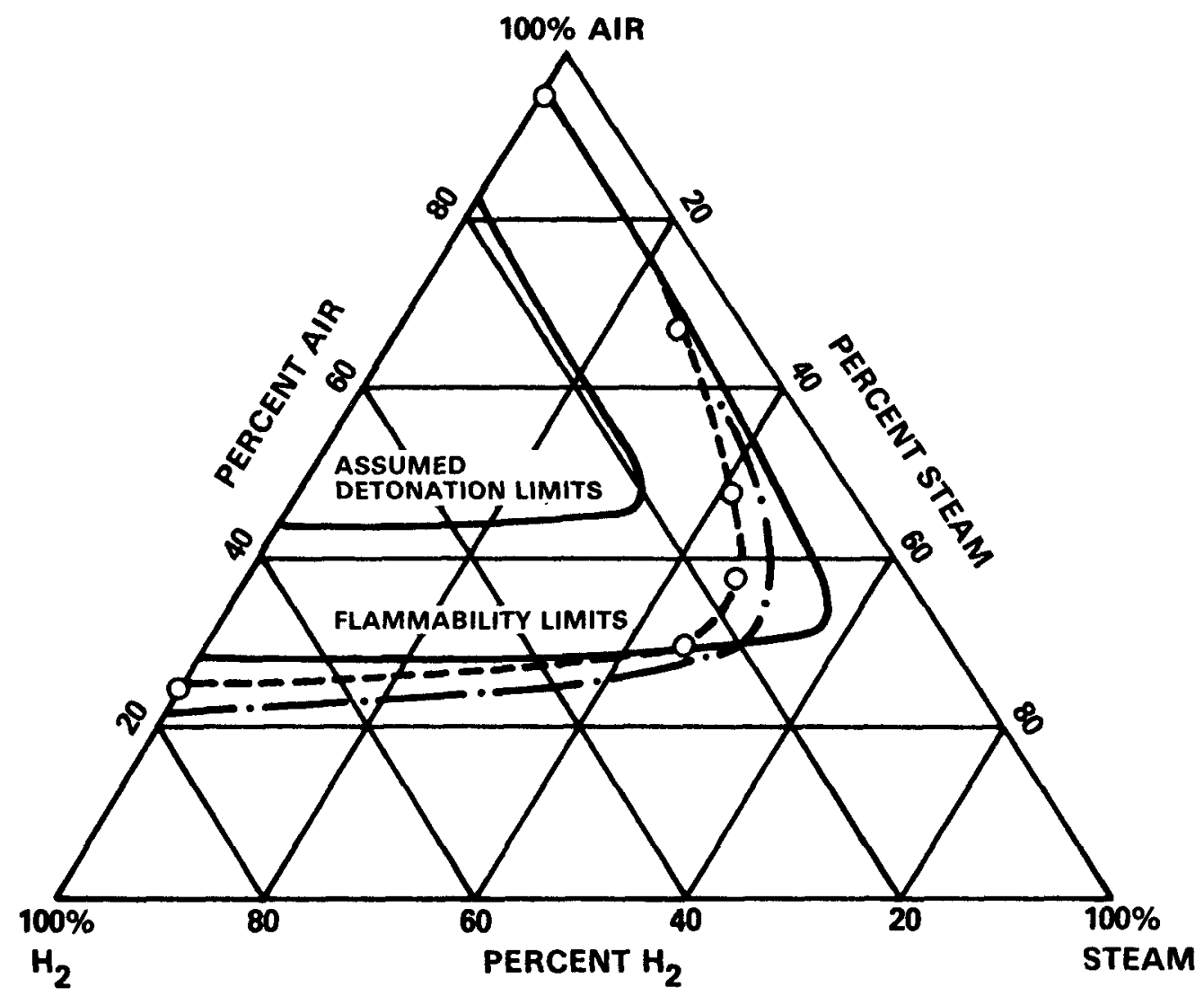

FLAMMABILITY LIMITS llimits may be lower

$$
\begin{aligned}
& \hline \text { for high - temperature and - pressure conditions) } \\
& -68^{\circ} \mathrm{F}-187^{\circ} \mathrm{F} \text { at } \mathrm{O} \text { psig } \\
& 0-300^{\circ} \mathrm{F}-0 \mathrm{psig} \\
& -300^{\circ} \mathrm{F}-100 \text { psia }
\end{aligned}
$$

Figure 4.12 Low-pressure and -temperature flammability and detonation limits of hydrogen, air, and steam mixtures Source: NUREG/CR-2726 
of stratification), will not necessarily fail containment. Generally a hydrogen detonation would need to take place in a high-pressure environment to be able to fail a containment. The probability of containment failure will depend on the ultimate pressure capacity of the containment and pressure as well as the shock wave characteristics of the detonation. Since hydrogen can be a threat to containment, there are provisions for its control and monitoring during accidents. Most PWR containments have recombiners or igniters that burn the hydrogen before dangerous amounts can accumulate. Most BWR containments are filled with nitrogen gas so that the hydrogen cannot burn. However, the containments are not normally filled with nitrogen during the first month of operation.

\subsection{Steam Explosions, Direct Heating, and Missiles}

In-vessel steam explosions have been postulated to cause the reactor vessel head to become detached with enough energy to penetrate the containment. Many recent studies performed on the potential for steam explosion-induced missiles have concluded that containment failures as a result of such explosions may be physically impossible and are considered highly unlikely. Steam explosioninduced missiles are mentioned here primarily because they have been considered in risk assessments (i.e., WASH-1400) and not because they are a likely containment failure mode.

In recent years a new concern has been raised. In certain reactor accidents, such as those initiated by station blackout or a smal1-break LOCA, degradation of the reactor core can take place while the reactor coolant system remains pressurized. Left unmitigated, core melt will slump and collect at the bottom of the reactor vessel. After boiling off the remaining water in the vessel, the molten core materials will start attacking the bottom head of the reactor. When the bottom head of the reactor vessel is breached in such accidents, the core melt will be ejected under pressure. The ejected materials are likely to be dispersed out of the reactor cavity into surrounding containment volumes as fine particles, quickly transferring thermal energy to the containment atmosphere. More importantly, metal contents of the ejected core debris, mostly zirconium and steel, can react with oxygen and steam in the atmosphere to generate a large quantity of chemical energy, heating and pressurizing the containment further. The hydrogen produced by this process results in burns or detonations that could result in very high loads on the containment. The term "direct containment heating" (DCH) is used in the present discussion to describe this complicated physical/chemical process. It has been postulated that this type of event could result in containment failure. Because the BWR automatic depressurization system (ADS) is considered very reliable and because of BWR geometry, DCH is usually considered only for PWRs; however, this is under review. For a further discussion of the current position on this issue, see Draft NUREG-1150, Vo1. 2, Appendix J, Section 5.

\subsection{Containment Overpressurization}

Containments are designed to accommodate the pressure resulting from a blowdown of the primary system. However, if the primary system continues to release energy into the containment, operation of safety systems are required to remove heat and prevent an overpressurization and possible failure of the containment. Therefore, failure of the safety system required to control containment pressure could result in catastrophic failure. 
The response of a specific containment above design pressures to include point of failure cannot be predicted. However, as part of the NRC effort to reassess the technical basis for estimating source term, the Containment Performance Working Group (CPWG) was established. This group concluded (NUREG-1037), for riskdominant sequences, that the accident environment (pressure/temperature) inside the containment does not challenge its integrity in most cases until several hours after the reactor vessel failure. Major reasons for this conclusion are (1) the more detailed accident progression modeling following the reactor vessel failure and (2) industry-wide studies of containment capability pressures. Containment capability pressures used by the CPWG are presented in Table 4.11. It is important to note from Table 4.11 that the estimated failure pressures are 2 to 3 times the design pressures.

Table 4.11 Sample containment design pressures and failure pressures

\begin{tabular}{lllll}
\hline & $\begin{array}{l}\text { Allowable } \\
\text { leak rate } \\
\text { volume } \\
(\% / \text { day) }\end{array}$ & $\begin{array}{l}\text { Total con- } \\
\text { tainment } \\
\text { free volume } \\
\left(10^{3} \mathrm{ft}^{3}\right)\end{array}$ & $\begin{array}{l}\text { Design } \\
\text { Pressure } \\
\text { (psig) }\end{array}$ & $\begin{array}{l}\text { Estimated } \\
\text { failure } \\
\text { pressure } \\
\text { (psig) }\end{array}$ \\
\hline Plant/type & 0.1 & 2,600 & 47 & 134 \\
Surry/PWR subatmospheric & 0.1 & 1,800 & 45 & 119 \\
Sequoyah/PWR ice condenser & 0.25 & 1,200 & 12 & 50 \\
Peach Bottom/BWR Mark I & 0.5 & 280 & 62 & $117^{\star}$ \\
Limerick/BWR Mark II & 0.5 & 410 & 55 & 140 \\
Grand Gulf/BWR Mark III & 0.4 & 1,670 & 15 & 60 \\
\hline
\end{tabular}

*The capability pressure predicted for Browns Ferry was used. Source: NUREG-1037.

\subsection{Containment Bypass}

As discussed in Section 4.5.2.1.4, there are accidents that can result in failures that allow releases of fission products from the primary system so that they bypass the containment. None of the containment reduction mechanisms can be assumed to affect this release. However, if the release is into another structure (e.g., auxiliary building), the reduction mechanism associated with this path should be considered (e.g., holdup).

\subsection{Controlled Venting of Containment}

As discussed in NUREG-1210, Vol. 3, the licensees have emergency operating procedures (EOPs) to be used by the control room staff to ensure that critical safety functions are maintained during severe accidents. In many cases these procedures call for venting of the containment as a last resort action to prevent catastrophic containment failure resulting from overpressurization. Some plants also may use venting to control hydrogen concentrations.

Plant conditions that would warrant venting would most likely also result in a highly contaminated containment atmosphere. Containment venting provides a pathway to the atmosphere for any suspended fission products. 
In BWRs venting is from the wet well (pathway B-5, Figures $4.7,4.8$, and 4.9) through the standby gas treatment system (pathway C-2, Figure 4.7). The RDFs for this pathway would be those associated with releases through the suppression pool (Section 4.5.2.1.7). The effectiveness of the standby gas treatment system was discussed in Section 4.5.1.1.3.1.

Many plants have EOPs that instruct the operators to consider venting before pressures in containment reach the ultimate capacity point. The major vent paths for a BWR Mark I containment are the wet-well and dry-well 18-in. vent and purge lines. There are smaller diameter lines (i.e., 2-in. and 6-in. lines) coming off the 18-in. headers that also can be used. The EOPs will generally instruct the operators to use smaller vent paths first, to ensure that the release path is no larger than necessary (NUREG/CR-4696). If core damage has occurred, suppression pool vent paths are to be used before dry well paths to take advantage of suppression pool scrubbing of fission products.

Although provisions for venting are included in the operator's EOPs, it is highly uncertain whether or not initiation of venting would be effective during a severe accident. Because only a short section of the vent path is schedule 40 steel pipe and the rest is duct work similar to that used in standard heating and ventilating systems, the vent path may rupture under high-pressure conditions. Because the vent and purge valves are containment isolation valves, they will get a signal to close on high dry well pressure. To open these valves, technicians will have to go down to the cabinet and jumperout the containment isolation signal. In the event of a station blackout, where there will be no power available to open the valves, the equipment operator will have to manually control the valve at its location. Opening the valve may require more than just turning a handwheel. For example, operators may have to connect a bottle of compressed gas to the valve operator with copper tubing and control the valve position by manual manipulation of the regulator on the gas bottle. Because of the extreme environment and high radiation levels that may be present (i.e., heat, radiation, steam, etc.), it may be impossible for the operator to stay at the valve location very long, if at all.

Venting under an anticipated-transient-without-scram (ATWS) condition is a special case. Because of the large pressures that may exist in containment, it might be necessary to use all four 18 -in. vent paths. Thus, most of the fission products released through venting would be unfiltered.

PWR venting would be directly to the atmosphere with no filtering (filter failure) and should be treated either as a failure to isolate (B-2, Figures 4.5 and 4.6) or catastrophic failure (B-3, Figures 4.5 and 4.6 ) depending on the release rates. Thus, the only advantage of venting in a PWR is that the release may be controlled. For a further discussion of containment venting, consult Vol. 3 of NUREG-1150.

\subsubsection{Other Barriers}

BWR primary containments are enclosed in a secondary building (containment) that is designed to confine and filter leakage. This structure is not designed to withstand the pressure from a major failure of the primary containment. However, studies suggest that this secondary structure would reduce the release fraction by a factor of 2 to 4 (Denning and Cybulskis, 1986). 
Some PWRs also have an enclosure that acts to collect and filter any containment leakage. In addition, any release pathway from the primary containment may release into other structures such as the auxiliary or turbine buildings. These structures most likely would not withstand a major release, but could confine leaks long enough for significant reduction to take place. In some cases, the structures also may have filtered vents.

If the release is into a structure and it does fail, the fission products will be reduced by processes discussed in Section 4.5.1.1.2.

If the structure has filter systems, the removal of fission products by the filter will be in accordance with that discussed in Section 4.5.1.1.3. In the PWR (Figures 4.5 and 4.6 ) this is shown as $C-3$. If the structure fails or there are no filters, the release is shown as $\mathrm{C}-2$.

In the BWR there is a standby gas treatment system (SBGTS) as discussed in Section 4.5.1.1.3.1. The SBGTS takes suction in many areas in the plant basically as shown in Figures 4.7, 4.8, and 4.9. If the flow through a filter system (e.g., SBGTS) (C-2, Figure 4.7) is slow and dry, it can be expected to have an RDF of 0.01 (99\% or greater efficiency). However, if the flow is heavily loaded with steam or aerosols or if it has a very high-pressure flow rate, the filters would be expected to rupture. In general, this would be the assumption if there were a major failure of the primary containment.

\subsection{Plant Instrumentation}

The method for determining the source term associated with a given release requires proper interpretation of only a minimum set of radiation monitors and key plant parameters to characterize a limited set of accident conditions as they were described previously. However, under accident conditions instruments can respond in unexpected and confusing ways. Radiation monitors can be offscale, be responding to unanticipated sources of radiation, be bypassed, be isolated or not be calibrated for the conditions. Temperature pressure or other key plant parameters also may provide confusing or conflicting information because they are operating under severe conditions for which they are not designed. These difficulties must be recognized. However, if all the information is considered without focusing on a single parameter or instrument, the severity of the accident should be apparent. This can be seen from the response of selected area radiation monitors during the TMI accident shown in

Figure 4.14. While any specific monitor response may be confusing, all of the monitors are showing a factor of 100 or more increase in a few hours.

Licensees have developed procedures to relate some instrumentation to plant conditions. Typically these procedures show the relationship between containment monitor readings, water level, or thermocouple readings to core conditions. These relationships must be used with caution (NUREG-1210, Vol. 2).

\subsubsection{Radiation Monitors}

During a major accident, radiation monitors can provide valuable information on release pathway, gross release rates, and gross levels of core damage. Unfortunately, the TMI accident demonstrated that these monitors also can be a source 
of confusion. Each of the three types of radiation monitors (process, containment, and area), with the potential to provide the most useful information, confused the issue instead. Figure 4.13 shows the response of some of the process monitors during the TMI accident. The figure is clear, although the information during the accident was not. Figure 4.13 is a summary of 30 in. of tape from the recorder chart with some monitors not shown. Initially most of the monitors showed little response to the accident. As Figure 4.14 illustrates, several instruments, containment, incore instrument tank, and south refueling bridge monitors all responded to the high radiation released at the start of fuel failure. The trend of the containment monitor shows two discrete steps of about a factor of 10 increase. The first step is at the start $(6: 25)$ of fuel failure (gap release) and the second at about $7: 15$. It is clear from the relative increases over 45 minutes that major releases from the core (and fue 1 damage) were in progress.

Figure 4.14 shows the area radiation monitor response during the TMI accident; again, this is a summary of $30 \mathrm{in}$. of tape from the recorder chart. The operators had to glean this information from $30 \mathrm{in.}$ of the tape from the recorder chart with twice the number of traces, all of which were printed poorly.

The containment monitor also was a major source of puzzlement because the containment dome monitor, located in a 2-in. lead shield, was yielding almost an identical dose rate as the unshielded south refueling bridge monitor. After considerable effort, it was determined that two errors were involved: (1) the wrong scale was on the recorder and (2) the monitor was not calibrated to account for the shielding. This was compounded during the actual event by the operator misreading the monitor. The monitor readings in milliroentgen were reported as roentgen. Calculations made after the accident show that the true radiation level was $700 \mathrm{R} / \mathrm{hr}$ by $7: 30$.

Derived relationships between containment monitor levels and postulated core damage states may be key indicators of the level of threat in many accident sequences (but not for containment bypass accident sequences). Because of the basic accident scenario (release) assumptions used for the estimates, monitoring efficiency, shielding, location in the containment, or other site-specific factors, there is a large variation in the plant-specific estimates associated with levels of core damage. Nevertheless, radiation monitor readings will increase by several orders of magnitude for progressively more severe core damage levels and the plant operator should be able to recognize the difference between a big and a little problem. For purposes of comparison, a 1- to 100-R/hr reading should be expected following a large-break LOCA. Further increases following this spike should be considered as an indication of core damage.

The nuclear service cooling monitor response shows a second point of confusion during the TMI accident. These monitors are in the auxiliary building and are intended to detect leaks into nonradioactive systems. These monitors, like many other monitors, were not responding to their "nameplate" source, but to other sources in the vicinity. In this case they were responding to highly radioactive gas in a vent header. If the operators had believed the "nameplates" on the monitors, they would have concluded erroneously that radioactive material was leaking into the nuclear service water. 


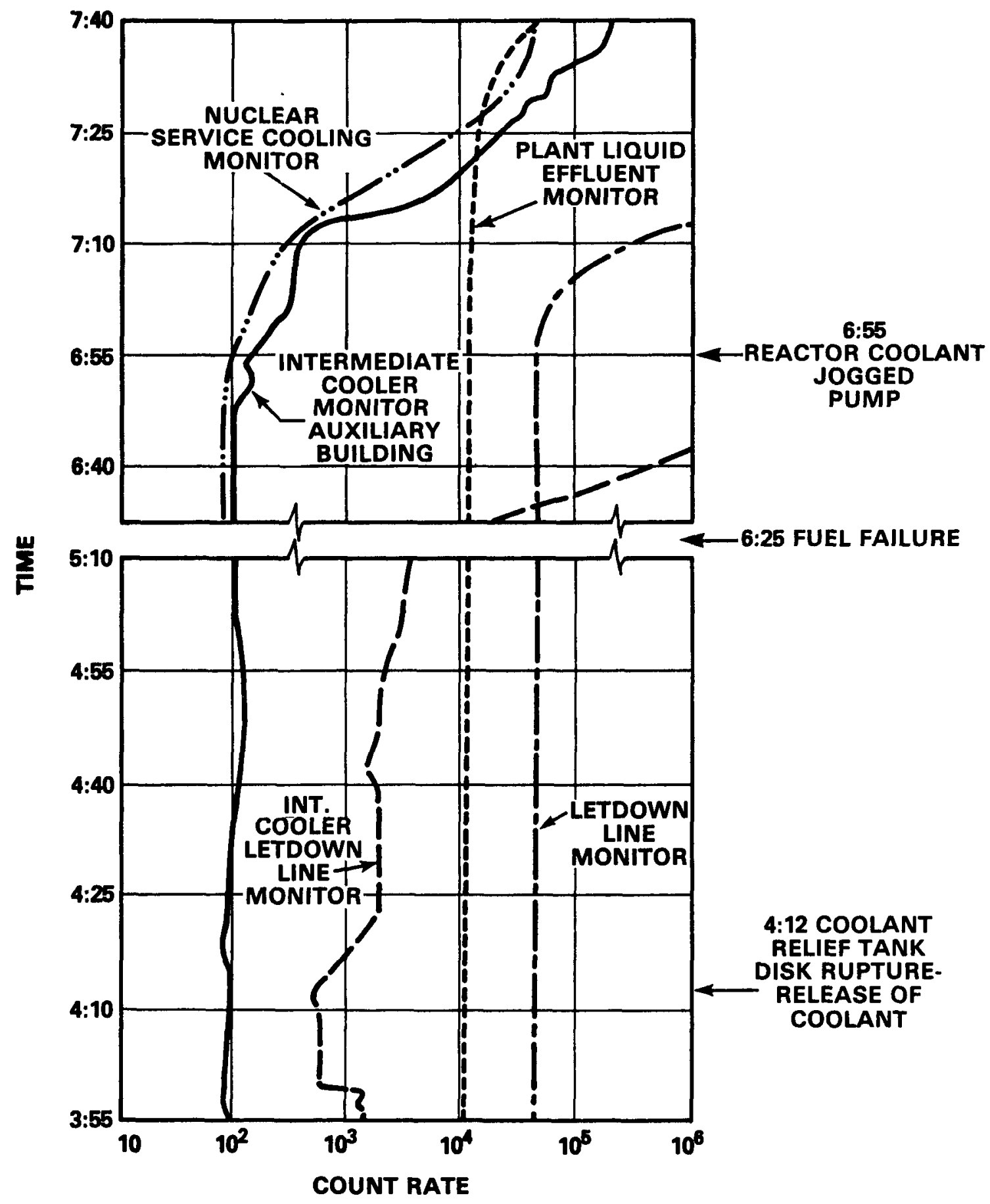

Figure 4.13 Response (cps) of selected process monitors during the TMI accident

Source: Babcock \& Wilcox, June 1981. 


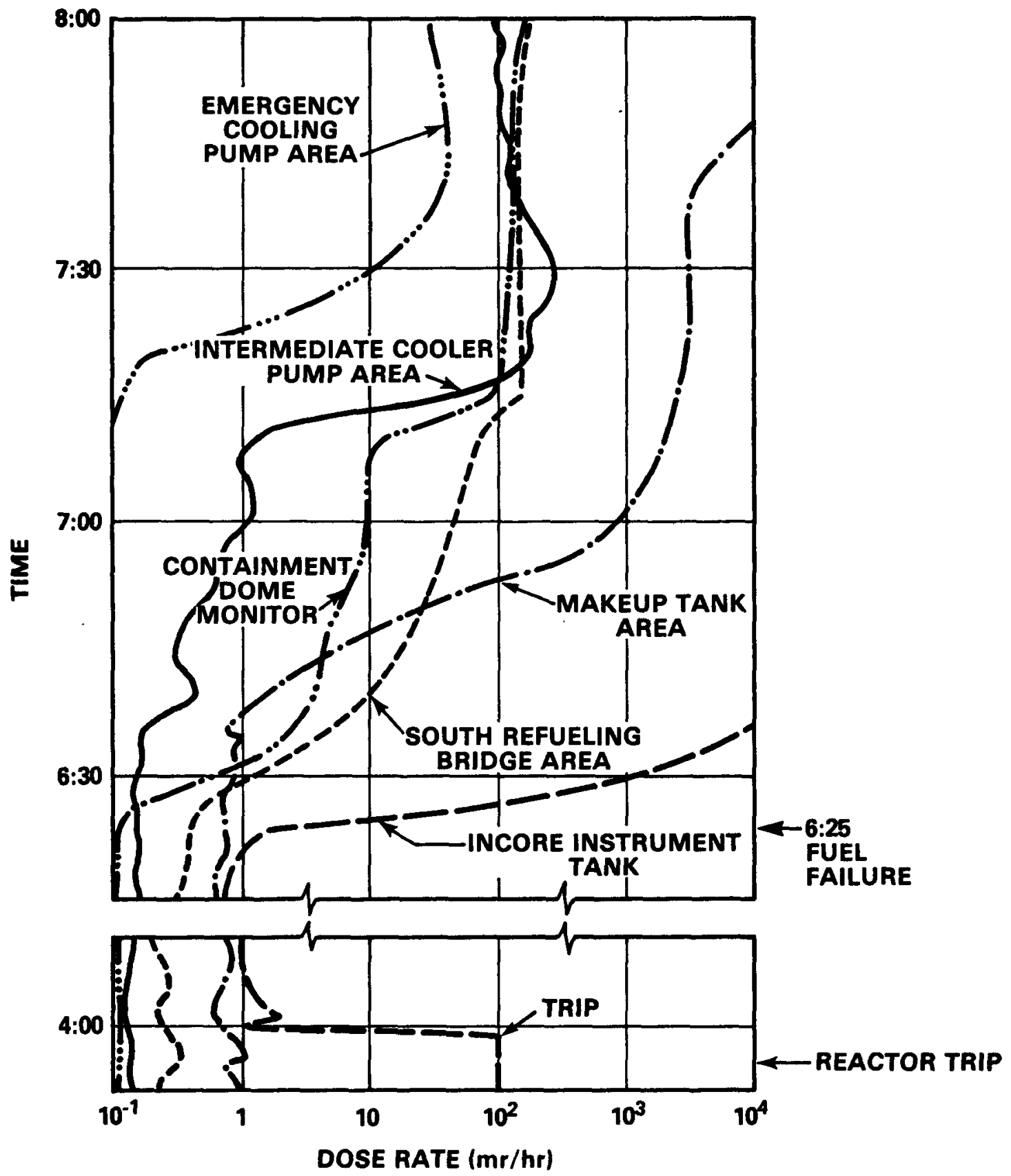

Figure 4.14 Response of selected area radiation monitors during the TMI accident

Source: Babcock \& Wilcox, June 1981. 
Finally, the way the radiation monitors fail during an accident can be very confusing. There were failures of radiation monitors at TMI and during other plant events that left the monitors on scale. In fact, some monitors may fail and show mid-scale readings.

In summary:

The radiation monitoring system has been designed generally for normal operation. In the event of an accident, many of the monitors would be isolated and not available to aid in the assessments. The area radiation monitoring system (ARMS) and exhaust monitor may provide limited information on the movement of material, pathway location, and gross level of problem. The containment monitoring system could be useful in determining the type of accident and gross degree of core damage for accidents involving releases into the containment, provided the precalculated relationships between monitor response and damage state are based on similar assumptions.

As discussed earlier, the radiation monitors during the TMI accident were more a source of "puzzlement than of enlightment" (Babcock \& Wilcox, June 1981).

Many of the monitors responded to sources of radiation that were not intended to be monitored (e.g., contaminated water being pumped through nearby lines). Therefore, many of the "nameplates" on the monitors did not indicate what was actually being monitored. In addition, the fact that a monitor does not indicate a problem does not mean that it is not being bypassed.

Information from radiation monitors should be considered along with all other information to determine what is going on. If a monitor reading is not consistent with accident conditions, the following questions should be asked:

- Is the monitor being influenced by some other source of radiation or other plant conditions?

- Is the flow/sample, etc., representative?

- Is the monitor shielded?

- What is the effect of different nuclide mixes?

- How was the instrument calibrated; what assumptions were used?

- Has the monitor failed?

- Is the monitor being read correctly?

Finally, the release may be by a pathway that is not being monitored.

\subsubsection{Grab Samples}

Under some circumstances, it may be desirable to take grab samples from selected locations within or surrounding the plant. Licensees are required to have provisions to sample and analyze effluent, primary coolant, and containment atmosphere samples within 3 hours. The capability to quantify radionuclides, hydrogen levels, and boron levels is provided. Detection of hydrogen in samples 
indicates core damage and may be useful in estimating the possibility of containment failure. Analysis of boron concentrations is important to ensure the core will remain subcritical. Grab samples can be analyzed using gamma-ray spectroscopy and a multichannel analyzer to identify the various radioisotopes that were included in the sample. Identification of radioisotopes will help identify the degree of core damage. The largest drawback associated with a grab sample is that it frequently requires a considerable amount of time to collect and analyze and does not provide the prompt feedback that may be necessary for emergency action decision-making purposes. In addition, the gaseous samples may not be representative of the area because of plateout in sample lines. As discussed in Section 1.4.1, samples may be the only method to fully characterize the release out of the effluent pathway.

Coolant samples taken before an accident are often used as the basis to calculate coolant release. The problems associated with this are discussed in Section 3.4. The actual concentration at the time of a release could be orders of magnitude off as a result of iodine and cesium spikes or further core damage.

\subsubsection{Key Plant Parameters}

Radiation monitors can provide very valuable information about the location, pathway, and magnitude of a release. However, radiation monitors may not be accurate indicators of release trends. Changes in the release rate occur primarily as a result of changes in the accident scenario that affect fission product release mechanisms. Thus, these changes in the accident scenario would provide the most valuable information relative to fission product release trends.

Changes in the accident scenario are determined primarily by monitoring and interpreting indications of key plant safety parameters. Although emphas is is placed on the key safety parameters, other parameters also may provide valuable information to the operator that would better enable the operator to correctly assess the progression of the accident. A brief discussion of some key plant parameters and their relationship to the accident follows.

\subsubsection{Core Temperature}

\subsection{Pressurized-Water Reactor}

The PWR core exit thermocouples are typically located 10 inches or more above the top of the active core. They respond to the temperature of the coolant when the core is covered or to steam and hydrogen if the core is uncovered. Generally the thermocouples are considered the best and most direct means of assessing the degree of core damage.

Some information relative to the accuracy of thermocouples during degraded accident conditions has been gleaned from the TMI-2 accident (see Figure 4.15). A temperature profile of the TMI-2 core was manually recorded on March 28, 1979 between 8:00 and 9:00 a.m. (NUREG-0600) from the readings taken by instrument and control technicians directly off the wires that lead to the in-core thermocouples. This action was taken when the thermocouple readings from the plant computer printout consisted of only question marks (????). Unbeknown to the operators, the plant computer was overburdened and underranged for the core temperatures that existed. As shown in Figure 4.15, very high temperatures 


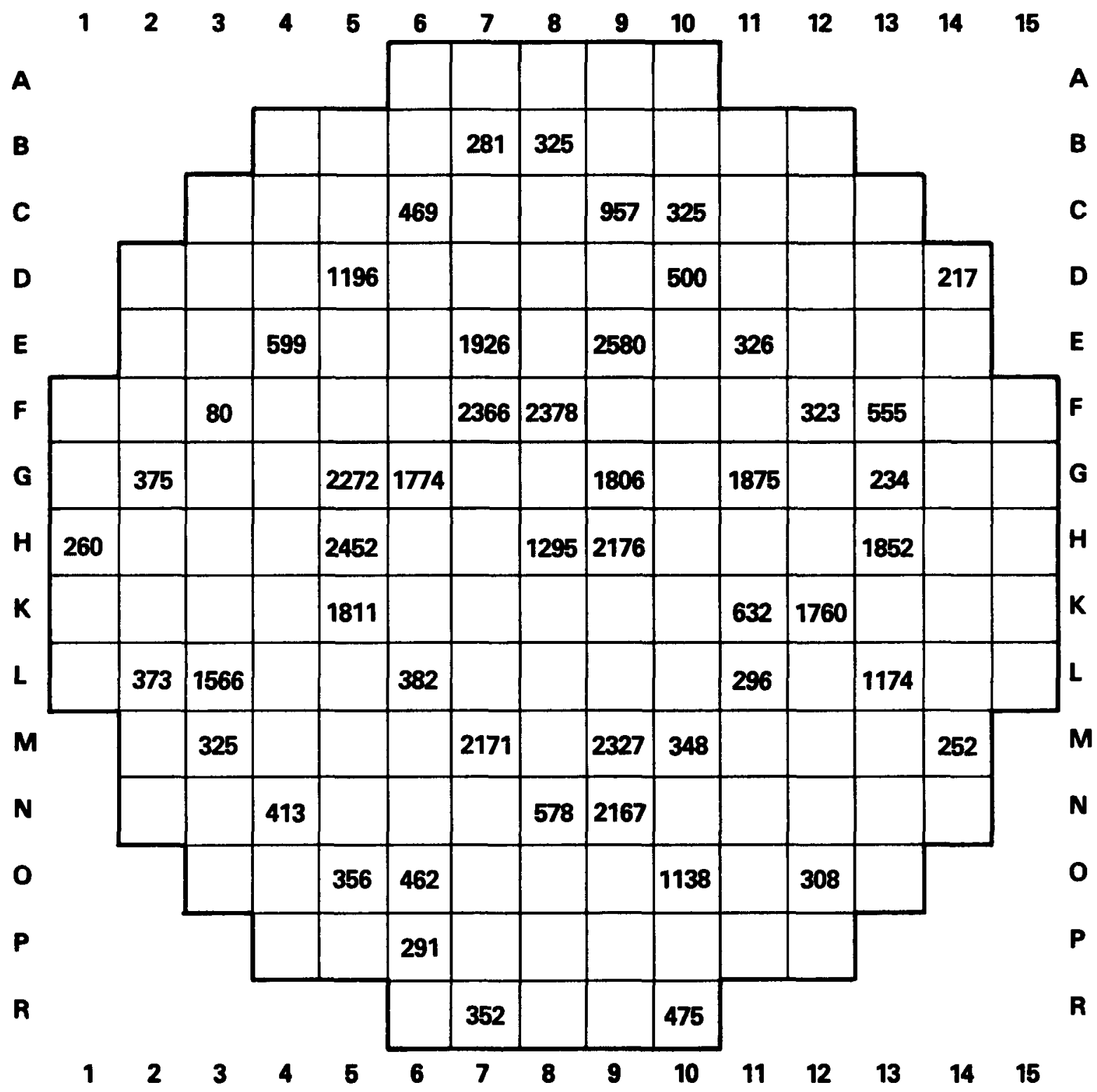

Figure 4.15 TMI-2 accident: map of core exit temperature $\left({ }^{\circ} \mathrm{F}\right)$, 8:00 a.m. $-9: 00$ a.m. , March 28, 1979

Source: NUREG-0600 
(i.e., greater than $2200^{\circ} \mathrm{F}$ ) were recorded in several locations (e.g., E9, F7, $\mathrm{M9}, \mathrm{G5}$, and $\mathrm{H5}$ ), whereas very low temperatures (i.e., less than $600^{\circ} \mathrm{F}$ ) were measured in other locations ( $H 1, L 6$, and $P 6)$. The reasons for these discrepancies are complicated and beyond the scope of this report. It should suffice here to say that the in-core thermocouple readings were rejected by plant personnel during the TMI-2 incident, primarily because of the discrepancies that existed.

Following the TMI-2 experience, it was concluded that thermocouple data can be relatively accurate below $1000^{\circ} \mathrm{F}$ and are most likely within $125 \mathrm{~F}^{\circ}$ of the sensed temperature. On the other hand, at temperatures above $2500^{\circ} \mathrm{F}$, the data are more likely to be inaccurate. However, the important lesson from TMI-2 is that, even if major discrepancies exist, core thermocouples readings should not be ignored and may provide confirmation of fuel damage when considered with other indications such as the radiation levels already discussed.

\subsection{Boiling-Water Reactor}

The BWR temperature instrumentation is found in the recirculation loops and on the outside of the reactor vessel. During accidents, the flow in the recirculation loops may be interrupted and the instruments outside the vessel would take a very long time to respond. For these reasons, the instruments are of little value in determining core temperature (NUREG/CR-2726).

\subsubsection{Reactor Coolant Temperature and Pressure}

The pressure and temperature of the reactor coolant are measured in various locations within the reactor coolant boundary. Typically, the hot-leg (reactor vessel outlet) temperature is measured by several sampling probes located inside the hot-leg piping of each reactor coolant loop. Similarly, the cold-leg (reactor vessel inlet) temperature is measured by probes located inside the cold-leg piping of each reactor coolant loop. In a PWR, an average loop temperature is calculated by adding the hot-leg and cold-leg temperatures and dividing by two. Reactor coolant system pressures are measured in selected locations with pressure transducers. Together, reactor coolant pressure and temperature indications can provide very valuable information relative to the thermodynamic state of the reactor coolant. If the temperature in the reactor coolant system is greater than the saturation temperature corresponding to the coolant pressure, then the reactor coolant has turned into steam. An indication of the presence of superheated steam is an indication of an uncovered core.

\subsubsection{PWR Pressurizer Leve1}

In a PWR, the pressure is maintained at a constant level by means of a pressurizer. Under normal steady-state operation, the pressurizer is filled with about $60 \%$ water and $40 \%$ steam. This mixture is maintained at saturation temperature by an electric immersion heater (located in the bottom of the pressurizer vessel) and a spray system (located at the top of the pressurizer vessel). In addition, the spray system and electric immersion system control minor increases and decreases in system pressure, respectively. Large pressure increases that cannot be controlled by the pressurizer spray system are accommodated by relief valves that open when a predetermined set point is reached. The steam from the pressurizer is vented through the relief valves to the pressurizer relief tank. The pressurizer relief tank is vented to the containment if the design pressure is exceeded. 
Pressurizer-level readings provide an indication of the water level in the pressurizer. They may not provide an accurate or reliable indication of reactor vessel water leve1. An important case in point is the TMI accident. Stuckopen relief valves led the TMI operators to believe that the primary coolant system was full of water when, in fact, the core was in the process of becoming uncovered.

\subsubsection{Reactor Vessel Water Level}

\subsection{BWR Water Level Indicator}

For a BWR the water level indicator is often considered the best indicator of potential core damage. If the core is sufficiently uncovered $(>2 / 3)$ for a period of time, fuel damage is expected. There are several reactor vessel level instrument ranges. The narrow- and wide-range instruments measure the reactor vessel water level in the annulus during normal operation. The shutdown-range instrument measures the reactor vessel level during shutdown and refueling. The shroud-range instrument, unlike the other instrumentation, measures the water level within the core shroud and would be utilized primarily during accident conditions.

One problem with old BWR designs is that a break into the dry well could cause the level reference leg to heat up. The result is that the instruments indicate a higher water level than actually exists. New plants do not have this problem. However, care should be taken and reliance should not be placed solely on BWR water level to predict core damage (NUREG/CR-2726).

\subsection{PWR Vessel Coolant Level Detectors}

Before the TMI accident, reactor vessel coolant level detectors were not used with PWRs. Currently, some type of level detector within the reactor vessel must be installed at all LWRs. The pressurizer-level detector provides a diverse means of determining whether the reactor core is covered with water.

\subsubsection{Engineered Safety Feature and Critical Safety Function Status Indication}

The operability of engineered safety features (ESFs) such as the emergency core cooling system (ECCS) and the residual heat removal system (RHRS) may be very important following the initiation of an accident. For example, during the TMI accident when a relief valve stuck in an open position and consequently caused the reactor coolant pressure to drop to $1600 \mathrm{psig}$, the high-pressure safety injection system (part of the emergency core cooling system) was automatically initiated. Had the operators not bypassed this system (i.e., placed the system on manual control) and throttled flow to the reactor, the core would have remained cooled. For LOCAs like that at TMI, the unavailability of an ESF may have a substantial effect on the magnitude of the release. The control panels of the ESFs are kept separate from other controls in the control room. The operability of the ESFs can be verified from this panel.

Since the TMI accident, the procedures used by the control room staff to respond to an accident have been revised to concentrate on maintaining a set of critical safety functions. The control room staff has procedures for monitoring the status of these critical safety functions. These functions have a direct 
relationship to maintaining fission product barriers as shown in Figure 4.16. These barriers can fail only if the appropriate critical safety function is lost. Obviously, critical safety function status can provide good indications of fission product barrier status. This is discussed further in NUREG-1210, Vol. 2, 3, and 4 .

\subsubsection{Containment Isolation Status}

As discussed previously, two primary reasons exist why containment may fail to isolate. The first involves a failure of the containment isolation signal that precludes initiation of isolation valve closure. This type of failure, which would allow all the containment penetrations to remain open, constitutes the largest release path attributable to containment isolation failures. The second involves the failure of one or more penetrations to close as a result of valve or instrument failure. The consequences of containment isolation failures of the second type would depend on the size and the nature of the line penetrating the containment. For example, failure to isolate the containment ventilation exhaust duct would lead to much greater consequences than failure to isolate a demineralized water return line.

The problem is that in many cases it will be difficult to determine directly if complete isolation has taken place. Failure to isolate would be indicated by unexpected temperature, pressure, or radiation outside the containment.

\subsubsection{Containment Atmosphere Temperature and Pressure}

Containment atmosphere temperature and pressure readings would be very valuable in determining the accident progression path. During the TMI accident, increases in containment building pressure and temperature were indicators that the pressurizer relief tank rupture disks had blown, thus allowing primary coolant to spill onto the containment building floor. Later during the accident, a large pressure spike of $28 \mathrm{psig}$ was recorded following ignition of the accumulated hydrogen gas in the containment. This was a clear indication that there must have been extensive core damage. In general, abnormally high pressure or temperature readings in the containment would indicate a loss of reactor coolant boundary integrity. However, care must be taken in assuming that containment pressures near design limits indicate imminent containment failure. Pressures 2 to 3 times design may be required for failure. 


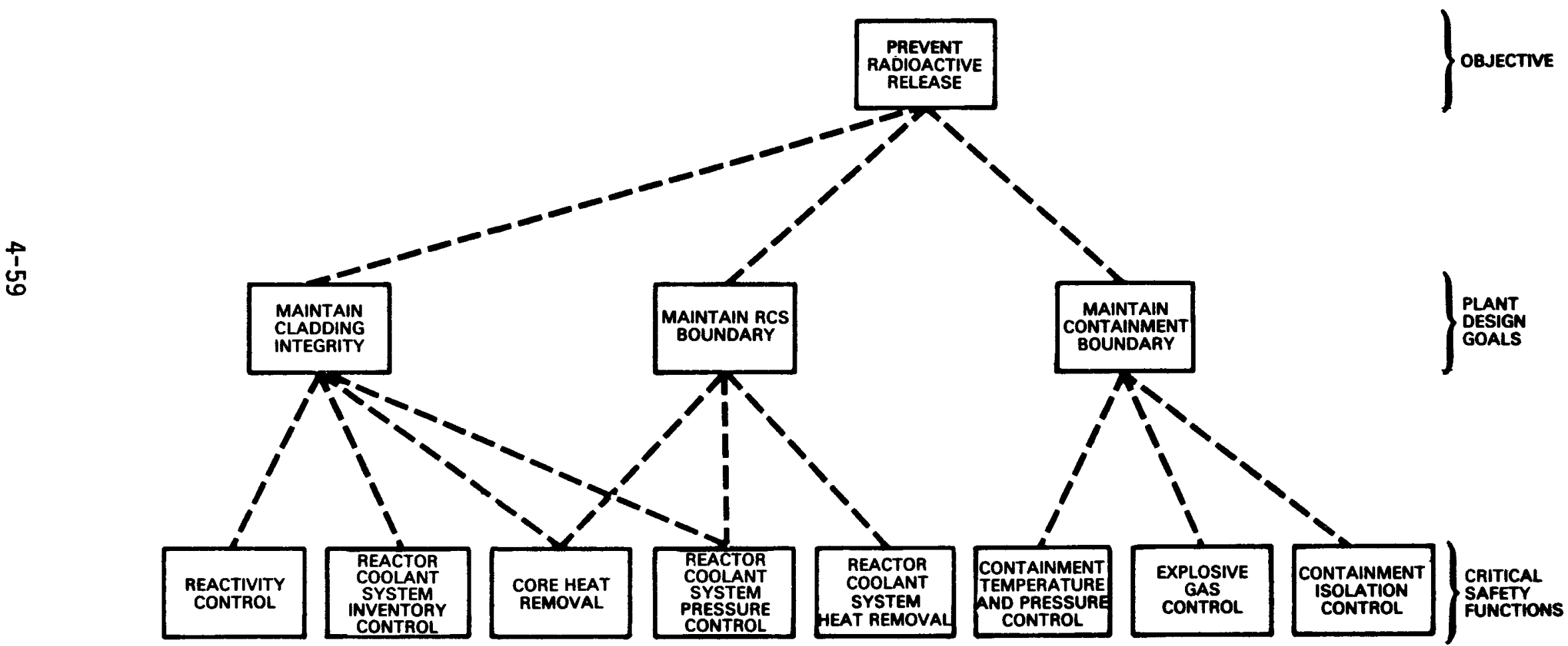

Figure 4.16 Relationship among critical safety functions, maintaining fission product barriers, and preventing a release Source: NUREG-1210 


\section{SOURCE TERM DETERMINATION}

\subsection{Objective}

To enable the reader to

work through a source term calculation using the approach discussed in this section and the information provided in the previous section

\subsection{Introduction}

The first step in determining the source term is to establish the origin of the release or the potential release and its characteristic. This determination is made by utilizing the information from plant parameters, radiation monitors, or samples. The plant parameters are most helpful in determining the extent of damage to the reactor core, whereas the radiation monitors are most helpful in locating the origin of the radioactivity and later in tracking the release from the origin through the plant and out into the environment. Enough information may be available to allow an estimate to be made of the amount of fission products for release from the containment atmosphere. If this is the case, this estimate should form the starting point of the analysis. The pathway removal mechanism and release rates from this point to the environment would be analyzed. If this information is not available, an analysis starting with the core would be required. The second step is to estimate the fission product inventory available for release based on the core temperature or other indications of the appropriate source regime. This initial inventory can be determined based on methods described in Section 4. The next step is to trace the source back through the plant to account for all pathways and to apply the appropriate fission product reduction factors. The basic method for estimating source term is shown by the following:

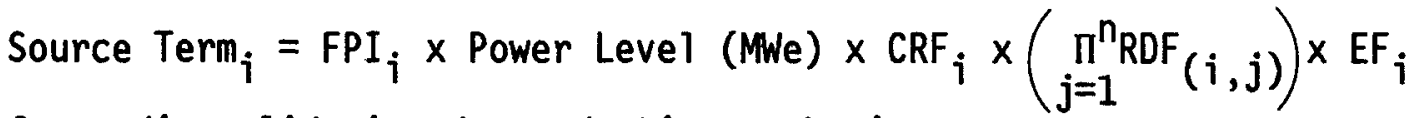
for radionuclide $i$ and $n$ reduction mechanisms

where

$$
\begin{aligned}
& \left.\mathrm{FPI}_{i}=\text { element } i \text { core or coolant inventory }(\mathrm{C} i / \mathrm{MWe}) \text { (Table } 2.2 \text { or } 3.2\right) \\
& \mathrm{CRF}_{i}=\frac{\text { element } i \text { released from core }}{\text { element } i \text { inventory in core }} \text { (Table } 4.1 \text { ) } \\
& \mathrm{RDF}_{i}=\frac{\text { element } i \text { available for release after reduction mechanisms }}{\text { element } i \text { available for release before reduction mechanisms }} \text { or } 4.8 \text { ) } \\
& \mathrm{EF}_{i}=\frac{\text { element } i \text { released to the environment }}{\text { element } i \text { available for release }}(T a b l e ~ 4.10)
\end{aligned}
$$

The referenced tables provide a summary of reasonable assumptions discussed in previous sections. As discussed in Section 4.2. a maximum total reduction 
factor of 0.001 should be assumed for the product of all non-filter reduction mechanisms.

Following is an example of a release, or a potential release, of radioactive materials to the environment. The steps involved in estimating the source term are described.

\subsection{Sample Source Term Calculation}

A severe flood caused loss of offsite power at the Perkins Point Nuclear Power Station. Perkins Point has an electric capacity of $1000 \mathrm{MW}$ and has been operating continuously for 6 months. Perkins Point, which is a PWR with an ice condenser containment, was first placed on line 3 years ago. Diesel generators $A$ and $B$, the station's source of onsite ac power, failed to start automatically when offsite ac power was lost. Subsequent attempts by the operators to start the diesel generators proved unsuccessful because the flood water entered the diesel generator room and disabled the vital buses. Additionally, the turbinedriven feedwater pump failed to supply emergency feedwater to the steam generators because a flow controller malfunction prohibited heat removal from the primary system.

About an hour into the incident, while the operators were still attempting to restore ac power, the area radiation alarm in the cell housing reactor coolant pump $A$ alarmed. About 20 minutes later, the area radiation monitors in the cells housing reactor coolant pumps $B$ and $C$ triggered an alarm. The operators observed that the reactor coolant system pressure was decreasing quickly despite the fact that the heat sink had not been regained. The containment building pressure was rising rapidly.

The operators postulated that the power-operated relief valves (PORVs) stuck open--as at TMI-2--despite the fact that the relief valve solenoid status lights indicated that the relief valves were closed and that the pressurizer level indication had bottomed out. These are indications the block valves have failed. The containment dome monitor reached $1000 \mathrm{R} / \mathrm{hr}$ and was rising rapidly. There were other numerous radiation alarms. Thermocouple readings of greater than $1500^{\circ} \mathrm{F}$ were recorded at some locations.

\subsubsection{Step 1: Gather/Assess Plant Information}

From the information given, the decreasing system pressure and increasing containment building pressure indicate that a LOCA has occurred. Furthermore, the radiation alarms sounding in the containment should have been a good indication that the primary system integrity had been compromised.

Because the area radiation monitors were within the containment, this should have told the operators that a release to the containment had occurred. The dome monitor in the containment was reading $1000 \mathrm{R} / \mathrm{hr}$. Does this mean that fuel damage has occurred, or could the high radiation level correspond to a release of noble gases from ruptured cladding? On the basis of available information, it is reasonable to assume that the plant cannot maintain the ability to remove decay heat or keep the core covered.

As discussed in Section 4.4.2, once the core is uncovered, cladding failure follows in about 15 minutes. Cladding failure is confirmed by the containment monitor reading of $1000 \mathrm{R} / \mathrm{hr}$ and the thermocouple readings. 
5.3.2 Step 2: Estimate the Fission Product Inventory Released From the Core Although the extent of core damage could not be ascertained from the information given, it is certain that a core melt release from the fuel would take place unless plant conditions improve. Thus, utilizing the assumed core melt release fractions from the core that were provided in Tables 4.1 and 2.5 and assuming a 1000-MWe operating history, the following calculations can be made:

\begin{tabular}{llllllll}
\hline Isotope & $\begin{array}{l}\text { Inventory, } \\
\text { Ci/MWe }\end{array}$ & $\times$ & $\begin{array}{l}\text { Power leve1 } \\
(1000 \text { MWe })\end{array}$ & $\times$ & $\begin{array}{l}\text { Core } \\
\text { release } \\
\text { fraction }\end{array}$ & $=$ & $\begin{array}{l}\text { Curies released } \\
\text { from core }\end{array}$ \\
\hline $\mathrm{Kr}-88$ & $6.8 \times 10^{4}$ & $\times$ & $1 \times 10^{3}$ & $\times$ & 1.0 & $=$ & $6.8 \times 10^{7}$ \\
$\mathrm{I}-131$ & $8.5 \times 10^{4}$ & $\times$ & $1 \times 10^{3}$ & $\times$ & 1.0 & $=$ & $8.5 \times 10^{7}$ \\
$\mathrm{Cs}-134$ & $7 \times 10^{3}$ & $\times$ & $1 \times 10^{3}$ & $\times$ & 1.0 & $=7 \times 10^{6}$ \\
\hline
\end{tabular}

\subsubsection{Step 3: Estimate the Fission Products Available for Release}

The obvious release path is into the containment building. However, small branch lines attached to the reactor coolant system may penetrate the containment and connect to support or safety systems in the auxiliary building or turbine building.

The following are typical important questions:

- Are there indications of containment failures?

- What is the containment pressure now and what will it be an hour from now?

- How does the measured or anticipated pressure compare to the overall design pressure and to the ultimate capacity?

- What is the hydrogen concentration?

- Will operation of containment spray cause the hydrogen concentration to approach detonable limits?

- Are the sprays operational?

- Are the recirculation fans operational?

- Has the ice bed been exhausted before the core damage?

The answers to many of these questions will be unknown. Accurate indication of plant parameters and knowledge of accident phenomena in containment may be the only means for making a decision regarding the fission products available for release from the containment and the containment leak rates. It will be assumed for this example that the containment integrity is maintained and leaks are at design rates. It also is assumed that the fans and sprays are not available 
as a result of the loss of ac power and that the ice was not exhausted. Now it will be necessary to estimate the inventory of fission products in the containment atmosphere that could be released if containment failure did occur.

The release path is illustrated in Figure 5.1. It will be assumed that all the fission products released from the core are released from the primary system.

Continuing with the assumption that the air return fans are unavailable as a result of a loss of ac power, the fission product aerosols released are assumed to make only one pass through the ice condenser bed. Thus, based on Table 4.7, about $50 \%$ (RDF of 0.5 ) of the fission product aerosols may be assumed to be removed by the ice beds. Noble gases are not filtered. The following estimate can be made of the inventory of fission products in the containment.

\begin{tabular}{llllll}
\hline Isotope & $\begin{array}{l}\text { Curies released } \\
\text { into containment }\end{array}$ & $\times \begin{array}{l}\text { RDF } \\
\text { (ice bed) }\end{array}$ & $=\begin{array}{l}\text { Inventory assumed } \\
\text { airborne }\end{array}$ \\
\hline $\mathrm{Kr}-88$ & $6.8 \times 10^{7}$ & $\times$ & 1.0 & $=$ & $6.8 \times 10^{7}$ \\
$\mathrm{I}-131$ & $8.5 \times 10^{7}$ & $\times$ & 0.50 & $=$ & $4.2 \times 10^{7}$ \\
$\mathrm{Cs}-134$ & $7.5 \times 10^{6}$ & $\times$ & 0.50 & $=3.7 \times 10^{6}$ \\
\hline
\end{tabular}

After several hours these inventories will decrease, as discussed in Section 4.5.1.1.2.1, by the factors shown in Table 4.7.

To estimate the release 2 hours after the material has been released into the containment, a 2-hour holdup time with no spray and only natural processes working to remove airborne fission products in the containment will be assumed (RDF of 0.04 , Table 4.7 ).

\begin{tabular}{|c|c|c|c|c|c|}
\hline Isotope & $\begin{array}{l}\text { Curies airborne } \\
\text { following passage } \\
\text { through ice }\end{array}$ & $x$ & $\begin{array}{l}\text { RDF } \\
\text { (natural } \\
\text { process) }\end{array}$ & $=$ & $\begin{array}{l}\text { Inventory assumed } \\
\text { airborne and available } \\
\text { for release after 2-hr } \\
\text { holdup }\end{array}$ \\
\hline $\begin{array}{l}\mathrm{Kr}-88 \\
\mathrm{I}-131 \\
\mathrm{Cs}-134\end{array}$ & $\begin{array}{l}6.8 \times 10^{7} \\
4.2 \times 10^{7} \\
3.7 \times 10^{6}\end{array}$ & $\begin{array}{l}x \\
x \\
x\end{array}$ & $\begin{array}{l}1.0 \\
4 \times 10^{-2} \\
4 \times 10^{-2}\end{array}$ & $\begin{array}{l}= \\
= \\
=\end{array}$ & $\begin{array}{l}6.8 \times 10^{7} \\
1.7 \times 10^{6} \\
1.4 \times 10^{5}\end{array}$ \\
\hline
\end{tabular}

\subsubsection{Step 4: Estimate 1-Hour Release}

The final step is to calculate the fission products actually released from the containment. Table 4.10, which summarizes typical escape fractions (EFs) released in 1 hour, shows that in 1 hour $1 \times 10^{-4}$ of a PWR ice condenser containment volume would be released at the design leak rate. Remember this is the upper limit; pressures below design limits would produce much lower leak rates. Thus: 


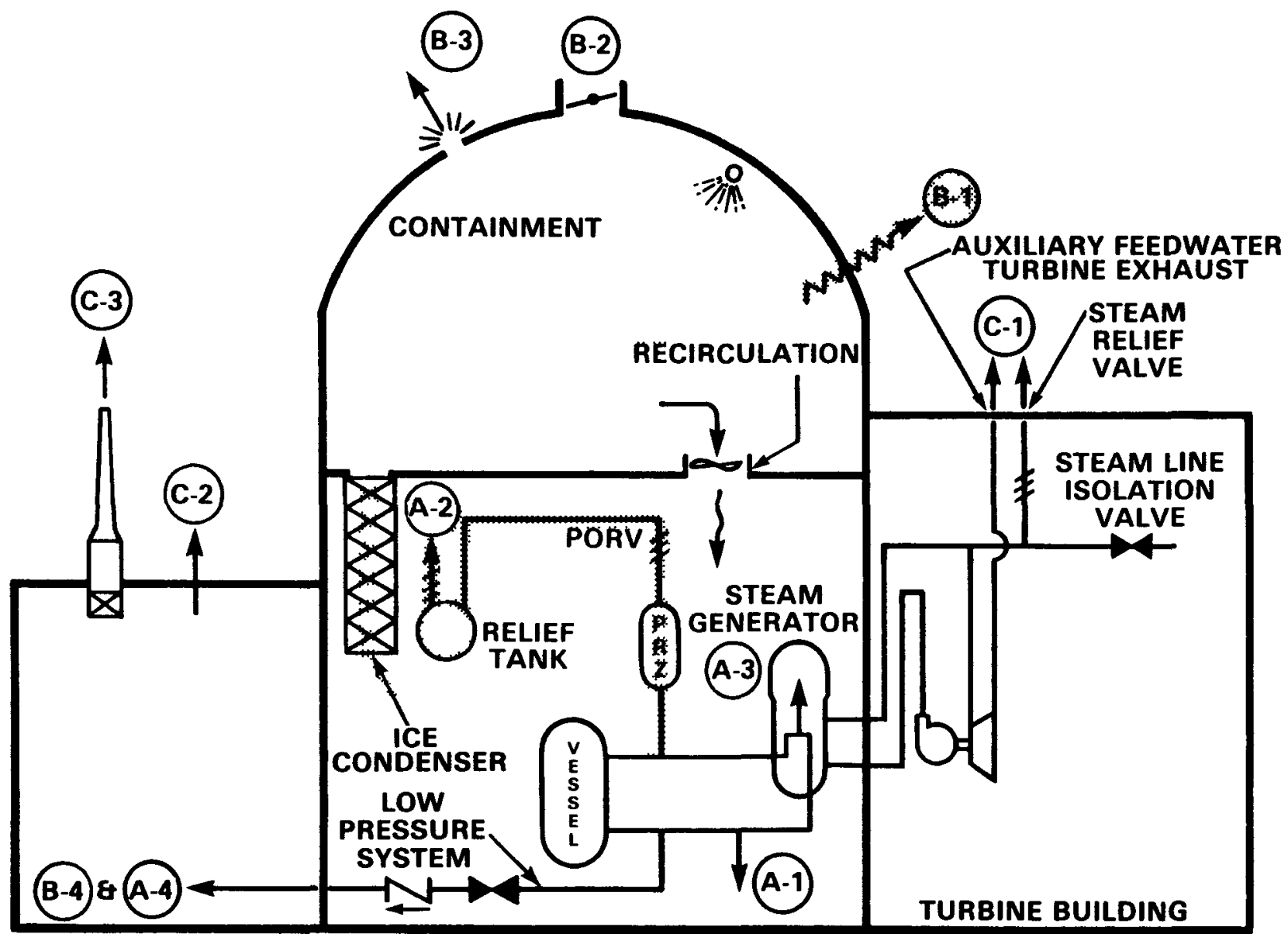

ज़

AUXILIARY BUILDING

F ReLIef VALVe

$\vdots O O$ SPRAY

I closed valve

$-\bigotimes$ FILTER

ZI cHeck VAlve

७PUMP

-A-7) RELEASE PATHWAY REFERENCE

I ISOLATION VALVE

Figure 5.1 Release pathway for sample calculation case 


\begin{tabular}{lllll}
\hline & $\begin{array}{l}\text { Curies airborne } \\
\text { in containment } \\
\text { available for } \\
\text { release }\end{array}$ & $\begin{array}{l}\text { 1-hr escape } \\
\text { fractions } \\
\text { (design } \\
\text { leak rate) }\end{array}$ & $\begin{array}{l}\text { Curies released } \\
\text { from containment } \\
\text { in } 1 \mathrm{hr}\end{array}$ \\
\hline $\mathrm{Kr}-88$ & $6.8 \times 10^{7}$ & $\times$ & $1 \times 10^{-4}$ & $=$ \\
$\mathrm{I}-131$ & $1.7 \times 10^{6}$ & $\times$ & $1 \times 10^{-4}$ & $=1.8 \times 10^{3}$ \\
$\mathrm{Cs}-134$ & $1.4 \times 10^{5}$ & $\times \quad 1 \times 10^{-4}$ & $=1.4 \times 10^{1}$ \\
\hline
\end{tabular}

\subsection{Use of Event Trees To Estimate Release}

Using the above method of calculation for a long list of isotopes would be very time consuming and still would not provide a direct estimate of possible offsite consequences. However, calculation of the amount of each isotope is not required to estimate offsite consequences (dose). A set of event trees has been developed that provides estimates of the whole-body and thyroid doses at 1 mile.

Event trees have been calculated and are grouped in the following figures by release pathway type with the letters designating the level of core damage:

(1) PWR large dry or subatmospheric containments (Figures 5.2A, 2B, 2C)

(2) PWR ice condenser containment (Figures 5.3A, 3B, 3C)

(3) PWR steam generator tube rupture (Figures 5.4A, 4B, 4C, 4D)

(4) BWR containment, dry-well leak/failure (Figures 5.5A, 5B, 5C)

(5) BWR containment, wet-we11 leak/failure (Figures 5.6A, 6B, 6C)

(6) BWR/PWR bypass (Figures 5.7A, 7B, 7C)

In each, the noble gas and particulate release fractions have been calculated for gap, grain boundary, and molten-core damage states. The release fraction in the trees is the fraction of the material released from the core that is released to the atmosphere. For example, to calculate the curies of I- 131 released to the atmosphere you must multiply the curies released from the core times the release fraction shown on the trees. For the steam generator tube rupture, normal coolant and coolant with 100 times iodine spike also were considered.

Doses were calculated for a 1000-MWe plant, and the release fractions were calculated using the reduction factor summarized in Tables 4.7 and 4.8, as appropriate for the release pathway. Transport was estimated assuming a ground level release and average meteorological conditions (4-mph wind speed and D stability). The conditions provide dose estimates that are within a factor of 10 of the range of reasonable meteorological condition given a specific source term. Doses were calculated using MESORAD computer code (NUREG/CR-4000), which is the dose assessment code used at the NRC Operations Center. The whole-body doses include cloud shine, inhalation dose, and 3 hours of ground shine. The thyroid dose is for an adult and is for inhalation only. Dose factors for the release of $100 \%$ of gap, grain boundary, and core melt particulate release fractions and $100 \%$ of the noble gases were calculated and are shown in Table 5.1.

The dose for a specific accident can be estimated by: 


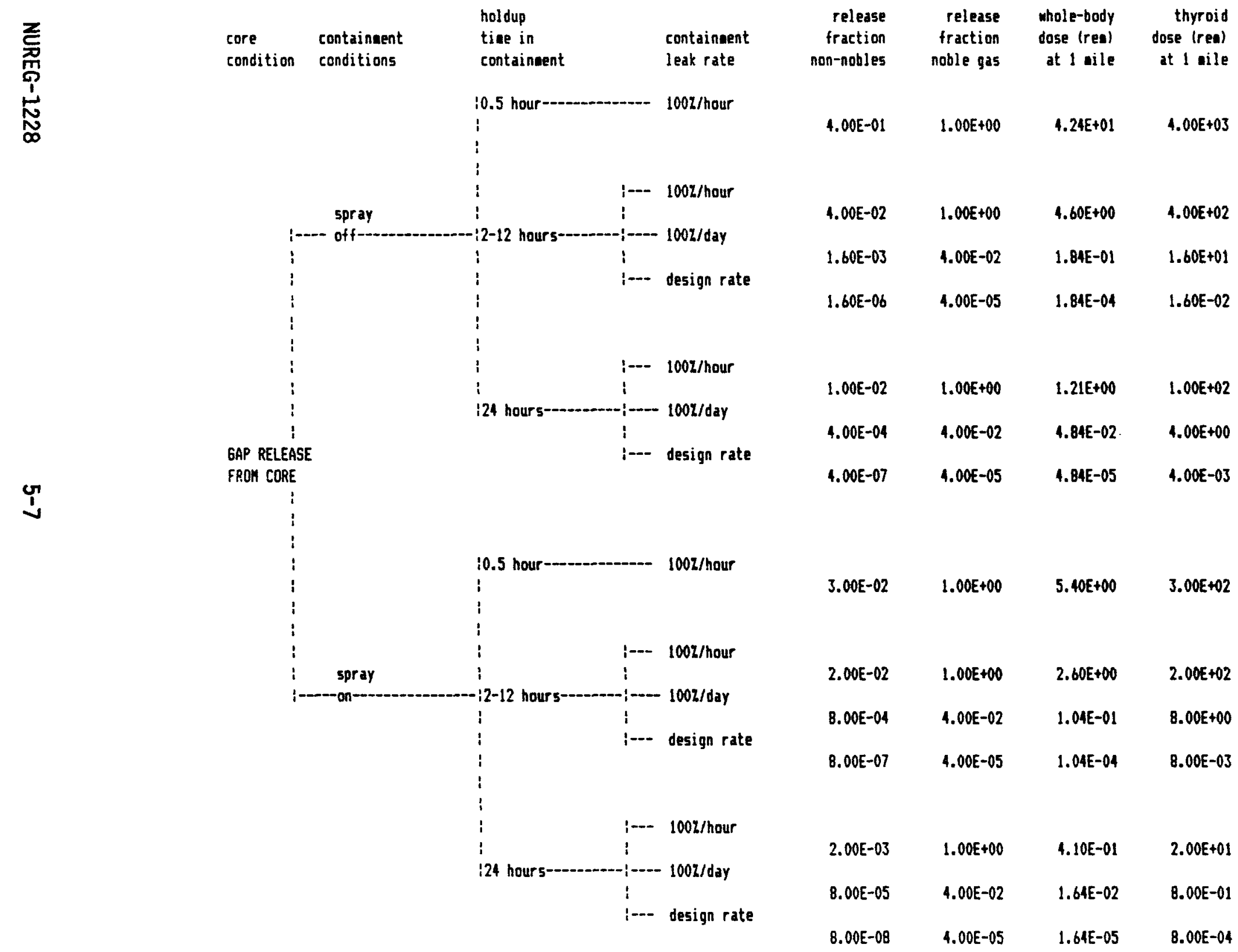

Figure 5.2A PWR large, dry or subatmospheric containment release event tree for a gap release from the core 


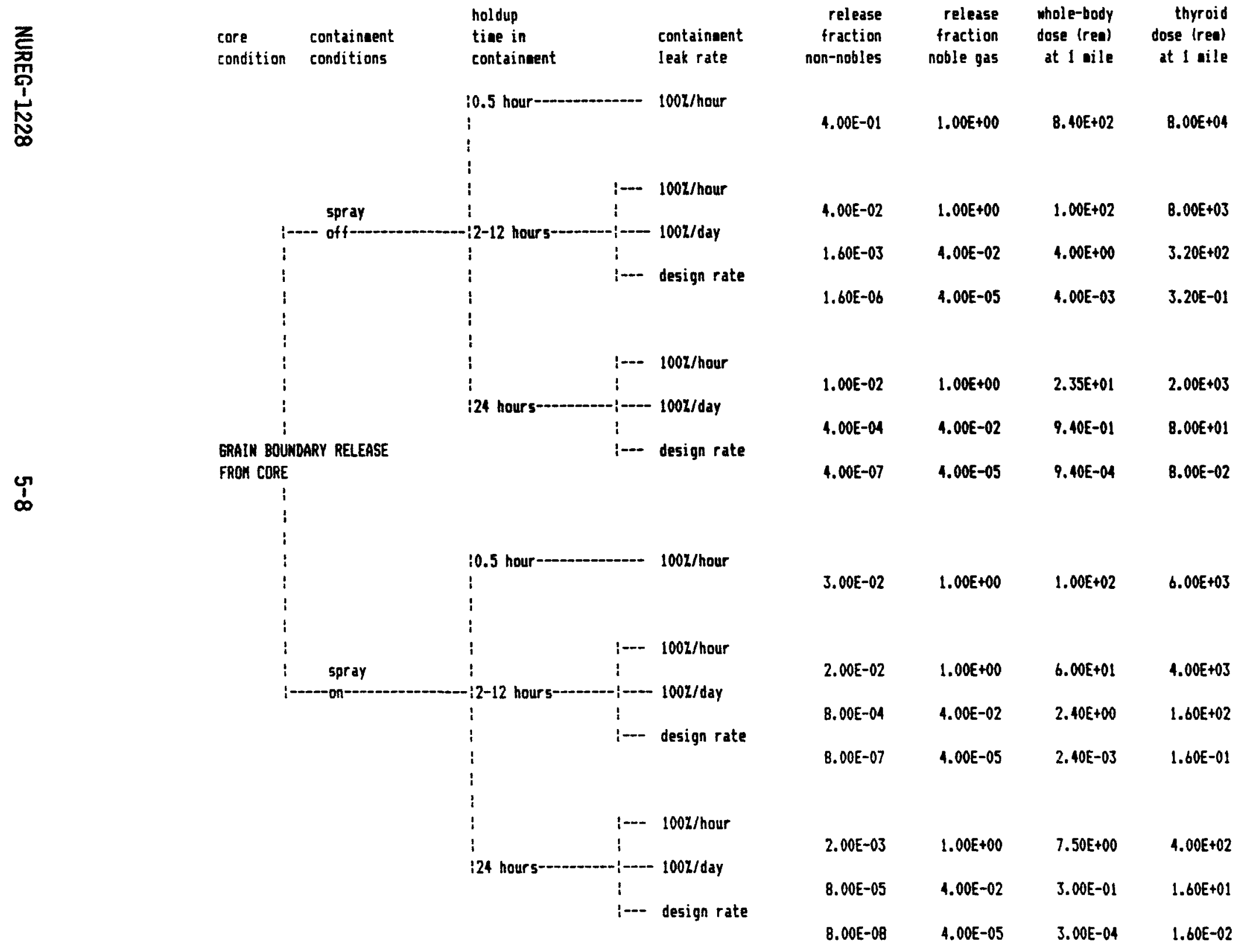

Figure 5.2B PWR large, dry or subatmospheric containment release event tree for a grain boundary release from the core 


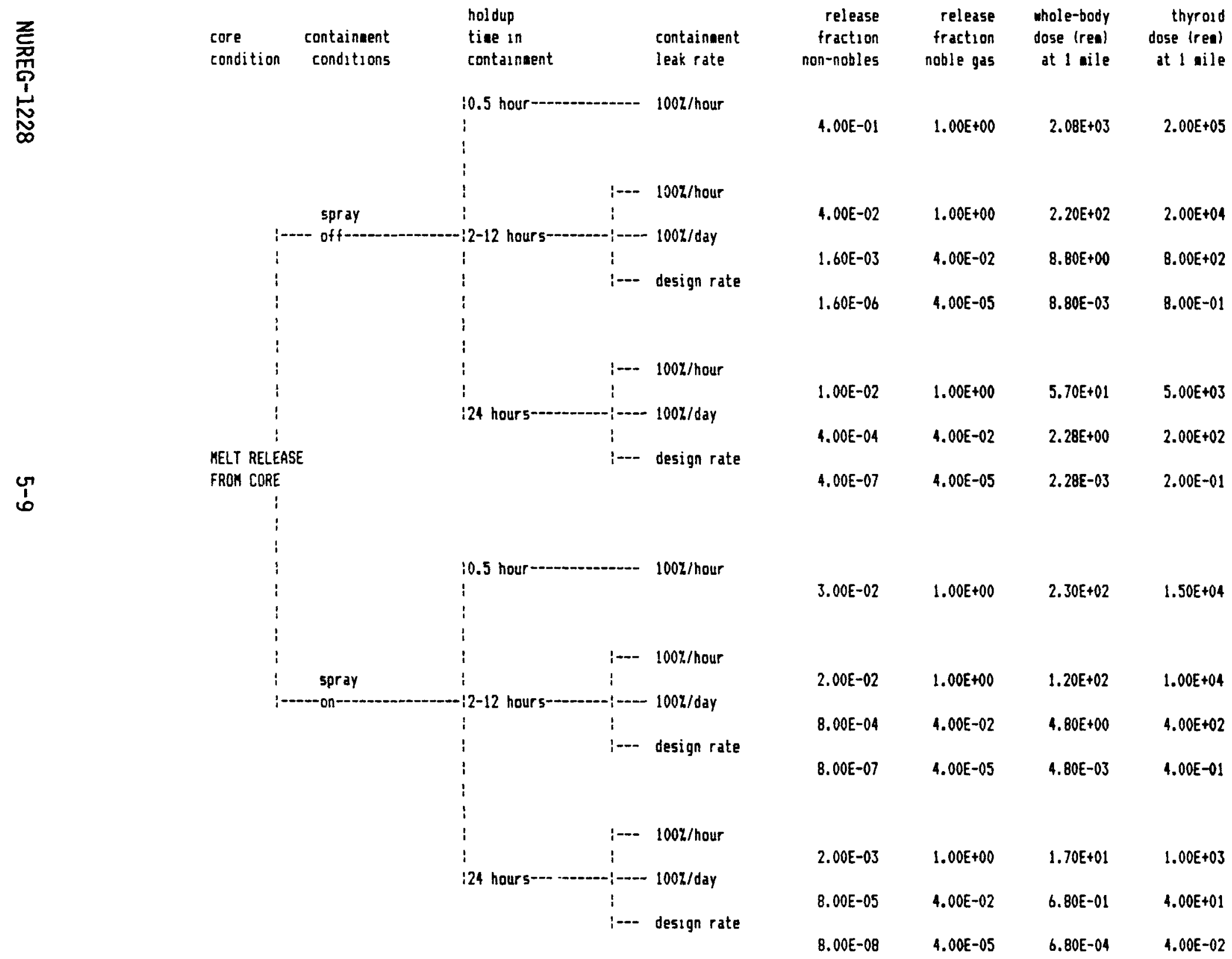

Figure 5.2C PWR large, dry or subatmospheric containment release event tree for a melt release from the core 


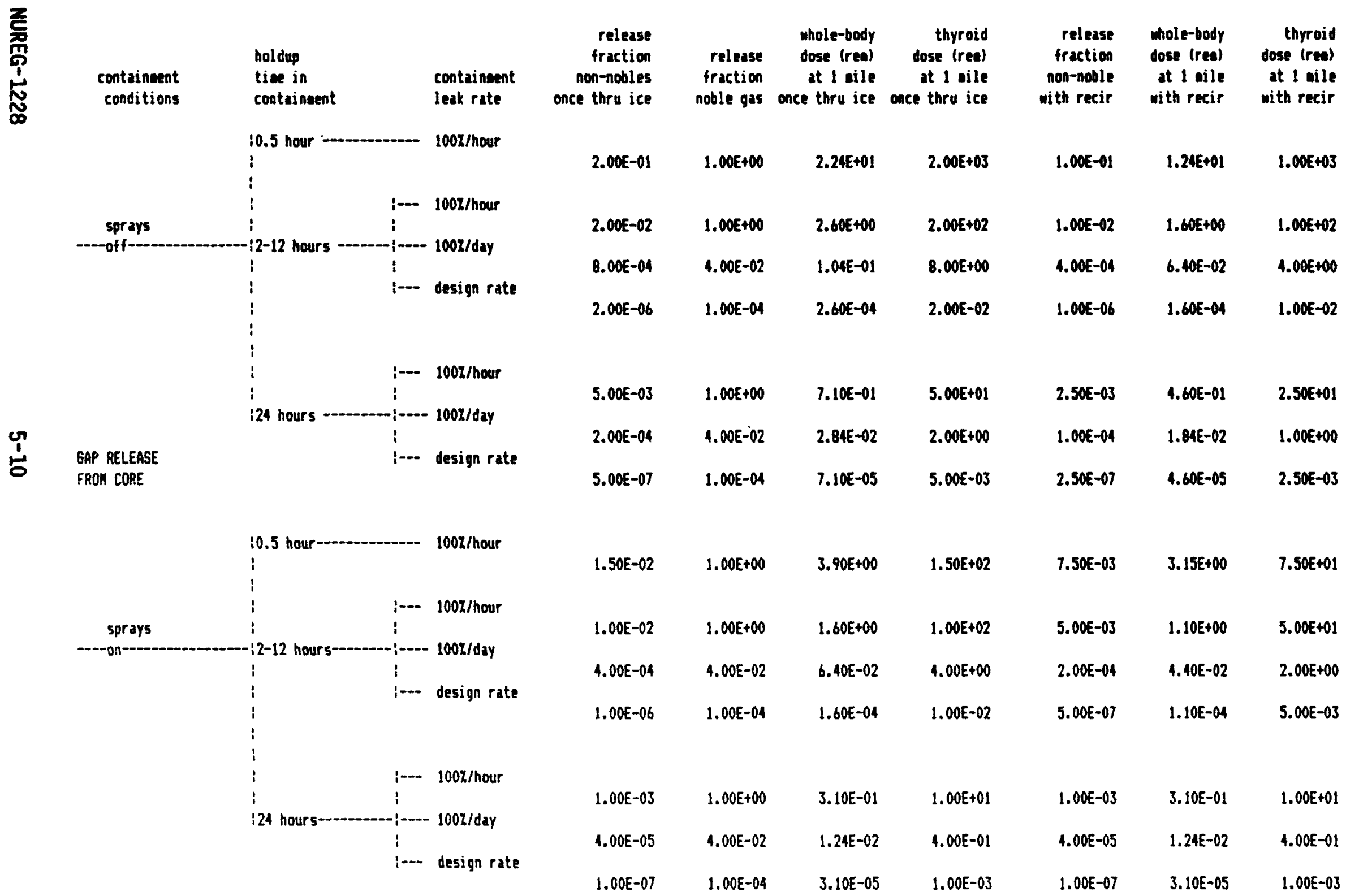

Figure 5.3A PWR ice condenser containment release event tree for a gap release from the core 


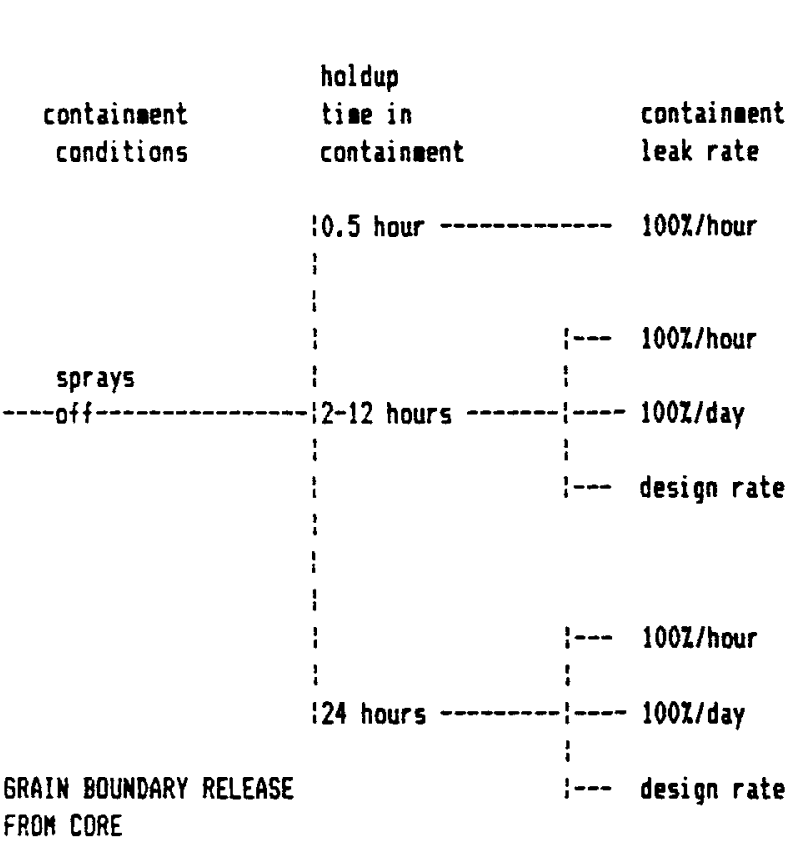

releas
fractio
non-noble
once thru ic

mole-body
release dose (rea) dose (rea
fraction at 1 aile at 1 ail
noble gas once thru ice once thru ice

release
fraction
non-noble

whole-body

dose (ree) noble gas once thru ice ance thru ice

with recir

at 1 oile

dose 1 real

with recir with recir

$\begin{array}{ccccccc}2.00 E-01 & 1.00 E+00 & 4.40 E+02 & 4.00 E+04 & 1.00 E-01 & 2.40 E+02 & 2.00 E+04 \\ 2.00 E-02 & 1.00 E+00 & 5.00 E+01 & 4.00 E+03 & 1.00 E-02 & 3.00 E+01 & 2.00 E+03 \\ 8.00 E-04 & 4.00 E-02 & 2.00 E+00 & 1.60 E+02 & 4.00 E-04 & 1.20 E+00 & 8.00 E+01 \\ 2.00 E-06 & 1.00 E-04 & 5.00 E-03 & 4.00 E-01 & 1.00 E-06 & 3.00 E-03 & 2.00 E-01\end{array}$

$\begin{array}{ccccccc}5.00 E-03 & 1.00 E+00 & 1.35 E+01 & 1.00 E+03 & 2.50 E-03 & 8.50 E+00 & 5.00 E+02 \\ 2.00 E-04 & 4.00 E-02 & 5.40 E-01 & 4.00 E+01 & 1.00 E-04 & 3.40 E-01 & 2.00 E+01 \\ 5.00 E-07 & 1.00 E-04 & 1.35 E-03 & 1.00 E-01 & 2.50 E-07 & 8.50 E-04 & 5.00 E-02\end{array}$

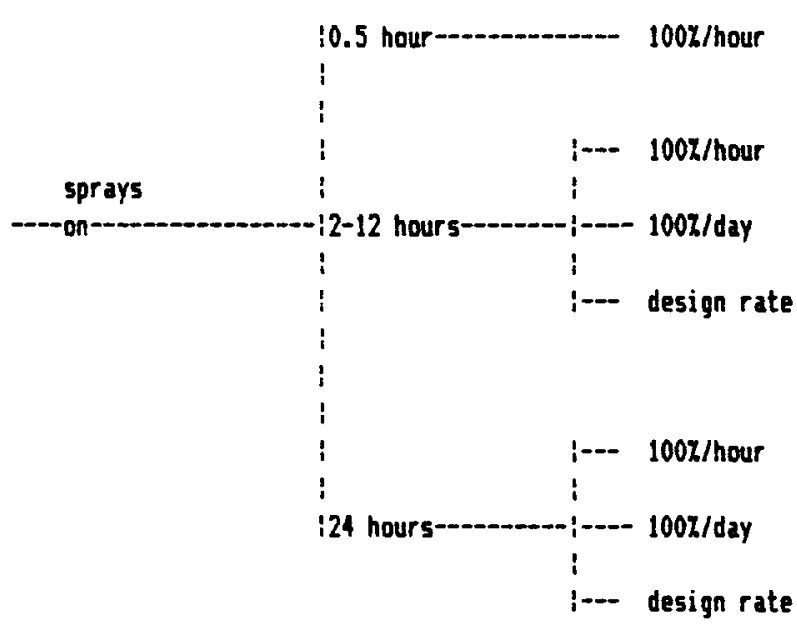

$\begin{array}{lllllll}1.50 E-02 & 1.00 E+00 & 7.00 E+01 & 3.00 E+03 & 7.50 E-03 & 5.50 E+01 & 1.50 E+03 \\ 1.00 E-02 & 1.00 E+00 & 3.00 E+01 & 2.00 E+03 & 5.00 E-03 & 2.00 E+01 & 1.00 E+03 \\ 4.00 E-04 & 4.00 E-02 & 1.20 E+00 & 8.00 E+01 & 2.00 E-04 & 8.00 E-01 & 4.00 E+01 \\ 1.00 E-06 & 1.00 E-04 & 3.00 E-03 & 2.00 E-01 & 5.00 E-07 & 2.00 E-03 & 1.00 E-01 \\ 1.00 E-03 & 1.00 E+00 & 5.50 E+00 & 2.00 E+02 & 1.00 E-03 & 5.50 E+00 & 2.00 E+02 \\ 4.00 E-05 & 4.00 E-02 & 2.20 E-01 & 8.00 E+00 & 4.00 E-05 & 2.20 E-01 & 8.00 E+00 \\ 1.00 E-07 & 1.00 E-04 & 5.50 E-04 & 2.00 E-02 & 1.00 E-07 & 5.50 E-04 & 2.00 E-02\end{array}$

Figure 5.3B PWR ice condenser containment release event tree for a grain boundary release from the core 


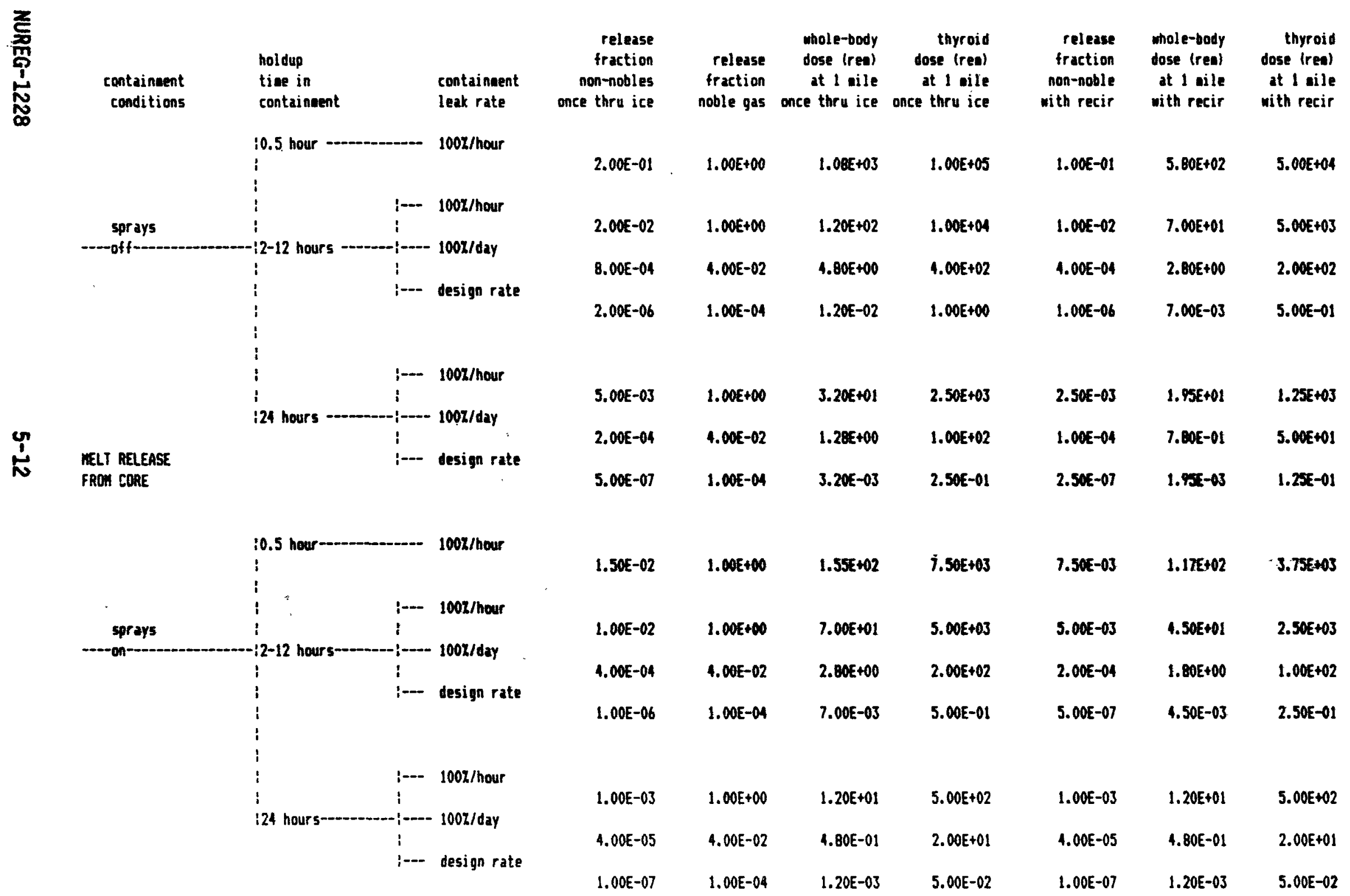

Figure 5.3C PWR ice condenser containment release event tree for a melt release from the core 


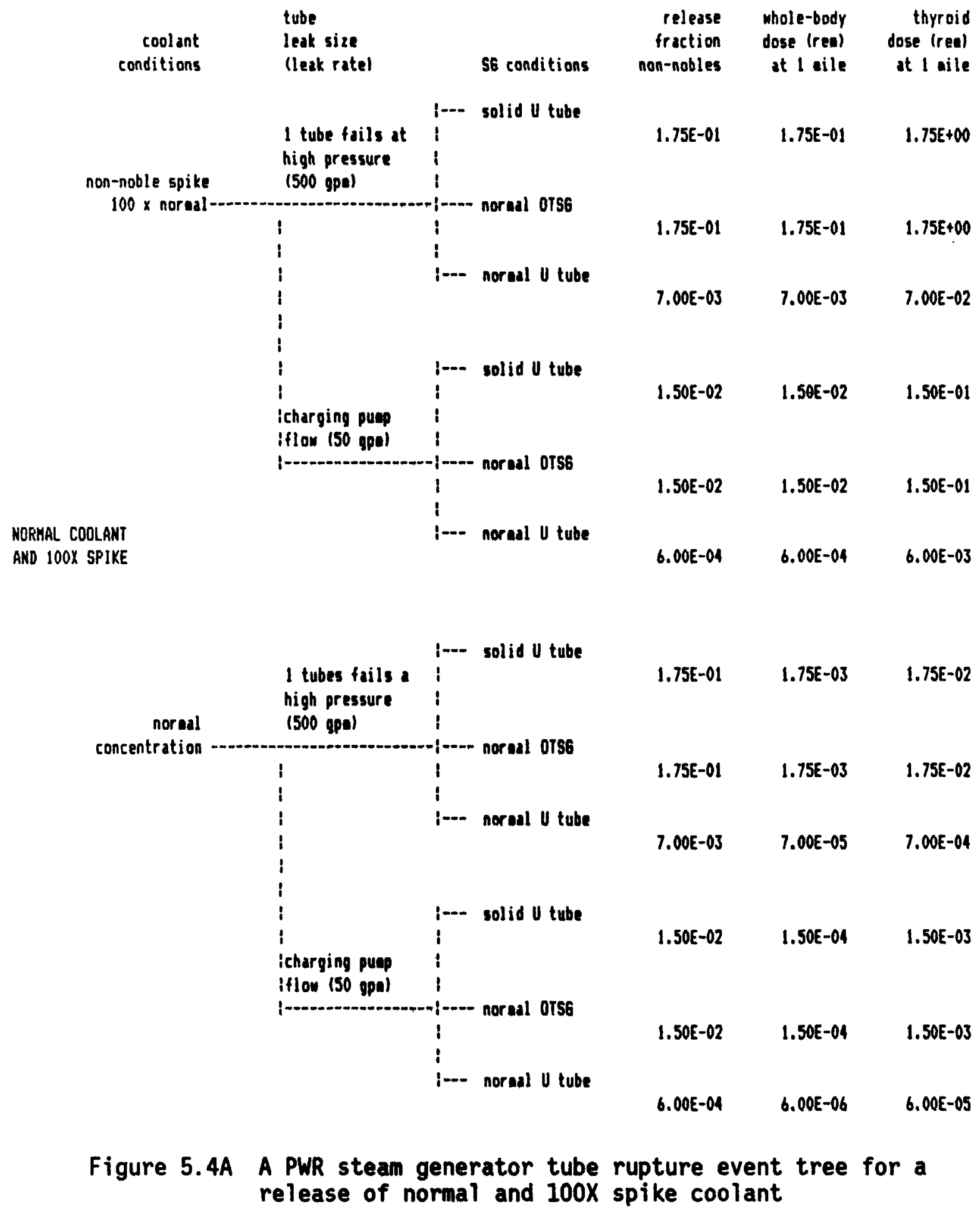


苔

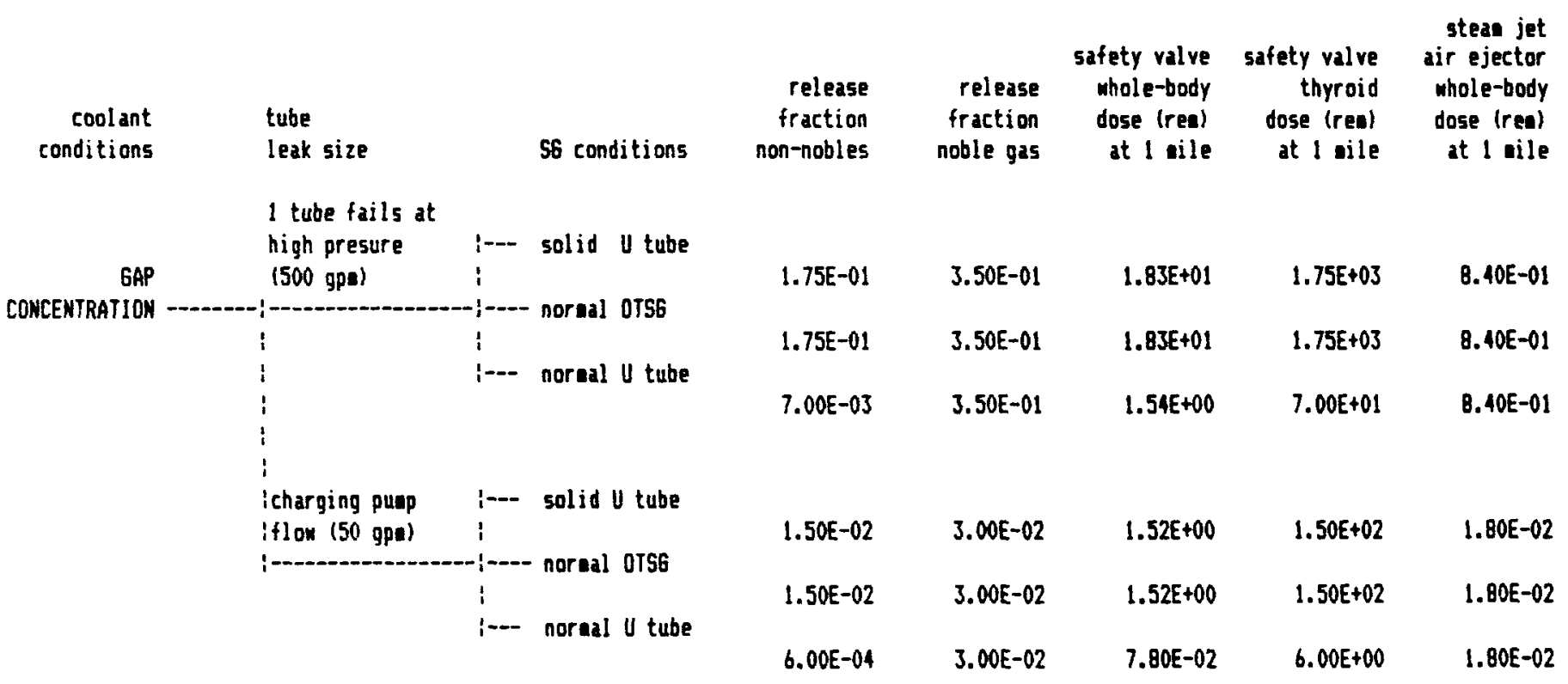

Figure 5.4B PWR steam generator tube rupture event tree for a release of coolant contaminated with a gap release from the core 


\begin{tabular}{|c|c|c|c|c|c|c|c|}
\hline $\begin{array}{r}\text { coolant } \\
\text { conditions }\end{array}$ & $\begin{array}{l}\text { tube } \\
\text { leak size }\end{array}$ & 56 conditions & $\begin{array}{r}\text { release } \\
\text { fraction } \\
\text { non-nobles }\end{array}$ & $\begin{array}{c}\text { release } \\
\text { fraction } \\
\text { noble gas }\end{array}$ & $\begin{array}{r}\text { safety valve } \\
\text { mole-body } \\
\text { dose (rea) } \\
\text { at I aile }\end{array}$ & $\begin{array}{r}\text { safety valve } \\
\text { thyroid } \\
\text { dose (rea) } \\
\text { at } 1 \text { aile }\end{array}$ & $\begin{array}{l}\text { stean jet } \\
\text { air ejector } \\
\text { whole-body } \\
\text { dose (ree) } \\
\text { at I aile }\end{array}$ \\
\hline \multirow[t]{6}{*}{$\begin{array}{l}\text { SRAIN BOUNDARY } \\
\text { CORCENTRATION }\end{array}$} & $\begin{array}{l}1 \text { tube fails at } \\
\text { high presure } \\
\text { \{500 gpol }\end{array}$ & $\begin{array}{c}:-- \text { solid U tube } \\
\vdots--- \text { norenl OTS6 }\end{array}$ & $1.75 E-01$ & $3.50 E-01$ & $3.64 E+02$ & $3.50 E+04$ & $1.40 E+01$ \\
\hline & $i$ & :- norsal y tube & $1.75 E-01$ & $3.50 E-01$ & $3.64 E+02$ & $3.50 E+04$ & $1.40 E+01$ \\
\hline & 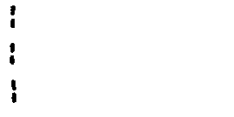 & & $7.00 E-03$ & $3.50 E-01$ & $2.80 E+01$ & $1.40 E+03$ & $1.40 E+01$ \\
\hline & $\begin{array}{l}\text { icharging putp } \\
\text { iflow (50 gpa) }\end{array}$ & :- solid U tube & $1.50 E-02$ & 3.00E-02 & 3.03E+01 & $3.00 E+03$ & $3.00 E-01$ \\
\hline & $1-\cdots$ & :-- noraal OTSG & $1.50 E-02$ & $3.00 E-02$ & $3.03 E+01$ & $3.00 E+03$ & $3.00 E-01$ \\
\hline & & & $6.00 E-04$ & $3.00 E-02$ & $1.50 E+00$ & $1.20 E+02$ & $3.00 E-01$ \\
\hline
\end{tabular}

Figure 5.4C PWR stean generator tube rupture event tree for a release of coolant contaminated with a grain boundary release from the core 


\begin{tabular}{|c|c|c|c|c|c|c|c|c|}
\hline $\begin{array}{r}\text { coolant } \\
\text { conditions }\end{array}$ & $\begin{array}{l}\text { tube } \\
\text { leak size }\end{array}$ & & 56 conditions & $\begin{array}{r}\text { release } \\
\text { fraction } \\
\text { non-nobles }\end{array}$ & $\begin{array}{r}\text { release } \\
\text { fraction } \\
\text { noble gas }\end{array}$ & $\begin{array}{r}\text { safety value } \\
\text { mole-body } \\
\text { dose (ree) } \\
\text { at } 1 \text { aile }\end{array}$ & $\begin{array}{r}\text { safety valve } \\
\text { thyroid } \\
\text { dose (ren) } \\
\text { at } 1 \text { aile }\end{array}$ & $\begin{array}{l}\text { steas jet } \\
\text { air ejector } \\
\text { whole-body } \\
\text { dose (rea) } \\
\text { at } 1 \text { nile }\end{array}$ \\
\hline \multirow{6}{*}{$\begin{array}{l}\text { MELT } \\
\text { CONCENTRATION }\end{array}$} & $\begin{array}{l}1 \text { tube fails at } \\
\text { high presure } \\
\text { (500 gpa) }\end{array}$ & $\begin{array}{c}-\cdots \\
\vdots \\
-\cdots\end{array}$ & $\begin{array}{l}\text { solid U tube } \\
\text { nornal OTS6 }\end{array}$ & $1.75 E-01$ & $3.50 E-01$ & $9.03 E+02$ & $8.75 E+04$ & $2.80 E+01$ \\
\hline & $i$ & : & nor al u tube & $1.75 E-01$ & $3.50 E-01$ & $9.03 E+02$ & $8.75 E+04$ & $2.80 E+01$ \\
\hline & $i$ & & & $7.00 E-03$ & 3.50E-01 & $6.30 E+01$ & $3.50 E+03$ & $2.80 E+01$ \\
\hline & $\begin{array}{l}\text { icharging puap } \\
\text { iflow (50 gpo) } \\
\text { t }\end{array}$ & $:-$ & solid U tube & $1.50 \mathrm{E}-02$ & $3.00 E-02$ & $7.56 E+01$ & $7.50 E+03$ & $6.00 E-01$ \\
\hline & 年- & :- & nornal U tube & $1.50 E-02$ & $3.00 E-02$ & $7.56 E+01$ & $7.50 E+03$ & $6.00 E-01$ \\
\hline & & & & $6.00 E-04$ & $3.00 E-02$ & $3.60 E+00$ & $3.00 E+02$ & $6.00 E-01$ \\
\hline
\end{tabular}

Figure 5.4D PWR steam generator tube rupture event tree for a release of coolant contaminated with a melt release from the core 


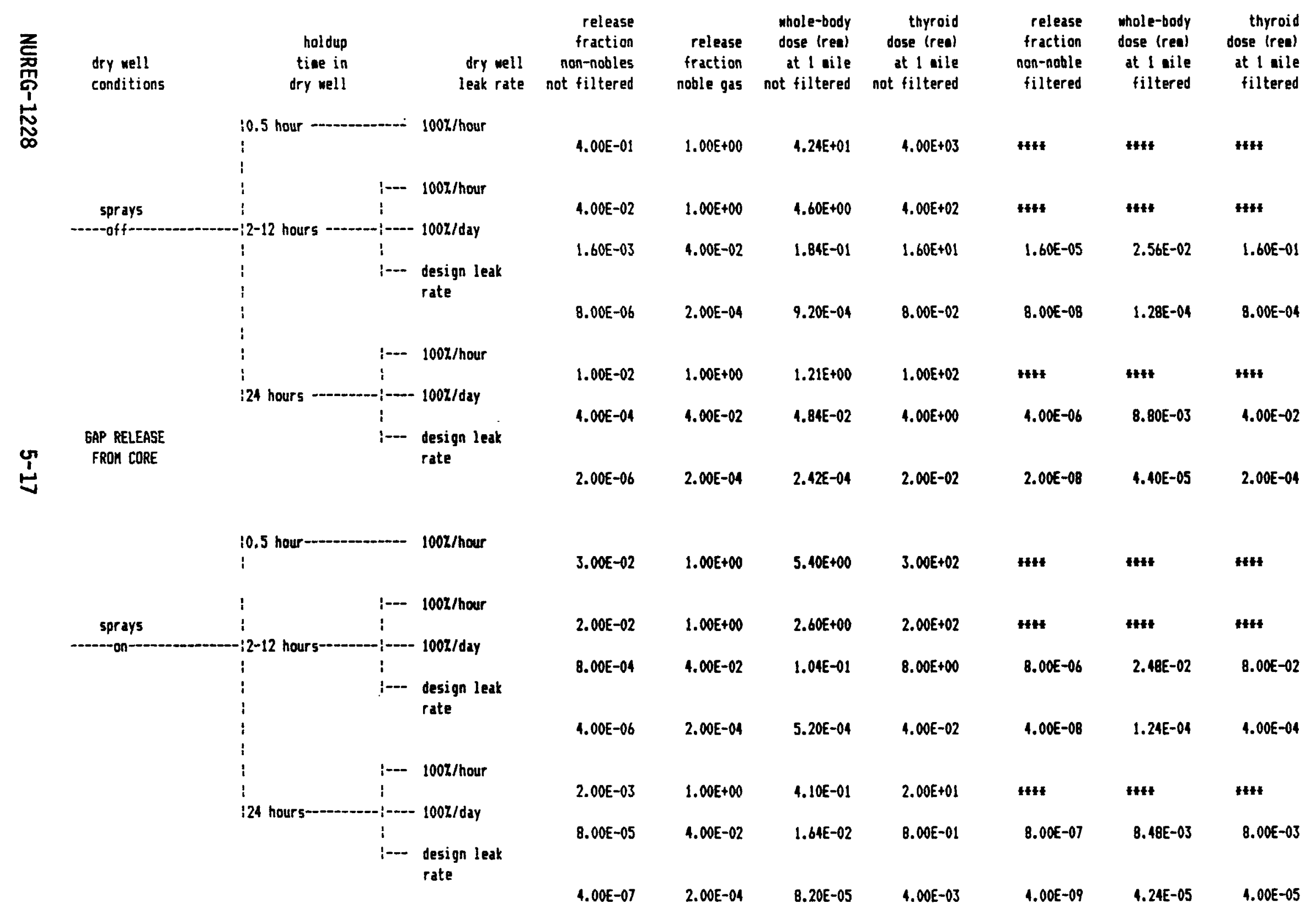

Figure 5.5A BWR containment, dry-well leakage/failure release event tree for a gap release from the core 


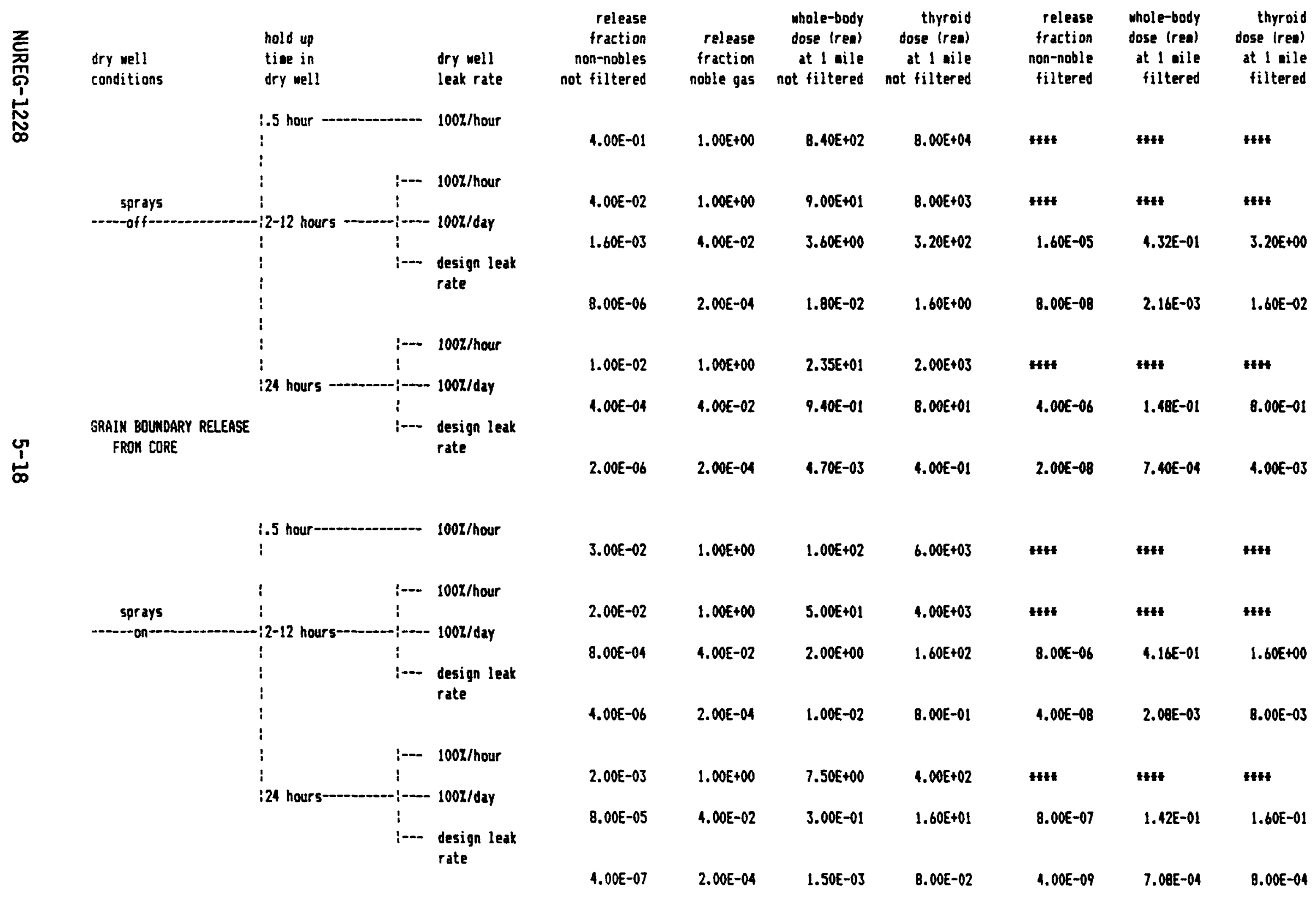

Figure 5.5B BWR containment, dry-well leakage/failure release event tree for a grain boundary release from the core 


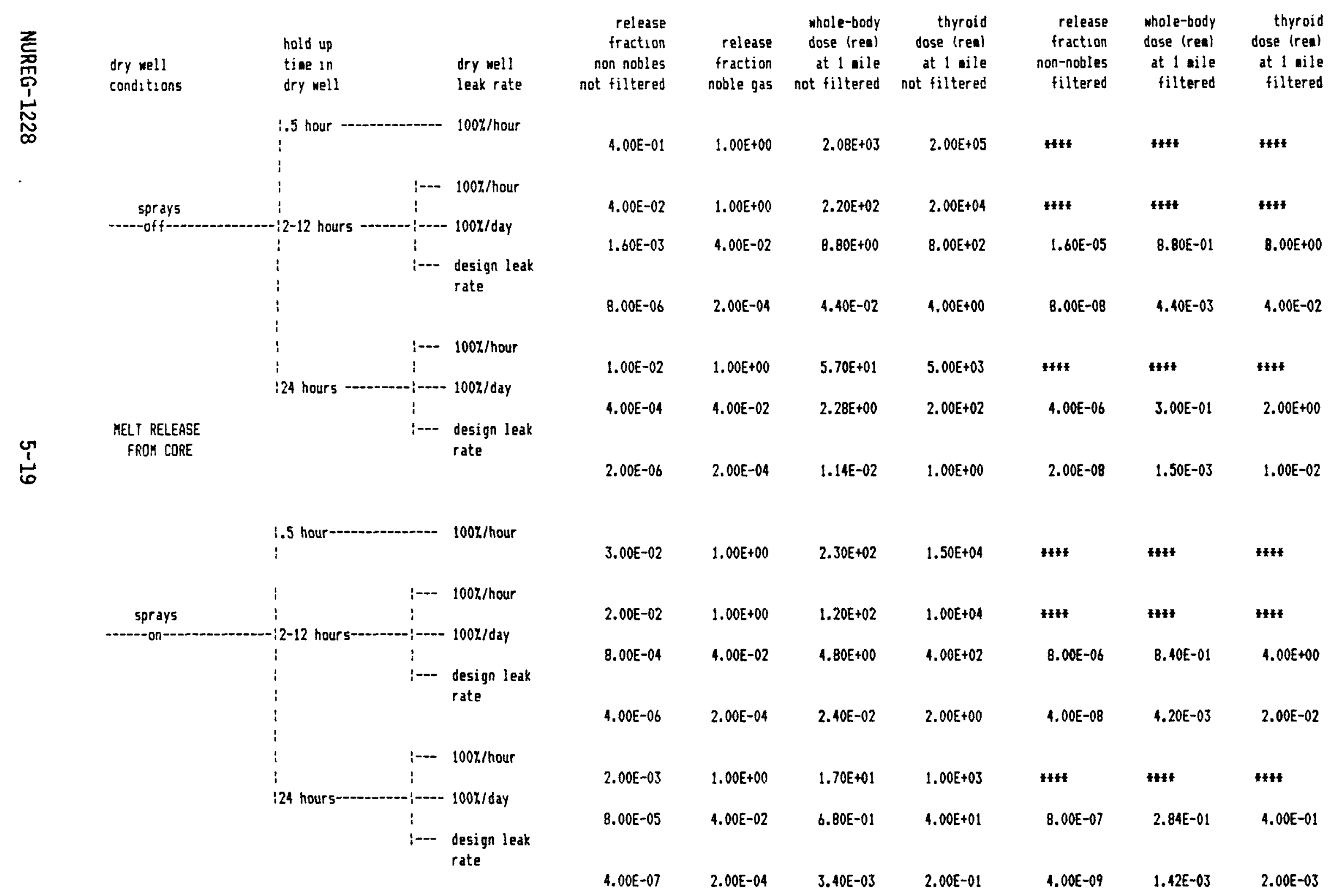

Figure 5.5C BWR containment, dry-well leakage/failure release event tree for a melt release from the core 


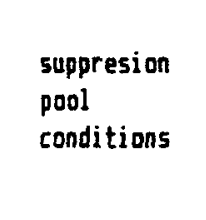

\section{hold up}

tive in

wet well

leak rate

release
fraction
non nobles
not filtered

release
fraction

whole-body
dose (rea)

noble gas

at 1 aile

not filtered
thyroid
dase (ren)
at 1 aile

2.00E-02

$1.00 E+00$

4. $40 E+00$

$2.00 E+02$

$2.00 E-03$

$1.00 E+00$

8.00E-01

8.00E-05

4.00E-07

4.00E-02

3.20E-02

$2.00 \mathrm{E}-04$

1.60E-04

8.00E-01

4.00E-03

8.00E-07

4.00E-09

\section{1. $00 E-03$ \\ 4. 00 E-0.5}

$1.00 E+00$

3.10E-01

$1.00 E+01$

464

2.00E-07

4. $00 \mathrm{E}-02$

$1.24 E-02$

4.00E-01

$2.00 E-03$

4.00E-07

$2.00 E-09$

$2.00 E-04 \quad 6.20 E-05$

$4.00 E+01$

+4*

$4+4$

1.00E-07

4.00E-01

4.00E-05 4.00E-02

2.00E-07

2.00E-04

2. $80 E-02$

$1.40 E-04$

2.00E-03

2.00E-09

I4t)

8. 44E-03

4. 22E-05

4.00E-03 $\quad 1.00 E+00 \quad 2.80 E+00 \quad 4.00 E+01 \quad$ \$\#\#

$1.00 E-03$
$4.00 E-05$
$2.00 E-07$

$1.00 E-03$

$1.00 E+00$

3.10E-01

$1.00 E+01$

\$4

1.24E-02 4.00E-01

4.00E-07

44t

4.00E-05

$$
\text { 4.00E-02 }
$$

2.00E-04
6.20E-05

$2.00 E-03$

$2.00 E-09$

8.44E-03

4.00E-03

Figure 5.6A BWR containment, wet-well leakage/failure release event tree for a gap release from the core 


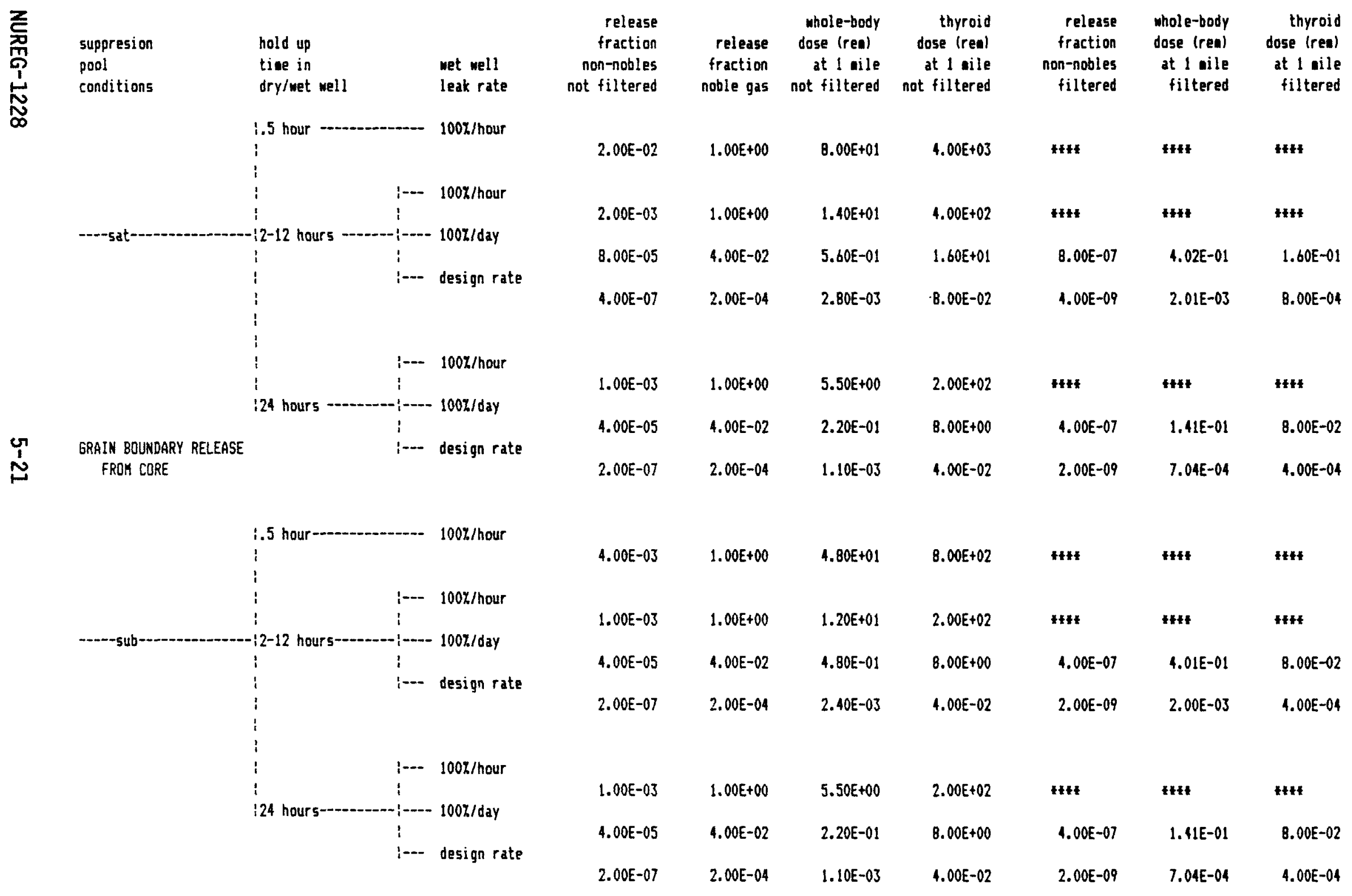

Figure 5.6B BWR containment, wet-well leakage/failure release event tree for a grain boundary release from the core 


suppresion
pool
conditions

\section{hold up}

tive in

wet well

dry/wet well

leak rate

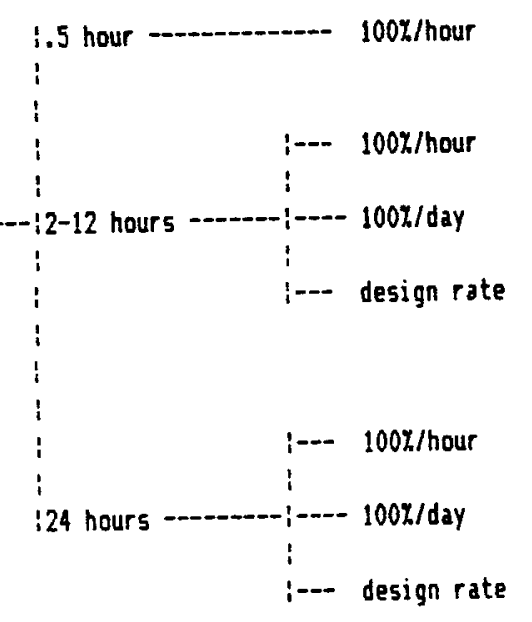

ut MELT RELEASE
N

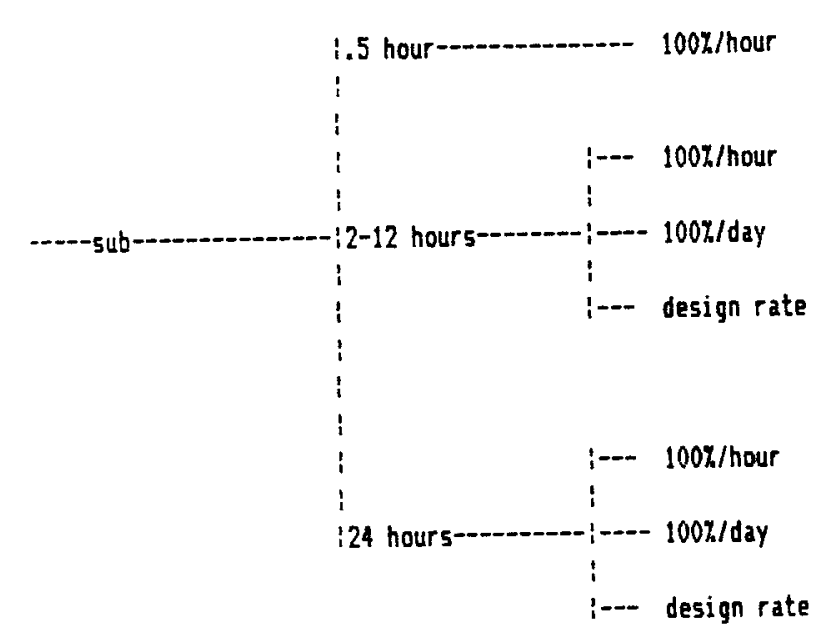

release
fraction
non-nobles
not filtered

mhole-body
release dose (rea)
fraction at 1 aile

thyroid dose (rea)

noble gas

at 1 aile

at 1 aile

frable gas not filtered not filtered

release
fraction
non noble gas
filtered

whole body dose (rea)

at 1 nile

filtered

thyroid dose (ren) at 1 aile

filtered

\begin{tabular}{|c|c|c|c|c|c|c|}
\hline $2.00 \mathrm{E}-02$ & $1.00 E+00$ & $1.80 E+02$ & $1.00 E+04$ & EffF & t*t*t & $+4+4$ \\
\hline $2.00 E-03$ & $1.00 E+00$ & $3.00 E+01$ & $1.00 E+03$ & $4+4$ & 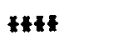 & $\$ \#$ \\
\hline $8.00 E-05$ & $4.00 E-02$ & $1.20 E+00$ & $4.00 E+01$ & $8.00 E-07$ & $8.04 E-01$ & $4.00 E-01$ \\
\hline $4.00 E-07$ & $2.00 \mathrm{E}-04$ & $6.00 E-03$ & $2.00 \mathrm{E}-01$ & $4.00 E-09$ & $4.02 E-03$ & 2.00E-03 \\
\hline
\end{tabular}

$\begin{array}{lllllll}1.00 E-03 & 1.00 E+00 & 1.20 E+01 & 5.00 E+02 & 4+\# & 4 \$ & \\ 4.00 E-05 & 4.00 E-02 & 4.80 E-01 & 2.00 E+01 & 4.00 E-07 & 2.82 E-01 & 2.00 E-01 \\ 2.00 E-07 & 2.00 E-04 & 2.40 E-03 & 1.00 E-01 & 2.00 E-09 & 1.41 E-03 & 1.00 E-03\end{array}$

\begin{tabular}{|c|c|c|c|c|c|c|}
\hline $4.00 E-03$ & $1.00 E+00$ & $1.00 E+02$ & $2.00 E+03$ & 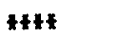 & t\$4 & 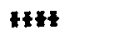 \\
\hline $1.00 E-03$ & $1.00 E+00$ & $2.50 E+01$ & $5.00 E+02$ & t*t* & $1 * \pm 4$ & 17+4 \\
\hline $4.00 E-05$ & 4.00E-02 & $1.00 E+00$ & $2.00 E+01$ & $4.00 E-07$ & $0.02 E-01$ & $2.00 E-0$ \\
\hline 2.00E-07 & 2. $00 \mathrm{E}-04$ & $5.00 E-03$ & 1.00E-01 & $2.00 E-09$ & $4.01 E-03$ & \\
\hline
\end{tabular}

\begin{tabular}{|c|c|c|c|c|c|c|}
\hline $1.00 \mathrm{E}-03$ & $1.00 E+00$ & $1.20 E+01$ & $5.00 E+02$ & $4+4$ & $4+4 t$ & $4+44$ \\
\hline 4.00E-05 & 4. $00 \mathrm{E}-02$ & $4.80 E-01$ & $2.00 E+01$ & $4.00 E-07$ & $2.82 E-01$ & $2.00 E-01$ \\
\hline $.00 E-07$ & 2.00E-04 & $2.40 E-03$ & $1.00 E-01$ & $2.00 E-09$ & $1.41 E-03$ & $1.00 E-03$ \\
\hline
\end{tabular}

Figure 5.6C BWR containment, wet-well leakage/failure release event tree for a melt release from the core 


\begin{tabular}{|c|c|c|c|c|c|c|c|}
\hline $\begin{array}{l}\text { core } \\
\text { conditions }\end{array}$ & $\begin{array}{l}\text { release } \\
\text { conditions }\end{array}$ & & $\begin{array}{l}\text { release } \\
\text { rate }\end{array}$ & $\begin{array}{r}\text { release } \\
\text { fraction } \\
\text { non-nobles }\end{array}$ & $\begin{array}{r}\text { release } \\
\text { fraction } \\
\text { noble gas }\end{array}$ & $\begin{array}{l}\text { whole-body } \\
\text { dose (ren) } \\
\text { at I nile }\end{array}$ & $\begin{array}{l}\text { thyroid } \\
\text { dose (rea) } \\
\text { at } 1 \text { aile }\end{array}$ \\
\hline & & i--- & 100\%/hour & & & & \\
\hline GAP RELEASE & & i & & 4.00E-01 & $1.00 E+00$ & $4.24 E+01$ & $4.00 E+03$ \\
\hline \multirow[t]{10}{*}{ FROH CORE -- } & -inot filtere & $-1---$ & $-100 \% / d a y$ & & & & \\
\hline & i & $i$ & & $1.60 E-02$ & $4.00 E-02$ & $1.62 E+00$ & $1.60 E+02$ \\
\hline & i & :--- & typical design rate & & & & \\
\hline & i & & & 4.00E-05 & $1.00 E-04$ & $4.06 E-03$ & $4.00 E-01$ \\
\hline & $\mathfrak{i}$ & & & & & & \\
\hline & : & & & & & & \\
\hline & 1 & $i--$ & 100\%/hour & & & & \\
\hline & I & i & & \$\$4 & t*t+*t & t+kt & $\$ 4 * 4$ \\
\hline & if 1 ltered - & :-- & $-100 \% / d a y$ & $1.60 E-04$ & $4.00 E-02$ & $4.00 E-02$ & $1.60 E+00$ \\
\hline & & & & 4.00E-07 & $1.00 E-04$ & $1.00 E-04$ & $4.00 E-03$ \\
\hline
\end{tabular}

Figure 5.7A PWR and BWR containment bypass release event tree for a gap release from the core 


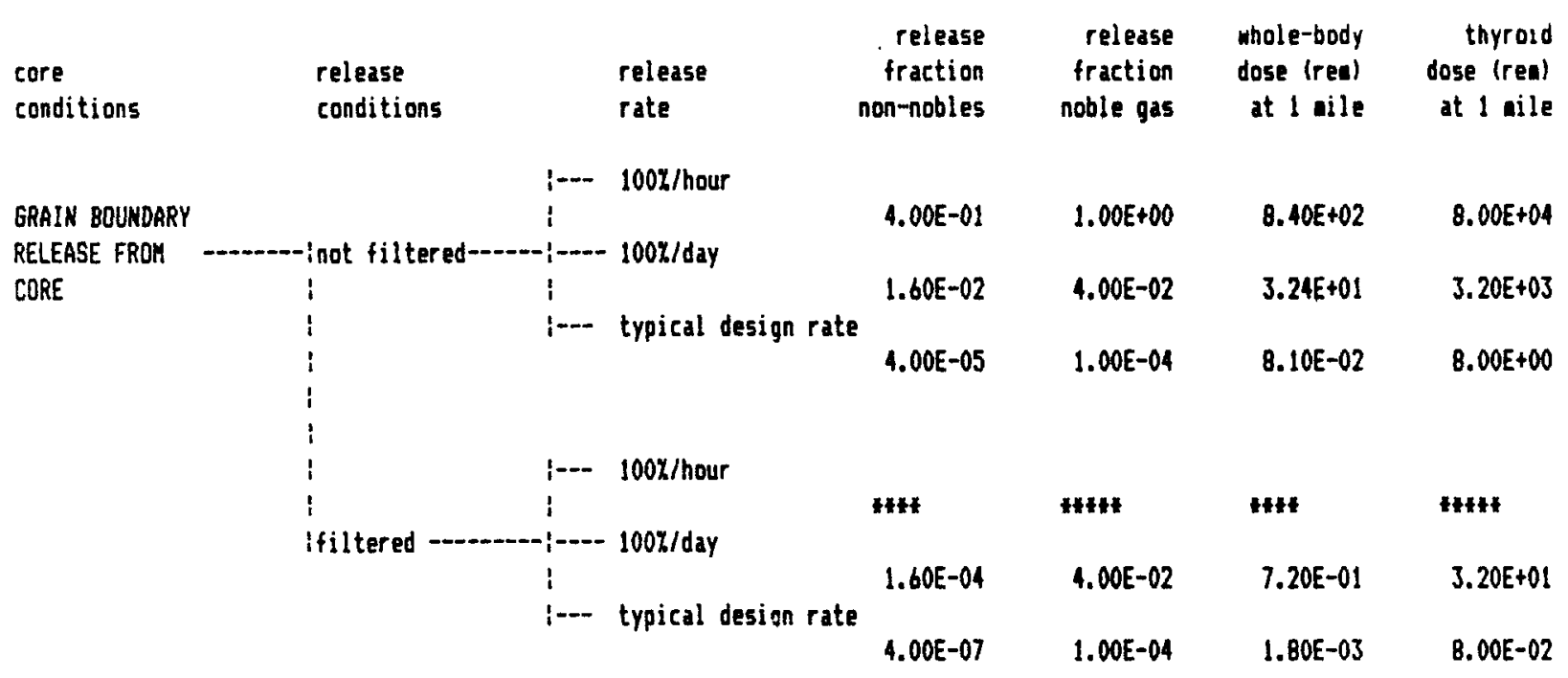

Figure 5.7B PWR and BWR containment bypass release event tree for a grain boundary release from the core 


\begin{tabular}{|c|c|c|c|c|c|c|c|}
\hline $\begin{array}{l}\text { core } \\
\text { conditions }\end{array}$ & $\begin{array}{l}\text { release } \\
\text { conditions }\end{array}$ & & $\begin{array}{l}\text { release } \\
\text { rate }\end{array}$ & $\begin{array}{r}\text { release } \\
\text { fraction } \\
\text { non-nobles }\end{array}$ & $\begin{array}{r}\text { release } \\
\text { fraction } \\
\text { noble gas }\end{array}$ & $\begin{array}{l}\text { hole-body } \\
\text { dose (rea) } \\
\text { at I aile }\end{array}$ & $\begin{array}{r}\text { thyroid } \\
\text { dose (rea) } \\
\text { at I ile }\end{array}$ \\
\hline \multirow{13}{*}{$\begin{array}{l}\text { MELT RELEASE } \\
\text { FROM CORE --- }\end{array}$} & & $1-\infty$ & 100\%/hour & & & & \\
\hline & & i & & $4.00 E-01$ & $1.00 E+00$ & $2.08 E+03$ & $2.00 E+05$ \\
\hline & -inot filtered & $-1-\cdots$ & $100 \% / d a y$ & & & & \\
\hline & $i$ & $i$ & & $1.60 E-02$ & $4.00 E-02$ & $8.08 E+01$ & 8.00E+03 \\
\hline & $i$ & $1-\cdots$ & typical design rate & & & & \\
\hline & $i$ & & & 4.00E-05 & $1.00 E-04$ & $2.02 \mathrm{E}-01$ & $2.00 E+0 !$ \\
\hline & i & & & & & & \\
\hline & i & & & & & & \\
\hline & $\mathbf{i}$ & i--- & 100\%/hour & & & & \\
\hline & 1 & 1 & & **** & E*\$4 & t+\$* & +\$4\$4 \\
\hline & ifiltered --- & 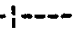 & $1004 /$ day & & & & \\
\hline & & i & typical design rate & 1.60E-04 & 4.00E-02 & $1.60 E+00$ & $8.00 E+01$ \\
\hline & & & & 4.00E- -07 & $1.00 E-04$ & 1.00E-03 & $2.00 E-01$ \\
\hline
\end{tabular}

Figure 5.7C PWR and BWR containment bypass release event tree for a melt release from the core 
Table 5.1 1-mile doses for release of various core and coolant inventories $(1)$

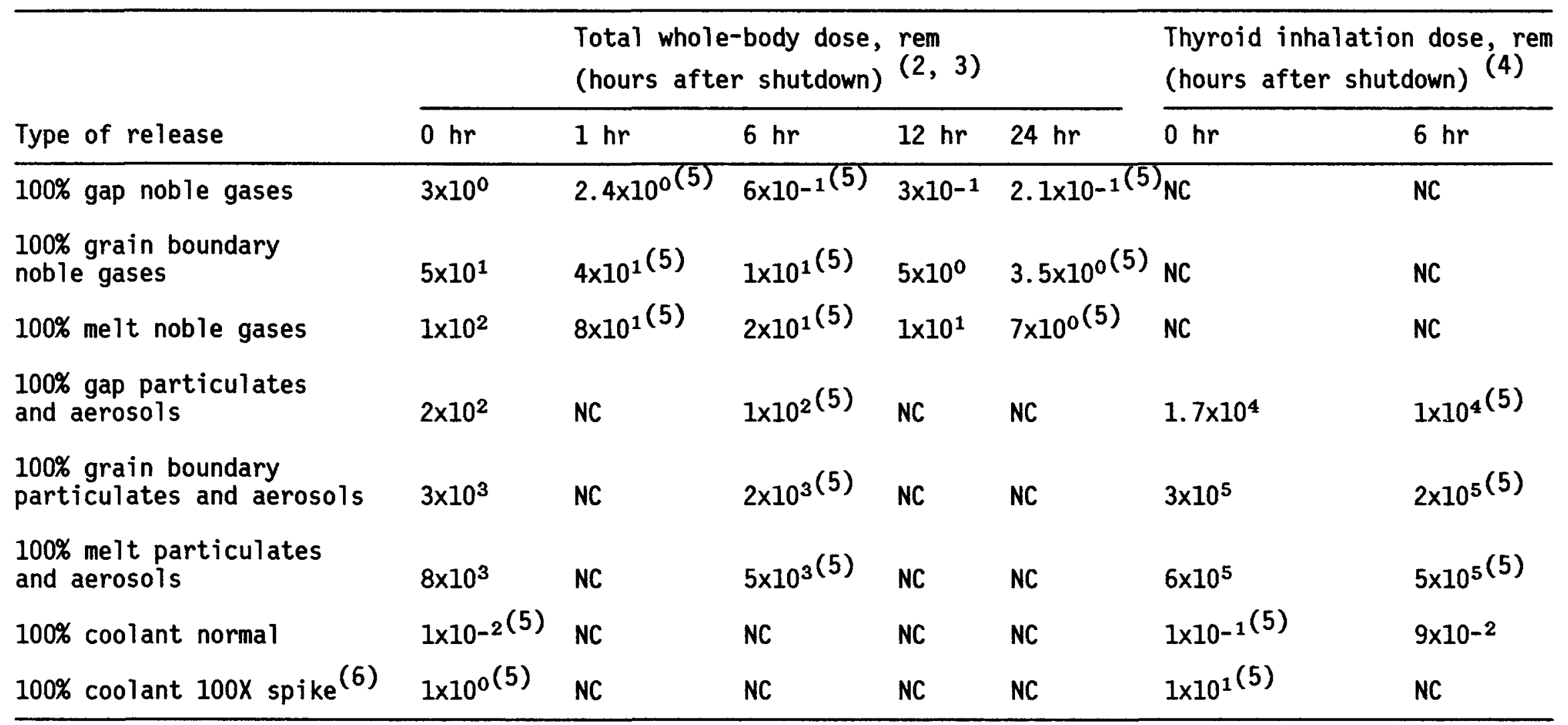

(1) 1-mile dose, $4 \mathrm{mph}$, D stability, ground level release, NRC MESORAD code.

(2) Hours after shutdown release is projected to start.

(3) Includes cloud shine, inhalation, and 3 hours of ground shine.

(4) Inhalation and adult thyroid only.

(5) Assumed in reactor event trees.

- For 0.5-, 6-, and 24-hour containment holdup cases, 1-, 6- and 24-hour noble gas factors were used, respectively.

- For SGTR high-pressure and low-pressure cases, 1-hour and w ioble gas factors were used, respectively.

- For bypass $100 \%$ /hour and other cases, the 1-hour and 6-hour nui ie gas factors were used, respectively.

(6) Spike of all non-noble fission products.

NOTE: $\quad$ NC $=$ not calculated. 
Dose $=$ [tree particulate/aerosol release fraction $\times 100 \%$ appropriate (e.g., gap) particulate/aeroso] dose factor] + [tree noble gas release fraction $\times 100 \%$ noble gas dose factor $x$ noble gas core release fraction] (Table 4.1).

As can be seen from Table 5.1, decay is not important except for noble gases. Therefore, only noble gas dose factors differ depending on decay time. For the particulates/aerosols, the 6-hour decay dose is used for all cases. For noble gases 1-, 6-, or 24-hour decay cases were used, as appropriate.

As an example, the plant conditions during the Perkins Point accident were as follows:

(1) Core melt was projected with release into the containment through the ice condenser.

(2) Sprays were not functional (once-through ice).

(3) Ice was available.

(4) The containment was assumed to leak at design leakage.

(5) A dose assessment was requested 2 hours after core damage.

Figure $5.3 \mathrm{C}$ is the event tree for a PWR ice condenser plant with core melt. These conditions correspond to the branch of the tree that is fourth from the top. The whole-body dose is shown for these conditions as $1.2 \times 10^{-2}$ rem, and the thyroid dose is 1.0 rem.

Note also that the non-noble release fraction is $2 \times 10^{-6}$ for the once-through ice condenser case. From the example of the 7000 curies of Cs-134 being released from the core, $7 \times 10^{6} \times 2 \times 10^{-6}=1.4 \times 10^{1}$ curies would be released to the atmosphere. This is the same answer as that calculated in the sample. As discussed in Section 1.3, source term can best be used to compare the possible consequences of various accident scenarios. As example, the following issue may be raised: Should a BWR containment be vented through the suppression pool or should the containment be allowed to fail in a few hours? One of the related questions is how do the possible consequences of these two accident courses compare? Insight to answer this question can be gained by looking at Figures $5.6 \mathrm{C}$ and $5.5 \mathrm{C}$ for a core melt accident. If it were assumed that there are no sprays, a catastrophic failure of the drywell would occur in 2 to 12 hours from the start of the accident. Figure 5.5C indicates (second branch from top) that the whole-body dose would be in the range of 220 rem (early health effects are possible). While Figure 5.6C shows that if the release is through a subcooled suppression pool 2 to 12 hours after the start of the accident and a 100\%/hour release rate (sixth branch from bottom), the whole-body dose would be about 25 rem (early health effects are not possible). Therefore, it appears that there is a substantial reduction in possible consequences if the containment is vented through the suppression pool. Obviously, this is not the only consideration. There are many other questions that must be answered before venting should be started; these questions include: 
(1) Can the venting system withstand the pressure and other conditions?

(2) Can it be stopped?

(3) What will be the impact of venting on other plant systems and areas?

\subsection{Comparison With Current Source Term Results}

Release fractions estimated from Figures $5.2 \mathrm{~A}$ through $5.7 \mathrm{C}$ were examined against NUREG-1150 release estimate ranges illustrated by the figures in Section 5 of NUREG-1150, Vol. 1. A typical result is shown in Figure 5.8. In this case, the 0.5 -hour holdup case with no sprays was assumed from Figure $5.2 \mathrm{C}$. Figure $5.2 \mathrm{C}$ indicates an estimated release of $100 \%$ of the noble gases and $40 \%$ of the non-noble fission products. The multiple of these release fractions and the release fractions from the core for a core melt are shown on Figure 5.8. The release fractions calculated using Figure $5.2 \mathrm{C}$ fell well within the range of releases estimated by NUREG-1150 as did the other cases examined. This also shows a major problem for the analyst: the problem of how to show the uncertainties when presenting results.

The 1-mile dose projections using the trees for conditions similar to the WASH-1400 PWR release categories (see Section 1.4.3) also were compared with the CRAC code dose projections for the PWR WASH-1400 release categories. The CRAC code results are for weather conditions similar to those assumed in the tree calculations. The CRAC dose whole-body projections assumed 4 hours of ground shine, and the tree calculations assumed only 3 hours of ground shine. The comparison is shown in Table 5.2. As can be seen, the results were always within a factor of 5 .

\subsection{Estimate the Uncertainties}

This final step is extremely important and the most difficult.

Consider first the uncertainties surrounding some of the assumptions made in this example. The initial core release fraction assumed was based on the referenced reactor core with similar burnup but with an entirely different operating history. All of the fission product release fractions are based on limited experimental data and will most likely correspond to a single temperature. Not only will the actual temperature conditions most likely be different from those of the experimentally obtained release fractions, but the temperatures of the fission products and their environment will continually change with time and with accident conditions. The transport and deposition of fission products in the reactor coolant system and in the containment also will be affected by pressures, viscosities, densities, hole sizes, material melting and boiling points, heat capacities, flows, time, surface areas, volumes, system availabilities, and chance. The bottom line is that any source term assessment made using this approach will be very crude. It has been estimated that the current codes used to estimate source term have an uncertainty ranging between 100 and 1000 (NUREG-0956) depending on the accident sequence. Because these ranges are for accidents for which a 11 conditions are known, the source term uncertainties during an actual accident would be much greater. The single greatest source of uncertainties during a major accident is the containment leak rate, which could range to $10^{7}$. All other effects after core damage are in the $10^{2}-$ to $^{-10^{3}}$ range of uncertainty. 
COMPARISON OF RESULTS STATION BLACKOUT, EARLY FAILURE SCENARIO

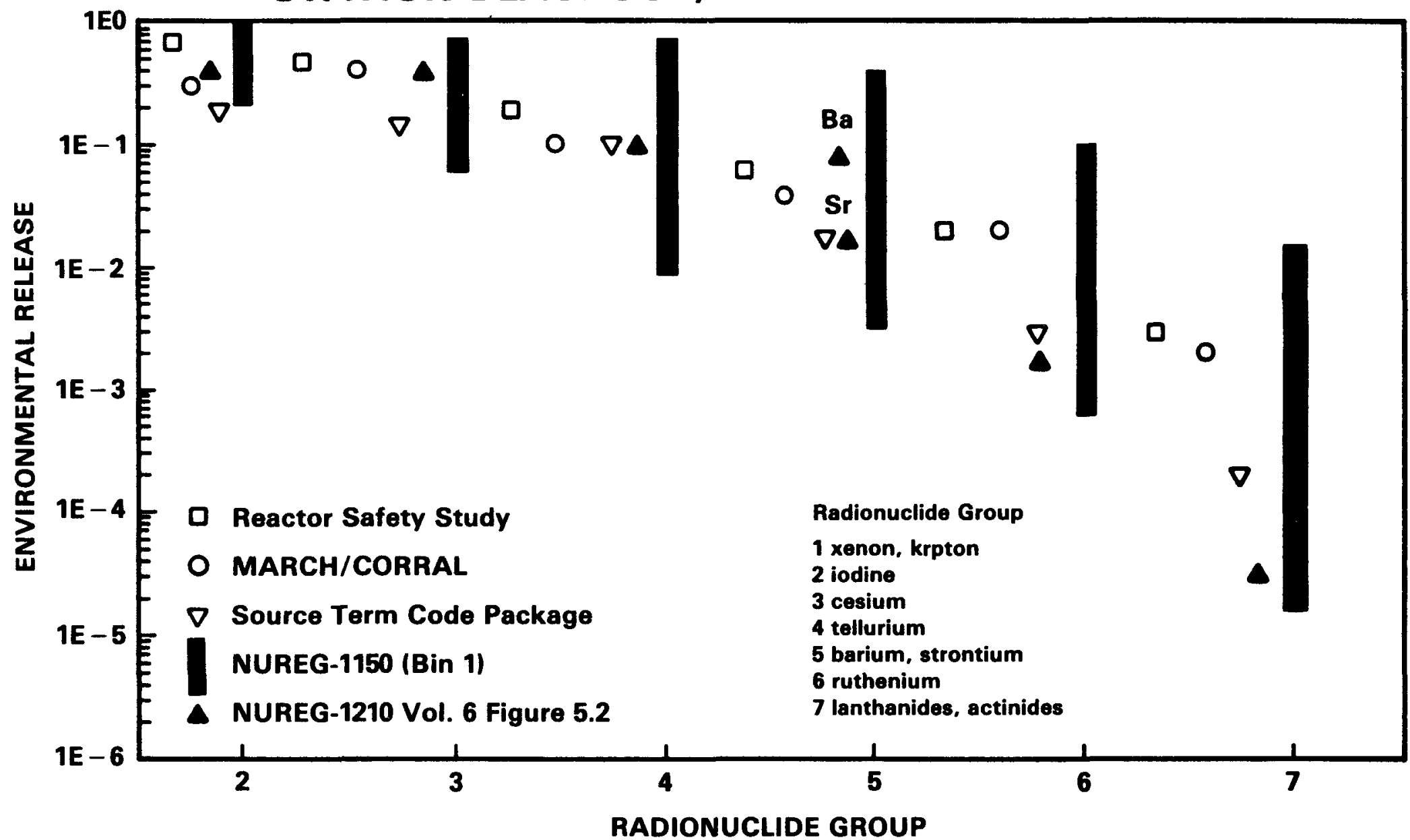

Figure 5.8 Comparison of source term projection results for station blackout scenarios at Surry Source: NUREG-1150 
Table 5.2 Comparison of event tree doses ${ }^{(1)}$ with CRAC whole-body dose projections for WASH-1400 PWR release categories at 1 mile

\begin{tabular}{lll}
\hline $\begin{array}{l}\text { WASH-1400 } \\
\text { release category }\end{array}$ & $\begin{array}{l}\text { WASH-1400 } \\
\text { whole-body dose (2) } \\
(\text { rem) at } 1 \mathrm{mile}\end{array}$ & $\begin{array}{l}\text { Tree } \\
\text { whole-body } \\
\text { dose at } 1 \mathrm{mile}\end{array}$ \\
\hline PWR 1 & $5 \times 10^{2}$ & $2 \times 10^{3}$ \\
PWR 4 & $1.5 \times 10^{2}$ & $2.6 \times 10^{1}(3)$ \\
PWR 5 & $4 \times 10^{1}$ & $1.4 \times 10^{1}$ \\
\hline
\end{tabular}

(1) Figure 5.2C.

(2) Source: NUREG-1062, Case 4.

(3) Assumed a 3-hour release.

As an illustration of uncertainties, Figure 5.8 shows the source term projection for various studies (e.g., WASH-1400) and the range projected by NUREG-1150. 


\section{REFERENCES}

American National Standards Institute/American Nuclear Society, ANSI/ANS 18.1, "Radioactive Source Term for Normal Operation of Light-Water Reactors," La Grange Park, Illinois, December 1984.

American Nuclear Society, "Report of the Special Committee on Source Terms," La Grange Park, Illinois, September 1984.

Babcock \& Wilcox, Study Guide, "Operator Training - Degraded Core Recognition and Mitigation," Vol. 3, TRG-81-3, 77-1125866-00, Lynchburg, Virginia, June 1981.

Battelle Columbus Laboratories, J. A. Gieseke, P. Cybulskis, et al., "Radionuclide Release Under Specific LWR Accident Conditions - PWR-Large, Dry Containment Design (Zion Plant)," Vol. VI, BMI-2104, Columbus, Ohio, July 1984.

Clinton, S. D., "Monthly Report for Experimental Determination of Iodine Transport From a Failed PWR Generator Tube (B0832)," Oak Ridge National Laboratory, February 1984.

Denning, R. S. and P. Cybulskis, "Secondary Containment Buildings Performance in Severe Accidents," Third Workshop on Containment Integrity, Washington, D.C., May 21-23, 1986.

Hanford Engineering Development Laboratory, R. K. Hilliard, A. K. Postma, "Large-Scale Fission Product Containment Test," HEDL-SA 2254 FP, American Nuclear Society Winter Meeting, November 16-21, 1980.

Postma, A. K. , Benton City Technology, "Iodine Evolution From Spray Water," BCT-LR-101, Benton City, Washington, October 1978.

U.S. Department of Energy (originally AEC), J. M. Harrer, J. G. Beckerley, "Nuclear Power Instrumentation Systems Handbook," Vol. 2, TID-25952-P2, Technical Information Center, Washington, D.C., 1974.

---, W. J. Bailey, M. Tokar, "Fuel Performance Annual Report for 1982," Nuclear Safety, Vol. 264, page 367, Office of Scientific and Technical Information, May-June 1985.

U.S. Environmental Protection Agency, "Manual of Protective Action Guides and Protective Actions for Nuclear Incidents," EPA-520/1-75-001, Washington, D.C., June 1980.

U.S. Nuclear Regulatory Commission, NUREG-75/014 (WASH-1400), "Reactor Safety Study," Washington, D.C. , December 1975.

---, NUREG-0396, H. E. Collins, B. K. Grimes, et al., "Planning Basis for the Technical Development of State and Local Government Radiological Emergency

Response Plans in Support of Light Water Nuclear Power Plants," December 1978. 
---, NUREG-0600, "Investigation Into the March 28, 1979 Three Mile Island Accident by Office of Inspection and Enforcement," August 1979.

---, NUREG-0737, "Clarification of TMI Action Plan Requirement," November 1980.

---, NUREG-0772, "Technical Basis for Estimating Fission Product Behavior during LWR Accidents," June 1981.

---, NUREG-0800, "Standard Review Plan for Review of Safety Analysis Reports for Nuclear Power Plants," July 1981.

--- , NUREG-0900, J. T. Larkins, M. A. Cunningham, "Nuclear Power Plant Severe Accident Research Plan," January 1983.

---, NUREG-0909, "NRC Report on the January 25, 1982 Steam Generator Tube Rupture at R. E. Ginna Nuclear Power Plant," April 1982.

---, NUREG-0956, M. Silberberg, J. A. Mitche11, et al., "Reassessment of the Technical Bases for Estimating Source Term," July 1985.

---, NUREG-1037, "Containment Performance Working Group Report," Draft Report for Comment, May 6, 1985.

---, NUREG-1062, T. S. Magrulies, J. A. Martin "Dose Calculation for Severe LWR Accident Scenarios," May 1984.

---, NUREG-1150, "Reactor Risk Reference Document," Draft for Comment, Vol. 3, "Reactor Risk Reference Document: Appendices J-0," February 1987.

---, NUREG-1210, J. A. Martin, T. J. McKenna et al., "Pilot Program: NRC Severe Reactor Accident Incident Response Training Manual," Vol. 2, "Severe Reactor Accident Overview," Vol. 3, "Response of Licensee and State and Local Officials," Vol. 4, "Public Protective Action," February 1987.

---, NUREG/CR-2239, D. C. Aldrich, J. L. Sprung, et al., "Technical Guidance for Siting Criteria Development," SANDIA 81-1549, Sandia National Laboratories, December 1982.

---, NUREG/CR-2672, R. P. Wichner, C. F. Weber, et al., "SBLOCA Outside Containment at Browns Ferry Unit One," Vol. 2, "Iodine, Cesium, and Noble Gas Distribution and Release," ORNL/TM-8119/V2, Oak Ridge National Laboratory, October 1983.

-- , NUREG/CR-2726, A. L. Camp, J. C. Cummings, et al., "Light Water Reactor Hydrogen Manual," SANDIA 82-1137, Sandia National Laboratories, August 1983.

---, NUREG/CR-2907, J. Tichler, K. Nonder, "Radioactive Material Released From Nuclear Power Plants - Annual Report 1982," BNL-NUREG-51581, Vol. 3, Brookhaven National Laboratory, February 1986.

---, NUREG/CR-2940, S. R. Greene, "Realistic Simulation of Severe Accidents in BWRs - Computer Modeling Requirements," ORNL/TM-8517, Oak Ridge National Laboratory, Apri1 1984. 
--- , NUREG/CR-3108, W. B. Wilson, T. R. England, R. J. La Bauve, "Extended Burnup Calculations for Operating Reactor Reflood Reviews," LA-9563-MS, Los Alamos National Laboratory, February 1983.

--- , NUREG/CR-3287, G. G. Killough, C. L. Begovich, A. L. Sjoreen, "A Guide for the TACT III Computer Code," ORNL/TM-8763, Oak Ridge National Laboratory, May 1983.

---, NUREG/CR-3727, F. R. Zalowdek, A. K. Postma, W. K. Winegardner, "Fission Product Removal in Engineered Safety Features (ESF) Systems, "PNL-5050, Pacific Northwest Laboratory, April 1984.

--- , NUREG/CR-4000, R. I. Scherpe 1z, T. J. Bander, G. F. Athey, J. V. Ramsdell, "The MESORAD Dose Assessment Model," Vol. 1, Technical Basis, PNL-5219, Pacific Northwest Laboratory, March 1986.

---, NUREG/CR-4081, M. F. Albert, "The Absorption of Gaseous Iodine by Water Droplets," ORNL/TM-9488, Oak Ridge National Laboratory, July 1985.

---, NUREG/CR-4467, D.S. Alpert, D. I. Chanin, L. T. Ritchie, "Relative Importance of Individual Elements to Reactor Accident Consequences Assuming Equal Release Fraction," SAN85-2575, Sandia National Laboratories, March 1986.

--- , NUREG/CR-4245, S. W. Duce, S. T. Croney, "In-Plant Source Term Measurements at Brunswick Steam Electric Station," EGG-2392, EG\&G Idaho Inc., June 1985.

---, NUREG/CR-4722, T. McKenna, A. L. Sjoreen, "Source Term Estimation Using MENU-TACT; ORNL-6314," Oak Ridge National Laboratory, to be submitted in draft.

---, Regulatory Guide 1.3, Rev. 2, "Assumptions Used for Evaluating the Potential Rádiological Consequences of a Loss-of-Coolant Accident for Boiling-Water Reactors," June 1974.

---, Regulatory Guide 1.4, Rev. 2, "Assumptions Used for Evaluating the Potential Radiological Consequences of a Loss-of-Coolant Accident for Pressurized-Water Reactors," June 1974. 
APPENDIX A

PROCEDURE FOR ESTIMATING OFFSITE CONSEQUENCES

BASED ON PLANT CONDITIONS 
This appendix uses a set-by-set system of tabs to walk the user through the analysis of a large range of accident conditions and reactor types. The figures and tables referenced in this appendix may be found in Sections 4 and 5 of NUREG-1228 and are called out as they are numbered in the main report. When this appendix is being built as a stand-alone procedure, these figures and tables would be taken from the main report and included here. Instruction on where material should be inserted if building a stand-alone procedure is given in brackets $([])$ throughout. 
Procedure:

Rev.

Dated:

\subsection{OBJECTIVE}

The objective of this procedure is to estimate offsite consequences and release source terms based on the projected status of a limited number of plant conditions.

\subsection{RESPONSIBILITY}

This procedure will be used by the source term specialist and the accident sequence analyst with the results provided to the appropriate radiological assessment manager.

\subsection{GUIDANCE}

\section{STEP 1}

See Tab $G$ for a discussion of the assumptions used in development of this method, if required.

\section{NOTE}

This procedure provides crude estimates accurate within a factor of 10-100, only if plant conditions are accurately represented. Results are for a 1000 Whe plant and should be adjusted if the plant is much smaller $(<1 / 2)$.

\section{ACTION}

Select appropriate tab for containment/leakage type.

Tab A PWR Large, Dry or Subatmospheric Containment Leakage

Tab B PWR Ice Condenser Containment Leakage

Tab C PWR Steam Generator Tube Rupture

Tab D

Tab E

Tab F

BWR Containment Dry-Well Leakage/Failure

BWR Containment Wet-Well Leakage/Failure

Tab G

BWR/PWR Containment Bypass (Event V)

General Description of Assumptions

Tab G.1 Core release fraction assumptions

Tab G.2 Core inventories ( $\mathrm{Ci} / \mathrm{MWe}$ )

Tab G.3 Summary of major PWR release pathway reduction mechanisms

Tab G.4 Summary of major BWR release pathway reduction mechanisms

Tab G.5 Assumed containment and steam generator tube rupture escape fraction for 1 hour (release rates)

Tab G.6 PWR baseline coolant concentrations for various levels of core damage

Tab G.7 BWR baseline coolant concentrations for various levels of core damage

Tab G. 8 1-mile dose factors used in the event tree 
TAB A

PWR LARGE, ORY OR SUBATMOSPHERIC CONTAINMENT RELEASE EVENT TREES FOR

A GAP (1), GRAIN BOUNDARY (2), OR MELT (3) RELEASE FROM CORE

NOTE

A general description of the assumptions used in the event trees follows Step 3.

\section{STEP 2}

ACTION

Gather following plant information:

Plant name

Core condition - check

gap release $\left(1300-2000^{\circ} \mathrm{F}\right)$

grain boundary $\left(>3000^{\circ} \mathrm{F}\right)$ melt ( $\left.>4500^{\circ} \mathrm{F}\right)$

Containment sprays - check

on

off

Holdup time before release

0.5 hour

2-12 hours

24 hours

Containment leak rate

design $(0.1 \% /$ day $)$

$100 \%$ /day

Time

$100 \%$ /hour

Analyst

\section{STEP 3}

Use the event trees, based on information above, to estimate dose and source term. Select appropriate event tree based on core condition.

Tab A-1 Gap

Tab A-2 Grain Boundary

Tab A-3 Melt 
PWR LARGE, DRY OR SUBATMOSPHERIC CONTAINMENT EVENT TREES

GENERAL DESCRIPTION: The core is uncovered and release fractions for a 1000 MWe plant typical of a gap $\left(1300-2000^{\circ} \mathrm{F}\right)$, grain boundary $\left(3000^{\circ} \mathrm{F}\right)$, or melt $\left(4500^{\circ} \mathrm{F}\right)$ release from the core are assumed. For the vessel melt-through cases (exvessel melt), the strontium release fractions could be substantially increased. This could increase the projected whole-body dose by $50 \%$ for cases involving releases of large fractions of the non-noble fission products. The release passes by a dry pathway through the primary system into the containment atmosphere as shown in Figure 4.5 pathway A-1 (primary leakage) or A-2 (PORV or SRV). Particulates and aerosols airborne in containment are reduced to account for the actions of sprays or natural processes for $0.5,2-12$, or 24 hours. Releases from the containment are estimated for $0.1 \%$ day, Figure 4.5 pathway $B-1$ (design leakage); $100 \% /$ day, pathway $B-2$ (isolation valve seal failure); or $100 \% /$ hour, pathway B-3 (catastrophic failure $>2 \mathrm{sq} f \mathrm{ft}$ ). Noble gas release fraction is a function of containment release rate only.

The doses are calculated for a 1-hour ground level release, $4 \mathrm{mph}$, and D stability wind conditions. Whole-body dose includes cloud shine, 3 hours of ground shine, and inhalation. Noble gas decay is accounted for. Thyroid dose (adult) is for inhalation only.

A further description of assumptions is contained in Tab G.

[Insert Figure 4.5 (NUREG-1228) after this page.] 
TAB A-1 GAP

STEP 4

Record from event tree (see Figure 5.2A):

Event description

Time

Analyst

Whole-body dose e $1 \mathrm{mi}$

Thyroid dose o $1 \mathrm{mi}$

\section{STEP 5}

Calculate baseline dose at 2, 5, and $10 \mathrm{mi}$.

Whole-body dose from event tree: Whole-body dose: $1 \mathrm{mi}$
(a) $1 \mathrm{mi} * 0.40=$
(อ $1 \mathrm{mi} * 0.09=$
อ $1 \mathrm{mi} * 0.03=$
(Q) $2 \mathrm{mi}$
(e) $5 \mathrm{mi}$
(c) $10 \mathrm{mi}$

Thyroid dose from event tree: Thyroid dose: $1 \mathrm{mi}$

e $1 \mathrm{mi} * 0.40=$

(e $1 \mathrm{mi} * 0.09=$

อ $1 \mathrm{mi} * 0.03=$

(e) $2 \mathrm{mi}$

(a) $5 \mathrm{mi}$

@ $10 \mathrm{mi}$

STEP 6

Present results.

NOTE

Because of great uncertainty, dose numbers should not be used in presenting results. Use the possible consequences as determined below.

\section{ACTION}

Based on criteria below, determine:

Distance to which early deaths are possible (WB dose $>200$ rem)

Distance to which early health effects are possible (WB dose $>50 \mathrm{rem}$ )

Distance to which PAG may be exceeded (WB dose $>1$ rem or thyroid dose $>5$ rem)

Assuming that the accident proceeds as projected, the actual releases could reasonably vary by a factor of 10 to 100 from the projected dose.

Combine this assessment with the general description (following Step 3), input information (Step 2), and a markup of figure showing assumed release pathway(s). Provide results to the Radiological Assessment Manager.

[Insert Figure 5.2A (NUREG-1228) after this page.] 
TAB A-2 GRAIN BOUNDARY

STEP 4

Record from event tree (see Figure 5.2B):

Event description

Time

Analyst

Whole-body dose o $1 \mathrm{mi}$

Thyroid dose e $1 \mathrm{mi}$

\section{STEP 5}

Calculate baseline dose at 2, 5, and $10 \mathrm{mi}$.

Whole-body dose from event tree: Whole-body dose: $1 \mathrm{mi}$
(c) $1 \mathrm{mi} * 0.40=$
(อ $1 \mathrm{mi} * 0.09=$
(อ $1 \mathrm{mi} * 0.03=$

Thyroid dose from event tree:

(e) $1 \mathrm{mi} * 0.40=$

@ $1 \mathrm{mi} * 0.09=$

(e) $1 \mathrm{mi} * 0.03=$ (e) $2 \mathrm{mi}$

de $5 \mathrm{mi}$

c $10 \mathrm{mi}$

Thyroid dose: $1 \mathrm{mi}$

c $2 \mathrm{mi}$

e $5 \mathrm{mi}$

c $10 \mathrm{mi}$

\section{STEP 6}

Present results.

\section{NOTE}

Because of great uncertainty, dose numbers should not be used in presenting results. Use the possible consequences as determined below.

\section{ACTION}

Based on criteria below, determine:

Distance to which early deaths are possible (WB dose $>200$ rem)

Distance to which early health effects are possible (WB dose $>50 \mathrm{rem}$ )

Distance to which PAG may be exceeded (WB dose $>1$ rem or thyroid dose $>5$ rem)

Assuming that the accident proceeds as projected, the actual releases could reasonably vary by a factor of 10 to 100 from the projected dose.

Combine this assessment with the general description (following Step 3), input information (Step 2), and a markup of figure showing assumed release pathway(s). Provide results to the Radiological Assessment Manager.

[Insert Figure 5.2B (NUREG-1228) after this page.] 


\section{TAB A-3 MELT}

\section{STEP 4}

Record from event tree (see Figure 5.2C):

Event description

Time

Analyst

Whole-body dose o $1 \mathrm{mi}$

Thyroid dose $1 \mathrm{mi}$

STEP 5

Calculate baseline dose at 2, 5, and $10 \mathrm{mi}$.

Whole-body dose from event tree: Whole-body dose: $1 \mathrm{mi}$
(c) $1 \mathrm{mi} * 0.40=$
(0 $1 \mathrm{mi} * 0.09=$
c $1 \mathrm{mi} * 0.03=$
Q $2 \mathrm{mi}$
(e $5 \mathrm{mi}$
ce $10 \mathrm{mi}$

Thyroid dose from event tree:

@ $1 \mathrm{mi} * 0.40=$
@ $1 \mathrm{mi} * 0.09=$
@ $1 \mathrm{mi} * 0.03=$

Thyroid dose: $\quad 1 \mathrm{mi}$

(e) $2 \mathrm{mi}$

C $5 \mathrm{mi}$

(a) $10 \mathrm{mi}$

STEP 6

Present results.

NOTE

Because of great uncertainty, dose numbers should not be used in presenting results. Use the possible consequences as determined below.

\section{ACTION}

Based on criteria below, determine:

Distance to which early deaths are possible (WB dose $>200$ rem)

Distance to which early health effects are possible (WB dose $>50 \mathrm{rem}$ )

Distance to which PAG may be exceeded (WB dose $>1$ rem or thyroid dose $>5$ rem)

Assuming that the accident proceeds as projected, the actual releases could reasonably vary by a factor of 10 to 100 from the projected dose.

Combine this assessment with the general description (following Step 3), input information (Step 2), and a markup of figure showing assumed release pathway(s). Provide results to the Radiological Assessment Manager.

[Insert Figure 5.2C (NUREG-1228) after this page.] 
TAB B

PWR ICE CONDENSER CONTAINMENT RELEASE EVENT TREES FOR

A GAP (1), GRAIN BOUNDARY (2), OR MELT (3) RELEASE FROM CORE

NOTE

A general description of the assumptions used in the event trees follows Step 3. ACTION

STEP 2

Gather following plant information:

Plant name
Core condition - check
gap release $\left(1300-2000^{\circ} \mathrm{F}\right)$
grain boundary $\left(>3000^{\circ} \mathrm{F}\right)$
melt $\left(>4500^{\circ} \mathrm{F}\right)$ - check
Containment sprays
on
off
Holdup time before release
0.5 hour
$2-12$ hours
24 hours
Containment leak rate
design (0.25\%/day)
$100 \% /$ day
$100 \% /$ hour
Recirculation fans*
on (with recirculation)
off (once-through ice)
Time
Analyst

STEP 3

Use the event trees, based on information above, to estimate dose and source term. Select appropriate event tree based on core condition.

Tab B-I Gap

Tab B-2 Grain Boundary

Tab B-3 Me1t

*If the ice condenser is bypassed or the ice is exhausted before the release from core, use PWR large, dry containment release trees, Tab A. 


\section{PWR ICE CONDENSER CONTAINMENT RELEASE EVENT TREES FOR}

\section{A GAP (1), GRAIN BOUNDARY (2), OR MELT (3) RELEASE FROM CORE}

GENERAL DESCRIPTION: The core is uncovered and release fractions typical of a gap $\left(1300-2000^{\circ} \mathrm{F}\right)$, grain boundary $\left(3000^{\circ} \mathrm{F}\right)$, or melt $\left(4500^{\circ} \mathrm{F}\right)$ release from the core are assumed. For the vessel melt-through cases (ex-vessel melt) the strontium release fractions could be substantially increased. This could increase the projected whole-body dose by $50 \%$ for cases involving releases of large fractions of the non-noble fission products. The release passes by a dry pathway through the primary system into the containment atmosphere through the ice condenser, shown in Figure 4.6 as pathway $A-1$ (primary leakage) or $A-2$ (PORV or SRV). Particulates and aerosols airborne in the containment are reduced to account for the actions of sprays and natural processes for $0.5,2-12$, or 24 hours. Ice condenser removal for once-through and recirculation is estimated. It is assumed that the ice is not depleted before core damage. If the ice condenser is bypassed or the ice is exhausted before the release from the core, the PWR large, dry containment release trees should be used. Releases from the containment are estimated for $0.25 \%$ day, Figure 4.6 pathway $B-1$ (design leakage); $100 \%$ day, pathway $\mathrm{B}-2$ (isolation valve seal failure); or $100 \%$ /hour, pathway $\mathrm{B}-3$ (catastrophic failure $>2 \mathrm{sq} f \mathrm{t}$ ). Noble gas release fraction is a function of containment release rate only.

Doses at $1 \mathrm{mi}$ are calculated for a 1-hour ground level release, $4 \mathrm{mph}$, and $D$ stability wind conditions. Whole-body dose includes cloud shine, 3 hours of ground shine, and inhalation. Noble gas decay was accounted for. Thyroid dose (adult) is for inhalation only.

[Insert Figure 4.6 (NUREG-1228) after this page.] 


\section{TAB B-1 GAP}

STEP 4

Record from event tree (see Figure 5.3A):

Event description

Time

Analyst

Whole-body dose o $1 \mathrm{mi}$

Thyroid dose $1 \mathrm{mi}$

\section{STEP 5}

Calculate baseline dose at 2, 5, and $10 \mathrm{mi}$.

Whole-body dose from event tree: Whole-body dose: $1 \mathrm{mi}$

(a $1 \mathrm{mi} * 0.40=$

e $1 \mathrm{mi} * 0.09=$

อ $1 \mathrm{mi} * 0.03=$

c $2 \mathrm{mi}$

(e) $5 \mathrm{mi}$

e $10 \mathrm{mi}$

Thyroid dose from event tree:

(e) $1 \mathrm{mi} * 0.40=$

(e $1 \mathrm{mi} * 0.09=$

(e $1 \mathrm{mi} * 0.03=$

Thyroid dose: $1 \mathrm{mi}$

e $2 \mathrm{mi}$

(e) $5 \mathrm{mi}$

c $10 \mathrm{mi}$

STEP 6

Present results.

\section{NOTE}

Because of great uncertainty, dose numbers should not be used in presenting results. Use the possible consequences as determined below.

\section{ACTION}

Based on criteria below, determine:

Distance to which early deaths are possible (WB dose $>200$ rem)

Distance to which early health effects are possible (WB dose $>50 \mathrm{rem}$ )

Distance to which PAG may be exceeded (WB dose $>1$ rem or thyroid dose $>5 \mathrm{rem}$ )

Assuming that the accident proceeds as projected, the actual releases could reasonably vary by a factor of 10 to 100 from the projected dose.

Combine this assessment with the general description (following Step 3), input information (Step 2), and a markup of figure showing assumed release pathway(s). Provide results to the Radiological Assessment Manager.

[Insert Figure 5.3A (NUREG-1228) after this page.] 
TAB B-2 GRAIN BOUNDARY

STEP 4

Record from event tree (see Figure 5.3B):

Event description

Time

Analyst

Whole-body dose o $1 \mathrm{mi}$

Thyroid dose e $1 \mathrm{mi}$

STEP 5

Calculate baseline dose at 2, 5, and $10 \mathrm{mi}$.

Whole-body dose from event tree: Whole-body dose: a $1 \mathrm{mi}$
(e) $1 \mathrm{mi} * 0.40=$
(อ $1 \mathrm{mi} * 0.09=$
c $1 \mathrm{mi} * 0.03=$
(c) $2 \mathrm{mi}$
(e) $5 \mathrm{mi}$
c $10 \mathrm{mi}$

Thyroid dose from event tree:

$1 \mathrm{mi} * 0.40=$
$1 \mathrm{mi} * 0.09=$
$1 \mathrm{mi} * 0.03=$

Thyroid dose: $1 \mathrm{mi}$

(e) $2 \mathrm{mi}$

(e $5 \mathrm{mi}$

(c) $10 \mathrm{mi}$

STEP 6

Present results.

NOTE

Because of great uncertainty, dose numbers should not be used in presenting results. Use the possible consequences as determined below.

\section{ACTION}

Based on criteria below, determine:

Distance to which early deaths are possible (WB dose $>200$ rem)

Distance to which early health effects are possible (WB dose >50 rem)

Distance to which PAG may be exceeded (WB dose $>1$ rem or thyroid dose $>5$ rem)

Assuming that the accident proceeds as projected, the actual releases could reasonably vary by a factor of 10 to 100 from the projected dose.

Combine this assessment with the general description (following Step 3), input information (Step 2), and a markup of figure showing assumed release pathway(s). Provide results to the Radiological Assessment Manager.

[Insert Figure 5.3B (NUREG-1228) after this page.] 


\section{TAB B-3 CORE MELT}

STEP 4

Record from event tree (see Figure 5.3C):

Event description

Time

Analyst

Whole-body dose e $1 \mathrm{mi}$

Thyroid dose o $1 \mathrm{mi}$

\section{STEP 5}

Calculate baseline dose at 2, 5, and $10 \mathrm{mi}$.

Whole-body dose from event tree: Whole-body dose: $1 \mathrm{mi}$
e $1 \mathrm{mi} * 0.40=$
e $1 \mathrm{mi} * 0.09=$
(e $1 \mathrm{mi} * 0.03=$

Thyroid dose from event tree:

e $1 \mathrm{mi} * 0.40=$
@ $1 \mathrm{mi} * 0.09=$
@ $1 \mathrm{mi} * 0.03=$ (e $2 \mathrm{mi}$

c $5 \mathrm{mi}$

(อ $10 \mathrm{mi}$

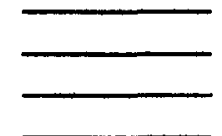

STEP 6

Present results.

Thyroid dose: $1 \mathrm{mi}$

c $2 \mathrm{mi}$

c $5 \mathrm{mi}$

(e) $10 \mathrm{mi}$

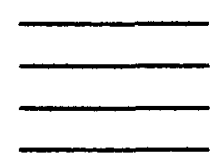

\section{NOTE}

Because of great uncertainty, dose numbers should not be used in presenting results. Use the possible consequences as determined below.

\section{ACTION}

Based on criteria below, determine:

Distance to which early deaths are possible (WB dose $>200$ rem)

Distance to which early health effects are possible (WB dose $>50$ rem)

Distance to which PAG may be exceeded (WB dose $>1$ rem or thyroid dose $>5$ rem)

Assuming that the accident proceeds as projected, the actual releases could reasonably vary by a factor of 10 to 100 from the projected dose.

Combine this assessment with the general description (following Step 3), input information (Step 2), and a markup of figure showing assumed release pathway(s). Provide results to the Radiological Assessment Manager.

[Insert Figure 5.3C (NUREG-1228) after this page.] 
$\underline{T A B} C$

PWR STEAM GENERATOR TUBE RUPTURE RELEASE EVENT TREES

FOR TYPICAL COOLANT AND SPIKE

NOTE

A general description of the assumptions used in the event trees follows Step 3. ACTION

STEP 2

Gather following plant information:

Plant name

Coolant concentration

normal

100X spike

gap release $\left(1300-2000^{\circ} \mathrm{F}\right)$

grain boundary $\left(3000^{\circ} \mathrm{F}\right)$

melt $\left(4500^{\circ} \mathrm{F}\right)$

Tube leak size

1 tube failure at high pressure (500 gpm)

1 charging pump flow (50 gpm)

Steam generator conditions*

normal " $U$ " tube

solid secondary " $U$ " tube

normal once-through steam generator (B\&W)

Atmospheric release point

safety valves

Time

condenser steam-jet air-ejector

Analyst

STEP 3

Use the event trees, based on information above, to estimate dose and source term. Select appropriate event tree based on coolant and core conditions.

Tab C-1 Normal and 100X spike (safety valve release only)

Tab C-2 Gap

Tab $\mathrm{C}-3$ Grain Boundary

Tab C-4 Melt

*For a dry (primary and secondary) release pathway use the BWR/PWR containment bypass trees. 
PWR STEAM GENERATOR TUBE RUPTURE EVENT TREE FOR A RELEASE OF COOLANT NORMAL AND $100 \times$ NORMAL (SPIKE) CONCENTRATIONS (1), GAP CONCENTRATIONS (2), GRAIN BOUNDARY CONCENTRATIONS (3), AND MELT CONCENTRATIONS (4)

GENERAL DESCRIPTION: Two normal range coolant concentrations (normal and 100X non-noble fission products spike) are assumed in addition to three accident concentrations. The accident concentrations assume that all of the gap, grain boundary, or melt core release fractions are contained in the coolant. The associated coolant concentrations are found in Tab G. The coolant is assumed to be released by a steam generator tube rupture (SGTR) to the secondary side and then to the atmosphere by the safety relief valves or through the condenser and then the steam-jet air-ejector (Figure 4.5 or 4.6 pathway $c-1$ or $C-4$ ). The release rate for total failure of one $S G$ tube at full pressure or for coolant (Figures 4.5 and 4.6 , pathway $A-3$ ) being pushed out by one charging pump is assumed. SG partitioning for normal and a solid secondary side of the SG are assumed. A $50 \%$ reduction of non-noble fission products, to account for secondary side dilution, is assumed. Release of all the noble gases is assumed for release by the steam-jet air-ejector. For a dry primary and secondary side release pathway, the BWR/PWR containment bypass trees should be used.

For large and/or multiple failures in a " $U$ " tube SG the once-through steam generator case should be used.

The doses at $1 \mathrm{mi}$ are calculated for a 1-hour ground level release, $4 \mathrm{mph}$, and D stability wind conditions. Whole-body dose includes cloud shine, 3 hours of ground shine, and inhalation. Noble gas decay is accounted for by assuming a 1-hour decay for the high-pressure release and a 6-hour decay for the lowpressure release. Thyroid dose (adult) is for inhalation only.

[Insert Figures 4.5 and 4.6 (NUREG-1228) after this page.] 
TAB C-1 NORMAL AND 100X SPIKE

STEP 4

Record from event tree (see Figure 5.4A):

Event description

Time

Analyst

Whole-body dose o $1 \mathrm{mi}$

Thyroid dose e $1 \mathrm{mi}$

\section{STEP 5}

Calculate baseline dose at 2,5 , and $10 \mathrm{mi}$.

Whole-body dose from event tree: Whole-body dose: $1 \mathrm{mi}$

C $1 \mathrm{mi} * 0.40=$
@ $1 \mathrm{mi} * 0.09=$
@ $1 \mathrm{mi} * 0.03=$

Thyroid dose from event tree:

(c) $1 \mathrm{mi} * 0.40=$

c $1 \mathrm{mi} * 0.09=$

e $1 \mathrm{mi} * 0.03=$ (e $2 \mathrm{mi}$

e $5 \mathrm{mi}$

(e) $10 \mathrm{mi}$

Thyroid dose: $\quad$ @ $1 \mathrm{mi}$

(e) $2 \mathrm{mi}$

(e) $5 \mathrm{mi}$

e $10 \mathrm{mi}$

$\underline{\text { STEP } 6}$

Present results.

NOTE

Because of great uncertainty, dose numbers should not be used in presenting results. Use the possible consequences as determined below.

\section{ACTION}

Based on criteria below, determine:

Distance to which early deaths are possible (WB dose $>200$ rem)

Distance to which early health effects are possible (WB dose $>50$ rem)

Distance to which PAG may be exceeded (WB dose $>1$ rem or thyroid dose $>5$ rem)

Assuming that the accident proceeds as projected, the actual releases could reasonably vary by a factor of 10 to 100 from the projected dose.

Combine this assessment with the general description (following Step 3), input information (Step 2), and a markup of figure showing assumed release pathway(s). Provide results to the Radiological Assessment Manager.

[Insert Figure 5.4A (NUREG-1228) after this page.] 


\section{TAB C-2 GAP}

STEP 4

Record from event tree (see Figure 5.4B):

Event description

Time

Analyst

Whole-body dose e $1 \mathrm{mi}$

Thyroid dose e $1 \mathrm{mi}$

STEP 5

Calculate baseline dose at 2, 5, and $10 \mathrm{mi}$.

Whole-body dose from event tree: Whole-body dose: (d $1 \mathrm{mi}$
(e) $1 \mathrm{mi} * 0.40=$
(d) $1 \mathrm{mi} * 0.09=$
(e $1 \mathrm{mi} * 0.03=$
(c) $2 \mathrm{mi}$
(c) $5 \mathrm{mi}$
(e) $10 \mathrm{mi}$

Thyroid dose from event tree:
e $1 \mathrm{mi} * 0.40=$
(e) $1 \mathrm{mi} * 0.09=$
อ $1 \mathrm{mi} * 0.03=$

Thyroid dose: @ $1 \mathrm{mi}$

(c) $2 \mathrm{mi}$

(c) $5 \mathrm{mi}$

(c) $10 \mathrm{mi}$

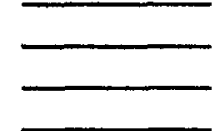

STEP 6

Present results.

\section{NOTE}

Because of great uncertainty, dose numbers should not be used in presenting results. Use the possible consequences as determined below.

\section{ACTION}

Based on criteria below, determine:

Distance to which early deaths are possible (WB dose $>200$ rem)

Distance to which early health effects are possible (WB dose $>50$ rem)

Distance to which PAG may be exceeded (WB dose $>1$ rem or thyroid dose $>5$ rem)

Assuming that the accident proceeds as projected, the actual releases could reasonably vary by a factor of 10 to 100 from the projected dose.

Combine this assessment with the general description (following Step 3), input information (Step 2), and a markup of figure showing assumed release pathway(s). Provide results to the Radiological Assessment Manager.

[Insert Figure 5.4B (NUREG-1228) after this page.] 
STEP 4

Record from event tree (see Figure 5.4C):

Event description

Time

Analyst

Whole-body dose o $1 \mathrm{mi}$

Thyroid dose e $1 \mathrm{mi}$

\section{STEP 5}

Calculate baseline dose at 2, 5, and $10 \mathrm{mi}$.

Whole-body dose from event tree: Whole-body dose: $1 \mathrm{mi}$

(e) $1 \mathrm{mi} * 0.40=$

(a $1 \mathrm{mi} * 0.09=$

(e $1 \mathrm{mi} * 0.03=$

$2 \mathrm{mi}$

c $5 \mathrm{mi}$

c $10 \mathrm{mi}$

Thyroid dose from event tree:

(c) $1 \mathrm{mi} * 0.40=$

d $1 \mathrm{mi} * 0.09=$

(c) $1 \mathrm{mi} * 0.03=$

Thyroid dose: $\quad$ a $1 \mathrm{mi}$

(e) $2 \mathrm{mi}$

(e) $5 \mathrm{mi}$

c) $10 \mathrm{mi}$

\section{STEP 6}

Present results.

NOTE

Because of great uncertainty, dose numbers should not be used in presenting results. Use the possible consequences as determined below.

\section{ACTION}

Based on criteria below, determine:

Distance to which early deaths are possible (WB dose $>200$ rem)

Distance to which early health effects are possible (WB dose $>50$ rem)

Distance to which PAG may be exceeded (WB dose $>1$ rem or thyroid dose $>5$ rem)

Assuming that the accident proceeds as projected, the actual releases could reasonably vary by a factor of 10 to 100 from the projected dose.

Combine this assessment with the general descripton (following Step 3), input information (Step 2), and a markup of figure showing assumed release pathway(s). Provide results to the Radiological Assessment Manager.

[Insert Figure 5.4C (NUREG-1228) after this page.] 


\section{TAB C-4 MELT}

STEP 4

Record from event tree (see Figure 5.4D):

Event description

Time

Analyst

Whole-body dose o 1 mi

Thyroid dose e $1 \mathrm{mi}$

STEP 5

Calculate baseline dose at 2, 5, and $10 \mathrm{mi}$.

Whole-body dose from event tree: Whole-body dose: $10 \mathrm{mi}$
e $1 \mathrm{mi} * 0.40=$
(e) $1 \mathrm{mi} * 0.09=$
(0) $2 \mathrm{mi}$
e $1 \mathrm{mi} * 0.03=$
c $5 \mathrm{mi}$
@ $10 \mathrm{mi}$

Thyroid dose from event tree: Thyroid dose: $1 \mathrm{mi}$
(e) $1 \mathrm{mi} * 0.40=$
@ $1 \mathrm{mi} * 0.09=$
c $1 \mathrm{mi} * 0.03=$
(a $2 \mathrm{mi}$
e $5 \mathrm{mi}$
(a $10 \mathrm{mi}$

STEP 6

Present results.

NOTE

Because of great uncertainty, dose numbers should not be used in presenting results. Use the possible consequences as determined below.

\section{ACTION}

Based on criteria below, determine:

Distance to which early deaths are possible (WB dose $>200$ rem)

Distance to which early health effects are possible (WB dose $>50$ rem)

Distance to which PAG may be exceeded (WB dose $>1$ rem or thyroid dose $>5$ rem)

Assuming that the accident proceeds as projected, the actual releases could reasonably vary by a factor of 10 to 100 from the projected dose.

Combine this assessment with the general description (following Step 3), input information (Step 2), and a markup of figure showing assumed release pathway(s). Provide results to the Radiological Assessment Manager.

[Insert Figure 5.4D (NUREG-1228) after this page.] 
TAB D

BWR CONTAINMENT DRY-WELL LEAKAGE/FAILURE FOR

A GAP (1), GRAIN BOUNDARY (2), OR MELT (3) RELEASE FROM CORE

NOTE

A general description of the assumptions used in the event trees follows Step 3.

STEP 2

ACTION

Gather following plant information:

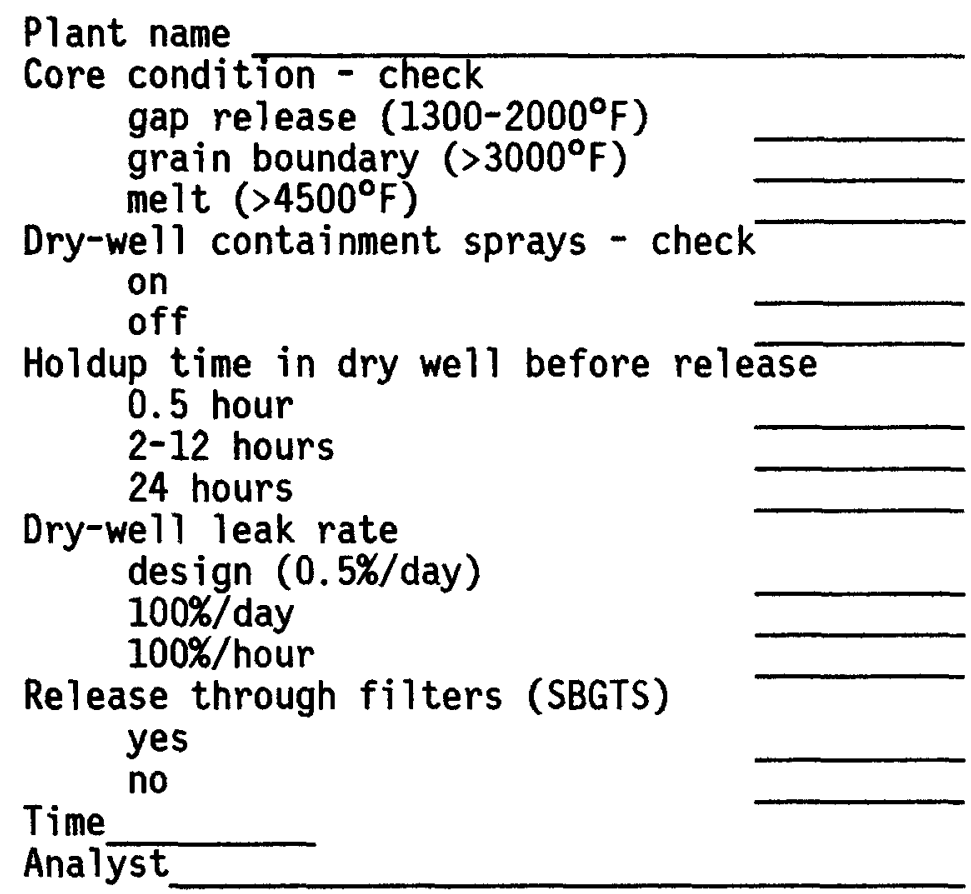

STEP 3

Use event trees, based on information above, to estimate dose and source term. Select appropriate event tree based on core condition.

Tab D-1 Gap

Tab D-2 Grain Boundary

Tab D-3 Melt 
BWR CONTAINMENT DRY-WELL LEAKAGE RELEASE EVENT TREES FOR A GAP (1), GRAIN BOUNDARY (2), OR MELT (3) RELEASE FROM CORE

GENERAL DESCRIPTION: The core is uncovered and release fractions for a 1000 MWe plant (Tab G) typical of a gap $\left(1300-2000^{\circ} \mathrm{F}\right.$ ), grain boundary $\left(3000^{\circ} \mathrm{F}\right.$ ), or melt $\left(4500^{\circ} \mathrm{F}\right)$ release from the core are assumed. For the vessel melt-through cases (ex-vessel melt) the strontium release fractions could be substantially increased. This could increase the projected whole-body dose by $50 \%$ for cases involving releases of large fractions of the non-noble fission products. The release passes by a dry pathway through the primary system into the containment dry-well atmosphere through a loss-of-coolant accident (LOCA), shown in Figures $4.7,4.8$, and 4.9 as pathway A-1 (primary leakage). Particulates and aerosols airborne in the containment dry well are reduced to account for the actions of sprays and natural processes for $0.5,2-12$, or 24 hours. Releases from the containment dry well are estimated for $0.5 \%$ /day (Figures $4.7,4.8$, and 4.9) pathway B-1 (design leakage), $100 \%$ day pathway B-2 (isolation valve seal failure), or $100 \%$ /hour pathway $B-3$ (catastrophic failure $>2 \mathrm{sq} f t$ ). The release can be filtered by the standby gas treatment system (SBGTS) (pathway $\mathrm{C}-2$ ) before release or bypass the SBGTS (pathway $(-1)$. Noble gas release fraction is a function of release rate only.

The doses at $1 \mathrm{mi}$ are calculated for a 1-hour ground level release, $4 \mathrm{mph}$, and D stability wind conditions. Whole-body dose includes cloud shine, 3 hours of ground shine, and inhalation. Noble gas decay is accounted for. Thyroid dose (adult) is for inhalation only.

[Insert Figures 4.7, 4.8, and 4.9 (NUREG-1228) after this page.] 
$\underline{T A B} \quad D-1$ GAP

STEP 4

Record from event tree (see Figure 5.5A):

Event description

Time

Analyst

Whole-body dose o $1 \mathrm{mi}$

Thyroid dose o $1 \mathrm{mi}$

STEP 5

Calculate baseline dose at 2, 5, and $10 \mathrm{mi}$.

Whole-body dose from event tree: Whole-body dose: $1 \mathrm{mi}$

C $1 \mathrm{mi} * 0.40=$
@ $1 \mathrm{mi} * 0.09=$
@ $1 \mathrm{mi} * 0.03=$

(a $2 \mathrm{mi}$

(a) $5 \mathrm{mi}$

Thyroid dose from event tree:

Q $1 \mathrm{mi} * 0.40=$

e $1 \mathrm{mi} * 0.09=$

(อ $1 \mathrm{mi} * 0.03=$

อ $10 \mathrm{mi}$

Thyroid dose: $1 \mathrm{mi}$

(อ 2 mi

e $5 \mathrm{mi}$

(อ) $10 \mathrm{mi}$

STEP 6

Present results.

NOTE

Because of great uncertainty, dose numbers should not be used in presenting results. Use the possible consequences as determined below.

\section{ACTION}

Based on criteria below, determine:

Distance to which early deaths are possible (WB dose $>200$ rem)

Distance to which early health effects are possible (WB dose $>50$ rem)

Distance to which PAG may be exceeded (WB dose $>1$ rem or thyroid dose, $>5$ rem)

Assuming that the accident proceeds as projected, the actual releases could reasonably vary by a factor of 10 to 100 from the projected dose.

Combine this assessment with the general description (following Step 3), input information (Step 2), and a markup of figure showing assumed release pathway(s). Provide results to the Radiological Assessment Manager.

[Insert Figure 5.5A (NUREG-1228) after this page.] 
TAB D-2 GRAIN BOUNDARY

STEP 4

Record from event tree (see Figure 5.5B):

Event description

Time

Analyst

Whole-body dose e $1 \mathrm{mi}$

Thyroid dose $1 \mathrm{mi}$

\section{STEP 5}

Calculate baseline dose at 2, 5, and $10 \mathrm{mi}$.

Whole-body dose from event tree: Whole-body dose: $1 \mathrm{mi}$

e $1 \mathrm{mi} * 0.40=$

e $1 \mathrm{mi} * 0.09=$

อ $1 \mathrm{mi} * 0.03=$

Thyroid dose from event tree:

c $1 \mathrm{mi} * 0.40=$

e $1 \mathrm{mi} * 0.09=$

c $1 \mathrm{mi} * 0.03=$

(c) $2 \mathrm{mi}$

(d) $5 \mathrm{mi}$

c $10 \mathrm{mi}$

Thyroid dose: $1 \mathrm{mi}$

(e) $2 \mathrm{mi}$

(e) $5 \mathrm{mi}$

(c) $10 \mathrm{mi}$

STEP 6

Present results.

NOTE

Because of great uncertainty, dose numbers should not be used in presenting results. Use the possible consequences as determined below.

\section{ACTION}

Based on criteria below, determine:

Distance to which early deaths are possible (WB dose $>200$ rem)

Distance to which early health effects are possible (WB dose $>50$ rem)

Distance to which PAG may be exceeded (WB dose $>1$ rem or thyroid dose $>5$ rem)

Assuming that the accident proceeds as projected, the actual releases could reasonably vary by a factor of 10 to 100 from the projected dose.

Combine this assessment with the general description (following Step 3), input information (Step 2), and a markup of figure showing assumed release pathway(s). Provide results to the Radiological Assessment Manager.

[Insert Figure 5.5B (NUREG-1228) after this page.] 


\section{TAB D-3 CORE MELT}

STEP 4

Record from event tree (see Figure 5.5C):

Event description

Time

Analyst

Whole-body dose o $1 \mathrm{mi}$

Thyroid dose $1 \mathrm{mi}$

STEP 5

Calculate baseline dose at 2,5 , and $10 \mathrm{mi}$.

Whole-body dose from event tree: Whole-body dose: a 1 mi
$1 \mathrm{mi} * 0.40=$
C $1 \mathrm{mi} * 0.09=$
(c) $1 \mathrm{mi} * 0.03=$
e $2 \mathrm{mi}$
c $5 \mathrm{mi}$
c $10 \mathrm{mi}$

Thyroid dose from event tree:

0 $1 \mathrm{mi} * 0.40=$
@ $1 \mathrm{mi} * 0.09=$
@ $1 \mathrm{mi} * 0.03=$

Thyroid dose: $1 \mathrm{mi}$

e $2 \mathrm{mi}$

c $5 \mathrm{mi}$

(อ $10 \mathrm{mi}$

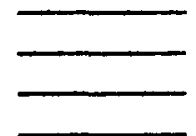

$\underline{\text { STEP } 6}$

Present results.

NOTE

Because of great uncertainty, dose numbers should not be used in presenting results. Use the possible consequences as determined below.

\section{ACTION}

Based on criteria below, determine:

Distance to which early deaths are possible (WB dose $>200$ rem)

Distance to which early health effects are possible (WB dose $>50$ rem)

Distance to which PAG may be exceeded (WB dose $>1$ rem or thyroid dose $>5$ rem)

Assuming that the accident proceeds as projected, the actual releases could reasonably vary by a factor of 10 to 100 from the projected dose.

Combine this assessment with the general description (following Step 3), input information (Step 2), and a markup of figure showing assumed release pathway(s). Provide results to the Radiological Assessment Manager.

[Insert Figure 5.5C (NUREG-1228) after this page.] 


\section{$\underline{T A B E}$}

BWR CONTAINMENT WET-WELL LEAKAGE/FAILURE FOR

A GAP (1), GRAIN BOUNDARY (2), OR MELT (3) RELEASE FROM CORE

\section{NOTE}

A general description of the assumptions used in the event trees follows Step 3.

STEP 2

\section{ACTION}

Gather following plant information:

Plant name

Core condition - check
gap release $\left(1300-2000^{\circ} \mathrm{F}\right)$
grain boundary $\left(>3000^{\circ} \mathrm{F}\right)$
melt $\left(>4500^{\circ} \mathrm{F}\right)$
Suppression pool conditions*
saturated
subcooled
Holdup time in dry/wet well before release
0.5 hour
$2-12$ hours
24 hours
Wet-well leak rate
design (0.5\%/day)
$100 \% /$ day
$100 \% /$ hour
Release through filters (SBGT)
yes
no
Time
Analyst

\section{STEP 3}

Use event trees, based on information above, to estimate dose and source term. Select appropriate event tree based on core condition.

Tab E-1 Gap

Tab E-2 Grain Boundary

Tab E-3 Melt

*For bypass of the suppression pool, use BWR containment dry-well trees, Tab $D$. 
BWR CONTAINMENT WET-WELL LEAKAGE RELEASE EVENT TREES FOR

A GAP (1), GRAIN BOUNDARY (2), OR MELT (3) RELEASE FROM CORE

GENERAL DESCRIPTION: The core is uncovered and release fractions (Tab G) typical of a gap $\left(1300-2000^{\circ} \mathrm{F}\right)$, grain boundary $\left(3000^{\circ} \mathrm{F}\right)$, or melt $\left(4500^{\circ} \mathrm{F}\right)$ release from the core are assumed. For the vessel melt-through cases (ex-vessel melt) the $\mathrm{Sr}$ release fractions could be substantially increased. This could increase the projected whole-body dose by $50 \%$ for cases involving releases of large fractions of the non-noble fission products. The release passes through the suppression pool into the containment wet-well atmosphere through a LOCA, shown in Figures $4.7,4.8$, and 4.9 as pathway A-2 (primary leakage) or A-3 (ADS/SRV). Particulates and aerosols airborne in the containment wet well are reduced to account for the actions of the suppression pool under subcooled and saturated conditions. For bypass of the suppression pool, use BWR containment dry-well trees. It is assumed that only decay heat is being released. If the reactor is not shut down, 10 to 20 times as much particulates could be released through the pool. In addition, it is assumed that the particulates are reduced to account for natural depletion while held up in the containment. Releases from the containment wet well are estimated for $0.5 \%$ day as shown in Figures 4.7 , 4.8 , and 4.9 , pathway $B-1$ (design leakage); $100 \% /$ day, pathway $B-2$ (isolation valve seal failure); or 100\%/hour, pathway B-3 (catastrophic failure $>2 \mathrm{sq} f \mathrm{ft}$ ). The release can be filtered by the SBGTS (pathway $\mathrm{C}-2$ ) before release or bypass the SBGTS (pathway $(-1)$. Noble gas release fraction is a function of release rate only.

Doses at $1 \mathrm{mi}$ are calculated for a 1-hour ground level release, $4 \mathrm{mph}$, and $\mathrm{D}$ stability wind conditions. Whole-body dose includes cloud shine, 3 hours of ground shine, and inhalation. Noble gas decay is accounted for. Thyroid dose (adult) is for inhalation only.

[Insert Figures $4.7,4.8$, and 4.9 (NUREG-1228) after this page.] 
$\underline{T A B} E-1$ GAP

STEP 4

Record from event tree (see Figure 5.6A):

Event description

Time

Analyst

Whole-body dose o $1 \mathrm{mi}$

Thyroid dose e $1 \mathrm{mi}$

\section{STEP 5}

Calculate baseline dose at 2, 5, and $10 \mathrm{mi}$.

Whole-body dose from event tree: Whole-body dose: $1 \mathrm{mi}$
e $1 \mathrm{mi} * 0.40=$
อ $1 \mathrm{mi} * 0.09=$
c $1 \mathrm{mi} * 0.03=$
(c) 5 mi
(อ) $10 \mathrm{mi}$

Thyroid dose from event tree: Thyroid dose: $1 \mathrm{mi}$
e $1 \mathrm{mi} * 0.40=$
อ $1 \mathrm{mi} * 0.09=$
c $2 \mathrm{mi}$
(e $5 \mathrm{mi}$
(c) $1 \mathrm{mi} * 0.03=$
c $10 \mathrm{mi}$

STEP 6

Present results.

\section{NOTE}

Because of great uncertainty, dose numbers should not be used in presenting results. Use the possible consequences as determined below.

\section{ACTION}

Based on criteria below, determine:

Distance to which early deaths are possible (WB dose $>200$ rem)

Distance to which early health effects are possible (WB dose >50 rem)

Distance to which PAG may be exceeded (WB dose $>1$ rem or thyroid dose $>5$ rem)

Assuming that the accident proceeds as projected, the actual releases could reasonably vary by a factor of 10 to 100 from the projected dose.

Combine this assessment with the general description (following Step 3), input information (Step 2), and a markup of figure showing assumed release pathway(s). Provide results to the Radiological Assessment Manager.

[Insert Figure 5.5A (NUREG-1228) after this page.] 
TAB E-2 GRAIN BOUNDARY

STEP 4

Record from event tree (see Figure 5.68):

Event description

Time

Analyst

Whole-body dose $1 \mathrm{mi}$

Thyroid dose $1 \mathrm{mi}$

\section{STEP 5}

Calculate baseline dose at 2,5 , and $10 \mathrm{mi}$.

Whole-body dose from event tree: Whole-body dose: $1 \mathrm{mi}$

$$
\begin{aligned}
& \text { C } 1 \mathrm{mi} * 0.40= \\
& 1 \mathrm{mi} * 0.09= \\
& \text { C } 1 \mathrm{mi} * 0.03=
\end{aligned}
$$

Thyroid dose from event tree: Thyroid dose: $1 \mathrm{mi}$

C $1 \mathrm{mi} * 0.40=$
$1 \mathrm{mi} * 0.09=$
C $1 \mathrm{mi} * 0.03=$

(e $2 \mathrm{mi}$

C $5 \mathrm{mi}$

(อ $10 \mathrm{mi}$

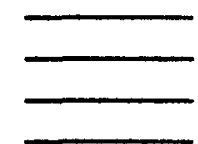

Thyroid $1 \mathrm{mi} * 0.40=$

C $1 \mathrm{mi} * 0.09=$

(e) $2 \mathrm{mi}$

e $5 \mathrm{mi}$

e $10 \mathrm{mi}$

\section{STEP 6}

Present results.

\section{NOTE}

Because of great uncertainty, dose numbers should not be used in presenting results. Use the possible consequences as determined below.

\section{ACTION}

Based on criteria below, determine:

Distance to which early deaths are possible (WB dose $>200$ rem)

Distance to which early health effects are possible (WB dose $>50$ rem)

Distance to which PAG may be exceeded (WB dose $>1$ rem or thyroid dose $>5$ rem)

Assuming that the accident proceeds as projected, the actual releases could reasonably vary by a factor of 10 to 100 from the projected dose.

Combine this assessment with the general description (following Step 3), input information (Step 2), and a markup of figure showing assumed release pathway(s). Provide results to the Radiological Assessment Manager.

[Insert Figure 5.6B (NUREG-1228) after this page.] 
STEP 4

Record from event tree (see Figure 5.6C):

Event description

Time

Analyst

Whole-body dose e $1 \mathrm{mi}$

Thyroid dose a $1 \mathrm{mi}$

\section{STEP 5}

Calculate baseline dose at 2,5 , and $10 \mathrm{mi}$.

Whole-body dose from event tree: Whole-body dose: $1 \mathrm{mi}$
c. $1 \mathrm{mi} * 0.40=$
(อ) $1 \mathrm{mi} * 0.09=$
(e) $1 \mathrm{mi} * 0.03=$

Thyroid dose from event tree:

巳 $1 \mathrm{mi} * 0.40=$
巳 $1 \mathrm{mi} * 0.09=$
@ $1 \mathrm{mi} * 0.03=$

@ $2 \mathrm{mi}$

e $5 \mathrm{mi}$

e $10 \mathrm{mi}$

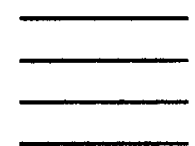

Thyroid dose: $1 \mathrm{mi}$

(e $2 \mathrm{mi}$

(a) $5 \mathrm{mi}$

c $10 \mathrm{mi}$

STEP 6

Present results.

NOTE

Because of great uncertainty, dose numbers should not be used in presenting results. Use the possible consequences as determined below.

\section{ACTION}

Based on criteria below, determine:

Distance to which early deaths are possible (WB dose $>200$ rem)

Distance to which early health effects are possible (WB dose $>50$ rem)

Distance to which PAG may be exceeded (WB dose $>1$ rem or thyroid dose $>5$ rem)

Assuming that the accident proceeds as projected, the actual releases could reasonably vary by a factor of 10 to 100 from the projected dose.

Combine this assessment with the general description (following Step 3 ), input information (Step 2), and a markup of figure showing assumed release pathway(s). Provide results to the Radiological Assessment Manager.

[Insert Figure 5.6C (NUREG-1228) after this page.] 


\section{TAB F}

BWR/PWR CONTAINMENT BYPASS FOR

A GAP (1), GRAIN BOUNDARY (2), OR MELT (3) RELEASE FROM CORE

NOTE

A general description of the assumptions used in the event trees follows Step 3.

$\underline{\text { STEP } 2}$

\section{ACTION}

Gather following plant information:

Plant name
Core condition - check
gap release $\left(1300-2000^{\circ} \mathrm{F}\right)$
grain boundary $\left(>3000^{\circ} \mathrm{F}\right)$
melt $\left(>4500^{\circ} \mathrm{F}\right)$
Release path conditions
filtered
not filtered
Release rate
typical design $(0.1 \% /$ day $)$
$100 \% /$ day
$100 \% /$ hour
Time
Analyst

\section{STEP 3}

Use event trees, based on information above, to estimate dose and source term. Select appropriate event tree based on core condition.

$\begin{array}{ll}\text { Tab F-1 } & \text { Gap } \\ \text { Tab F-2 } & \text { Grain Boundary } \\ \text { Tab F-3 } & \text { Melt }\end{array}$




\section{BWR/PWR CONTAINMENT BYPASS RELEASE EVENT TREES FOR \\ A GAP (1), GRAIN BOUNDARY (2), OR MELT (3) RELEASE FROM CORE}

GENERAL DESCRIPTION: The core is uncovered and release fractions for a 1000 MWe plant (Tab G) typical of a gap $\left(1300-2000^{\circ} \mathrm{F}\right)$, grain boundary $\left(3000^{\circ} \mathrm{F}\right)$, or melt $\left(4500^{\circ} \mathrm{F}\right)$ release from the core are assumed. For the vessel melt-through cases (ex-vessel melt) the strontium release fractions could be substantially increased. This could increase the projected whole-body dose by $50 \%$ for cases involving releases of large fractions of the non-noble fission products. The release passes through a line that bypasses the containment, shown in Figures 4.5, 4.6, $4.7,4.8$, and 4.9 as pathways B-4/A-4. Particulates and aerosols airborne in the containment are reduced to account for plateout in the line. The NUREG0956 results were used as the basis for the amount of reduction. Releases from the containment are estimated for $0.1 \%$ /day (typical design leakage), $100 \%$ /day (isolation valve seal failure), or 100\%/hour (catastrophic failure). Noble gas release fraction is a function of release rate only.

Doses at $1 \mathrm{mi}$ are calculated for a 1-hour ground level release, $4 \mathrm{mph}$, and $D$ stability wind conditions. Whole-body dose includes cloud shine, 3 hours of ground shine, and inhalation. Noble gas decay was considered by assuming 1-hour decay for 100\%/hour release case and 6-hour decay for others. Thyroid dose (adult) is for inhalation only.

[Insert Figures $4.5,4.6,4.7,4.8$, and 4.9 (NUREG-1228) after this page.] 
TAB F-1 GAP

STEP 4

Record from event tree (see Figure 5.7A):

Event description

Time

Analyst

Whole-body dose o $1 \mathrm{mi}$

Thyroid dose $1 \mathrm{mi}$

STEP 5

Calculate baseline dose at 2, 5, and $10 \mathrm{mi}$.

Whole-body dose from event tree: Whole-body dose: $1 \mathrm{mi}$

@ $1 \mathrm{mi} * 0.40=$
$1 \mathrm{mi} * 0.09=$
@ $1 \mathrm{mi} * 0.03=$

(e) $2 \mathrm{mi}$

c $5 \mathrm{mi}$

e $10 \mathrm{mi}$

Thyroid dose from event tree:

@ $1 \mathrm{mi} * 0.40=$
d $1 \mathrm{mi} * 0.09=$
巳 $1 \mathrm{mi} * 0.03=$

Thyroid dose: $1 \mathrm{mi}$

e $2 \mathrm{mi}$

(e) $5 \mathrm{mi}$

(e) $10 \mathrm{mi}$

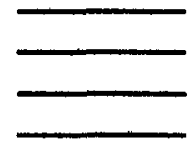

STEP 6

Present results.

NOTE

Because of great uncertainty, dose numbers should not be used in presenting results. Use the possible consequences as determined below.

\section{ACTION}

Based on criteria below, determine:

Distance to which early deaths are possible (WB dose $>200$ rem)

Distance to which early health effects are possible (WB dose $>50$ rem)

Distance to which PAG may be exceeded (WB dose $>1$ rem or thyroid dose $>5$ rem)

Assuming that the accident proceeds as projected, the actual releases could reasonably vary by a factor of 10 to 100 from the projected dose.

Combine this assessment with the general description (following Step 3), input information (Step 2), and a markup of figure showing assumed release pathway(s). Provide results to the Radiological Assessment Manager.

[Insert Figure 5.7A (NUREG-1228) after this page.] 
TAB F-2 GRAIN BOUNDARY

\section{STEP 4}

Record from event tree (see Figure 5.7B):

Event description

Time

Analyst

Whole-body dose o $1 \mathrm{mi}$

Thyroid dose $1 \mathrm{mi}$

\section{STEP 5}

Calculate baseline dose at 2,5 , and $10 \mathrm{mi}$.

Whole-body dose from event tree: Whole-body dose: $1 \mathrm{mi}$ e $1 \mathrm{mi} * 0.40=$ e $1 \mathrm{mi} * 0.09=$

e $1 \mathrm{mi} * 0.03=$

(e) $2 \mathrm{mi}$

(c) $5 \mathrm{mi}$

(e $10 \mathrm{mi}$

Thyroid dose from event tree:

e $1 \mathrm{mi} * 0.40=$

e $1 \mathrm{mi} * 0.09=$

C $1 \mathrm{mi} * 0.03=$

Thyroid dose: $1 \mathrm{mi}$

(e $2 \mathrm{mi}$

(e) $5 \mathrm{mi}$

c $10 \mathrm{mi}$

\section{STEP 6}

Present results.

NOTE

Because of great uncertainty, dose numbers should not be used in presenting results. Use the possible consequences as determined below.

\section{ACTION}

Based on criteria below, determine:

Distance to which early deaths are possible (WB dose $>200$ rem)

Distance to which early health effects are possible (WB dose $>50$ rem)

Distance to which PAG may be exceeded (WB dose $>1$ rem or thyroid dose $>5 \mathrm{rem}$ )

Assuming that the accident proceeds as projected, the actual releases could reasonably vary by a factor of 10 to 100 from the projected dose.

Combine this assessment with the general description (following Step 3), input information (Step 2), and a markup of figure showing assumed release pathway(s). Provide results to the Radiological Assessment Manager.

[Insert Figure 5.7B (NUREG-1228) after this page.] 


\section{TAB F-3 CORE MELT}

STEP 4

Record from event tree (see Figure 5.7C):

Event description

Time

Analyst

Whole-body dose o $1 \mathrm{mi}$

Thyroid dose a $1 \mathrm{mi}$

\section{STEP 5}

Calculate baseline dose at 2, 5, and $10 \mathrm{mi}$.

Whole-body dose from event tree: Whole-body dose: $1 \mathrm{mi}$ (2) $1 \mathrm{mi} * 0.40=$ e $1 \mathrm{mi} * 0.09=$

อ $1 \mathrm{mi} * 0.03=$

C $2 \mathrm{mi}$

(c) $5 \mathrm{mi}$

e $10 \mathrm{mi}$

Thyroid dose from event tree:

(d) $1 \mathrm{mi} * 0.40=$

(e) $1 \mathrm{mi} * 0.09=$

(2) $1 \mathrm{mi} * 0.03=$

Thyroid dose: $\quad 1 \mathrm{mi}$

(e) $2 \mathrm{mi}$

(c) $5 \mathrm{mi}$

e $10 \mathrm{mi}$

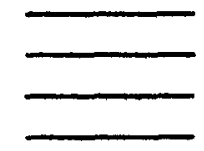

STEP 6

Present results.

NOTE

Because of great uncertainty, dose numbers should not be used in presenting results. Use the possible consequences as determined below.

\section{ACTION}

Based on criteria below, determine:

Distance to which early deaths are possible (WB dose $>200$ rem)

Distance to which early health effects are possible (WB dose $>50$ rem)

Distance to which PAG may be exceeded (WB dose $>1$ rem or thyroid dose $>5$ rem)

Assuming that the accident proceeds as projected, the actual releases could reasonably vary by a factor of 10 to 100 from the projected dose.

Combine this assessment with the general description (following Step 3), input information (Step 2), and a markup of figure showing assumed release pathway(s). Provide results to the Radiological Assessment Manager.

[Insert Figure 5.7C (NUREG-1228) after this page.] 
$\underline{T A B}$ G

GENERAL DESCRIPTION OF ASSUMPTIONS

Tab G.1 Core release fractions

[Insert Table 4.1]

Tab G.2 Core inventory ( $\mathrm{Ci} / \mathrm{MWe}$ )

[Insert Table 2.2]

Tab G.3 Summary of major PWR release pathway reduction mechanism [Insert Table 4.7]

Tab G.4 Summary of major BWR release pathway reduction mechanism [Insert Table 4.8]

Tab G.5 Assumed containment and steam generator tube rupture escape fractions for $1 \mathrm{hr}$ (release rates)

[Insert Table 4.10]

Tab G.6 PWR baseline coolant concentration for various levels of core damage

[Insert Table 4.3]

Tab G.7 BWR baseline coolant concentration for various levels of core damage

[Insert Table 4.4]

Tab G.8 1 mile dose factors

[Insert Table 5.1] 


\section{TAB G BASIC METHOD}

To make a first approximation of a severe accident source term, follow the event tree method below.

(1) Estimate the amount of fission products in the core.

(2) Estimate the fraction of the fission product inventory released from the core.

(3) Estimate the fraction of the fission product inventory released from the core that is removed on the way to the environment.

(4) Estimate the amount of the available fission product inventory actually released to the environment.

(5) Estimate the dose at $1 \mathrm{mi}$.

The event trees estimate source terms by:

$$
\text { Source term } \text { te }_{i}=\mathrm{FPI}_{\mathbf{i}} \times \mathrm{CRF}_{\mathbf{i}} \times\left(\prod_{j=1}^{\mathrm{n}^{\mathrm{RDF}}}(\mathbf{i}, \mathbf{j})\right) \times \mathrm{EF}_{\mathbf{i}}
$$

for radionuclide $i$ and $n$ reduction mechanisms

where

$$
\begin{aligned}
& \mathrm{FPI}_{i}=\text { element } i \text { core or coolant inventory } \\
& \text { [assume a } 1000 \text { MWe core] - See Tab G.2 } \\
& \mathrm{CRF}_{\mathbf{i}}=\frac{\text { element } i \text { released from core (based on core damage state)(Tab G.1) }}{\text { element } i \text { inventory in core }} \\
& \mathrm{RDF}_{i}=\frac{\text { element } i \text { after reduction mechanisms available for release (Tab G.3 or G.4) }}{\text { element } i \text { before reduction mechanisms available for release }} \\
& E F_{i}=\frac{\text { element } i \text { released (Tab G.5) }}{\text { element } i \text { available for release }}
\end{aligned}
$$

The steam generator tube rupture case was somewhat different in that the starting point was an assumed coolant concentration (Tab G.6 or G.7) that assumes all the material released from the core is contained in the coolant.

Dose at $1 \mathrm{mi}$ is based on MESORAD. Tab G. 8 shows the dose factors calculated by MESORAD that were used to calculate the doses shown in the event trees. Doses at 2, 5, and $10 \mathrm{mi}$ are based on $\frac{1}{r 1.5}$ which represents the fall off associated with D stability (see NUREG-0396).

Dose $=[$ tree non-noble gas release fraction $X 100 \%$ appropriate (e.g. , gap) non-valuable gas dose factor] + [tree noble gas release fraction $X$ noble gas release fraction $X 100 \%$ noble gas dose factors]. See Tab G. 8 for dose factors used. 